\title{
Un modelo de planeación de bibliotecas digitales para méxico
}

\section{JUAn UOUTSSÁS mÁRQUEZ}

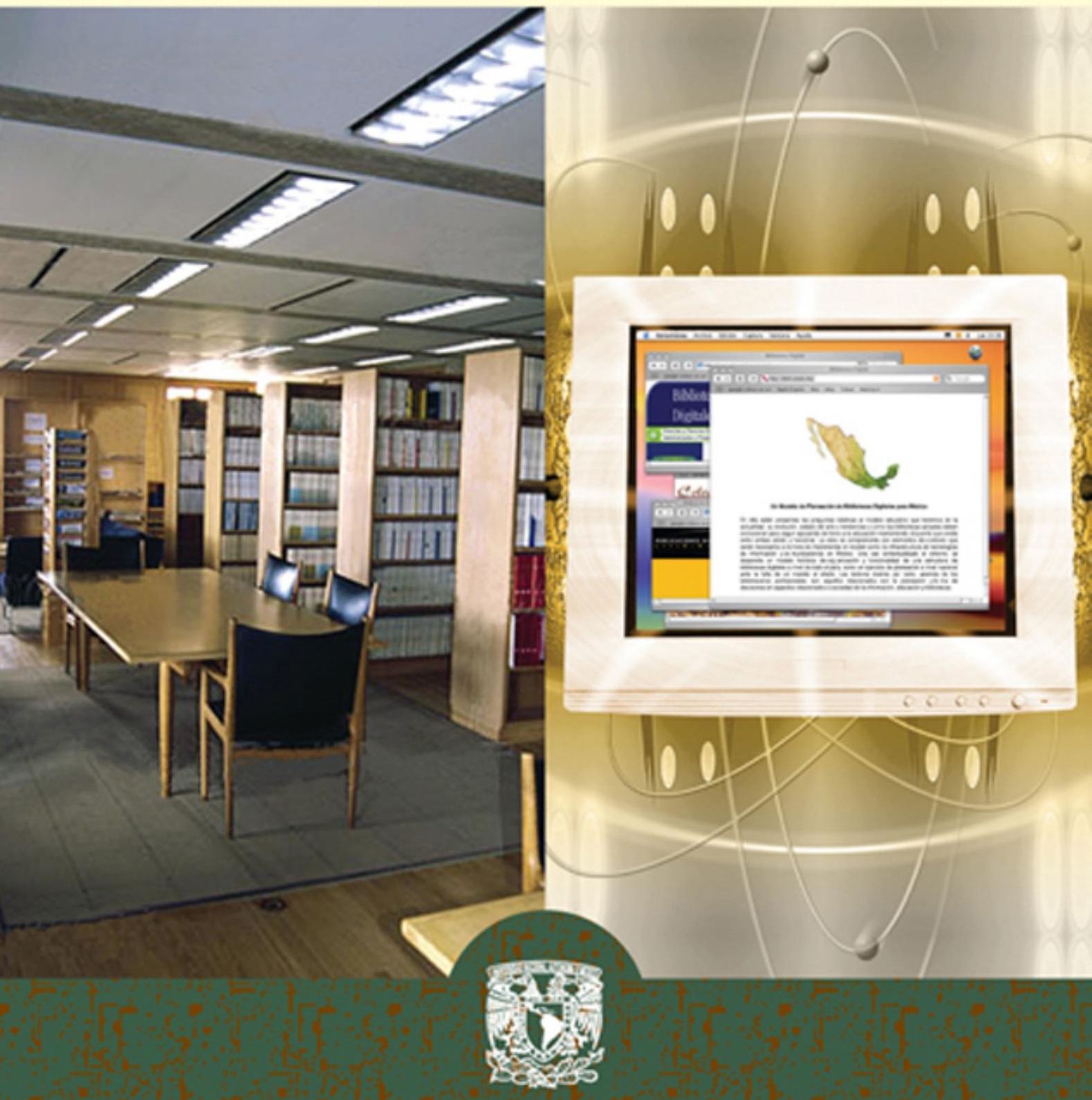




\section{La presente obra está bajo una licencia de:}

\section{http://creativecommons.org/licenses/by-nc-sa/3.0/deed.es MX}

\section{Atribución-No Comercial-Licenciamiento Reciproco 3.0 Unported}

Eres libre de:

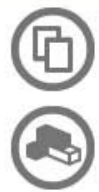

copiar, distribuir y comunicar públicamente la obra

hacer obras derivadas

Bajo las condiciones siguientes:

Atribución - Debes reconocer la autoria de la obra en los términos

especificados por el propio autor o licenciante.

No comercial - No puedes utilizar esta obra para fines comerciales.

D Licenciamiento Reciproco - Si alteras, transformas o creas una obra a

partir de esta obra, solo podrás distribuir la obra resultante bajo una licencia

igual a ésta.

\section{Esto es un resumen fácilmente legible del: texto legal (de la licencia completa)}

\section{En los casos que sea usada la presente} obra, deben respetarse los términos especificados en esta licencia.

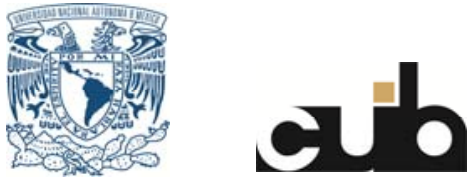




\section{Un modelo de planeación de bibliotecas}

digitales para México 


\section{COLECCIÓN}

TECNOLOGÍAS DE LA INFORMACIÓN

CENTRO UNIVERSITARIO DE INVESTIGACIONES BIBLIOTECOLÓGICAS 


\title{
Un modelo de planeación de bibliotecas digitales para México
}

\author{
Juan Voutssás Márquez
}

Universidad Nacional Autónoma de México 2007 
ZA4082 Voutssás Márquez, Juan

M4V68 Un modelo de planeación de bibliotecas digitales para México / Juan Voutssás Márquez. - México : UNAM, Centro Universitario de Investigaciones Bibliotecológicas, 2007.

xvi, 309 p. - (Tecnologías de la Información)

ISBN: 970-32-4111-5

1. Bibliotecas Digitales - México - Modelos 2. Planificación Bibliotecaria - Modelos 3. Sociedad de la Información 4. Tecnologías de la Información y las Comunicaciones - México

Diseño de portada: Mario Ocampo Chávez

Primera edición: 2007

DR (C) Universidad Nacional Autónoma de México

Ciudad Universitaria, 04510 México, D.F.

Impreso y hecho en México

ISBN: 970-32-4111-5 


\section{Tabla de contenido}

PRÓLOGO

IX

INTRODUCCIÓN XI

Capítulo 1

LA BIBLIOTECA DIGITAL

1.1 Concepto y resumen ...................................................................... 3

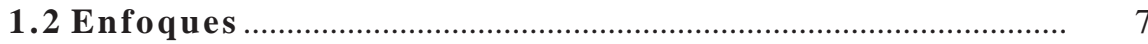

\section{Capítulo 2}

SOCIEDAD DE LA INFORMACIÓN, SOCIEDAD DEL CONOCIMIENTO Y BIBLIOTECAS DIGITALES

2.1 La sociedad de la información ................................................ 27

2.2 Las iniciativas contemporáneas ……....................................... 37

2.2.1 Paradigmas en las estructuras de las iniciativas de otras naciones .................................................................................... 43

2.2.2 Énfasis en la infraestructura en las diferentes

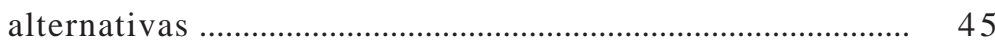

2.2.3 La sociedad del conocimiento .............................................. 47

2.2.4 La iniciativa mexicana para la sociedad del conocimiento y el acceso a la información: e-México ................................ 66

2.3 La educación en la sociedad de la información ................... 80 
2.4 Áreas estratégicas entre bibliotecas y educación ................ 102

2.4.1 Bibliotecas digitales y ambientes de aprendizaje .................. 103

2.4.2 Portafolios digitales .............................................................. 105

2.4.3 Alfabetización en información ............................................... 106

2.4.4 Diseño multidisciplinario de cursos .................................... 107

2.5 Ambientes de aprendizaje .................................................... 108

2.6 Áreas estratégicas de desarrollo en un sistema micro de bibliotecas digitales ........................................................ 113

2.7 Resumen de áreas estratégicas de desarrollo en sistemas micro de bibliotecas digitales .................................................. 117

\section{Capítulo 3 \\ LA INFRAESTRUCTURA MEXICANA EN TECNOLOGÍAS DE INFORMACIÓN Y COMUNICACIÓN (TIC)}

3.1 Las cifras de la infraestructura .............................................. 123

3.2 Proporciones de la infraestructura ....................................... 135

\section{Capítulo 4}

DIVERSIDAD CULTURAL E INTEGRACIÓN NACIONAL

4.1 Diversidad cultural e integración nacional .......................... 143

\section{Capítulo 5}

El MODELO DE PLANEACión DE BIBLIOTECAS DigITALES PARA MÉXICO

5.1 Contexto del modelo ............................................................. 155

5.2 Premisas del modelo ................................................................ 160

5.3 Marco de referencia propuesto para el modelo .................. 170

5.4 Definiendo el modelo .......................................................... 177

5.5 Desarrollando el modelo: acciones y grupos........................ 183

5.5.1 Definición detallada y organización de los sectores que conformarán el modelo 
5.5.2 Evaluación del entorno nacional de bibliotecas tradicionales y digitales

5.7 Detalle de las ocho líneas de acción

5.7.1 Creación, desarrollo y no redundancia de colecciones y servicios documentales digitales nacionales.

5.7.2 Normalización y estandarización de registros digitales desde el punto de vista bibliográfico

5.7.3 Revisión y actualización de la legislación acerca del acceso a la información, derechos de propiedad electrónica y privacidad

5.7.4 Desarrollo de especialistas y personal calificado en modelos educativos, tecnologías y servicios de información

5.7.5 Promoción del uso efectivo de la información; acceso gratuito o económico

5.7.6 Desarrollo de infraestructuras de cómputo y telecomunicaciones; desarrollo en innovaciones tecnológicas que impulsen el proyecto

5.7.7 Impulso a la inversión privada en tecnologías de información y comunicaciones

5.7.8 Integración del proyecto a la identidad, valores y cultura nacionales

RESUMEN Y CONCLUSIONES

CONSIDERACIONES FINALES

GLOSARIO

REFERENCIAS BIBLIOGRÁFICAS

\section{Anexos}

ANEXo 1. Producción mundial estimada de contenidos originales digitales, 1999 
Contenido

ANEXO 1bis. Producción mundial estimada de contenidos originales almacenados digitalmente

AnEXo 2. Proceso evolutivo de la Internet en las PyME 303

ANEXo 3. México - Numeralia 304

AnEXo 4. Tablas de tipos de datos y formatos utilizados en proyectos de digitalización ............................................... 306

AnEXo 5. Tablas de datos de uso del proyecto e-México .................... 309 


\section{Prólogo}

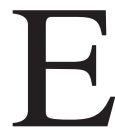

ste trabajo, publicado originalmente como tesis doctoral, tuvo dos enfoques distintos y a la vez complementarios, en virtud de lo cual se conformó en dos grandes secciones. Bajo un primer enfoque el objeto de estudio fue la biblioteca digital en sí misma, partiendo de las preguntas que se hacen actualmente los encargados de las bibliotecas, los profesionales de las mismas, los profesores y los estudiantes de bibliotecología, y a ellos fue dirigida esa parte la cual fue presentada en la obra Bibliotecas y publicaciones digitales. En ella se estudia y conoce a la biblioteca digital bajo un enfoque reduccionista; se analizan minuciosamente todos y cada uno de sus componentes principales, se intenta descubrir sus características, separar sus mitos y realidades y ayudar a comprender de la manera más precisa posible el origen, evolución, estado del arte y tendencias de la biblioteca digital; cómo concebir, diseñar y construir una biblioteca digital, estudiando cada una de sus partes y sus interrelaciones. Se describe cómo se puede ir construyendo una colección digital, con material digital original o digitalizado. Se explica cuándo, cómo y por qué debe digitalizarse tal o cual material, y las ventajas y desventajas de hacerlo; qué implicaciones legales tiene el uso o copia de los materiales digitales y cómo el bibliotecario actual puede desenvolverse adecuadamente en ese entorno, abundando sobre su perfil profesional en el mundo digital. Esta aproximación no cuestiona en sí la naturaleza social de la bi- 
blioteca, ni la necesidad o pertinencia de su existencia; nace del supuesto de que un profesional de la biblioteca desea diseñar y construir una biblioteca digital pública, o una biblioteca para una escuela, un centro de investigación, una entidad gubernamental o una empresa privada y trata de describir cómo hacerlo partiendo de un mejor entendimiento de la misma.

La segunda parte tuvo como objeto abrir el horizonte y plantear desde las cuestiones de la sociedad de la información actual hasta los proyectos y paradigmas que la conforman, tanto a escala nacional como internacional y se expone en la presente obra, Un modelo de planeación de bibliotecas digitales para México. En ella plenteo también las preguntas relativas al modelo educativo que tenemos en la actualidad, su evolución, estado del arte y tendencias y cómo las bibliotecas actuales deben evolucionar también para seguir apoyando de lleno a la educación, como lo han hecho por mucho tiempo, y que el puente entre ambas siga sólido y funcional. Se extiende la reflexión a la función de las bibliotecas digitales como apoyo al trabajo. Se complementa planteando elementos de contexto que serán necesarios a la hora de exponer el modelo, como la infraestructura de tecnologías de información y comunicaciones en México, etcétera. Una vez contextualizado el entorno, se desarrolla y plantea un modelo holístico de organización y funcionalidad de una estructura de bibliotecas digitales a nivel de todo el país, como un ejercicio de planeación a nivel nacional, ante la falta de un modelo al efecto y a ese nivel. Los lectores destino, por tanto, además de los bibliotecarios profesionales, son aquellos relacionados con la planeación y toma de decisiones en aspectos que tienen que ver con la sociedad de la información, la educación y las bibliotecas. 
El bien de un libro consiste en ser leído. Un libro está hecho de signos que hablan de otros signos que, a su vez, hablan de las cosas. Sin unos ojos que lo lean, un libro contiene signos que no producen conceptos. $Y$ por tanto, es mudo.

UMBERTO ECO

\section{Introducción}



asi desde el principio de mi proyecto de investigación doctoral, me percaté de que en el intento de desarrollar un modelo de bibliotecas para nuestro país, había dos aproximaciones básicas al mismo, las cuales eran sustancialmente distintas y mutuamente excluyentes; por un lado, existía la posibilidad de estudiar y explicar el concepto de biblioteca digital desde un enfoque reduccionista, como un ente aislado o cuando mucho, como un grupo de ellas dentro de una organización. Por el otro lado podía analizarse bajo un enfoque holístico y bajo éste debería verse a un modelo de bibliotecas digitales como el total de ellas, un inmenso conjunto o sistema, o una enorme organización a nivel de todo el país, y por tanto sus partes serían sus sectores, componentes y relaciones funcionales a nivel nacional.

El tratamiento y objeto de estudio eran por consecuencia distintos. Bajo el primer enfoque, el objeto de estudio era la biblioteca digital en sí misma, sus partes y sus interrelaciones: las preguntas pertinentes al respecto serían entonces ¿qué es exactamente una biblioteca digital y qué rasgos la definen? ¿de dónde viene? ¿existe un solo tipo de ellas o cuáles son sus variantes? ¿qué partes la conforman? ¿cuáles son sus servicios y colecciones y cómo se desarrollan ambos? ¿cómo es el mundo de las publicaciones digitales que se integran a sus colecciones? ¿cuáles son las semejanzas y las diferencias entre una biblioteca digital y una tradicional? ¿cómo 
se diseña y construye una biblioteca digital? ¿qué esperan los usuarios de una biblioteca de este tipo?

Éstas, entre otras preguntas que personalmente me hacía, son las que se hacen actualmente los encargados de las bibliotecas, los profesionales de las mismas, los profesores y los estudiantes de bibliotecología. Entonces, abordar la investigación desde este enfoque permitiría, teniendo como centro la biblioteca digital, poder analizar minuciosamente todas y cada una de sus partes principales, explicar sus interrelaciones, descubrir sus características, separar sus mitos y realidades y, enfocándome a un lector que fuese un profesional de la biblioteca, ayudarme y ayudarle a comprender de la manera más precisa posible el origen, evolución, estado del arte y tendencias de la biblioteca digital; y también informarle cómo concebir, diseñar y construir una biblioteca digital, estudiando cada una de sus partes y sus interrelaciones; cómo se va construyendo una colección digital con material digital original o digitalizado; explicarle cuándo, cómo y por qué debe digitalizarse tal o cual material y las ventajas y desventajas de hacerlo; cuáles implicaciones legales tiene el uso o la copia de los materiales digitales y cómo el bibliotecario actual puede desenvolverse adecuadamente en ese entorno.

Por supuesto, este enfoque era sin duda atractivo. Parecía muy interesante poder adentrase en detalle en las entrañas de la biblioteca digital, estudiarla, analizarla y descubrir sus secretos y paradigmas, y tratar de explicarlos a otros bibliotecólogos que tienen la necesidad, el encargo, o simplemente la inquietud de explorar el mundo de la biblioteca digital. Naturalmente habría que decantar algunas características propias a nuestro medio mexicano, teniendo en cuenta sus necesidades, recursos y contexto.

Esta aproximación no cuestiona en sí la naturaleza social de la biblioteca, ni la necesidad o pertinencia de su existencia. Estas respuestas en sí ya están dadas por cerca de tres milenios de historia. Nace del supuesto de que un profesional de la biblioteca desea diseñar y construir una biblioteca digital pública, o para una escuela, un centro de investigación, una entidad gubernamental o una empresa privada; y podría tratar de explicar cómo hacerlo partiendo del en- 
tendimiento cabal de la misma. No por ser reduccionista y puntual este enfoque dejaba de ser atractivo como objeto de estudio.

La segunda aproximación o enfoque, como ya se ha mencionado, era el holístico. En este caso el objeto de estudio son todas las posibles bibliotecas digitales existentes o potencialmente creables en nuestro país. Las preguntas cambian: en primer lugar, es necesario replantear el problema desde la función misma de las bibliotecas a nivel nacional. Para ello era indispensable abrir mucho más el horizonte y comenzar con un objeto de estudio mucho más amplio. De ahí, y dado que la biblioteca es una institución de servicio para la sociedad, es necesario entonces analizar detalladamente esa sociedad en la que se inserta; cuáles son sus características, sus necesidades y su problemática; por supuesto, hablamos de la sociedad mexicana actual. Pero esta sociedad no es una isla en el planeta; es necesario entonces analizar antes a la sociedad mundial para contextualizar dentro de ella a la sociedad mexicana actual. Se dice que actualmente la sociedad en la que vivimos a nivel mundial es la denominada sociedad de la información. Era necesario entonces empezar a estudiar y definir a esta así llamada sociedad actual: ¿qué rasgos la definen? ¿en qué es nueva y en qué es igual a otras predecesoras? ¿desde cuándo existe? ¿cuál es su contexto? ¿cuáles son sus tendencias, fortalezas y problemática? ¿cuáles son sus riesgos, injusticias y omisiones?

A continuación, surgió el hecho de que existen múltiples proyectos de muchas naciones o conglomerados de ellas tendientes a la construcción de esa sociedad de la información, todos ellos de creación reciente, inclusive hay un proyecto mexicano: e-México. ¿Por qué se generaron todos esos proyectos? ¿cuáles son sus propuestas, tendencias, características, semejanzas y diferencias? ¿por qué tanta preocupación, a nivel mundial, de tenerlos? ¿por qué uno en México? ¿cómo puede ayudar a nuestra sociedad mexicana? ¿qué riesgos corremos de no hacerlo? y lo más importante: ¿qué responsabilidad tienen las bibliotecas y los bibliotecarios mexicanos respecto a ellos?

De este estudio, saltó a la vista el hecho de que, independientemente de que la biblioteca tiene múltiples funciones sociales, el 
puente primigenio entre las bibliotecas y la sociedad ha sido y es la educación, y más recientemente, el trabajo. Surgieron entonces nuevas preguntas a responder: ¿cómo es la educación dentro de esta sociedad de la información? ¿en qué se parece o diferencia de la anterior? ¿está cambiando esa educación, y hacia dónde? ¿cuáles son las nuevas modalidades educativas? y más importante aún, ¿cuáles son los nuevos modelos educativos? ¿cómo son los nuevos educadores y educandos en este contexto? Si están cambiando modalidades y modelos educativos y las bibliotecas están intrínsicamente ligadas a la educación ¿̇se seguirán requiriendo bibliotecas en un mundo internetizado? Si ése es el caso ¿cómo deben evolucionar las bibliotecas, digitales por supuesto, frente a este cambio educativo? ¿cuál es el perfil de los profesionales de la bibliotecología que las conciben, construyen y operan?

Estos dos últimos bloques de preguntas, como puede observarse, plantean una nueva relación sociedad-educación-bibliotecas-trabajo, que debe ser analizada, discutida y explicada con mucho cuidado: el futuro está en juego; es particularmente relevante el estudio de esta relación en nuestro país y por tanto, nuestro futuro.

Una vez definido este contexto previo, pasaremos a la elaboración de un modelo funcional nacional de bibliotecas digitales: ¿cómo las organizamos a nivel de país? ¿partimos de una gran super biblioteca digital? ¿será un selecto conjunto de ellas? ¿será todo un conglomerado articulado a todo lo largo del país? ¿cómo se concibe y organiza la propuesta? ¿quiénes deben intervenir en ella? ¿cuáles son las responsabilidades de los sectores nacionales en este proyecto? Bajo este enfoque los lectores serían los responsables e interesados para planear los diversos sectores del país, y quienes podrían obtener material interesante de esta propuesta para una mejor toma de decisiones.

Este enfoque, como puede observarse, y las preguntas que se plantean y a las que se pretendería responder son también a todas luces interesantes. Durante un tiempo existió la duda acerca de seleccionar alguno de los dos enfoques y se encontraron válidas razones para desarrollar uno y otro. ¿Qué será mas interesante: estudiar los árboles o el bosque? Difícil decirlo. Ambos enfoques re- 
presentan también un vacío en la literatura existente en nuestro país, y ambos se percibían como igualmente relevantes para nuestro medio. Por un tiempo seguí investigando las dos vertientes y acumulando notas y datos al respecto.

En un momento dado, decidí que podría intentar desarrollar ambos enfoques en esta obra, y así empezó a organizarse. Por supuesto, ello implicaba profundizar con menos detalle en cada uno de ellos, pero siempre se cuidó que la información tratada fuera siempre la requerida en cada capítulo para hacerse una buena idea del tema, la más relevante y representativa, sin menoscabo, en lo posible, de la calidad y pertinencia de la misma.

De esta forma, el trabajo fue dividido en dos grandes partes: la primera cubrió ese primer enfoque mencionado, el reduccionista o puntual, en que el objeto de estudio y modelo es una biblioteca digital y en donde se plantean las preguntas enunciadas previamente $\mathrm{y}$, por supuesto, se pretende darles respuesta. Como se mencionó, el lector a quien va dirigida es el profesional o el estudiante de bibliotecología que quiere entender la biblioteca digital; aquél que desea conocer cómo se diseña, construye y opera ésta. La obra Bibliotecas y publicaciones digitales presentó los resultados de la observación de la biblioteca desde este enfoque.

La segunda parte abre el horizonte y plantea las cuestiones de la sociedad de la información actual, así como los proyectos y paradigmas que la están conformando. Plantea también las preguntas relativas al modelo educativo que tenemos en la actualidad, su evolución, estado del arte y tendencias, y cómo las bibliotecas actuales deben evolucionar también para seguir siendo apoyo fundamental de la educación, como lo han sido por mucho tiempo, y que el puente entre ambas siga sólido y funcional.

Una vez contextualizado el entorno, se procede finalmente a plantear el modelo de organización y funcionalidad de una estructura de bibliotecas digitales como un ejercicio de planeación a nivel nacional. Los lectores destino, por tanto, además de los bibliotecarios, son aquellos relacionados con la planeación en aspectos de sociedad de la información, educación y bibliotecas. En la presente obra abordo este segundo enfoque. 
El total de la obra puede leerse de varias formas: se puede comenzar por el primer título si uno está interesado en el enfoque minimalista y puntual, y si desea conocer la biblioteca digital como un ente, o puede leerse primero este segundo libro si el interés está en los aspectos del contexto social y educativo y en conocer la propuesta del modelo en sí. El capítulo 1 de este libro hace un resumen de la primera obra, por lo que puede ser omitido si ya se leyó ésta o puede ser utilizado como repaso. Un libro puede ser leído sin necesidad de haber leído el otro sin que ello ponga en riesgo la comprensión total, aunque es obvio que una parte complementa a la otra y nada mejor que estudiar tanto los árboles como el bosque.

No pretendo en modo alguno haber agotado todos los temas relacionados con la biblioteca digital. El tema es de tal forma extenso que sería imposible afirmar siquiera que se ha tratado medianamente bien. Cada tópico a desarrollar era una puerta que al abrirla conducía a un corredor lleno de más puertas, cada una de ellas conduciendo a su vez a otro corredor en forma infinita, como La biblioteca de Babel de Borges. La biblioteca digital es sin duda a su vez una biblioteca de Babel, infinita, complicada, pero por lo mismo interesante y con innumerables secretos aún por descubrir y por explicar. Ahora tengo muchas más respuestas que cuando comencé; por lo mismo tengo muchísimas más preguntas.

Tampoco pretendo afirmar que el modelo propuesto es el mejor o el único modelo posible; no aspiro a que se vuelva un modelo oficial; sería muy pretencioso de mi parte. Mi única intención al respecto es demostrar que mediante un método de planeación adecuado, moderno, coparticipativo e integral es posible diseñar un modelo articulado a nivel de todo el país, con el objeto de lograr que nuestras bibliotecas, digitales por lo que se verá, se inserten realmente en un verdadero desarrollo de nuestra sociedad. Si alguien que pueda tomar decisiones al respecto encuentra algo útil en estas obras y lo aplica, por poco que sea, habrá cumplido su propósito y habrá valido la pena. Al fin y al cabo a todos nos interesa el desarrollo social, cultural y económico de nuestro país. 
e todo sabían y han de saber los caballeros andantes, Sancho -dijo don Quijote-, porque caballero andante hubo en los pasados siglos que así se paraba a hacer un sermón o plática en mitad de un campo real como si fuera graduado por la Universidad de París; de donde se infiere que nunca la lanza embotó la pluma, ni la pluma la lanza.

El ingenioso hidalgo don Quijote de la Mancha [I, XVIII] 


\section{Capítulo 1}

\section{La biblioteca digital}



El universo -que otros llaman la Biblioteca-se compone de un número indefinido, y tal vez infinito, de galerías hexagonales, con vastos pozos de ventilación en el medio, cercados por barandas bajísimas. Desde cualquier hexágono se ven los pisos inferiores y superiores: interminablemente. La distribución de las galerías es invariable... una de las caras libres da a un angosto zaguán, que desemboca en otra galería, idéntica a la primera y a todas... por ahi pasa la escalera espiral, que se abisma y se eleva hacia lo remoto. ${ }^{1}$

$\mathrm{E}$ ste primer capítulo es un resumen de la obra anterior: Bibliotecas y publicaciones digitales. Puede omitirse si ya se ha leído o ser utilizado como repaso de la misma.

\subsection{CONCEPTO Y RESUMEN}

Desde la primera vez que lé, hace ya varios años, el cuento de Jorge Luis Borges "La biblioteca de Babel" traté de hacerme mentalmente una figura de cómo se vería ese intrincado edificio interminable, lleno de esas galerías hexagonales que se acoplaban unas con otras hasta el infinito. A pesar de lo ímprobo del esfuerzo siempre me ha resultado una figura fascinante y misteriosa, que de vez en vez, de modo recurrente, vuelve a mi mente para que trate de imaginarla de nuevo, siempre escabulléndose, siempre cambiante, quizá por su parecido con el aedificium de Umberto Eco. Tal vez por ello en algún momento cuando empecé a estudiar las bibliotecas digitales hice la asociación entre éstas y la de Babel: todas son

${ }^{1}$ Jorge Luis Borges, 1941. "La biblioteca de Babel". El jardín de senderos que se bifurcan. Incluido en Ficciones (1944). Buenos Aires, Alianza Editorial. Disponible noviembre 3 de 2005 en http://babel.webcindario.com/ 
misteriosas, escurridizas, cambiantes. En ellas cada puerta de una galería lleva a otra galería, cada descubrimiento lleva a otro descubrimiento, y así infinita y sucesivamente. Empero, lejos de desalentarme, ello estimula mi curiosidad por seguir recorriendo esas interminables "galerías" de conceptos, relaciones, funciones y temas que le son propias.

Como fue enunciado desde la introducción de este trabajo, el tratamiento hecho a la biblioteca digital fue desde dos enfoques sustancialmente distintos y mutuamente excluyentes: por un lado, se estudió y explicó la biblioteca digital desde un enfoque reduccionista, como un ente aislado o cuando mucho, como un grupo de ellas dentro de una organización. Ese aspecto fue tratado en la obra Bibliotecas y publicaciones digitales. Por otro lado las bibliotecas digitales en México fueron analizadas desde el punto de vista holístico, a través del cual se estudió el modelo de bibliotecas digitales como un inmenso conjunto o sistema, o como una enorme organización a nivel de todo el país, y por tanto sus partes fueron sus sectores, componentes y relaciones funcionales a nivel nacional. Este enfoque es el tratado y presentado en la presente obra.

Bajo el primer enfoque, el objeto de estudio fue la biblioteca digital en sí misma, sus partes y sus interrelaciones: las preguntas pertinentes al respecto fueron: ¿qué es exactamente una biblioteca digital y qué rasgos la definen? ¿de dónde viene? ¿existe un solo tipo de ellas o cuáles son sus variantes? ¿qué partes la conforman? ¿cuáles son sus servicios y colecciones y cómo se desarrollan ambos? ¿cómo es el mundo de las publicaciones digitales que se integran a sus colecciones? ¿cuáles son las semejanzas y las diferencias entre ellas y una biblioteca tradicional? ¿cómo se diseña y construye una biblioteca digital? ¿qué esperan los usuarios de una biblioteca de este tipo?

De esta forma y teniendo como centro la biblioteca digital, hemos tratado de analizar minuciosamente todas y cada una de sus partes principales, explicar sus interrelaciones y descubrir sus características, pensando en un lector profesional de la bibliotecología para ayudarle a comprender de la manera más precisa posible el 
origen, evolución, estado del arte y tendencias de la biblioteca digital; cómo concebir, diseñar y construir una biblioteca digital, estudiando cada una de sus partes y sus interrelaciones. Cómo se va construyendo una colección con material digital original o digitalizado. Hemos tratado de explicar cuándo, cómo y por qué debe digitalizarse tal o cual material, y las ventajas y desventajas de hacerlo; qué implicaciones legales tiene el uso o copia de los materiales digitales y cómo el bibliotecario actual puede desenvolverse adecuadamente en ese entorno. Como hemos mencionado también, ese enfoque no cuestionó en sí la naturaleza social de la biblioteca, ni la necesidad o pertinencia de su existencia, consolidada por más de cuatro milenios de historia.

Como resultado de ello se establecieron las siguientes conclusiones que nos servirán de material básico:

- El concepto de biblioteca digital no es simple; de hecho, varía dependiendo de la comunidad que pretenda definirlo. Es un concepto que ha evolucionado por varias décadas a partir de términos tales como biblioteca electrónica, virtual, sin paredes, ciberteca, de medios, etcétera, para desembocar en el concepto más actual, el de biblioteca digital, que abarca los anteriores en un contexto más actual de acuerdo con el estado del arte de hoy en día.

Podemos agregar además, como lo resume Clifford Lynch, ${ }^{2}$ que

La Internet no es la biblioteca mundial de la era digital. Esta afirmación no se sostiene más allá de una afirmación casual. La Internet, y en particular su colección de recursos documentales conocidos como la World Wide Web, no fueron diseñados para

2 Clifford Lynch, 1997. "Searching the Internet". Scientific American. Marzo 1997. Disponible noviembre 3 de 2005 en: http://www.hackvan.com/pub/ stig/articles/trusted-systems/0397lynch.html/ 
sostener la publicación organizada ni la recuperación de información como lo fueron las bibliotecas. Ha ido evolucionando como un caótico repositorio de la "publicación electrónica" mundial, pero no es una biblioteca digital.

Extiendo esta conclusión con el corolario: "Las bibliotecas digitales están contenidas dentro de la Internet y por tanto son parte de los recursos documentales de la red mundial. La red como un todo no es una biblioteca digital".

Como definición, la mejor que encontré desde mi punto de vista fue la del Taller de Planeación de Santa Fe acerca de medio ambientes de trabajo de conocimiento distribuido (Santa Fe Planning Workshop on Distributed Knowledge Work Environments, 1997) donde se estableció el consenso, cada vez más aceptado a nivel mundial de que

el concepto de biblioteca digital no es simplemente el equivalente de colecciones digitalizadas con herramientas de manejo de información. Es más bien un ambiente digital para integrar colecciones, servicios y personas en apoyo a un ciclo vital de creación, diseminación, uso y preservación de datos, información y conocimiento. Las oportunidades y retos que motiven ulteriores investigaciones acerca de las bibliotecas digitales deben asociarse a esta amplia visión del ambiente que representan estas bibliotecas.

Y como la mejor caracterización-definición de biblioteca digital para la comunidad bibliotecaria podemos establecer que, sin duda, es la del "Taller de UCLA-NSF" (UCLA-NSF, 1996). De acuerdo con este foro se establece que:

Las bibliotecas digitales son un conjunto de recursos electrónicos y capacidades técnicas asociadas para la creación, búsqueda y uso de la información. En este sentido son una extensión y mejora de los sistemas de almacenamiento y recuperación que manipulen datos en cualquier medio -texto, sonido, imagen estática o dinámica- existentes en redes distribuidas. El contenido de las biblio- 
tecas digitales incluye datos, metadatos descriptivos y metadatos de hipervínculo. Las bibliotecas digitales están construidas -colectadas y organizadas- por una comunidad de usuarios, y las capacidades funcionales de la biblioteca apoyan las necesidades de información y costumbres de esa comunidad. Son componente de esa comunidad en la cual grupos e individuos interactúan unos con otros, utilizando recursos y sistemas de datos, información y conocimiento. En este sentido ellas son una extensión, mejora e integración de una variedad de instituciones de información en lugares físicos donde los recursos son seleccionados, colectados, organizados, preservados y accesados en apoyo a comunidades específicas de usuarios. Estas instituciones de información incluyen, entre otras, a bibliotecas tradicionales, museos, archivos, y escuelas, extendiendo sus servicios a estos lugares, y además a aulas, oficinas, laboratorios, hogares y áreas públicas.

- A continuación menciono los aspectos más importantes a considerar en el diseño e implementación de una biblioteca digital.

\subsection{ENFOQUES}

Para un correcto análisis de una biblioteca digital es importante observarla desde varias perspectivas o "enfoques", los cuales permiten entenderla y diseñarla desde puntos de vista complementarios:

Desde el enfoque de las colecciones

- Definición del perfil de la colección; políticas de selección, preservación y descarte.

- Conversión a soportes digitales de documentos que se encuentran originalmente en medios tradicionales.

- Documentos originalmente digitales; publicaciones digitales.

- Establecimiento de grandes bibliotecas depositarias.

- Sustentabilidad de las colecciones a lo largo del tiempo. 
Desde el enfoque de la tecnología

- Arquitectura de la plataforma computacional.

- Criterios de digitalización; viabilidad de proyectos; recursos propios o contratados.

- Almacenamiento de las colecciones: costos actuales y proyectados. Almacenamiento en línea y fuera de línea.

- Establecimiento de los formatos aceptados en la biblioteca para cada tipo de material digital y técnicas de compresión aceptadas.

- Recuperación de información. Diseño de las políticas computacionales de registro de los materiales para cada colección. Tipo de metadatos aceptados: MARC 21, MODS, Dublin Core, XML, Z39.50, etc. Planes de viabilidad del desarrollo de esos metadatos.

- Establecimiento de las interfaces para usuarios aceptadas para los servicios digitales.

- Presentación de la biblioteca digital: el portal, página Web o sitio de la misma.

- Políticas y costos para la entrega de los contenidos y servicios.

- Estándares aceptados por la biblioteca, como por ejemplo: OEB, Z39, TCP/IP), etcétera.

- Políticas de interoperabilidad con otros sistemas.

- Modelos de continuidad del servicio; éste debe incluir planes de contingencia en caso de fallas.

- Manejo de versiones tecnológicas.

Desde el enfoque de los usuarios

- Establecimiento de niveles de usuarios: hacia arriba -de quién somos usuarios-, mismo nivel -de quién somos pares-, hacia abajo -quiénes son nuestras nuevas comunidades de usuarios.

- Características de los usuarios: profesores, investigadores, creadores, estudiantes, comunicadores, profesionales, distribuidores, gran público. 
- Métodos de evaluación: necesidades, preferencias, comportamiento y habilidades de los usuarios, ya sean individuales, en grupo o gremiales.

Desde el enfoque de la organización documental

- Recuperación de información. Diseño de las políticas bibliográficas de registro de los materiales para cada colección.

- Tipo de metadatos descriptivos aceptados: MARC 21, MODS, Dublin Core, Z39.50, etcétera. Planes de viabilidad del desarrollo de esos metadatos.

- Clasificación e indización, manual y automatizada.

- Metadatos administrativos, técnicos, descriptivos, de hipervínculo con entes exteriores al documento, etcétera.

- Lenguajes de marcado: MTML, SGML, XML, MODS, METS, etcétera.

Desde el enfoque legal

- Establecimiento claro de los límites y prerrogativas que la ley autoral ofrece a esa biblioteca.

- Definición de las políticas de "uso ético de la información" (fair use) para esa biblioteca.

- Definición de material para intranets.

- Costos de transmisión de derechos.

- Definición de políticas de copia para lo que la biblioteca produce por parte de la propia institución.

- Uso de definiciones externas para cesión de derechos de lo propio (Creative Commons).

- Establecimiento de criterios de privacidad por parte de la biblioteca.

\section{Desde el enfoque social}

- Declaración de principios de la biblioteca respecto a la sociedad de la información o sociedad del conocimiento. 
- Establecimiento de la relación acerca de nuevos modelos educativos, modalidades educativas y la biblioteca.

- Alfabetización digital; reducción de la brecha digital.

- Proyectos desprendidos de colaboración estrecha de la biblioteca digital con la educación.

- Derecho a la accesibilidad.

- Creación de contenidos por parte de la biblioteca digital.

- Modelo de sustentabilidad económica de la biblioteca digital; costos y financiamientos.

- Preservación de valores, identidad y cultura.

- Perfil deseado del personal profesional en la biblioteca digital.

- Balance entre intereses de los productores y de los usuarios.

- Educación para el aprovechamiento de las bibliotecas digitales.

Algunos de estos puntos de vista se complementan, se superponen o se contraponen, y queremos tratarlos con cierta organización metodológica al momento del análisis, pero esperamos haber incluido todos y cada uno de ellos durante esta etapa del estudio detallado de la biblioteca digital, previamente al planteamiento del modelo nacional. Cabe recordar que en esta primera parte queremos definir las partes que componen una biblioteca digital vista como un ente aislado, con objeto de ir entendiendo sus partes e interrelaciones.

Una primera conclusión muy pertinente a este capítulo: "Las bibliotecas digitales están contenidas dentro de la Internet y por tanto son parte de los recursos documentales de la red mundial. La red como un todo no es una biblioteca digital".

Dentro de los elementos analizados en cada uno de estos enfoques, vale la pena resaltar las siguientes conclusiones:

- De acuerdo con el consenso de los principales grupos de especialistas a nivel mundial, después de varios años de observación del desarrollo de las tecnologías para digitalización: sus capacidades, costos, etcétera, la conclusión es que "la digitalización es una excelente forma de maximizar el acceso a materiales; es decir, para fines de distribución es una formidable 
herramienta". Para fines de preservación de documentos a largo plazo el contexto tecnológico todavía no está maduro y puede usarse con cautela, teniendo algún "respaldo" de otro tipo y reconvirtiendo con cierta frecuencia o cuando los materiales están muy deteriorados o en riesgo.

- Es sumamente importante que toda biblioteca digital establezca con precisión sus criterios para digitalizar sus colecciones de documentos que se encuentran en soportes tradicionales, con objeto de evitar errores, inconsistencias y proyectos sin sustento a largo plazo. Esta definición de criterios permitirá clarificar y establecer a la vez aspectos técnicos como son los formatos a utilizarse en la digitalización dependiendo de sus fines de preservación y/o distribución; tipos de compresión, resolución, etc.; aspectos de tipo legal; "uso ético", etcétera. Muy importantes son también los "veintidós principios" para el desarrollo ideal de una colección digital. Para más detalle véase el apartado 2.3 de Bibliotecas y publicaciones digitales.

En cuanto a las publicaciones originalmente digitales se tienen como principales conclusiones las siguientes.

En lo relativo a revistas académicas

- Las revistas digitales académicas presentan, en efecto, una serie de ventajas atractivas a los usuarios; por ello van incrementándose cada vez más en las bibliotecas a nivel mundial. Por lo mismo, cada vez es menor la proporción de bibliotecarios que siguen manteniendo colecciones de revistas exclusivamente en papel.

- Todavía muchos bibliotecarios manejan con cautela este cambio, manteniendo en una proporción muy alta suscripciones en ambos soportes.

- A nivel general Norteamérica-Europa, el motor principal del cambio a la versión electrónica proviene de los usuarios y académicos; en Latinoamérica el motor principal son las restricciones presupuestales. 
Un modelo de planeación de bibliotecas digitales para México

- El modelo de Open Access es medianamente popular en Estados Unidos y la Unión Europea; no así en bibliotecas latinoamericanas.

En lo relativo a libros electrónicos

- El libro electrónico, e-book, ha ido desarrollándose también en los últimos años aunque a un ritmo más lento que el de las revistas académicas. Diversos problemas han ido retrasando su auge, al mismo nivel que otro tipo de documentos digitales, ya que las soluciones y propuestas tienen ventajas sólo en ciertos aspectos. Estos problemas se pueden agrupar en tres grandes grupos:

- En el primero, los problemas relativos a los dispositivos, a falta de uno que reúna realmente todas las características inherentes a un libro en papel: capacidad, comodidad, costo, portabilidad, confiabilidad, etcétera, que en conjunto tiene un libro. Estamos todavía en espera del dispositivo perfecto.

- El segundo grupo de problemas es el que los editores y distribuidores encuentran en relación con la seguridad y control de las obras que se venden, así como algunos mecanismos para control de venta y versiones. Algunas soluciones y medidas, como las marcas de agua electrónicas o filigranas, encriptado, temporalidad, etcétera, fueron analizadas.

- El tercer grupo de problemas es el derivado de la estandarización al respecto. Desde un principio y por bastante tiempo, la edición de libros electrónicos ha sido anárquica en cuanto a alguna normalización, ya que cada editor ha asumido los formatos, metadatos, estilos, patrones y dispositivos que ha querido. Sólo recientemente se han empezado a introducir y a aceptar algunos estándares internacionales como el OEBPS (Open eBook Forum Publications Structure Specification) versión 1.2 y posteriores, que integran lo mejor de la experiencia adquirida en este tema y prometen empezar a dar alguna luz en lo relativo a estándares de libros electrónicos. 
- Respecto a otras publicaciones electrónicas, encontramos que se van consolidando más y más como parte de las colecciones bibliotecarias digitales; entre ellas lo más observado es: imágenes digitales, audio digital, video digital, bancos de datos de todo tipo y sitios Web.

Como conclusión final en lo tocante a publicaciones electrónicas se observa que ya existen bibliotecas que poseen algunos de los siguientes tipos de colecciones de publicaciones digitales: libros y revistas de todo tipo; atlas, enciclopedias, diccionarios, partituras, mapas, periódicos, semanarios, manuscritos, catálogos, encuadernaciones, iluminaciones, impresos, dibujos y fotografías, archivos, filatelia, patentes, grabaciones digitales de música, naturaleza, narraciones, teatro, literatura, lenguas, dialectos, etcétera.

Respecto al registro documental, es de particular interés subrayar que tan importante es la creación y el desarrollo de colecciones -ahora digitales- como implementar mecanismos que permitan su recuperación y distribución. De nada sirve crear copiosas cantidades de información si ésta no puede ser localizada cuando se requiere o si se debe invertir gran cantidad de tiempo en decantar datos no relevantes para nuestra actividad. La información para el estudio, la investigación, el trabajo o la capacitación debe estar a unos cuantos golpes de tecla cuando se requiera. Debe ser veraz, oportuna, pertinente y suficiente; sus premisas son la organización, la recuperabilidad, la autenticidad y la invariabilidad. De hecho, ésa ha sido y sigue siendo la diferencia esencial entre una verdadera colección documental y una masa amorfa de información. No debe crearse una colección digital sin algún mecanismo pertinente de registro y recuperación.

Es un hecho indubitable que el acumulamiento de experiencias por parte de la bibliotecología, lo preciso de las metodologías y el rigor de los procedimientos lograron mucho en el control documental. El formato MARC, las normas ISBD, las Reglas Angloamericanas de Catalogación (AACR2) nos han llevado mucho más cerca del Control Bibliográfico Universal. Pero la creciente expansión del número de documentos a controlar, la enorme variedad de los mis- 
mos, impone una búsqueda continua de nuevas herramientas todavía más potentes para contender con la tarea. Las computadoras ayudaron mucho en el procesamiento de esta información pero trajeron a su vez nuevas variedades de documentos -los documentos digitales o electrónicos- en tal cantidad que nuevamente incrementaron el problema a cotas impredecibles.

Ha habido siempre un problema de balance en el registro documental desde que éste se formalizó: los mejores registros documentales son aquellos hechos por profesionales de esta actividad, siguiendo métodos precisos, auxiliándose con extensas y poderosas herramientas documentales al efecto, pero su elaboración consume mucho tiempo y recursos humanos calificados, además requiere insumos caros, y no hay manera de seguirle el paso a la producción documental. Por otra parte, se han desarrollado mecanismos diseñados para un personal con menos entrenamiento, con unos cuantos elementos prácticos de registro documental; son económicos, rápidos y fáciles de aplicar, al alcance de casi cualquier persona o institución; pero la calidad de los registros es baja y genera problemas al momento de la recuperación. Esta otra aproximación al problema permite procesar mucha más información pero conlleva falta de precisión en la recuperación, dificultando el acceso a gran cantidad de material. Las preguntas son, por tanto: ¿se procesa bien y con calidad sólo una parte del material documental o se trata de procesar todo con poca calidad? ¿qué material electrónico vale la pena registrar?

Obviamente ambas posturas han generado debates desde hace muchísimo tiempo, habiendo defensores de la calidad sobre la cantidad, conscientes de que mucho se quedará fuera, y por otro lado hay quien defiende la postura de que todos los materiales estén procesados, aunque sea pobremente, en lugar de dejarlos afuera. La respuesta a este debate no es sencilla y depende de muchos elementos a analizar; depende de los entornos, contextos, recursos y tiempos de quien se hace la pregunta. Ha habido posiciones fundamentalistas en ambos extremos y ha habido quienes buscan algo que optimice las dos soluciones y se ubique en algún punto medio. 
Como resultado de ello han surgido nuevas herramientas para el control documental que han venido a sumarse y no a sustituir a los antiguos mecanismos ya mencionados, y que son de distinta naturaleza, potencia y alcance. Como todas las herramientas, éstas se han creado para distintas tareas y funciones y por ello la herramienta adecuada debe ser seleccionada para la tarea apropiada. Como hemos visto, a muchas de estas nuevas herramientas se les ha llamado "metadatos", aunque el término, formalmente hablando, abarca perfectamente bien a una ficha catalográfica AACR2 impresa sobre cartón y una ficha MARC, como ya hemos establecido. Entre estas nuevas herramientas se encuentran las ya conocidas de MARC, Z39.50, etcétera, si bien en nuevas versiones, como MARC 21 o MODS (Metadata Object Description Schema). A ellas se han agregado el Código del Núcleo de Dublín (Dublin Core) y los lenguajes de marcado: SGML, HTML y el más nuevo, poderoso y prometedor XML, las nuevas definiciones de la especificación OEBPS 1.2 (Open eBook Forum Publications Structure Specification) para la definición formal para máquina de libros electrónicos, etcétera.

Las conclusiones más importantes en lo tocante al control documental, bajo mi perspectiva, son las siguientes:

- El registro documental organizado es fundamental para toda colección, digital o no. Nunca deben crearse colecciones digitales sin un mecanismo de registro y recuperación documental.

- Es necesario establecer el nivel del registro documental necesario que sea apropiado a la naturaleza del material documental. Colecciones de objetos muy elementales: recetas de cocina, catálogos de venta, colecciones personales, etc., tendrán suficiente con mecanismos de registro muy sencillos. Conforme la importancia y el tamaño de la colección vayan en aumento, el Núcleo de Dublín u otros esquemas parecidos serán adecuados. Las colecciones formales de libros, revistas, mapas, videos, etc., deben utilizar las mejores herramientas de registro: registros ISBDMARC-AACR2, OEBPS 1.2, MODS y esquemas XML.

- Las nuevas herramientas mencionadas vienen a sumarse y no a sustituir a las anteriores herramientas de registro. 
- No existe ningún tipo de metadato que sea la "bala de plata" que nos resuelva todas las situaciones de registro documental para todas las colecciones. Así como para algunas de ellas creábamos fichas AACR2 y para otras índices o resúmenes, o fichas analíticas, es responsabilidad del bibliotecólogo saber escoger una mezcla de herramientas adecuadas que brinden un balance entre precisión, velocidad de registro y recuperación, economía, tamaño de la colección, interfaces, etcétera, para todas y cada una de sus colecciones digitales.

- Hay personas y organizaciones que por mucho tiempo han defendido y siguen defendiendo la ortodoxia del registro documental sólo para ver cómo son rebasadas vertiginosamente por la variedad y abundancia documental. Incluso, hubo quien pensó que ya no era necesaria ninguna regla de registro o que las reglas podían ser absolutamente laxas, y que a "fuerza bruta" de procesamiento de computadora toda la información podía ser recuperada. Ahí están como prueba algunos de los "buscadores" de Internet, quienes recuperan un verdadero océano de basura documental donde encontrar lo relevante es tarea imposible, lo que resulta de poca utilidad para los usuarios. La mejor combinación a la fecha sigue siendo un buen buscador aunado a una estructura formal de registros documentales.

- Será necesario seguir insistiendo y profundizando en ese delicado balance entre calidad y precisión, contra rapidez y economía. Debemos continuar la investigación bibliotecológica e informática buscando todavía mejores soluciones a estos problemas. Algunas cosas apuntan ya como mejoras al respecto, pero aún estamos lejos de la solución definitiva.

Respecto a las publicaciones electrónicas y los derechos de autor y de propiedad cabe resaltar que el concepto de derecho de autor como concepto jurídico es diferente del copyright. El primero proviene del derecho romano-canónico, típico de nuestros países iberoamericanos y tiene que ver más con el aspecto subjetivo del acto de creación de una obra por un cierto autor; el derecho moral consagrado en estas legislaciones tiene su origen en el Hu- 
manismo y la Revolución francesa, de donde se extiende a España y de ahí a los países latinoamericanos y a algunos otros de Europa. Su esencia reside en que la obra forma parte integral de la personalidad del autor; es una creación de su espíritu, el fruto de su pensamiento, de manera que no puede ser disociado enteramente de él por lo que, incluso, cuando ha cedido sus derechos patrimoniales sobre la obra, ésta continúa asociada a él y en cierta medida bajo su dependencia. En resumen, es un derecho del "ser". En contraste, el copyright proviene del derecho consuetudinario anglosajón (common law). Ahí, los derechos morales no son primordiales y su esencia está más intrínsecamente ligada al derecho de copiar o explotar una obra; es decir, su enfoque es más comercial, es un derecho del "tener". En las legislaciones actuales se conocen como derechos morales y patrimoniales.

Los bibliotecarios están, por tanto, más relacionados con el derecho de copia, esto es, los derechos patrimoniales que tienen que ver con la explotación y copia de una obra dada. En particular y dentro del ambiente de las bibliotecas digitales es necesario tener muy claro qué se puede copiar y en qué circunstancias. El advenimiento de las publicaciones electrónicas ha ido transformando notoriamente el contexto de los derechos de copia inherentes a las publicaciones y no puede simplemente extrapolarse a lo que anteriormente estaba establecido para obras en papel, ya que ello inducirá a caer en lagunas o errores en el manejo adecuado de los derechos de copia en una biblioteca que contenga o acceda a este tipo de material.

Las publicaciones que se pueden copiar sin restricción de derechos patrimoniales o de copia son:

- Las que son parte del dominio público, ya sea por su propia naturaleza, porque sus derechos han prescrito o porque así lo ha decidido expresamente el autor. En este sentido se ha hecho un análisis detallado que el bibliotecario profesional debe estudiar con cuidado, ya que las prescripciones cambian de acuerdo con leyes internacionales o de cada país y se mueven en función de extensiones y prórrogas establecidas sobre las obras. 
- Las contempladas en las siete excepciones que menciona la ley mexicana en su capítulo II, artículo 148.

La falta de precisiones en las legislaciones autorales respecto a nuevas variantes que contemplen de manera adecuada las características de las publicaciones digitales, introduce serias lagunas y riesgos enormes para la existencia misma de las bibliotecas y sus usuarios y deben ser vigiladas y enmendadas por los responsables de esas bibliotecas. Es de capital importancia buscar modelos que restablezcan el equilibrio entre la protección a los autores y el derecho de los usuarios a la información. Es absolutamente vital rescatar los principios de jurisprudencia de las legislaciones mundiales en el sentido de que "el propósito del copyright es promover el progreso del conocimiento dando al autor de una obra un incentivo económico para crear nuevas obras". La fallida "Acta del Milenio" lo prevé aunque no lo cumple, pero es sumamente importante rescatarlo:

[...] nuestro mandato debía evaluar los efectos de las enmiendas hechas por el título I de la DMCA y el desarrollo del comercio electrónico y las tecnologías asociadas y emergentes sobre la operación de las secciones relativas al título. [...] expresamente, este informe se concentra en tres propuestas que nos fueron presentadas durante nuestras consultas: la creación de una doctrina de la primera venta digital; la creación de una excepción que permita crear ciertas copias incidentales temporalmente y la ampliación de excepciones al archivado de copias de programas de cómputo. [Las cursivas son mías.]

Como ha podido observarse, si bien algunas legislaciones han extendido las protecciones de sus leyes de derechos de autor mucho más allá de lo usual en materiales impresos, también puede observarse que existen ya algunos contrapesos que buscan permitir a las bibliotecas continuar con su labor, conscientes que de otra forma corren el riesgo de ser asfixiadas por estas disposiciones.

Por siglos hemos desarrollado y arraigado la idea de que si nos gusta algo que compramos para leer, podemos recomendarlo, pres- 
tarlo o regalarlo a un amigo o colega, y además si decidimos que ya no deseamos esa obra, podemos tirarla o venderla. Estos principios son tan importantes en nuestro quehacer intelectual que debemos tenerlos presentes siempre y encontrar la manera de trasladarlos al entorno de las publicaciones digitales [Soules, A., 2002].

Esta preocupación de que los derechos de los usuarios no pueden estar desbalanceados con los derechos de los autores, ha sido recogida claramente por las bibliotecas y sus organizaciones. La Federación Internacional de Asociaciones e Instituciones Bibliotecarias (IFLA) establece claramente estas posturas en su documento "Position Paper on Copyright in the Electronic Environment" sancionado por sus comités en 1996 en la XLII Conferencia Mundial de esta organización (International Federation of Library Associations and Institutions, 1996).

El derecho de poseer físicamente un ejemplar de una obra por parte de un comprador ha sido consagrado en todas las legislaciones del mundo por casi dos siglos. Por ello podemos poseerlo indefinidamente, regalarlo, prestarlo, venderlo, subastarlo, anotarlo, transportarlo, leerlo en voz alta e inclusive destruirlo. Esto se ha vuelto un derecho intrínseco a la naturaleza del que posee un libro u obra semejante. Las bibliotecas y sus colecciones de libros o revistas encajaban perfectamente en este esquema y todo estaba en equilibrio.

Con el advenimiento de los mecanismos de copia masiva al alcance del público y de las bibliotecas, este equilibrio empezó a romperse. La fotocopia en los impresos y la grabadora en los registros sonoros permitieron al público y a las bibliotecas obtener mucha mayor cantidad de páginas u obras. A partir de ese momento los editores arremetieron contra el derecho de copia que había estado intrínsecamente ligado a un lector y que no había sido cuestionado en los siglos anteriores. Las bibliotecas pagaron caro el delito de lesa copyright por el servicio que otorgaban a sus usuarios; los precios de las suscripciones y otros materiales se vieron incrementados para este tipo de instituciones, dado su nefando pecado de obtener copias para el público, y de algún modo el equilibrio se 
reestableció, a pesar de que, como ya hemos mencionado, las bibliotecas sólo aplican la esencia del derecho de copia consagrado en esa original premisa constitucional contenida en la mayoría de las legislaciones autorales del mundo: "el propósito del copyright es promover la ciencia y las artes útiles a través de la difusión del conocimiento" y "el autor se beneficia de la distribución ya que ello disemina su obra, creando además de nuevo conocimiento, nuevas ventas".

Con la llegada de las publicaciones electrónicas y la posibilidad de las bibliotecas y del público de efectuar copias fidedignas y masivas de las obras, es necesario poner en contexto nuevamente las legislaciones mundiales para que el equilibrio sea restablecido. Es cierto que el público se vuelve ahora un riesgo potencial para el editor en la medida que puede copiar y distribuir masivamente una obra y por ende debe ser controlado, pero también es verdad que el público no puede ser tratado y restringido partiendo del supuesto de que siempre se convertirá en otro editor comercial. El público ha creado derechos y costumbres acerca de cómo usar una obra y obtener sus copias incidentales temporales - como ha sido ratificado nuevamente en la DMCA- a lo largo de siglos, y es imposible ahora simplemente pretender que cuando se paga por una obra sólo se adquiere el derecho de verla por un periodo finito de tiempo, o en un solo lugar, y que es exclusivamente para sus ojos y no puede ser compartida en modo alguno. Eso va en contra de la naturaleza hombre-libro. Ningún modelo comercial, tecnológico o legal de alta restricción entre los establecidos hasta la fecha parece prometer algo real a futuro. El equilibrio entre el derecho de unos de comercializar y el derecho de otros de copiar debe ser restablecido en la era digital; la fórmula debe ser de ganancia para ambos; ninguna otra fórmula funcionará a la larga: "todos los extremos son malos".

En resumen, pienso que si los editores rescatan los principios y el espíritu básicos que han regido los derechos de copia y los modelos de negocio de algunas industrias editoriales, no sólo la del libro, y son replanteados con honestidad, podrían encontrarse mejores soluciones para el mundo digital; algunos de ellos ya se han mencionado y vienen de origen desde la primera legislación autoral: los 
autores y editores deben protegerse de otros editores sin escrúpulos que lesionan sus intereses; ellos son los antagonistas y tienen todo el derecho de luchar contra ellos. Sólo cuando un miembro del público decide convertirse en "editor" ilegal se vuelve un antagonista: considerar al público en general siempre como otro editor potencial restringiéndole absolutamente sus prerrogativas de copia "legal" o "ética" va contra la esencia misma con que se creó el libro y contra la creación y divulgación del conocimiento. Ningún modelo que vaya en contra del restablecimiento del balance entre el legítimo derecho de copiar y poseer de los usuarios y el legítimo derecho de comercializar y obtener ganancias de los autores y editores funcionará. Cualquier cosa orientada hacia uno de los extremos estará destinada al fracaso, escindiendo cada vez más el espacio entre editores y usuarios, con el beneplácito de quienes detentan esas obras para obtener un lucro indebido. Usuarios y editores deben plantearse mutuamente el paradigma: "si tú me ves como tu socio, seré tu socio; si tú me ves como tu enemigo, seré tu enemigo".

Ante la falta de legislaciones adecuadas y modernas al efecto, existe una tendencia a nivel mundial de utilizar las denominadas normas aceptadas para el "uso ético" -fair use- de la información pensando en las aplicaciones de docencia e investigación relacionadas con las bibliotecas. Destaca el hecho de que desde este enfoque se permite la reproducción limitada de obras protegidas con fines de investigación, crítica, reportaje, parodia y docencia (incluyendo varias copias para uso en el aula). Los cuatro principales parámetros para determinar si un cierto documento se copia bajo el principio del "uso ético" y no infringe la ley son:

- El propósito y carácter del uso, considerando si éstos son de naturaleza comercial o con fines educativos no lucrativos.

- La naturaleza del trabajo protegido.

- La cantidad y relevancia de la porción copiada, en relación con la obra en su conjunto.

- El efecto de ese uso sobre el mercado o valor potencial de la obra copiada. Véase el apartado 5.2.2 de la obra Bibliotecas y publicaciones digitales para más detalle. 
No hay absolutamente ninguna receta que permita realizar una copia cien por ciento exenta del riesgo de una reclamación, sobre todo en el ámbito internacional, pero los criterios del "uso ético" tienden a ser cada vez más utilizados como un estándar de facto y su ventaja enorme es su aceptación internacional. Por ello, el número de bibliotecarios que se rigen por él es cada vez mayor en el medio de la información digital.

Otro de los mecanismos que han tomado auge en la distribución de material dentro de la red, es el denominado principio del copyleft. El propósito del copyleft, y de ahí su nombre, era originalmente el de mantener libre una pieza de software dada, evitando su privatización. Bajo este principio la declaración del copyleft en una obra es en apariencia la misma que la del copyright, informando del nombre del autor y su calidad de creador o la propiedad intelectual sobre la obra, sólo que en el copyleft el autor autoriza explícitamente a los usuarios a agregar, modificar, mejorar, adaptar, etcétera, los trozos de código que considere pertinentes. Permite además obtener copias de la obra y distribuirla libremente a discreción, pero lo más importante de todo es que agrega una restricción, la de agregar restricciones propias a los subsecuentes usuarios o autores. Esto es de singular importancia, ya que esta restricción de restringir, paradójicamente, se vuelve la clave de una distribución libre. De esta forma, cada usuario es libre de distribuir la obra, pero no puede imponer restricciones adicionales a su distribución. Ese nuevo usuario puede modificarla, señalando inclusive dentro de la obra la parte que es de su autoría, pero no puede restringir la capacidad de otros de modificarla a su vez o distribuirla. De esta manera se garantiza que la obra no podrá ser llevada al régimen de propiedad más adelante por alguna persona o institución malintencionadas. Si bien el concepto de copyleft ha sido utilizado como un mecanismo de distribución de software, ha probado ya sus bondades y ha ganado muchos adeptos; por ello ha empezado a extenderse a otro tipo de obras, como las musicales o textos, sobre todo aquellos que viajan a través de la red mundial. Cada vez es más frecuente encontrarse con algún tipo de documento, texto u obra artística que establece su esencia de copyleft, 
manteniendo así su capacidad de circular ampliamente y sin restricciones por la red.

Finalmente, como una idea derivada de estos conceptos del uso ético y el copyleft encontramos otra instancia interesante denominada Creative Commons. En esencia, es una metodología que permite al público en general que desee publicar una obra en Internet -texto, música, imagen, video, etc.- seleccionar al instante en su sitio Web y sin ayuda de asesoría legal una serie de diversas "licencias tipo" que ya han sido redactadas por expertos en las que el autor selecciona ciertos derechos que él quiere otorgar a quienes lo consulten, y ciertos derechos que él se reserva. Las combinaciones de derechos son muy numerosas donde el autor pueda hacer una cesión muy pormenorizada de lo que permite y lo que no. De esta forma, el que encuentra el documento en la Web y desea utilizarlo sabe exactamente lo que el autor le permite hacer y lo que no, sin necesidad de contactos o permisos adicionales. Esta "licencia" queda adosada al instante a su documento electrónico en tres formas: legible al público en general, en redacción legal y en formato de máquina legible por computadora por un navegador. Esta metodología ha sido adoptada ya en 20 países y está en vías de estudio en otros tantos ya que simplifica enormemente el otorgamiento y retención de derechos en publicaciones electrónicas, sin sustituir las leyes de derechos de autor ni de dominio público. Ha probado ser ya un excelente complemento a las disposiciones legales en el mundo de las publicaciones electrónicas. 

Capítulo 2

Sociedad de la información, sociedad del conocimiento y bibliotecas digitales 

Los dos errores clásicos que se cometen al predecir el futuro de un cambio tecnológico son sobrestimar su impacto a corto plazo y subestimar su impacto a largo plazo.

JAKOB NIELSEN

\subsection{LA SOCIEDAD DE LA INFORMACIÓN}

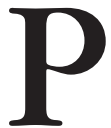

ara poder establecer un modelo de biblioteca digital correctamente es indispensable abrir un poco el horizonte y analizar exactamente cómo debe insertarse esa biblioteca digital en el contexto de la sociedad a la que sirve: la biblioteca no es un ente aislado ni es un fin en sí misma. Si bien tiene muchas funciones sociales, es claro que la biblioteca se ha consolidado como uno de los principales soportes para la educación. La sociedad la utiliza primordialmente como un auxiliar en sus procesos educativos; para ello ha sido necesariamente conformada y definida por esa sociedad que le da origen y ante la cual tiene que responder. Si vamos a definir un modelo de biblioteca, es indispensable, por tanto, analizar esa relación sociedad-educación-biblioteca en la que se encuentra esa entidad a definir y el entorno al que se debe; de otro modo podemos sesgar el objetivo de esas bibliotecas en la sociedad del siglo XXI. La sociedad de principios del siglo XXI es sin duda diferente de la sociedad promedio del siglo Xx; la educación de principios del siglo XXI no es igual que la educación promedio del siglo $\mathrm{XX}$, por lo que no podemos simplemente extrapolar la relación entre bibliotecas, educación y sociedad promedio del siglo que terminó al siglo que comienza; es necesario revisar esta relación para definir qué se conserva, qué tiende a cambiar y qué debe cambiar. Establecido entonces el objeto de análisis previo podemos iniciar definiendo y acotando esa sociedad. 
Para comenzar hablaremos de la sociedad de comienzos del siglo XXI, y debemos tener en cuenta por tanto sus paradigmas, sus características, sus necesidades, sus inercias, etcétera, en suma, su contexto, y en particular el de la sociedad mexicana, para saber en qué marco se inserta esa biblioteca. Debemos establecer además un marco de referencia en el tiempo para ese análisis. Mucho se habla y escribe ya de la "sociedad de la información" en la cual vivimos actualmente. Según muchos autores a partir de la segunda Guerra Mundial, y sobre todo en el último cuarto del siglo XX la tecnología de la información, especialmente las computadoras y las redes de telecomunicaciones, ha cambiado todo. Vivimos ya en una economía de la información, como contraparte de la economía industrial, y consecuentemente en una sociedad de la información como contraparte de esa sociedad industrial. Así, Daniel Bell, ya en 1973, llamó la atención acerca del hecho de que el sector principal de la economía en los países más desarrollados, tanto en producción como en número de trabajadores, había dejado de ser la industria, para dar paso al de la prestación de servicios. A esta nueva sociedad emergente la llamó sociedad posindustrial: el paso de una sociedad productora de bienes a una sociedad de información o de conocimiento. Según Bell, otra característica de esta sociedad es la importancia de la tecnología, y en particular de las computadoras o sistemas informáticos, como fuente de cambios económicos, políticos, sociales y culturales. A este cambio de la sociedad hacia el sector terciario, basado en el conocimiento y en la tecnología, se le ha llamado, con matices, de distintas formas. A principios de los años ochenta, el profesor japonés Yoneji Masuda introdujo la expresión en su libro The Information Society as a Post-Industrial Society, y desde ese momento se ha utilizado en un mismo sentido.

Por mucho tiempo este tipo de afirmaciones me pareció muy convincente hasta que leí el libro The Control Revolution de James Beniger, ${ }^{3}$ escrito en 1986, antes del florecimiento de la Internet y

3 James R. Beniger, 1986. The Control Revolution: Technological and Economic Origins of the Information Society. Cambridge, MA: Harvard University Press. 
Sociedad de la información, sociedad del conocimiento y bibliotecas...

de la globalización; ahí, el autor hace un excelente análisis del desarrollo de la sociedad de la información. El punto clave de Beniger es que no se puede tener una economía industrial sin un aparato masivo de procesamiento de información, simplemente para seguir la pista de las cosas y de las personas con el propósito de asegurarse de que llegarán a donde se suponía que debían llegar cuando se suponía que debían llegar. Los carruajes y las caravanas podían desplazarse sin itinerarios, sin despachadores y sin seguimiento; los trenes no. Las grandes innovaciones de la industrialización no fueron tanto máquinas como procedimientos: estandarización, partes intercambiables, producción en serie, archivo de registros, regularidad, mercadotecnia, administración. Beniger afirma que con el advenimiento del ferrocarril, en 1830, la sociedad recién industrializada empieza a moverse y crea el "gran salto" al procesamiento de información. Beniger continúa después con el análisis de la sociedad de Estados Unidos en donde se presenta este fenómeno entre 1880 y 1930, donde según sus números el porcentaje de personas empleadas en información pasa de 6 a 24 por ciento en ese periodo, mientras que el de los obreros en las industrias es alrededor de 35 por ciento.

Si aceptamos el punto de vista del autor y esa sociedad de la información se remonta hasta 1830 aproximadamente, ¿por qué en los últimos años ha sido tan visible y nuestra sociedad se autoadjudica este nombre para definirse? Las posibles respuestas son muchas y complejas, pero muy probablemente se encuentren entre las principales la introducción de nuevas organizaciones y tecnologías específicas de información. En efecto, en las últimas décadas vimos florecer organizaciones y empresas que ofrecían específicamente "productos de información" y así nos lo hacían saber. A diferencia de las empresas que originalmente vendían bienes y servicios, ahora tenemos la especialización de "sólo servicios"; más aún: sólo servicios de información. Las tecnologías de información vinieron a reafirmar este concepto. Las computadoras proliferaron, entre otras cosas, porque vinieron a ofrecernos en una sola caja muchas herramientas para procesamiento de información que ya existían: sumadoras y calculadoras, 
máquinas de escribir, circuitos de conmutación y control, perforadora de tarjetas de datos, tarjetas catalográficas, agendas, etcétera. En la segunda mitad del siglo xx el desarrollo de esas organizaciones y tecnologías se hizo más sobresaliente, marcando más a nuestra sociedad y haciendo más notoria esa "sociedad con información", tanto que decidió empezar a denominarse con ese nombre. Finalmente, en la última década del siglo $\mathrm{xx}$, el desarrollo acelerado de esas organizaciones y tecnologías de información se incrementó de tal forma, que ha quedado ya marcado como el denominador casi absoluto de nuestra sociedad de los albores del siglo XXI.

Lo anterior no se contrapone con los autores que afirmaron que la sociedad de la información data de la segunda mitad del siglo Xx; pienso que sólo ensancha la ventana del tiempo. De todos modos, siempre es difícil ubicar una época de la humanidad mientras se está inmerso en ella. La Revolución Industrial no empezó a ser llamada así sino hasta 1880, casi 100 años después de que había comenzado, y la primera Guerra Mundial sólo empezó a ser llamada así hasta que comenzó una segunda.

Es importante recalcar aquí que aunque esta caracterización sólo define a una parte de la sociedad mundial, y esos rasgos y características existen sólo en ciertos segmentos del conglomerado humano, debemos estar conscientes de que conforman rasgos típicos de lo que podríamos denominar "el estadio más avanzado de la civilización humana" - que no de su cultura- aunque no todos los habitantes del planeta se encuentren en él. Esto no descalifica la caracterización. Consciente de que hoy en día convivimos en este mundo desde sociedades neolíticas de recolectores-cazadores, pasando por sociedades agrícolas y sociedades industriales hasta llegar a la sociedad de la información, presento la caracterización. Más de la mitad del planeta no ha llegado a la sociedad industrial, pero ello no quiere decir que no haya existido o no exista tal sociedad. No es el punto de juzgar lo bueno o malo de que coexistan varias sociedades en el planeta, sino de caracterizarlas, aunque obviamente tendremos que llegar en esta obra al punto de debatir brechas y desigualdades. 
Sociedad de la información, sociedad del conocimiento y bibliotecas...

Lo que está fuera de discusión es el hecho de que las organizaciones y las tecnologías de información están moldeando y reconformando sensiblemente la manera en que la vida se desarrolla en la actualidad, y se desarrollará en los próximos años en buena parte del mundo, y por ello es importante que sean analizadas y sobre todo, planeadas. En esta sociedad empiezan a surgir nuevas preguntas en relación con su principal denominador, la información: ¿quiénes van a controlar las fuentes y diferentes formas de información? ¿quiénes van a distribuirla y cómo? ¿quiénes van a tener acceso a la educación y a la información y cómo? ¿cuánto va a costar la información y quién va a pagar por ella? ¿quién la posee legalmente y cómo se transfieren esos derechos? ¿quiénes van a ser los "marginados" de la educación y la información y qué consecuencias tendrá ello en una sociedad de la información? ¿quiénes quedarán excluidos de esa sociedad y por cuánto tiempo? ¿cuáles son los nuevos usos y abusos de la información? y ¿dónde está el límite entre lo público y lo privado?

Estas preguntas y sus respuestas atañen obviamente a muchos sectores de la sociedad y deben ser analizadas en un contexto acorde con cada uno de ellos. Faltan, además, las preguntas propias que cada sector necesita agregar para poder encontrar respuestas dentro de un contexto general. Desde el punto de vista de las bibliotecas como entes que desempeñaron un papel preponderante en esa sociedad industrializada y de principios de la era de la información, podemos añadir las siguientes preguntas: ¿qué papel social deben representar las bibliotecas en esta sociedad de la información? ¿cómo es la biblioteca que responde a esas necesidades? ¿cómo debe transformarse de su estructura de "segunda mitad del siglo $\mathrm{XX}$ " a la nueva estructura requerida? ¿cómo es el bibliotecario que las diseña, crea y administra? ¿cuáles son los matices y particularidades de esas bibliotecas en nuestro país? y finalmente ¿cómo las organizamos en México?

Como pudo observarse, podemos trazar varios hitos en el estudio de la sociedad de la información y podríamos remontarnos 175 años de acuerdo con Beniger, pero no es objeto de este trabajo establecer un exhaustivo estudio de la historia de la sociedad de la 
información. La he mencionado porque creo que puede establecerse el contexto histórico un poco más allá de lo que normalmente hacemos y ello puede ayudarnos a comprender mejor a esta sociedad. Para establecer el contexto de las bibliotecas actuales y las necesidades de la sociedad, creo que bastará con analizar las principales propuestas de las últimas décadas del siglo $\mathrm{xx}$, ya que nos introducen de lleno a las visiones contemporáneas de los dos entes relevantes ya mencionados: organizaciones y tecnologías de información.

Una última reflexión acerca de la sociedad industrial del ferrocarril y de las computadoras. Si bien es pertinente explicarlas a través de sus iconos más representativos, estas sociedades no pueden definirse únicamente a través de sus símbolos. El ferrocarril y la computadora han sido fuerzas impulsoras de esta sociedad, pero a su vez han sido impulsados por una sociedad cuyos antecedentes, características y estructura dieron forma a los símbolos que identificaron el cambio; esa sociedad ha dado sentido $y$ espíritu a ese cambio. No es conveniente explicar una sociedad solamente por las herramientas más identificables sin considerar además sus contextos e interacciones sociales, culturales, ideológicas, estructurales, etcétera. Sin duda el ferrocarril es el icono más representativo del siglo XIX, pero sería muy riesgoso tratar de explicar esa sociedad sólo a través del ferrocarril. Del mismo modo, existe la tendencia a tratar de explicar la sociedad actual a través de su icono más representativo, la Internet, mezclando a veces a la sociedad con su icono, lo cual sin duda es igualmente riesgoso e impreciso.

Independientemente de sus denominaciones, y como ya hemos mencionado, la sociedad moderna, ese enorme conglomerado humano que existe a lo largo de todo el planeta, no es una sociedad única, homogénea, monolítica. En realidad, está formada por múltiples sociedades correspondientes a cada cultura, país, región, etnia o comunidad. En esencia es una "sociedad de sociedades". De la misma forma, cuando nos referimos a la "sociedad de la información", en realidad debemos tener en mente un conglomerado de "sociedades de la información" que aspiran en mayor o menor 
Sociedad de la información, sociedad del conocimiento y bibliotecas...

grado a esta característica, encontrándose más o menos lejos de su objetivo. Para medir la distancia que hay que recorrer hacia ese objetivo, es necesario conocer las características que definen a una sociedad de la información típica. De acuerdo con el consenso actual son cuatro las características que definen a las "sociedades de información".

\section{Poseen organizaciones con uso intensivo de información.}

En estas sociedades una gran cantidad de organizaciones, tanto públicas como privadas, usan la información y las tecnologías asociadas para incrementar su eficiencia y creatividad, mejorando con cierta frecuencia la calidad de los bienes y/o servicios producidos. Ello se refleja en una continua reorganización industrial y de servicios que agrega más y más valor a la cadena productiva y al PIB de esa sociedad.

\section{Poseen un sector de información significativo.}

La segunda característica de estas sociedades es el desarrollo de un importante sector dedicado a la producción de servicios de información y se refleja en su economía; es decir, gran parte de la riqueza generada por esa sociedad proviene de empresas y servicios de información. En esas sociedades, el sector de información se subdivide básicamente en tres segmentos: contenidos, distribución y procesamiento. En el primero encontramos a los individuos y organismos que producen y desarrollan el material y contenido intelectual: autores, compositores, investigadores, artistas, editores, productores de radio y televisión y diarios.

El segmento de distribución está relacionado, por un lado con los aspectos de redes de comunicaciones y diseminación a través de las cuales se envía información: esto incluye las compañías y organismos de telecomunicaciones, redes de transmisión de radio, televisión y cable, telefonía, Internet, celulares, etcétera. Por otro lado se refiere a los canales para distribuir la información; aquí se encuentran las bibliotecas y las librerías, los proveedores de infor- 
mación, bases de datos, servicios de valor agregado, desde datos del clima hasta complejos reportes selectivos.

El tercer segmento, el de procesamiento de información, tiene que ver con los productores de equipo y programas para cómputo y telecomunicaciones, alojadores de servicios de información (ISP) y procesamiento de datos.

\section{Hay uso social de la información.}

La tercera característica de las sociedades de la información es el alto nivel de uso de información entre el público en general. En ellas, la gente usa información más intensivamente en sus actividades cotidianas, desde opciones como consumidor, el acceso a diversos servicios públicos y como ciudadano para el ejercicio de sus derechos y responsabilidades al efecto. En esencia debe tender a mejorar su nivel de vida.

\section{Hay una sociedad del aprendizaje.}

La última característica que define a una sociedad de la información es la importancia que en ella se da a la educación continua. El conocimiento debe adquirirse y actualizarse en un conglomerado con habilidades de manejo de información que lo habilitan permanentemente para un adecuado desarrollo de la actividad y aseguran competitividad permanente y acceso a un mejor nivel de vida, tanto económica como intelectualmente.

Por tanto, los principales agentes del cambio en una sociedad de la información y que además tienen una seria responsabilidad al participar en la misma son los siguientes sectores:

- Información gubernamental.

- Proveedores de telecomunicaciones.

- Proveedores de Internet.

- Bibliotecas y Servicios de Información.

- Productores y proveedores de textos.

- Productores y proveedores de material audiovisual. 
Sociedad de la información, sociedad del conocimiento y bibliotecas...

- Proveedores de servicios educativos.

- Museos, galerías y archivos.

- Investigación y consultoría.

- Proveedores de equipo, programas y servicios de cómputo.

Reitero que no debemos confundir a la sociedad de la información con su icono más representativo, la Internet, es interesante estudiarlo un poco. Para profundizar en esta caracterización de la Internet, presento a continuación un resumen de lo que, de acuerdo con Manuel Castells, el gran sociólogo español de la sociedad de la información, nos señala como las seis grandes lecciones de la red.

La primera lección sobre Internet es que se desarrolla a partir de la interacción entre la ciencia, con la investigación universitaria fundamental, los programas de investigación militar en Estados Unidos - una combinación curiosa- y la contracultura radical libertaria. Las tres cosas a la vez. Simplemente señalo que el programa de Internet nace como programa de investigación militar pero que, en realidad, nunca tuvo aplicación militar. [...] La cuarta fuente que se desarrolló más fue la cultura empresarial que, 25 años más tarde, se encargó de dar el salto entre Internet y la sociedad.

Segunda lección sobre Internet: el mundo de la empresa no fue en absoluto la fuente de Internet; es decir, Internet no se creó como un proyecto de ganancia empresarial. [...] Recuerden de todas maneras que eran más o menos los años en que el presidente de Digital Corporation, una gran empresa de informática, declaró que no veía ninguna razón para que alguien quisiera una computadora en su casa, o pocos años después de que Thomas Watson, el presidente de IBM, declarase que en el año 2000 en el mundo sólo habría cinco computadoras, y que todas serían, obviamente un "Mainframe" de IBM. No fue pues la empresa la fuente de Internet.

Tercera lección: Internet se desarrolla a partir de una arquitectura informática abierta y de libre acceso desde el principio. Los protocolos centrales de Internet TCP/IP, creados en 1973- 
1978 , son protocolos que se distribuyen gratuitamente y a cuya fuente de código tiene acceso cualquier tipo de investigador o tecnólogo.

Cuarta lección: los productores de la tecnología de Internet fueron fundamentalmente sus usuarios, es decir, hubo una relación directa entre producción de la tecnología por parte de los innovadores pero, después, hubo una modificación constante de aplicaciones y nuevos desarrollos tecnológicos por parte de los usuarios, en un proceso de retroalimentación, de retroacción constante, que está en la base del dinamismo y del desarrollo de Internet [...] Entonces y ahora los usuarios modifican constantemente la tecnología y las aplicaciones de Internet. Esto es una vieja historia de la tecnología [...] Pero con Internet se ha hecho mucho más todavía, porque la flexibilidad, la ductibilidad de esta tecnología permite el efecto de retroacción en tiempo real.

Quinta lección de la historia de Internet: en contra de la muy difundida opinión de que Internet es una creación norteamericana, Internet se desarrolla desde el principio a partir de una red internacional de científicos y técnicos que comparten y desarrollan tecnologías en forma de cooperación, incluso cuando Internet era algo que estaba dentro del Departamento de Estado estadounidense. La tecnología clave de Internet, la conmutación de paquetes, el packet switching, la inventan en paralelo, y sin establecer comunicación alguna durante mucho tiempo, Paul Baran en la Rand Corporation en California y Donald Davies, en el National Physics Laboratory de Gran Bretaña. [...] El desarrollo de los protocolos TCP/IP se hace por Vinton Cerf, en Estados Unidos colaborando estrechamente con Gérard Lelan del grupo francés Cyclades. El caso más interesante es que la World Wide Web, que es el programa que permite la navegación que hoy practicamos todos, lo creó Tim Berners-Lee, un británico, trabajando en sus horas libres, sin que se lo pidiera nadie, en el CERN de Ginebra. [...] El desarrollo de lo que luego sería Internet por su lado libertario, por su lado de base, tenía que ser mucho más internacional, porque dentro del aspecto más central de Internet, Arpanet sólo podía ser norteamericano por las barreras gubernamentales.

Sexta lección: desde el principio Internet se autogestiona, de manera informal, por una serie de personalidades que se ocupan del desarrollo de Internet sin que el gobierno se meta demasiado 
Sociedad de la información, sociedad del conocimiento y bibliotecas...

con ellos. Nadie le dio mucha importancia a Internet y se creó una especie de club aristocrático, meritocrático, que, todavía hoy, ha generado instituciones absolutamente únicas. El gobierno de Internet lo tiene hoy una sociedad de carácter privado apoyada por el gobierno norteamericano y por gobiernos internacionales pero que es privada, se llama ICANN por cierto; su comité ejecutivo tiene, entre otras cosas, la característica de que elige su consejo de administración ejecutivo por votación global entre cualquier persona que se quiera apuntar a ICANN mediante correo electrónico [Castells, 1999. Internet y...].

Me parece que con lo establecido hasta este punto es suficiente para una primera aproximación y caracterización de la sociedad de la información tal como se concibe hoy en día. Para continuar con su comprensión, creo que lo mejor será introducirnos a las iniciativas contemporáneas al respecto.

\subsection{LAS INICIATIVAS CONTEMPORÁNEAS}

Hagamos una breve revisión de las características relevantes de las iniciativas contemporáneas más importantes en materia de sociedades de la información a nivel mundial con objeto de entender sus principales postulados y factores determinantes. Como en muchas otras acciones, una de las primeras iniciativas fue la de Estados Unidos denominada el programa HPCC (High Performance Computing and Communications), establecida en el año de 1991. Puede ser considerada una de las primeras en proponer el proceso en el que entidades gubernamentales y privadas establecen un plan de desarrollo de una sociedad de la información. Originalmente estaba destinada al avance de la tecnología de computadoras y redes en ese país, pero para 1993 ya había evolucionado incluyendo la iniciativa NII (National Information Infraestructure) y para 1994 fue complementada con la GII (Global Infraestructure Initiative) (NCOITR\&D, 1994). El programa final de 1994 de la HPCC se estructuró en cinco ejes principales: 
- Sistemas de procesamiento de alto rendimiento.

- Tecnología de programación de computadora avanzada.

- Redes para educación e investigación.

- Infraestructura nacional para la información.

- Investigación teórica y desarrollo de recursos humanos.

El modelo de ejecución del programa HPCC, apoyado y llevado a cabo por una serie de agencias federales (National Science Foundation, National Aeronautic and Space Administration, Department of Energy, Environmental Pollution Agency, etc.), es ejemplar y ha servido como base para una serie de iniciativas subsecuentes.

Más allá de la sociedad de la información, en particular y en lo relativo a bibliotecas, desde el 1 de mayo de 1995 estas organizaciones formaron la Federación de Bibliotecas Digitales (Digital Libraries Federation) como el principal esfuerzo de investigación y desarrollo en el tema. De hecho el número de Communications of the ACM de abril de ese año fue dedicado íntegramente a las bibliotecas digitales por primera vez (Communications of the ACM, 1995). De esta organización surgió la Iniciativa de Bibliotecas Digitales I y II (Digital Libraries Initiatives I, II) con objeto de ir investigando y desarrollando proyectos de infraestructura que desembocaran en un proyecto ulterior llamado National Digital Library o Biblioteca Digital Nacional de Estados Unidos. Este programa dio origen a una serie de esfuerzos al respecto, tales como: American Memory, Journal Storage (JSTOR), Open Book, etcétera. En particular desde 1999, este programa se ha ido cristalizando en un proyecto denominado NSDL, National Science, Technology, Engineering, and Mathematics Education Digital Library, consolidándose cada vez más como la biblioteca nacional en ciencia, tecnología, ingeniería y matemáticas de la Unión Americana. A la fecha, cuenta con casi 300 colecciones y sigue creciendo día a día; al efecto cuenta con un esquema de "colecciones por cooperación" muy interesante. Más de 400 "iniciativas" de proyectos han ido enriqueciendo tanto su colección como su estructura y servicios y es un ejemplo sumamente interesante en la tendencia o énfasis estadounidense 
Sociedad de la información, sociedad del conocimiento y bibliotecas...

(NSDL, 2001). Me referiré a estos énfasis posteriormente con más detalle.

Respecto a Europa, en diciembre de 1993, el entonces presidente de la Comisión Europea, Jacques Delors, presentó el Libro blanco sobre el crecimiento, la competitividad y el trabajo. En él se establecían las directrices que debían seguir los estados miembros de la Comunidad Europea. El capítulo 5 de ese documento, titulado "La sociedad cambiante, las nuevas tecnologías", desarrollaba el concepto de sociedad de la información. En este texto, Delors relacionaba el imparable proceso de las nuevas tecnologías con la organización social y económica.

Posteriormente, el informe encabezado por el comisario Bangemann "Europa y la sociedad global de la información. Recomendaciones al Consejo Europeo", presentado en Corfú en junio de 1994, alertaba sobre la urgente necesidad que tenía la Unión Europea de adaptarse a las nuevas tecnologías de manera que no quedara relegada en el desarrollo e investigación de esta importante industria. Igualmente, destacaba la importancia de que la ciudadanía europea tuviera acceso a toda la información existente en la red.

Dos años más tarde, se presentó el Libro verde: Vivir y trabajar en la sociedad de la información: prioridad para las personas. La comisión hizo una convocatoria para que se presentaran propuestas que permitieran integrar las nuevas tecnologías y su aplicación en las políticas de desarrollo regional en las zonas más desfavorecidas de Europa.

Poco después, en 1999, la Unión Europea presentó a su vez su programa, denominado e-Europe en el que sobresale su muy articulada forma de presentar las cosas. Entre muchos aspectos, destacan las siguientes siete prioridades:

- Impulsar el acceso a la información en sus naciones a nivel doméstico, llegando al mayor público posible como un factor de igualdad social.

- Impulsar el desarrollo de contenidos atractivos para todos los europeos. 
- Impulsar la interacción del público en línea con los servicios y la administración gubernamental, propiciando mayor eficiencia y transparencia de esa actividad.

- Impulsar y favorecer el desarrollo de las culturas y patrimonios culturales europeos y su acceso con fines de favorecer una identidad regional, así como el acceso en los idiomas locales.

- Favorecer el comercio y la competitividad de las personas, organizaciones y naciones de esa comunidad en un mercado y entorno globalizado.

- Favorecer el desarrollo de mayores anchos de banda y servicios sobre ellos.

- Fomentar la confianza en el uso y seguridad del ciberespacio.

Éste es sin duda uno de los proyectos más relevantes, si no el más relevante, en lo tocante a la construcción de una sociedad de la información. Aparte de haber sido uno de los primeros, es el que empezó a manejar mayores alcances y variables, al ser propuesto como un proyecto de toda la Unión Europea, vista como un todo, al margen de sus retos derivados de la variedad de idiomas, culturas, razas, avances, etcétera.

Resumiendo, las cinco prioridades del proyecto e-Europe en lo tocante a su sociedad de la información, tal como ellos lo han establecido, son las siguientes:

- Promover contenidos atractivos y útiles para todos los europeos.

- Proveer servicios públicos en línea.

- Buscar la inclusión de todos los europeos al acceso digital.

- Promover el desarrollo de una Internet más rápida y económica.

- Asegurar confianza y seguridad en el ciberespacio.

Estos dos ejemplos conformarían de manera por demás definitiva los proyectos de sociedad de la información; a partir de ese momento, las iniciativas de los demás países se han estructurado sobre bases con alta influencia europea. Países como Canadá y Australia trazaron sus propias iniciativas bajo la sombra de los esfuerzos de grupos internacionales como el G7, la OCDE, etcétera. Desta- 
Sociedad de la información, sociedad del conocimiento y bibliotecas...

can también los programas de los países escandinavos que trazaron una muy exitosa política de cómputo y telecomunicaciones desde hace décadas, por encima de Estados Unidos y a quienes, por lo mismo, les fue sencillo transitar hacia sus propias iniciativas de sociedad de la información, siendo de las más avanzadas al momento. No es casualidad que algunas de las compañías más exitosas a nivel mundial en el ramo de telecomunicaciones sean escandinavas: Ericsson, Nokia, etc. En Oriente sin duda el más ambicioso y hasta el momento más exitoso proyecto de sociedad de la información es el de Singapur, sin dejar de notar también el proyecto chino.

En Europa, particularizando en iniciativas para bibliotecas digitales derivadas de estas políticas de sociedad de la información, destacan las del Reino Unido, quien fundó el International Institute for Electronic Library Research, del cual han surgido múltiples iniciativas y servicios, tanto en Inglaterra como en el resto de Europa. En Francia, el esfuerzo de bibliotecas digitales ha sido comandado por las iniciativas de la Biblioteca Nacional de Francia, que ha puesto especial énfasis en una serie de enormes colecciones digitales retrospectivas, bajo el nombre genérico de Gallica (Gallica, 2004) y Bibliothèque Nationale de France (2004). Los países escandinavos, en particular Suecia y Noruega, han llegado a conformar proyectos espléndidos para sus respectivas sociedades.

Regresando a América, una iniciativa muy interesante y bien estructurada, basada en el modelo de la HPCC, es la brasileña. Se trata probablemente del modelo más avanzado en Latinoamérica y es la que ha presentado más método, estructura y profundidad en la región. Su documento básico es conocido en el medio como el Libro verde (Brazil. Ministry of Science and Technology, 2000). No debe confundirse este documento con otro "Libro verde" emanado de la Comisión Europea del G7 como un comunicado de esa agencia bajo el número $\operatorname{COM(97)623~y~cuyo~título~es~Libro~verde~}$ sobre la convergencia de los sectores de telecomunicaciones, medios de comunicación y tecnologías de la información y sobre sus consecuencias para la reglamentación (European Comission, 1997). 
El modelo canadiense acerca de la sociedad del conocimiento es muy interesante porque ha sido proyectado para un país de características en cierta forma parecidas a las nuestras. Luego de tres años de diversos trabajos e investigaciones, finalmente se conformó un consejo para el estudio, el Information Highway Advisory Council (IHAC) que presentó su informe final en 1997 (Information Highway Advisory Council, 1997).

En dicho trabajo de nueve capítulos se presenta el concepto de construcción canadiense para su inserción en la era digital. El primer capítulo establece las bases del concepto con el apropiado título "Hacia una sociedad basada en el conocimiento". Los siguientes dos y tres se refieren a la infraestructura que hay que desarrollar para organizar la "nueva economía”, orientándola hacia Internet. Aquí se hace énfasis en desarrollar esta red en Canadá para aprovechar su potencial comercial, así como los beneficios sociales y culturales.

En su capítulo 4 se ocupa de cómo asegurar para todos los canadienses los beneficios del acceso universal y especialmente el acceso a la red. El capítulo 5 se enfoca en el reto de conservar las raíces culturales del país, en un medio tan heterogéneo y en un país bilingüe. En su capítulo 6 aborda los aspectos esenciales del crecimiento económico y la generación de empleos. En este caso el enfoque también se concentra en la "creación de contenidos y servicios de información" que serán el "fluido vital" de la economía basada en el conocimiento, mientras que el capítulo 7 se ocupa de temas laborales y de la necesidad de modernizar los estándares de trabajo en ese país.

El capítulo 8, relativo al gobierno, se concentra en cómo éste debe actuar "rápida y agresivamente" para ser un "modelo utilizador de las tecnologías de información”. El capítulo 9 y final resume las conclusiones más importantes del estudio.

Los trabajos realizados en este campo en Canadá no se han detenido ahí; este informe fue el punto de partida de nuevos estudios que han continuado analizando todas las implicaciones y prioridades. De allí se desprende su proyecto de Bibliotecas Digitales Canadienses soportado por la Biblioteca Nacional de Canadá al que me referiré más adelante. 
Sociedad de la información, sociedad del conocimiento y bibliotecas...

2.2.1 Paradigmas en las estructuras de las iniciativas de otras naciones

El Libro verde brasileño presenta un análisis interesante de las entidades que han estudiado y convocado las iniciativas de los países a propósito de infraestructura de información o sociedad de la información. Puede observarse que han sido coordinadas mayormente por tres tipos de organización, básicamente por un ministerio o agencia similar gubernamental ligada a las actividades e instancias de la industria o el comercio. Como ejemplos, podemos observar en Estados Unidos la ya mencionada agencia gubernamental NCOITR\&D ligada al Departamento de Comercio de ese país; en Canadá fue el Ministerio de Industria; en Francia los ministerios de Finanzas e Industria; y en Japón el Ministerio de Comercio Internacional e Industria (MITI). Otros ejemplos de países que utilizaron esta aproximación para su propuesta son Dinamarca, Finlandia, Noruega, Holanda y Singapur.

En otros países la coordinación ha sido encargada al organismo responsable de la ciencia y la tecnología. Como ejemplo pueden observarse los casos de España, Portugal y Brasil. En este último la responsabilidad del Ministerio de Ciencia y Tecnología (MCT), además de tener razones de competencia de la entidad, tenía razones históricas, ya que fue ese ministerio el que administró, financió y encabezó el esfuerzo para la instalación de la Internet en Brasil entre 1988 y 1996.

Finalmente, se observa una tercera manera de aproximación a las propuestas a través de un cuerpo consultivo de expertos provenientes de diversos sectores de la sociedad; tal es el caso de los proyectos de Suecia y Australia, así como el ya mencionado interesante e-Europe.

A nivel mundial la línea de características evolutivas de las iniciativas más avanzadas es una secuencia de eventos, en la que se observan típicamente cuatro pasos y tres enfoques de énfasis: 
- Propuesta. Una institución gubernamental es puesta a cargo o toma la iniciativa de coordinar el proceso para la elaboración de la propuesta inicial, a nivel de enunciados de voluntad política, con pocas especificaciones técnicas en esta fase. Generalmente una comisión es formada para llevar a cabo la tarea, con un itinerario mensual y bajo gran presión política tanto interna como externa.

- Gestión. La comisión inicia un proceso de consulta con especialistas en información y con ejecutivos de negocios del ramo, produciendo una breve y bien articulada propuesta, la cual es sometida al nivel más alto del poder ejecutivo: presidente o primer ministro, miembros del gabinete, etcétera. La opinión del poder legislativo está incluida en la propuesta para garantizar apoyo a la iniciativa, presupuesto, iniciativas legales, aspectos sociales, etcétera. Este proceso llega a involucrar en algún país en un momento dado, a cientos de participantes de los sectores público, privado y académico.

- Consulta pública. Con excepción de los países en donde la planeación se hace de forma centralizada, el proceso de divulgar la iniciativa y retroalimentarla con comentarios y sugerencias del público ha sido bastante aceptado. Las encuestas y cuestionarios, listas de discusión, buzones, etcétera, usados en forma planeada son una excelente fuente de afinación de detalles y sobre todo, de apoyo del público.

- Puesta en marcha. Se ha desarrollado un gran esfuerzo para poner en marcha la iniciativa. Actividades previamente planeadas de infraestructura, proyectos con aplicaciones, amplia divulgación de resultados parciales, entre otros, empiezan a ser realizados.

- Enfoque en la legislación y la normatividad. Una vez que la puesta en marcha está estabilizada, le sigue una segunda ola de actividad en aspectos legales desde el punto de vista informático: propiedad, identidad, seguridad, privacidad, delitos, etcétera, así como los aspectos normativos, estándares, autorregulación, códigos éticos, etcétera.

- Enfoque en los negocios electrónicos. En las últimas iniciativas se ha observado un énfasis en los aspectos de negocio electró- 
Sociedad de la información, sociedad del conocimiento y bibliotecas...

nico, tanto en los sectores público como privado: comercio electrónico, pago de impuestos, oferta de servicios vía electrónica, trámites públicos y privados, etcétera.

- Enfoque en contenidos. Finalmente, se ha iniciado una tendencia a incluir el desarrollo de contenidos en las propuestas. Ya estable la puesta en marcha y la infraestructura, las iniciativas se han hecho conscientes de que al final lo más importante de todo esto son los contenidos que pueden ofrecerse, y se observa el esfuerzo en las nuevas fases de antiguas iniciativas de favorecer el desarrollo de contenidos, y también se observa en las nuevas iniciativas un énfasis en este punto.

\subsection{2 Énfasis en la infraestructura en las diferentes alternativas}

En cuanto a la infraestructura, se perciben dos tendencias principales. Los países con una alta infraestructura de telecomunicaciones y cómputo ya instalada, como es el caso de Estados Unidos, Japón y los países escandinavos, han puesto énfasis en la integración de sistemas, telecomunicaciones, redes, etc., dejando que las aplicaciones, contenidos y servicios tomen su lugar por su propia fuerza. Ello puede verse claramente en la National Information Infraestructure (NII) de la Unión Americana, entre 1994 y 1996 (NII. Relationship..., 1998), y puede percibirse todavía más claramente en el resultado de esta iniciativa, la Biblioteca Nacional Digital de Ciencia y Tecnología (NSDL). La segunda tendencia se detecta en otros países, principalmente la Unión Europea y Canadá, en donde el énfasis ha estado en el desarrollo de contenidos, aplicaciones y servicios, dejando que la infraestructura se vaya desarrollando por su propia fuerza.

Independientemente de las tendencias en las propuestas originales, el segundo elemento o etapa observado como común denominador a nivel mundial es que una vez establecidas las propuestas base, se procedió a establecer e impulsar proyectos piloto estratégicos que sirvieran como plataformas de experimentación y detonación de otros proyectos de mayor alcance. Esto puede verse en la 
Unión Americana con iniciativas tales como la GII (Global Infraestructure Initiative), la DLI2 (Digital Libraries Initiative 2) y la Biblioteca Nacional de Ciencia y Tecnología. En julio de 1994, los jefes de Estado del G7 pusieron en marcha una iniciativa con 11 proyectos que funcionan como catalizadores del impulso de esa sociedad de la información en diversas áreas. Esta iniciativa se desarrolló en vista del gran impacto que tuvo la iniciativa GII (Global Infraestructure Initiative) de la Unión Americana. Una vez en marcha, algunos de esos proyectos fueron a su vez adoptados por países fuera del G7, tratando de integrarse al proyecto de una sociedad de información globalizada. Los proyectos piloto fueron planteados entonces alrededor de las áreas consideradas más relevantes por la iniciativa; entre ellas podemos mencionar:

- Desarrollo de bibliotecas digitales.

- Acceso multimedial al patrimonio cultural de la humanidad.

- Administración racional de recursos naturales y del medio ambiente.

- Aplicaciones mundiales sobre salud.

- Aplicaciones gubernamentales y de trámites en línea.

- Negocios electrónicos para pequeñas y medianas empresas.

La mayoría de los proyectos piloto han concluido ya, algunos con mayor éxito que otros, pero en términos generales han dejado satisfechos a los jefes de Estado impulsores convenciéndolos de iniciar esfuerzos más profundos al respecto. Cabe subrayar que una de las principales áreas establecidas fue la de bibliotecas digitales, como polos de desarrollo, educación y empleo, dentro de este esquema de sociedad de la información. Entre ellos el más importante es el denominado Bibliotheca Universalis para formar una vasta red de colecciones digitales internacionales (Bibliotheca Universalis, 2004).

De hecho, el paso de los proyectos piloto a proyectos de desarrollo propiamente dichos de esta sociedad de la información es lo que podemos asumir como la tercera gran etapa de la evolución de estas propuestas. Las tres grandes etapas: propuesta teórica, pro- 
Sociedad de la información, sociedad del conocimiento y bibliotecas...

yectos piloto y proyectos de desarrollo son de suma importancia para el análisis de la propuesta mexicana y las utilizaré posteriormente.

\subsubsection{La sociedad del conocimiento}

Para comenzar, cabe resaltar que en la cumbre de la UNESCO de 2003, alrededor de este tópico el énfasis consistió en establecer que

el acceso a la información es esencial para la creación de sociedades del conocimiento; numerosos ministros procedentes de todas las partes del mundo convinieron en que la utilización de las tecnologías de la información y la comunicación debe guiarse por un conjunto de principios, comprendidos el del acceso universal a información y el de la libertad de prensa, a fin de optimizar su eficacia en beneficio de los individuos, las comunidades y el desarrollo de cada país. Los ministros participantes hacen un llamamiento a los gobiernos para que "reexaminen sus prioridades de desarrollo, a fin de efectuar las inversiones que necesita la edificación de las sociedades del conocimiento" que, según recalcan, "comprenden muchos más aspectos que los de la tecnología y la conectividad" [World Summit on the Information Society (WSIS), 2003].

Esta última propuesta adquiere singular importancia, dado que la propia UNESCO, a través de la International Telecommunication Union (ITU) decide privilegiar ahora el uso del término "sociedad del conocimiento" en lugar de "sociedad de la información" precisamente para comenzar a hacer una distinción entre el concepto que ha hecho énfasis alrededor de la tecnología y la conectividad y el que contempla también contenidos y derecho al acceso, así como nuevos paradigmas, tal como los describe Beatriz Busaniche:

aprender a aprender, trabajar en redes, fomentar el concepto de colaboración colectiva por encima de los conceptos de competencia individual; entrar en una nueva ética del trabajo basado 
en la pasión, la libertad y la cooperación pueden sonar a utopía pero son oportunidades reales. Ninguna política de trabajo y educación basada en tecnología será posible si se la remite sencillamente al problema del acceso a la infraestructura y la conectividad.

\section{Estela Morales complementa esta idea:}

El contenido de los servicios de información es fundamental para el usuario que no se resigna a ser parte de la masa; no se satisface sólo con las temáticas de corte global o universal -aunque éstas también pueden ser de gran utilidad para cierto tipo de necesidades y conocimiento-; cada vez más, los individuos requieren de información que se acerque a su idiosincrasia, a su lengua, a su forma de ver la vida, a las peculiaridades de su zona geográfica, de su religión, de su ideología, de su entorno socio-económico [Morales, 2004].

\section{En el comunicado se dice también que}

las sociedades del conocimiento están relacionadas con las capacidades para identificar, producir, procesar, transformar, difundir y utilizar información destinada a crear conocimientos y aplicarlos en beneficio del desarrollo humano. Esto supone respetar un conjunto de principios y prioridades: "libertad de expresión, acceso universal a la información y al conocimiento, respeto de la dignidad humana y la diversidad cultural y lingüística, educación para todos de buena calidad, realización de inversiones en ciencia y tecnología, y entendimiento e incorporación de los sistemas de conocimiento autóctonos".

En la sociedad del conocimiento, tal como la ha conceptualizado la Comisión Europea, se debe incrementar el nivel de conocimiento de las personas, fomentar la adquisición de nuevos conocimientos y valorar los conocimientos adquiridos. En ella, las nuevas tecnologías deben estar siempre al servicio de la formación y no ser consideradas únicamente como una meta a alcanzar. 
Sociedad de la información, sociedad del conocimiento y bibliotecas...

Algunos estudiosos de este fenómeno sociocultural, afirman que en la época actual se está gestando un nuevo modo de desarrollo, entendido en el sentido que le da Castells a este concepto:

Así, los modelos de desarrollo son las fórmulas tecnológicas mediante las cuales el trabajo actúa sobre la materia para generar el producto, determinando en último término el nivel de excedente. Cada modo de desarrollo queda definido por el elemento que es fundamental para determinar la productividad del proceso de producción. En el modo de desarrollo agrario, los incrementos en el excedente son resultado de un incremento cuantitativo del trabajo y de los medios de producción, incluida la tierra. En el modo de desarrollo industrial, el origen del incremento del excedente se basa en la introducción de nuevas fuentes de energía, así como en la calidad del uso de dicha energía. En el modo de desarrollo informacional, sobre cuyo surgimiento vamos a hipotetizar, la fuente de la productividad se basa en la calidad del conocimiento, el otro elemento intermediario en la relación entre fuerza de trabajo y medios de producción [Castells, 1999].

Taichi Sakaiya, secretario de la Agencia Japonesa para la Planeación Económica del Estado, en su obra La historia del futuro: la sociedad del conocimiento, establece:

El impulso empático que lleva al hombre a consumir aquello que existe en abundancia reaccionará vigorosamente [...] ello va a contribuir a definir el perfil que tendrá la sociedad venidera. Será una sociedad que tenderá a consumir gran cantidad de tiempo en el saber y tendrá menos interés en la cantidad de bienes materiales. La gente de la época venidera utilizará su tiempo para asimilar conocimiento, una necesidad vital en una atmósfera caracterizada por la diversificación y una subjetividad social en mutación constante y que obligará con frecuencia a optar y a decidir con rapidez [...] de ello se desprende una nueva forma de valor -el "valor-conocimiento" o "valor-inteligencia" - que demostrará que su poseedor está en la avanzada de la subjetividad social; dicho de otra forma, posee buena "inteligencia" o información [Sakaiya, 1995]. 
Los postulados de Sakaiya se enmarcan en los de aquellos autores que vienen anunciando desde hace años un cambio radical en la cultura humana. De acuerdo con él, uno de los puntos centrales de este nuevo paradigma de la civilización moderna lo constituirán la acumulación y el procesamiento de una cantidad enorme de información y saber: el saber es, pues, el bien que existe en mayor abundancia. Por lo mismo, en la nueva sociedad que se está configurando, el estilo de vida que obtendrá mayor respeto se basará en el consumo del saber, en su acepción más amplia y los productos que se venderán mejor serán los que revelen que el comprador es una persona "que sabe".

Independientemente de que estemos de acuerdo o no con estos postulados que pueden sonar utópicos en un mundo que tiende a la tecnificación y la globalización, es importante destacar este nuevo énfasis de la sociedad del conocimiento en el que se privilegian los contenidos, la libertad, el espíritu colaborativo, etc., sobre el simple problema de accesibilidad tecnológica, y por tanto es un paso más hacia adelante en la conceptualización de esta sociedad moderna, además de que a mí en lo personal me agrada más este enfoque humanista sobre el puramente técnico.

Dada su importancia, he elaborado un resumen de los once principios fundamentales que, de acuerdo con la cumbre mundial, deben regir la construcción de una "sociedad del conocimiento":

1. La función de los gobiernos y de todas las partes interesadas en la promoción de las tecnologías de información y comunicación (TIC) para el desarrollo.

Los gobiernos, el sector privado, la sociedad civil, las Naciones Unidas y otras organizaciones internacionales tienen una función y una responsabilidad importantes en el desarrollo de la sociedad de la información y, en su caso, en el proceso de adopción de decisiones. Crear una sociedad de la información cuya prioridad sea la persona supone un esfuerzo conjunto que necesita la cooperación y la asociación de todas las partes interesadas.

2. Infraestructura de la información y la comunicación: fundamento básico de una sociedad de la información para todos. 
Sociedad de la información, sociedad del conocimiento y bibliotecas...

La conectividad es uno de los importantes factores habilitadores para crear la sociedad de la información. El acceso universal, ubicuo, equitativo y asequible a la infraestructura y los servicios de las tecnologías de información y comunicación (TIC) incluyendo, por supuesto, el acceso a la energía así como los servicios postales, es una de las ambiciones de la sociedad de la información y debe ser un objetivo de todos los que participan en su creación, y debe garantizarse de conformidad con la legislación nacional de cada país. Un buen desarrollo de infraestructuras de red y aplicaciones de comunicación e información adaptadas a las condiciones locales, regionales y nacionales, fácilmente accesibles y asequibles, con adecuado ancho de banda y de ser posible, con otras tecnologías innovadoras, puede acelerar el progreso económico y social y mejorar el bienestar de todas las personas, comunidades, orgnizaciones y poblaciones.

Habrá que concebir y aplicar políticas que creen un clima favorable de estabilidad, previsibilidad y competencia leal a todos los niveles, de tal forma que se atraiga más inversión privada para el desarrollo de infraestructura de las TIC y que ésta sirva también para cumplir las obligaciones del servicio universal en regiones en las cuales las condiciones tradicionales del mercado no lo permiten. En las zonas menos aventajadas el establecimiento de puntos de acceso público a las TIC en oficinas de correos, escuelas, bibliotecas y archivos pueden garantizar eficazmente el acceso universal a los servicios y la infraestructura de la sociedad de la información.

\section{Acceso a la información y al conocimiento.}

Que todos puedan acceder y contribuir a la información, las ideas y el conocimiento es indispensable en una sociedad de la información incluyente. Es posible mejorar el intercambio y el incremento de los conocimientos mundiales para favorecer el desarrollo, si se eliminan las barreras que impiden un acceso equitativo a la información para realizar actividades económicas, sociales, políticas, sanitarias, culturales, educativas y científicas, y si se facilita el acceso a la información que existe en el dominio público, lo que puede lograrse, entre otras cosas, mediante el diseño universal y la utilización de tecnologías auxiliares. Un dominio públi- 
co rico es un factor capital del crecimiento de la sociedad de la información, ya que genera ventajas tales como un público informado, nuevos empleos, innovación, oportunidades comerciales y el avance de las ciencias. El acceso sin dificultad a la información del dominio público es esencial en la sociedad de la información, como lo es la protección de dicha información contra toda apropiación indebida. Habrá que fortalecer las entidades públicas tales como bibliotecas y archivos, museos, colecciones culturales y otros puntos de acceso comunitario para promover la preservación de los registros de documentos y el acceso libre y equitativo a la información. Nos esforzamos en propiciar el acceso universal y equitativo al conocimiento científico y la creación y divulgación de información científica y técnica, con inclusión de las iniciativas encaminadas al acceso abierto en el campo de las publicaciones científicas.

\section{Creación de capacidades.}

Hay que ofrecer a cada persona la posibilidad de adquirir las competencias y los conocimientos necesarios para comprender, participar activamente y beneficiarse plenamente de la sociedad de la información y la economía del conocimiento. La alfabetización y la educación primaria universal son factores esenciales para crear una sociedad de la información integradora para todos, teniendo en cuenta en particular las necesidades especiales de las niñas y las mujeres. A la vista de la amplia gama de especialistas en las TIC y la información que serán necesarios a todos los niveles, debe prestarse particular atención a la creación de capacidades institucionales. Debe promoverse el empleo de las TIC a todos los niveles en la educación, la formación y el perfeccionamiento de los recursos humanos, teniendo en cuenta las necesidades particulares de las personas con discapacidades y los grupos desfavorecidos y vulnerables. La formación continua y de adultos, la capacitación en otras disciplinas y el aprendizaje continuo, la enseñanza a distancia y otros servicios especiales, tales como la telemedicina, pueden ser claves a la hora de beneficiarse de las nuevas posibilidades ofrecidas por las TIC para los empleos tradicionales, los profesionales liberales y las nuevas profesiones. A este respecto, la conciencia acerca de la importancia que revis- 
Sociedad de la información, sociedad del conocimiento y bibliotecas...

ten las TIC y la adquisición de conocimientos en esta esfera son un cimiento fundamental.

Los creadores, editores y productores de contenido, así como los profesores, instructores, archivistas, bibliotecarios y alumnos deben desempeñar una función activa en la promoción de la sociedad de la información, particularmente en los países menos adelantados. Para alcanzar un desarrollo sostenible de la sociedad de la información, deben reforzarse las capacidades nacionales en materia de investigación y desarrollo de TIC. Por otro lado, las asociaciones entre países desarrollados y países en desarrollo, incluidos los países con economías en transición, con fines de investigación y desarrollo, transparencia de tecnologías, producción y utilización de los productos y servicios TIC, son indispensables si se desea propiciar la creación de capacidades y una participación mundial en la sociedad de la información. La fabricación de productos para las TIC representa una oportunidad importante de creación de riqueza. El logro de nuestras aspiraciones compartidas para que los países en desarrollo y los países con economías en transición se conviertan en miembros eficaces de la sociedad de la información y conseguir que se integren positivamente en la economía del conocimiento, depende en gran parte de la mayor creación de capacidad en las esferas de la educación, los conocimientos técnicos y el acceso a la información, esferas todas ellas determinantes para el desarrollo y la capacidad de competencia.

5. Crear confianza y seguridad en la utilización de las TIC.

Reforzar el marco de confianza que abarca, entre otras cosas, la seguridad de la información y la seguridad de las redes, la autenticación, la privacidad y la protección de los consumidores, es requisito previo para que se desarrolle la sociedad de la información y se promueva la confianza de usuarios en las Tic. Se debe fomentar, desarrollar y poner en práctica una cultura mundial de la ciberseguridad en cooperación con todas las partes interesadas y los organismos internacionales especializados. Habrá que respaldar dichos esfuerzos con una mayor cooperación internacional. Dentro de esta cultura mundial de la ciberseguridad, es importante mejorar la seguridad y garantizar la protección de los datos y la privacidad al tiempo que se mejora el acceso y el comercio. Por 
otra parte, es necesario tener en cuenta el nivel de desarrollo social y económico de cada país, así como los aspectos de la sociedad de la información relacionados con el desarrollo. Si bien se reconocen los principios de acceso universal y sin discriminación a las TIC para todas las naciones, apoyamos las actividades de $\mathrm{Na}$ ciones Unidas encaminadas a impedir que se utilicen estas tecnologías con fines incompatibles con el mantenimiento de la estabilidad y seguridad internacionales, lo que podría menoscabar la integridad de las infraestructuras nacionales al atentar contra su seguridad. Es necesario evitar que las tecnologías y los recursos de la información se utilicen para fines delictivos o terroristas, respetando siempre los derechos humanos. El envío masivo de mensajes electrónicos no solicitados -spam- es un problema considerable y creciente para los usuarios, las redes y la Internet en general. Conviene abordar nacional e internacionalmente la ciberseguridad y el control del envío masivo de este tipo de mensajes.

\section{Entorno habilitador.}

Para promover la sociedad de la información es indispensable crear un entorno propicio a nivel nacional e internacional; las TIC deben utilizarse como una herramienta importante de gobierno eficaz. El imperio de la ley, acompañado por un marco de política y reglamentación propicio, transparente y favorable a la competencia, neutral desde el punto de vista tecnológico, predecible y que refleje las realidades nacionales, es insoslayable si se desea construir una sociedad de la información centrada en la persona. Los poderes públicos deben intervenir, según proceda, para corregir los fallos del mercado, mantener una competencia leal, atraer inversiones, fomentar el desarrollo de infraestructura y aplicaciones de las TIC para aumentar al máximo los beneficios económicos y sociales y atender a las prioridades nacionales. Las TIC son un importante factor habilitador del crecimiento, ya que mejoran la eficacia e incrementan la productividad, especialmente en las pequeñas y medianas empresas (PyMEs). Por esta razón, el desarrollo de la sociedad de la información es importante para lograr un crecimiento económico general en los países desarrollados y en desarrollo. Se debe fomentar la mejora de la productividad por medio de las TIC y la aplicación de la innovación en 
Sociedad de la información, sociedad del conocimiento y bibliotecas...

todos los sectores económicos. La distribución equitativa de los beneficios contribuye a la erradicación de la pobreza y al desarrollo social. Las políticas que fomentan la inversión productiva y permiten a las empresas, en particular a las PYMEs, efectuar los cambios necesarios para aprovechar los beneficios de las TIC, son probablemente las más beneficiosas.

La protección de la propiedad intelectual es importante para propiciar la innovación y la creatividad en la sociedad de la información, como también lo son la amplia divulgación, la difusión y el intercambio de conocimientos. Facilitar la participación significativa de todos en todas las esferas de la propiedad intelectual, mediante la sensibilización y la creación de capacidades, es parte irrenunciable de una sociedad de la información integradora. La normalización es otro de los elementos constitutivos importantes de la sociedad de la información. Conviene destacar muy especialmente la preparación y adopción de normas internacionales. La concepción y el empleo de normas abiertas, compatibles, no discriminatorias e impulsadas por la demanda, en que se tengan en cuenta las necesidades de los usuarios y los consumidores, es un factor básico del desarrollo y la mayor propagación de las TIC, así como de un acceso más asequible a las mismas, sobre todo en los países en desarrollo. Las normas internacionales tienden a crear un entorno en el cual los consumidores tengan acceso a servicios en todo el mundo, independientemente de la tecnología subyacente.

La mejor forma de promover el desarrollo sostenible en la sociedad de la información consiste en integrar plenamente los programas e iniciativas TIC en las estrategias de desarrollo nacionales y regionales. Alentamos a la comunidad internacional a promover las medidas relacionadas con las TIC comprendidas en el marco de esta iniciativa, así como las desplegadas en el marco de esfuerzos similares en otras regiones. La distribución de los beneficios resultantes del mayor crecimiento debido a las TIC contribuye a la erradicación de la pobreza y a un desarrollo sostenible. Se insta enérgicamente a los estados a que, al crear la sociedad de la información, adopten medidas para evitar y se abstengan de adoptar medidas unilaterales no conformes con la legislación internacional y con la Carta de las Naciones Unidas, que impida la plena consecución del desarrollo económico y social de la población de los países 
interesados, y sea contraria al bienestar de sus ciudadanos. Reconociendo que las TIC están alterando progresivamente nuestras prácticas de trabajo, es indispensable crear un entorno de trabajo seguro y sano que sea adecuado para la utilización de las TIC, así como conforme a las normas internacionales pertinentes.

La Internet se ha convertido en una facilidad disponible para el público mundial y su gobernanza debe ser una de las cuestiones esenciales en el programa de la sociedad de la información. La gestión internacional de la Internet debe ser multilateral, transparente y democrática, y contar con plena participación de los gobiernos, el sector privado, la sociedad civil y las organizaciones internacionales. En esta gestión habría que garantizar la distribución equitativa de recursos, facilitar el acceso a todos, garantizar un funcionamiento estable y seguro de la Internet, y tener en cuenta el multilingüismo. La gestión de la Internet abarca cuestiones técnicas y de política y debe contar con la participación de todas las partes interesadas y de organizaciones internacionales e intergubernamentales competentes; a este respecto se considera que:

a) La autoridad política en materia de política de la Internet que concierne al público es un derecho soberano de los estados, los cuales tienen derechos y responsabilidades en los aspectos de la Internet de alcance internacional y relacionados con las políticas que conciernen al público;

b) El sector privado ha desempeñado y debe seguir desempeñando un importante papel en el desarrollo de la Internet, tanto en los campos técnicos como económicos;

c) La sociedad civil también ha desempeñado y debe seguir desempeñando un importante papel en asuntos relacionados con la Internet, especialmente a nivel comunitario;

d) Las organizaciones intergubernamentales han desempeñado y deben seguir desempeñando una función de apoyo en la coordinación de los aspectos de la Internet que guardan relación con las políticas que conciernen al público;

e) Las organizaciones internacionales han desempeñado y deben seguir desempeñando una importante función en el desarrollo de normas técnicas y políticas pertinentes relativas a la Internet. La gobernanza de los aspectos de la Internet que tienen alcance internacional debe llevarse a cabo de manera coordinada. 
Sociedad de la información, sociedad del conocimiento y bibliotecas...

7. Aplicaciones de las TIC: ventajas en todos los aspectos de la vida.

La utilización y despliegue de las TIC debe orientarse a la creación de beneficios en todos los ámbitos de la vida cotidiana. Las aplicaciones de las TIC son potencialmente importantes para las actividades y servicios gubernamentales, la atención y la información sanitaria, la educación y la capacitación, el empleo, la creación de empleos, la actividad económica, la agricultura, el transporte, la protección del medio ambiente y la gestión de los recursos naturales, la prevención de catástrofes y la vida cultural, así como para fomentar la erradicación de la pobreza y otros objetivos de desarrollo acordados. Las TIC también deben contribuir al establecimiento de pautas de producción y consumo sostenibles y a reducir las barreras tradicionales, ofreciendo a todos la oportunidad de acceder a los mercados nacionales y mundiales de manera más equitativa. Las aplicaciones deben ser fáciles de utilizar, accesibles para todos, asequibles, adaptadas a las necesidades nacionales en materia de idioma y cultura, y favorables al desarrollo sostenible. A tal efecto, las autoridades nacionales deben desempeñar una importante función en el suministro de servicios de las TIC en beneficio de sus poblaciones.

8. Diversidad e identidad culturales, diversidad lingüística y contenido local.

La diversidad cultural es el patrimonio común de la humanidad; la sociedad de la información debe fundarse en el respeto de las identidades y diversidades culturales y lingüísticas, las tradiciones y las religiones y estimular ese respeto, además de promover un diálogo entre las culturas y las civilizaciones. El fomento, la afirmación y preservación de los diversos idiomas e identidades culturales, tal como se consagran en los correspondientes documentos acordados por las Naciones Unidas, incluida la Declaración Universal de la UNESCO sobre la Diversidad Cultural, contribuirán a enriquecer aún más la sociedad de la información. La creación, difusión y preservación de contenido en varios idiomas y formatos deben considerarse altamente prioritarias en la construcción de una sociedad de la información integradora, prestán- 
dose particular atención a la diversidad de suministro de obras creativas y al debido reconocimiento de los derechos de los autores y artistas. Es esencial promover la producción de contenidos y la accesibilidad a los mismos, sea con propósitos educativos, científicos o culturales o con fines recreativos, en diferentes idiomas y formatos. La creación de contenido nacional que se ajuste a las necesidades nacionales o regionales fomentará el desarrollo socioeconómico y estimulará la participación de todas las partes interesadas, incluyendo a los habitantes de zonas rurales, distantes y marginales.

La preservación del patrimonio cultural es un elemento crucial de la identidad personal y el conocimiento de sí mismo, que son, a su vez, el enlace de una comunidad con su pasado. La sociedad de la información debe aprovechar y preservar el patrimonio cultural para el futuro, para lo cual utilizará todos los métodos adecuados, entre otros, la digitalización.

9. Medios de información.

Reafirmamos nuestro compromiso con los principios de libertad de la prensa y libertad de la información, así como los de la independencia, el pluralismo y la diversidad de los medios de comunicación, que son esenciales para la sociedad de la información. También es importante la libertad de buscar, recibir, divulgar y utilizar la información para la creación, recopilación y divulgación de conocimiento. Abogamos por que los medios de comunicación utilicen y traten la información de manera responsable de acuerdo con los principios éticos y profesionales más exigentes. Los medios de comunicación tradicionales, en todas sus formas, tienen un importante papel que desempeñar en la sociedad de la información, y las TIC deben servir de apoyo a este respecto. Debe fomentarse la diversidad de regímenes de propiedad de los medios de comunicación, de acuerdo con la legislación nacional y habida cuenta de los convenios internacionales pertinentes. Reafirmamos la necesidad de reducir los desequilibrios internacionales en materia de medios de comunicación, en particular en lo que respecta a la infraestructura, los recursos técnicos y el desarrollo de capacidades humanas. 
Sociedad de la información, sociedad del conocimiento y bibliotecas...

10. Dimensiones éticas de la sociedad de la información.

La sociedad de la información debe respetar la paz y regirse por los valores fundamentales de libertad, igualdad, solidaridad, tolerancia, responsabilidad compartida y respeto a la naturaleza. Reconocemos la importancia de la ética para la sociedad de la información, quien debe promover la justicia, así como la dignidad y el valor de la persona humana. Habrá que acordar la protección más amplia posible a la familia y permitir que ésta desempeñe su papel cardinal en la sociedad. Al utilizar las TIC y crear contenidos habrá que respetar los derechos humanos y las libertades fundamentales de otros, lo que incluye la privacidad personal y el derecho a la libertad de opinión, conciencia y religión. Todos los actores de la sociedad de la información deben adoptar las medidas preventivas y las acciones necesarias, con arreglo a la legislación, para impedir la utilización abusiva de las TIC que dan lugar a, entre otros, actos ilegales o de otro tipo motivados por el racismo, la discriminación racial, la xenofobia y la intolerancia, el odio, la violencia que ello entraña; todo tipo de abuso infantil, así como el tráfico y la explotación de seres humanos.

\section{Cooperación internacional y regional.}

Nuestro objetivo es utilizar plenamente las oportunidades que ofrecen las TIC en nuestros esfuerzos por alcanzar los objetivos de desarrollo convenidos internacionalmente, incluyendo los que figuran en la Declaración del Milenio, y sostener los principios clave que establece dicha declaración. La sociedad de la información es por naturaleza intrínsecamente mundial y los esfuerzos realizados a nivel nacional han de ser respaldados por una cooperación eficaz, a nivel interregional y regional entre los gobiernos, el sector privado, la sociedad civil y las demás partes interesadas, incluidas las instituciones financieras internacionales. La integración regional contribuye al desarrollo de la sociedad de la información mundial y hace que la intensa cooperación entre las regiones y en el interior de éstas sea indispensable. El diálogo regional debe contribuir a la creación de capacidades a nivel nacional y a la armonización de las estrategias nacionales de manera compatible con los objetivos de esta declaración de principios, 
respetándose al mismo tiempo las particularidades nacionales y regionales. En este sentido, acogemos con agrado las medidas relacionadas con las TIC que forman parte de esas iniciativas, y alentamos a la comunidad internacional a promoverlas.

Tenemos la firme convicción de que estamos entrando colectivamente en una nueva era que ofrece inmensas posibilidades, es decir la era de la sociedad de la información y la expansión de la comunicación humana. En esta sociedad incipiente es posible generar, intercambiar, compartir y comunicar informaciones y conocimientos entre todas las redes del mundo. Si tomamos las medidas necesarias, pronto todos los particulares podrán colaborar para construir una nueva sociedad de la información basada en el intercambio de conocimientos y asentada en la solidaridad mundial y una mejor comprensión entre los pueblos y las naciones. Confiamos en que estas medidas abran una vía hacia el futuro desarrollo de una verdadera sociedad del conocimiento.

Estos 11 principios que he resumido me parecen de capital importancia. Sin ellos, toda la cuestión de la sociedad de la información pierde su rumbo. ¿Para qué queremos una sociedad informatizada? ¿El simple acceso a las TIC y a las redes pone a sus beneficiarios en un plano superior? Si las personas no pueden obtener de ello los mecanismos para propiciar el desarrollo de cada individuo informatizado y de su entorno social todo habrá sido en vano. Hay que ofrecer a cada persona la posibilidad de adquirir las competencias y los conocimientos necesarios para comprender, participar activamente y beneficiarse plenamente de la sociedad de la información y la economía del conocimiento; los miembros de esta sociedad deben poder estar informados y ser creativos. La utilización y despliegue de las TIC debe orientarse a la creación de beneficios en todos los ámbitos de la vida cotidiana. De otra forma tendremos cada vez más millones y millones de personas que tienen acceso a la red mundial y que saben conectarse y utilizar las herramientas más elementales de conexión, como navegador y correo, pero que simplemente lo hacen para cuestiones sin relevancia, sin incorporarlo realmente a una mejora en su nivel de vida y para colmo quedando expuestos a grandes volúmenes de mediatización sin desa- 
rrollar mecanismos de defensa. Es decir, tendremos millones de personas "alfabetizadas" digitalmente pero de las cuales la inmensa mayoría será "analfabeta digital funcional". Esto sería tanto como afirmar en la actualidad que simplemente enseñar a leer y escribir a todos los individuos los deja listos para iniciar su educación y desarrollo por sus propios medios sin mayor esfuerzo adicional. Peor aún, es como pretender que simplemente con llevar a los alumnos a la escuela y mostrarles los libros de texto los ponemos en el camino del saber. Recordando el diálogo entre los bomberos Beatty y Montag, en Fahrenheit 451: “ “.. un poco de instrucción es peligrosa. Bebe copiosamente, o no pruebes del manantial de la sabiduría”.

En resumen: no es sólo un problema de conectividad y acceso. El riesgo mayor que enfrenta la sociedad de la información es el de alfabetizar digitalmente en masa a millones de personas creando a la vez en masa millones de "analfabetas digitales funcionales". Sería la más cruel de las paradojas respecto a lo que promete. Los once principios de la sociedad del conocimiento sin duda alguna hacen la diferencia. Vale la pena recordar en este momento a William Butler Yeats: "educar no es llenar un recipiente; es encender una llama".

Una vez que hemos destacado las características superiores de este concepto de "sociedad del conocimiento" y su importancia para el desarrollo humano, es pertinente hacer una reflexión acerca de la posibilidad de acceder a dicha sociedad. Hemos planteado previamente las preguntas: ¿quiénes van a ser los "marginados" de la educación y la información y qué consecuencias tendrá ello en una "sociedad de la información"? ¿Quiénes quedarán excluidos de esa sociedad y por cuánto tiempo? Es el momento de analizar el fenómeno conocido como "brecha digital".

Según Arturo Serrano y Evelio Martínez 5 la brecha digital se define como

\footnotetext{
${ }^{4}$ Ray Bradbury, 1981. Fahrenheit 451. Barcelona: Plaza \& Janés.

5 Arturo Serrano S. y Evelio Martínez M. 2003. La brecha digital: mitos y reali-
} 
[...] la separación que existe entre las personas, comunidades, estados, países, etc., que utilizan las nuevas tecnologías de la información como una parte rutinaria de su vida diaria y aquellas que no tienen acceso a las mismas y que aunque las tengan no saben cómo utilizarlas. La "brecha digital" puede ser definida en términos de la desigualdad de posibilidades que existen para accesar a la información, al conocimiento y la educación mediante las tecnologías de información. La brecha digital no se relaciona solamente con aspectos exclusivamente de carácter tecnológico, es un reflejo de una combinación de factores socioeconómicos y en particular de limitaciones y falta de infraestructura de telecomunicaciones e informática.

Es de suma importancia recalcar lo que aquí se define: la brecha digital tiene dos componentes primordiales y distintos; uno es la posibilidad de acceder a las tecnologías de información, y otro es un factor socieconómico relativo a la capacidad de aprovechar estas tecnologías en favor del propio desarrollo.

En relación con este segundo componente, Phillip J. Tichenor, profesor de periodismo y comunicación de masas; George Donohue, profesor de sociología y Clarice N. Olien, profesora de sociología rural, todos ellos de la Universidad de Minnesota, formularon desde 1970, mucho antes del advenimiento de la computadora personal y la Internet la hipótesis de la "brecha del conocimiento" en relación con los efectos de los medios masivos de comunicación, conocida también como Knowledge Gap Hypothesis o KGH, ampliada posterioriormente en su obra Community Conflict and the Press. ${ }^{6}$ Fue esencialmente una propuesta basada en análisis empíricos, ligada a los planteamientos difusionistas de la innovación comunicativa en ámbitos urbanos y rurales y en países en vías de desarrollo. Esta hipótesis ha sido tomada como la base de futuros planteamientos

dades. Mexicali: Universidad Autónoma de Baja California, FoECA (Fondo Editorial de Baja California), 175 pp.

6 PhilipJ. Tichenor, George Donohue y Clarice Olien. 1980. Community Conflict and the Press. Sage: Newbury Park, Cal. 
Sociedad de la información, sociedad del conocimiento y bibliotecas...

acerca de las brechas o gaps comunicacionales, incluida la que hoy se define como la "brecha digital" (Tichenor et al., 1970).

Los mencionados autores advierten que:

[...] la capacidad receptiva, de comprensión y asimilación de conocimiento está directamente relacionada con el conocimiento previo del receptor, su inclusión en redes sociales y el nivel selectivo de exposición ante los medios. Con el tiempo, la estratificación socioeconómica establece una correlación con el interés informativo de la población, de modo que, por lo general, son las clases menos favorecidas las que menor cantidad de información reciben, y no porque ésta no esté a su alcance, sino porque muestran menor destreza receptiva y mayor dificultad de comprensión, circunstancias que, en consecuencia, generan una autoprivación informativa. Pero son también las clases más bajas, por su menor capacidad de contextualización y elaboración de criterios, las más vulnerables a los efectos persuasivos o mediáticos. Las clases menos favorecidas suelen limitar sus consumos al ámbito de lo audiovisual, de modo que la televisión se convierte en fuente dominante y gratificante, sin otros contrastes o complementos. Constituirán entonces el estrato de los "info-pobres".

Las clases más favorecidas, los "info-ricos", no sólo tienen mayor facilidad en el acceso a las fuentes -éste no sería el elemento determinante-, sino que es su conocimiento el que desarrolla el interés y la predisposición hacia una mayor riqueza informativa; además, su información previa las habilita para una contextualización estructurada de lo que acontece.

Si en un sistema social se incrementa la información disponible a través de los medios, los segmentos de población con un estatus socieconómico más elevado y mayor formación tienden a adquirirla más rápidamente como un valor de su estatus, acentuando su distancia de conocimiento con los segmentos más deprimidos. Entre las personas cultivadas el saber no disminuye, sino que tiende a aumentar y a hacerlo de manera más rápida que entre las personas con bajo conocimiento previo.

La hipótesis destaca que "conocimiento llama conocimiento" y por ende "ignorancia llama ignorancia", y cobra especial interés en 
un periodo marcado por un fuerte desarrollo de las fuentes y estructuras tecnológicas destinadas a la distribución de información y conocimiento. La falta de acceso para el aprovechamiento adecuado y oprtuno de las nuevas oportunidades supone aumento de la brecha o gap, esto es, un distanciamiento entre las posiciones de los info-ricos y los info-pobres, pero no sólo entre zonas del planeta donde las condiciones económicas desiguales crean el problema, sino en áreas geográficas donde las diferencias están determinadas no tanto por barreras económicas de acceso a los medios como por la autoexclusión cultural derivada de los intereses mediáticos y culturales. Los autores mencionados observaron en sus trabajos de campo que la "brecha del conocimiento" se reducía cuando en los hábitos de consumo de medios de información se incluía la prensa impresa, ya que este ingrediente suponía un desarrollo de la capacidad de abstracción y reflexión, así como un alejamiento de posiciones cercanas o propicias para el desarrollo del analfabetismo funcional.

Las desigualdades de clase en la recepción de la información acentúan las posiciones de poder, en la medida en que la privación de conocimiento incrementa la incertidumbre y la inseguridad personal y social. Según esta percepción, "la brecha tiende a ampliarse, de forma tal que a medida que crecen las posibilidades de obtener información y conocimiento, la probabilidad de que aumente la diferencia de conocimientos es mayor".

Otro de los aspectos muy importantes que la hipótesis establecía también y que tiene que ver directamente con este estudio, consiste en el hecho de que "la aparición de nuevos medios incrementa la brecha, en la medida en que los menos habilitados para la recepción del conocimiento muestran cierta indolencia o actitud refractaria a variar la composición de sus hábitos de acceso a la información y el conocimiento, independientemente de que la aparición de un nuevo medio suponga o no una barrera económica adicional". Reducir o anular esta brecha del conocimiento mediante políticas educativas y de comunicación presupone cambiar el estado general de los hábitos de distribución y consumo de información dentro de una sociedad dada. 
Sociedad de la información, sociedad del conocimiento y bibliotecas...

Puede observarse entonces que en este aspecto de la marginación de la información y el conocimiento, deberemos cuidar tanto la posibilidad de ofrecer el acceso a las tecnologías de información y comunicación, como la creación de un entorno que elimine las barreras socioeconómicas y culturales que limitan la capacidad de aprovechar estas tecnologías en favor del propio desarrollo aumentando la destreza receptiva y la comprensión, circunstancias que, en consecuencia, incrementan la habilidad para contextualizar estructuradamente lo que acontece.

Tan importante es entonces el trabajo en este sentido que muchas instancias a nivel mundial están preparando iniciativas en esta dirección. La ONU está preparando una en este contexto de salvar la brecha en cuanto a la tecnología digital: un servicio de tecnología de la información de las Naciones Unidas que se llamaría UNITes (United Nations Information Technology Service). Este servicio sería un consorcio de cuerpos de voluntarios con conocimientos técnicos avanzados, como Net Corps Canada y Net Corps America, coordinado con ayuda de los voluntarios de las Naciones Unidas. El UNITes proporcionará formación en países en desarrollo sobre la utilización de la tecnología de la información, dará a conocer las oportunidades que ofrece esa tecnología y fomentará la creación de otros cuerpos dedicados a la tecnología de la información en el Norte y el Sur. Actualmente se están explorando fuentes externas de financiamiento para el proyecto UNITes.

Termino este apartado con una reflexión de lo que Estela Morales dice acerca de la sociedad de la información:

El valor social y económico de la información radica en su reconocimiento individual o colectivo, así como en la necesidad de utilizarla o poseerla. La sociedad actual, denominada sociedad de la información, no sería tal si no se considera como prioridad el que todos los grupos que la forman ejerzan la lectura como parte de la riqueza humana que propiciará el crecimiento sostenido. Se plantea entonces la necesidad de crear bibliotecas universitarias, con medios reales y virtuales, para ser compartidas desde cualquier parte del mundo. Por otro lado, se propone la urgencia 
de generar información, como un insumo básico para el desarrollo cultural, económico y político de cualquier país [Morales, 2001].

2.2.4 La iniciativa mexicana para la sociedad del conocimiento y el acceso a la información: e-México

A principios del año 2001, la administración federal entrante presentó el Plan Nacional de Desarrollo 2001-2006. En él se introdujo, entre muchos otros aspectos, la iniciativa de que las tecnologías de información y comunicación debían ser pieza importante en el desarrollo nacional. De ese documento extraemos, del capítulo "Crecimiento con calidad", apartado 6.3 "Objetivos rectores y estrategia", el objetivo 6.3, inciso 6.3.2 "Competitividad", que dice en su diagnóstico:

En México, buena parte de la población no tiene acceso a una educación de calidad, competitiva en las nuevas posibilidades que el desarrollo tecnológico ofrece. Es necesario adoptar una estrategia que permita a los trabajadores mexicanos contar con una capacitación continua que fortalezca el uso y aprovechamiento de las nuevas tecnologías. En el mundo moderno, la capacitación continua constituye la mejor garantía de seguridad y progreso para el trabajador.

El mismo documento, en su objetivo rector 2 plantea como estrategia general "elevar y extender la competitividad del país"; en su estrategia f) plantea: "uso y aprovechamiento de la tecnología y de la información”. Al respecto establece:

Es imprescindible promover acciones para el uso y aprovechamiento de las tecnologías como recursos estratégicos que contribuyan a la satisfacción de las necesidades de la sociedad mexicana y adoptar los mejores estándares tecnológicos y medidas que protejan la propiedad intelectual. El Ejecutivo federal fortalecerá el sistema nacional de metrología, normalización y evaluación de la conformidad. 
Sociedad de la información, sociedad del conocimiento y bibliotecas...

La incorporación y aprovechamiento de los últimos avances científicos y tecnológicos debe basarse en la aplicación de una estrategia coherente que incluya los siguientes puntos: a] divulgación entre la sociedad de la cultura tecnológica; b] fomento de la tecnología local y adaptación de la tecnología extranjera; c] incorporación de las tecnologías de la información -computación, telecomunicación y telemática- al desarrollo de la cultura empresarial; d] impulso a la producción agrícola mediante el uso de tecnologías para cultivo, explotación de recursos acuíferos e identificación de mercados, para así liberar recursos para otros usos; e] investigación agropecuaria para incrementar la apropiación de conocimientos, de información y de tecnologías y para facilitar el acceso a éstos; f] innovación en la generación, desarrollo, asimilación y aplicación del conocimiento científico y tecnológico, y la formación de recursos humanos para apoyar el avance del sector energético y de comunicaciones y transportes, así como para mantener la diversidad de fuentes generadoras de energía; g] inversión en investigadores jóvenes con nuevas ideas; h] apoyo a la sistematización y ampliación de las bases de información importantes para la actividad científica y tecnológica; i] mejoramiento y ampliación, a empresarios, académicos y público en general, del acceso a centros y fuentes de información que apoyen la competitividad de las empresas, la formación de recursos humanos y la actividad científica y tecnológica; j] fomento de mejores prácticas de comercialización al mayoreo y al detalle; $\mathrm{k}$ ] impulso al desarrollo de la industria de tecnologías de información; 1] fomento de la reconversión digital de procesos dentro de las empresas, especialmente las pequeñas; $\mathrm{m}$ ] promoción del encadenamiento digital de proveedores, y n] aplicación de nuevas tecnologías para la producción, así como políticas para inhibir el uso de técnicas y costumbres dañinas al medio ambiente.

Se aprovechará la coyuntura de la convergencia tecnológica de telecomunicaciones e informática para ofrecer a la población nuevos y mejores servicios en materia de aprendizaje, capacitación, salud, servicios de gobierno, comercio y entretenimiento, así como para procurar la promoción del país en el extranjero. Fomentar y difundir la industria del desarrollo del software, así como adoptar los mejores estándares tecnológicos y medidas que 
protejan la calidad de los servicios a los usuarios, así como la propiedad intelectual [Presidencia de la República, 2001. Plan Nacional de Desarrollo 2001-2006].

Otra referencia importante se encuentra en el Programa Nacional de Educación 2001-2006 (Secretaría de Educación Pública, 2001). He aquí un resumen de las principales ideas al respecto:

México, como los demás países del orbe, está experimentando un cambio radical de las formas en que la sociedad genera, se apropia y utiliza el conocimiento. Ésta es, sin duda, una de las transformaciones sociales de mayor trascendencia, que determinará las oportunidades y desafíos de la educación en las próximas décadas. Los cambios abarcan no sólo el ámbito de las capacidades cognitivas, sino que afectan todos los campos de la vida intelectual, cultural y social, dando expresión concreta a los múltiples tipos de inteligencia humana y, en conjunto, están dando origen a una nueva sociedad caracterizada por el predominio de la información y el conocimiento.

La nueva sociedad del conocimiento se ha sustentado en un cambio acelerado y sin precedentes de las tecnologías de la información y la comunicación, así como en la acumulación y diversificación del conocimiento. En el campo tecnológico, se observa una clara tendencia hacia la convergencia global de los medios masivos de comunicación, las telecomunicaciónes y los sistemas de procesamiento de datos, que determina la emergencia de nuevas oportunidades para la producción y difusión de contenidos culturales, educativos, informativos y de esparcimiento.

En el escenario que se está perfilando será necesario abrir un amplio debate sobre el papel de las nuevas tecnologías, y en especial de los medios de comunicación, tendiente a la definición de una política nacional, que permita orientar las potencialidades de las nuevas tecnologías en beneficio de la educación y el desarrollo nacional.

[...] Se requiere, por lo tanto, estimular la participación de las instituciones educativas nacionales, así como de empresas públi- 
Sociedad de la información, sociedad del conocimiento y bibliotecas...

cas y privadas, en el intercambio internacional de servicios educativos, de conocimientos y experiencias, aprovechando los espacios de acción que existen en el marco de las relaciones bilaterales y en el de los organismos internacionales, lo que supone nuevos mecanismos y marcos normativos.

[...] En este contexto la vida útil del conocimiento tiende a abreviarse. Y si bien es cierto que para tener acceso en condiciones favorables al mundo de la competencia globalizada, al del empleo bien remunerado y al disfrute de los bienes culturales, se requieren cada día mayores conocimientos, también lo es que éstos tienden a tener una aplicación y una vigencia cada vez más limitadas. En estas circunstancias, la educación tendrá que ser más flexible en cuanto al acceso, más independiente de condicionamientos externos al aprendizaje, más pertinente a las circunstancias concretas de quienes la requieren, y más permanente a lo largo de la vida.

[...] Las instituciones educativas pueden adquirir nuevas capacidades para trascender sus fronteras tradicionales. Las redes de comunicación, que se diversifican y amplían en la nueva sociedad del conocimiento, permiten establecer nuevos vínculos, $\mathrm{y}$ fortalecer los existentes entre instituciones educativas, culturales y laborales.

[...] Las instituciones tienen que realizar esfuerzos extraordinarios de apertura, para proporcionar nuevos espacios de aprendizaje que aseguren oportunidades de educación para todos a lo largo de la vida. Las tecnologías de información y comunicación seguirán abriendo nuevas perspectivas para la educación a distancia, que permitirán atender, de manera más amplia y mejor, las necesidades educativas, cada día más urgentes y diversas, de quienes no han podido terminar su educación básica, pero también de los egresados de niveles superiores.

También a principios del año 2001, en el contexto del Plan Nacional de Desarrollo 2001-2006, la administración federal entrante presentó la versión mexicana del proyecto de sociedad de la información para nuestro país. A la fecha no existe un documento explícito y completo, un "libro verde", pero ello no quiere decir que no haya una iniciativa al respecto. De hecho, existe una serie de docu- 
mentos en los que se percibe todavía una estructura de tipo sectorial, no totalmente articulada, y en donde es difícil encontrar después programas y acciones específicos de cobertura horizontal nacional. De una lectura conjunta puede extraerse el contexto de esa iniciativa; su cristalización más explícita se ha denominado eMéxico; en esencia contempla lo ya presentado en anteriores iniciativas mundiales, de acuerdo con el estado del arte del momento en que fue presentado a la opinión pública. Respecto a e-México, he aquí la definición, misión y visión del proyecto, según se presenta en la página Web del proyecto:

Es un proyecto integrador, que articula los intereses de los distintos niveles de gobierno, de diversas entidades y dependencias públicas, de los operadores de redes de telecomunicaciones, de las cámaras y asociaciones vinculadas a las Tecnologías de la Información y las Comunicaciones (TIC), así como de diversas instituciones, a fin de ampliar la cobertura de servicios básicos como educación, salud, economía, gobierno y ciencia, tecnología e industria, así como de otros servicios a la comunidad.

OBJETIVO: Generar alternativas de valor a través de un sistema tecnológico con contenido social, que ofrezca las herramientas y oportunidades que hoy es posible alcanzar por medio de las Tecnologías de la Información y las Comunicaciones para mejorar la calidad de vida de todos los mexicanos.

VISIÓN AL 2025: El Sistema Nacional e-México como un proyecto de Estado y no de gobierno, con una sociedad integrada y totalmente intercomunicada, en donde cada mexicano vive en un entorno de igualdad de oportunidades entre sí y con el resto del mundo, respetando y preservando la riqueza pluricultural de México.

Misıón: Ser un agente de cambio en el país, al integrar los esfuerzos que realizan diversos actores públicos y privados en la eliminación de la brecha digital y las diferencias socioeconómicas entre los mexicanos, a través de un sistema con componentes tecnológicos y sociales que ofrezca servicios básicos como aprendizaje, salud, intercambio comercial, y trámites de gobierno, siendo al mismo tiempo punta de lanza del desarrollo tecnológico de México. 
Sociedad de la información, sociedad del conocimiento y bibliotecas...

ORGANIZACIÓN: El sistema está organizado en tres grandes ejes: conectividad, contenidos y sistema [Sistema Nacional e-México, 2001].

En la página de la Secretaría de Desarrollo Social, SEDESOL, se define al proyecto de la siguiente forma:

El Objetivo del Sistema Nacional e-México es reducir la brecha digital existente entre diferentes sectores de la población del país e integrarlas a la Sociedad de la Información. Su diseño debe responder a la necesidad de comunicaciones, mediante el uso de las carreteras de información. Esto permitirá a la población tener acceso a numerosas oportunidades de desarrollo individual y colectivo, la integración de los individuos y grupos de la sociedad, el fortalecimiento de la democracia y la participación ciudadana, el incremento del conocimiento, la capacitación y la competitividad y una mejora en oportunidades de desarrollo y calidad de vida. Esto es, que el Sistema Nacional e-México se convierta en motor de desarrollo y conecte a todos los mexicanos [Secretaría de Desarrollo Social, 2004].

En ese mismo sitio, se agrega que este proyecto se construiría sobre tres ejes rectores principales:

El Sistema Nacional e-México tiene definidos tres ejes principales para su desarrollo; aunque estos ejes deben mantenerse coordinados como un todo, dadas sus características, se manejarán independientemente para efectos de ejecución. Los ejes rectores son:

- Conectividad

- Contenidos

- Sistemas

La conectividad se refiere a la oferta de servicios integrales de comunicación, capaces de llevar la Internet a las poblaciones del país, inicialmente a través de la creación de los Centros Comunitarios Digitales (CCD), principales vehículos que permitirán enlazar a las diversas localidades que lo integran. 
Los contenidos son parte indispensable para el sistema, puesto que la conectividad que se ofrezca deberá utilizarse para la distribución y acceso de todo tipo de contenido digital que ofrezca a la población: datos, información, conocimientos y servicios que se traduzcan en un beneficio manifiesto en su desarrollo. Dentro de los contenidos destacan entre otros temas de importancia: Educación, Salud, Economía, Gobierno, Ciencia y Tecnología. Estos temas son, evidentemente, una parte medular de los servicios gubernamentales.

A través de los sistemas de programación computacional se integrarán los contenidos con sus aplicaciones. La conectividad y el acceso se harán disponibles para el público en general a través del uso de sistemas y tecnologías de información, bases de datos y otros avances tecnológicos afines.

Finalmente, y de acuerdo con el Programa Sectorial de Comunicaciones y Transportes 2001-2006 (Secretaría de Comunicaciones y Transportes, 2001) y con ayuda de documentos de presentaciones personales del Dr. Julio César Margáin, entonces Coordinador General del Proyecto e-México, he extraído los diez puntos más sobresalientes en torno a este proyecto que nos dan idea del énfasis que el gobierno mexicano quiso darle a esta iniciativa, sin lugar a dudas muy ambiciosa.

- El propósito es integrar la tecnología e ingeniería de todas las redes existentes, tanto públicas como privadas; seleccionar contenidos adecuados que permitan mejorar los servicios en cada comunidad, nivel territorial o auditorio, que incluya la interacción de sistemas en los que se despliegue información clara en sus contenidos y de fácil consulta, así como contemplar aspectos legales y jurídicos que permitan el uso universal de ciertos servicios que garanticen la privacía y protección legal en el caso de ciertos trámites gubernamentales, entre otros aspectos.

- Para que México pueda realmente superar los enormes contrastes que existen en el desarrollo, es necesario unir cada vez más a los mexicanos y dar igualdad de acceso y oportunidades a cada uno de los que en este país vivimos. El proyecto e-México permitirá enlazarnos entre sí y con el resto del mundo. 
Sociedad de la información, sociedad del conocimiento y bibliotecas...

- El Gobierno Federal y las empresas privadas han invertido miles de millones de dólares en infraestructura, redes individuales que conectan al mínimo de puntos indispensables y consecuentemente tienen una capacidad que no está debidamente utilizada, tanto en las redes privadas como en las diferentes dependencias gubernamentales.

- En México, la mayoría de la población no tiene teléfono ni acceso a una computadora y mucho menos Internet. No obstante, con e-México se planea llevar el teléfono y otras tecnologías de información a cerca de 2500 municipios y a unas 14000 localidades del país en los próximos cinco años, lo cual representaría un aumento de entre 30 y 40 por ciento de dichos servicios. El propósito es que las comunidades más apartadas puedan contar con un entronque mínimo de dos megabits que les facilite el acceso a cuatro puertos: uno para gobierno, otro para salud, otro para educación y otro para comercio.

- Esta conectividad se dará en condiciones exactamente iguales a las que tendría una población o habitante de cualquier parte del mundo. Entramos a una globalización impresionante, de la noche a la mañana, y las poblaciones marginadas podrán hacer uso paulatino de esta tecnología, en beneficio propio y de su comunidad.

- La Secretaría de Comunicaciones y Transportes ya modificó las especificaciones para la construcción de carreteras, con el fin de que éstas tengan ductos para cables de fibra óptica y otros sistemas.

- El e-Business se ha extendido globalmente como el intercambio de bienes y servicios, y este manejo electrónico ha abierto una enorme cantidad de posibilidades. En el momento en el que exista esa megared, seguramente existirán más posibilidades de negocios para las empresas.

- El proyecto e-México se propone revisar los aspectos legales y jurídicos relativos a la Internet para fortalecer la seguridad y privacía de los usuarios.

- Para el desarrollo del plan, el Gobierno Federal ha consultado a importantes firmas como IBM, Hewlett Packard, Microsoft, Teléfonos de México, Ericsson, Nortel Networks, Cisco Systems, Nextel Communications y Pricewaterhouse Coopers. Integran un primer grupo de trabajo del sistema e-México representan- 
tes de las empresas Axtel, Alestra, Unefon, Pegaso, Iusacell, Telcel, Avantel, Bestel y Telmex, así como funcionarios de la Secretaría de Gobernación y del Sector Comunicaciones y Transportes.

- México cuenta en promedio con cinco computadoras por cada cien habitantes, y la Internet es usada sólo por 1.7 millones de los 97 millones de habitantes en nuestro país. A la fecha de publicación de este artículo existen 72742 dominios registrados en México (.mx), de los cuales $92 \%$ son comerciales (.com.mx), $1.5 \%$ son de dependencias gubernamentales (.gob.mx), 1\% de proveedores de Internet (.net.mx), 1.5\% pertenecientes al sector educación (.edu.mx) y $4 \%$ a diversas organizaciones (.org.mx). Sólo el año pasado se registraron 33766 nuevos dominios para una tasa de crecimiento de $120 \%$. En lo que va de este año se han registrado 10846 nuevos dominios para un promedio de 1549 dominios por mes, lo que representa un crecimiento parcial de $17.5 \%$ de enero a julio de 2001. Para el año 2005 existirá acceso universal a la Web para todos los mexicanos y para 2006 el acceso a la Internet de alta velocidad estaría disponible en muchas localidades, permitiendo la transmisión de voz y video por la red.

Debe recordarse que estos últimos datos son de 2001, fecha de publicación de este plan. Cabe resaltar que en realidad, para fines del año 2005, existen casi de 17 millones de usuarios de la Internet en el país, así como cerca de 150000 nombres de dominio mexicanos. Véase el capítulo 3 para datos más actualizados y completos al respecto.

Adicionalmente, al momento de escribir esta obra, México ocupa el lugar 44 entre 102 países en cuanto al aprovechamiento de las tecnologías de información, según la evaluación realizada por el Foro Económico Mundial, la Escuela de Negocios Francesa y el Banco Mundial. Este estudio consideró diversos aspectos del uso de la tecnología como herramienta para el desarrollo, tales como el nivel de preparación del gobierno, las empresas y las personas; su uso efectivo, el ambiente macroeconómico, la normatividad, etc. Como puntos de referencia de la región, Chile ocupa el lugar 32, Brasil el 39, 
Sociedad de la información, sociedad del conocimiento y bibliotecas...

Costa Rica el 49 y República Dominicana el 57, por citar algunos (World Economic Forum, 2004).

Como puede observarse, la iniciativa mexicana, si bien no fue original, fue ambiciosa, como debía serlo. Sigue la línea de la iniciativa brasileña la cual a su vez fue adaptada a un contexto latinoamericano a partir de la línea básica de la iniciativa europea, lo cual desde mi punto de vista fue un enfoque acertado. Desde 1999 el CONACyT había ya realizado un taller y elaborado un documento que manifestaba el creciente interés de las instituciones mexicanas alrededor de este tema, el Programa Nacional de Bibliotecas Digitales, el cual en esencia era una especie de iniciativa como la de la Federación de Bibliotecas Digitales de la Unión Americana en el sentido de empezar a revisar los avances de las principales instituciones en este aspecto, fomentar la discusión y organización alrededor del tema y la promoción de proyectos en este rubro. El documento era oportuno para el momento y sentaba las bases para iniciar un desarrollo de bibliotecas en un proyecto de sociedad de la información mexicana. Con el cambio de administración federal, nunca quedó claro cómo este proyecto se insertaba desde el CONACyT hasta e-México (Sánchez, 1999).

Es conveniente hacer notar que después de la iniciativa federal para la sociedad mexicana de información a principios de 2001, el único documento de planeación con cierto grado de detalle para estrategias y líneas de acción relacionando a e-México y a la educación es el Plan Nacional de Educación 2001-2006 de la SEP, en el que no parece haber la articulación deseada en dos proyectos tan cercanos entre sí. No existió tampoco una iniciativa para bibliotecas digitales por parte de ninguna entidad federal o de cobertura nacional dentro de esta administración sino hasta mayo de 2002 cuando el ejecutivo lanzó una iniciativa nacional de impulso a las bibliotecas, aunque no detallada y mínimamente articulada con el proyecto e-México. En resumen: hay en México iniciativas alrededor del eje sociedad de la información-educación-bibliotecas, aunque carecen de organización y articulación entre sí.

Desde mi punto de vista hay una brecha en el proyecto mexicano, la cual después de un arranque en cierta forma rápida y consis- 
tente con las otras propuestas semejantes a nivel mundial se ha visto estancado en los últimos tres años.

De acuerdo con los proyectos observados en distintos países o comunidades, la primera etapa consistió en el planteamiento teórico basado en su propio entorno; en este aspecto la iniciativa mexicana fue desarrollada dentro de un lapso y con características adecuados. La segunda etapa que hemos observado a nivel mundial fue la de proyectos piloto estratégicos que después de un tiempo razonable de aprendizaje pasaban a grandes proyectos específicos de desarrollo. Esta segunda etapa prácticamente no se realizó en México donde se pasó de la propuesta base casi directamente al establecimiento de una sola propuesta de desarrollo donde me parece que el proyecto mexicano comenzó a diluirse. No se observan proyectos piloto estratégicos durante el año 2001. El único proyecto grande de desarrollo relacionado con e-México es el de los Centros Comunitarios Digitales o CCD, el cual no tenía las características de proyecto piloto sino de proyecto de fondo y su énfasis estaba sólo en la conectividad y el acceso a la tecnología descuidando otros aspectos que, como se ha analizado, son también indispensables. Mi percepción es que en este sentido, el país omitió la etapa de pilotaje, tal vez en un afán de avanzar más rápido y apostó todo a un proyecto de conectividad. De todas formas el objetivo de ese proyecto con los 10000 centros comunitarios ofrecidos para el año 2006 está dudoso ya que a principios del año 2005 apenas se llegaba a los 3200 centros; durante este año se pusieron en marcha otros 4300 llegando hasta 7 500; si bien muchos de éstos sólo funcionan parcialmente. Desafortunadamente, ni la página de la Secretaría de Comunicaciones y Transportes ni la de e-México proporcionan absolutamente ningún dato acerca del uso de esos centros, factor que permitiría estimar su impacto, pues el número de centros por sí mismo dice poco o nada al respecto.

De ahí, y como ya se mencionó, el siguiente proyecto surge hasta 2002 con el Programa de Acceso a Servicios Digitales en Bibliotecas Públicas derivado a su vez del programa Hacia un país de lectores. Nuevamente, este proyecto hace énfasis en los aspectos de conectividad y accesibilidad tecnológica y soslaya otros aspec- 
Sociedad de la información, sociedad del conocimiento y bibliotecas...

tos importantes como los contenidos, si bien rescata aspectos de capacitación de recursos humanos. En cuanto a contenidos, el proyecto más ambicioso es el de Enciclomedia, aunque desde mi perspectiva se quedó corto. La meta central del proyecto Acceso a Servicios Digitales es la de dotar a poco más de 1700 bibliotecas públicas de infraestructura de TIC para el año 2006. Las cifras de Conaculta en este sentido han sido muy confusas. No está claro cuántas computadoras van a ser instaladas en estos 1700 centros, cuál es el ancho de banda, el horario de servicio, cuáles los contenidos, etcétera.

Ha habido ciertos avances en otros proyectos como el de e-Salud y el de e-Gobierno en cuanto a trámites e información, si bien su énfasis ha sido en el aspecto tributario. Mi percepción final es que al haberse omitido la etapa de progamas y pilotaje, su encadenamiento con proyectos de fondo introdujo confusión y falta de avance consistente en diversos frentes, además de que sólo algunos aspectos del proyecto de sociedad fueron contemplados. Lo demás se percibe sólo como algunos esfuerzos aislados sin mucha trascendencia a nivel nacional.

Más allá de la conectividad teórica o real, creo que los defectos más visibles del proyecto son la falta de contenidos documentales y la falta o incongruencia de las cifras de resultados para análisis. En el portal e-México se anunciaba a fines de 2004 y hasta bien entrado 2005 que había 5000 "contenidos de valor" (sic), y también ahí mismo se informaba que el portal alcanzó 1.5 millones de accesos mensuales; el Informe de Gobierno de la Presidencia de la República 2004 dice textualmente:

El Portal e-México ha incorporado más de 5391 contenidos en materia de e-Aprendizaje, e-Salud, e-Economía y e-Gobierno, así como nueve comunidades interactivas con diversos temas de interés y que cuenta con una red interinstitucional de 180 colaboradores del sector público y de la Sociedad Civil. Actualmente se cuenta en el portal con un registro de 12280 usuarios y el número de páginas desplegadas crece mes con mes. Para junio de 2004 se desplegaron aproximadamente un millón y medio de páginas. 
Las cifras inducen al error y no cuadran: 1.5 millones de visitas al mes significa 50000 visitas diarias en promedio. Si había 5000 "contenidos de valor" en el portal y 50000 visitas diarias, significaba que cada "contenido" recibía en promedio 10 visitas al día. ¿Con 3200 Centros Comunitarios Digitales consultando además del público en general? no es nada. Esto sólo podía significar dos cosas: la primera, que el número de los contenidos de valor es en realidad mucho menor que el expresado en el portal; o la segunda, que en efecto sí son 5000 los contenidos pero realmente interesan a muy pocos y por tanto su "valor" es muy cuestionable. Para dar una idea de "contenidos de valor" en México, el diario La Jornada en la Internet recibe alrededor de 250000 visitas ¡diarias! La página central de la UNAM recibe más de medio millón de visitas ¡diarias!, sin contar las que penden de ella, cuyos accesos oscilan en otra cantidad similar.

El misterio se explica en una presentación del sistema e-México para la cuarta reunión conjunta México-India celebrada en Nueva Delhi en octubre de 2005 del que se obtienen las siguientes actualizaciones:

De la láminas 32 y 33, "Contents thru e-México's Portals Program" e "Internet Hits thru e-México Portals Platform", podemos corroborar que el número de contenidos en junio de 2004 rebasó los 5000 en algun momento entre junio y julio de 2004 (4 967-5 603) y que el número de páginas desplegadas en junio de 2004 era aproximadamente de 1.5 millones (1.47). Estas mismas láminas nos indican que las cifras han subido a 10984 contenidos y a 2.30 millones de páginas desplegadas para septiembre de $2005 .^{7}$

En esta misma presentación se encontró otra lámina sumamente importante no reseñada en el texto del informe 2004: la lámina 34, "Internet Hits in September thru Digital Community Centers

7 Javier Pérez Mazatán, 2005. "e-México National System”. En: Fourth India Mexico Joint Commision. Nueva Delhi, India: octubre 21-22, 2005. Presentación Power Point. Láminas 32-34. Disponible noviembre 3, 2005 en: http:// www.e-mexico.gob.mx/wb2/eMex/eMex_the_emexico_nationa 
Sociedad de la información, sociedad del conocimiento y bibliotecas...

consigna no sólo las páginas desplegadas en septiembre, sino una serie de casi dos años de las páginas accedidas a través de los CCD. Aquí empiezan a aparecer algunas cifras perdidas: para junio de 2004 las páginas desplegadas a través de los centros que funcionaban entonces era de 36.7 millones, mismas que para septiembre de 2005 ascienden a 224.2 millones. Es distinto hacer las cuentas de acceso a la red con 1.5 millones de accesos que con 36.7 millones.

En esas mismas láminas 33 y 34, comparando las páginas desplegadas en septiembre de 2005, el número de ellas es de 2.30 millones en el portal e-México y el número de páginas desplegadas por los CCD es de 224.2 millones. Será importante aclarar esta relación en una lámina conjunta en las series de uso de e-México ya que si sólo se menciona la primera, como en el caso del cuarto informe de gobierno, sólo se está mencionando algo así como el uno por ciento del sistema. En esas mismas series, se reseñan las ya mencionadas 2.3 millones de páginas desplegadas por el portal para septiembre de 2005. En otra lámina donde se reseñan páginas desplegadas en el portal e-México por lugar de consulta, se consignan para el mismo mes 3181699 páginas desplegadas en México y 1955389 desplegadas en Estados Unidos. La suma da 5136088 , ¿cuál es su correspondencia con los 2.3 millones? Si quiero averiguar a cuánta gente atendieron y por cuánto tiempo, que al fin y al cabo es el dato importante en cuanto a números, partiendo de la lámina 35 "Digital Community Center's thousand hours of internet navigation in september" (2005), si dividimos 314000 horas de navegación de los CCD entre los 7500 centros existentes obtenemos poco menos de 42 horas por centro por mes; esto es algo así como diez horas por semana por cada centro. No creo que funcionen tan poco, pero es lo que los números dan así en frío. Sospecho que hay mucho mejores cifras de uso de los CCD. Me quedan otras preguntas: ¿cuántas computadoras hay en total dentro de los 7500 CCD? ¿a cuántas personas se atendió? ¿cuántas horas promedio por persona? ¿cuántas veces a cada uno? etcétera, etcétera.

Desgraciadamente, sin cifras de uso adecuadas proporcionadas por el proyecto e-México es sumamente difícil tratar de deducir 
alguna causa, efecto o tendencia. Seguramente hay resultados buenos, pero es difícil seguirlos sin cifras sólidas y bien presentadas en un lugar ad hoc dentro del portal. Ojalá y en el proyecto e-México alguien se ocupe del principio de las colecciones digitales número 6, reseñado previamente en esta obra: "una buena colección tiene mecanismos para proveer datos acerca de su uso, así como otros datos que permitan mediciones estandarizadas acerca de su utilidad y demanda”.

\subsection{LA EDUCACIÓN EN LA SOCIEDAD DE LA INFORMACIÓN}

En la sociedad de la información ya no se aprende para la vida; se aprende toda la vida.

ALFONS CORNELLA

Si bien como ente social la biblioteca tiene muchas funciones, queda claro que una de las principales es la de soporte a la educación en su acepción más amplia: docencia, investigación, capacitación, divulgación cultural, etc. Como veremos más adelante, no cabe duda de que el sistema educacional está sufriendo profundos cambios a nivel mundial, dada la incesante presión sobre él; en parte debido a que en la sociedad actual el trabajo alrededor del conocimiento y la información se vuelve día a día más importante, y en parte porque las mismas tecnologías de la información y comunicación por sí mismas están transformando nuestra sociedad y nuestra economía. Esta presión sobre el sistema educativo se extiende, por supuesto, a las bibliotecas dentro de esa esfera de influencia que conllevan esos cambios. No puede discutirse la evolución hacia las bibliotecas del futuro sin considerar muy de cerca los cambios en el sector educativo y la educación del futuro. Si bien los autores que he podido analizar hacen un énfasis mayor de estos fenómenos en las bibliotecas de nivel superior, los principios ahí establecidos pueden extrapolarse sin duda a bibliotecas de menores niveles, siendo sólo un factor de tiempo que estos principios lleguen a ellas. 
Sociedad de la información, sociedad del conocimiento y bibliotecas...

Tony Bates $^{8}$ realizó un muy extenso estudio al respecto del cual extraigo algunas ideas básicas.

En efecto, la educación está cambiando y no es la primera vez que esto pasa. Los antiguos griegos, por ejemplo, no aprendían como hoy lo hacemos, la lección en un aula no era utilizada. Platón popularizó el diálogo sobre la instrucción, y quién puede poner en duda todo lo que lograron en Gracia con su enseñanza. En efecto, la "lección" en el aula es un invento tecnológico de culturas posteriores. La misma palabra lección proviene del latín lectio, "lectura". Dado que los libros en la Edad Media eran penosamente escritos y copiados a mano generalmente por monjes en los conventos, eran entes raros y preciosos. Por lo mismo, el profesor universitario leía en el aula a sus discípulos de esa única copia. Ello conllevaba a que la instrucción y, por tanto, el conocimiento estaban controlados por la Iglesia con miras a evitar desviaciones en la ortodoxia del pensamiento. No es accidental que el advenimiento de la imprenta y sus múltiples copias propiciara la llegada del protestantismo y la proliferación de escuelas laicas.

La Revolución Industrial, en su necesidad de educar a grandes cantidades de personas en esa sociedad industrial y comercial llevó a la educación en masa, y por ello el método de enseñar cada vez a grupos más grandes en un aula fue la solución más práctica y económica para lograr dicho objetivo. No obstante, mientras que la tecnología del siglo $\mathrm{xx}$ ha ido revolucionando las comunicaciones, llevándonos a la ya mencionada sociedad de la información, nuestras instituciones educativas aún están inmersas en la dinámica de la sociedad de la Revolución Industrial. Los métodos y formas de la educación y entrenamiento contemporáneos no han cambiado sensiblemente en dos siglos. En general, los niños y jóvenes son educados en grupos, dentro de instituciones llamadas escuelas, colegios, universidades, etc., con instrucción proporcionada por profesores presenciales. Aun hoy, con tecnologías educativas modernas el

8 Anthony W. Bates, 1995. Technology, Open Learning and Distance Education. New York: Routledge. 
impacto al cambio ha sido mínimo. Las computadoras y la televisión integradas al aula han sido principalmente una ayuda para el profesor. La educación a distancia, en su modalidad de una vía apenas ha mostrado todo su potencial educativo.

Mucho se insiste en que la tecnología nos ofrece la oportunidad de enseñar diferente, y que es una forma de contender con los retos que plantea la cambiante sociedad actual. En efecto, hay evidencia clara de que la tecnología nos permite cambiar el modelo educativo y no sólo las formas, y llegar a nuevas poblaciones poco o nulamente atendidas, con costos menores que los obtenidos en modelos más convencionales. Esto requiere de nuevas aproximaciones a los paradigmas de la enseñanza-aprendizaje. No se trata sólo de utilizar la tecnología como una nueva manera de realizar el mismo proceso, sino de actualizar el proceso en sí. En suma, debe crearse un nuevo modelo de enseñanza, y no sólo nuevas modalidades de enseñanza. Es necesario inventar o replantear métodos para enseñar y aprender acordes con el número de personas que requieren ser instruidas hoy en día, con el inmenso número de conocimientos que deben ser enseñados, así como con los diferentes objetivos de la enseñanza y las distintas y cambiantes necesidades de estos educandos del siglo XXI. Esto requiere también de nuevos modelos de enseñanza y aprendizaje que se integren adecuadamente con las posibilidades tecnológicas. Es un grave error y sin embargo una tentación muy explicable creer que el uso de la tecnología por sí mismo es la solución al problema. La tecnología sigue siendo una herramienta, igual que la lección en clase o el libro impreso, y no un objetivo educativo en sí mismo, y es necesario estar atento a las fortalezas y debilidades de las diversas tecnologías disponibles en la actualidad y mezclarlas con adecuados modelos de enseñanza.

La tecnología no puede conformarse hoy en día como una simple réplica del modelo instruccional conductivista pero asistido por máquinas. El modelo educativo futuro debe ir planteando sus propios paradigmas asistido por la tecnología. Los actuales y a la vez antiguos métodos de instrucción a grupos pequeños en un aula con un contacto presencial y frecuente de un profesor, serán difíci- 
les de sostener con miras a atender a grandes poblaciones, sobre todo en esta época donde es cada vez más necesario conducir a esos públicos a niveles educativos cada vez más altos y por tanto de mayor duración. La educación a nivel medio es cada vez menos una opción terminal, y la educación continua se prevé en la actualidad como un proceso permanente durante toda la vida profesional de una persona de ese nivel. Por otro lado, la educación masiva en bloques a distancia basada en modalidades unidireccionales convence cada vez menos a los planeadores pedagogos y ha quedado ya rebasada en la búsqueda de algo mejor. La educación a distancia requiere de opciones cada vez más personalizadas de acuerdo con las necesidades y expectativas del público, y por tanto merece una cuidadosa reflexión y planeación.

No es el propósito de esta obra hacer un estudio exhaustivo acerca de cuál es la mejor aproximación educativa: conductivista, cognoscitivista, constructivista, etc.; para eso están los expertos en la materia. Mi intención en este momento es analizar y estudiar de forma básica las necesidades, tendencias y modalidades tecnológicas de enseñanza y su probable interacción con nuevos modelos educativos que aprovechen las Tic y a la vez su interacción con las bibliotecas digitales. A lo largo de múltiples lecturas al respecto, he podido establecer modelos muy novedosos de educación digital -como es llamada ahora- basados en perspectivas conductivistas, constructivistas, etc., e inclusive híbridas, como presentaré más adelante. Esto es importante pues ayuda a destacar algunos hechos relevantes:

- Las TIC pueden interactuar con diversos modelos de enseñanza del gusto de muchos pedagogos, pues no están atadas a ninguno en particular.

- Pueden establecerse modelos híbridos entre diversas perspectivas pedagógicas auxiliadas con TIC.

- Es totalmente necesario ir evolucionando hacia modelos más avanzados que exploten el potencial de las tecnologías y estén acordes con las tendencias y "buenas prácticas" a nivel mundial. 
Analicemos poco a poco cada uno de los elementos que nos permiten llegar a tales conclusiones.

Uno de los debates más importantes en educación actualmente, y en especial en tecnología educativa, es la discusión entre conductivismo y constructivismo. ${ }^{9}$ Esta discusión se ve reflejada en los diferentes enfoques que asumen las instituciones de enseñanza superior al momento de diseñar e implementar sus cursos virtuales. La perspectiva conductivista tiene algunos aspectos positivos que la han convertido en la teoría de aprendizaje de mayor influencia durante el siglo pasado. De acuerdo con Andrés Núñez, dos de esos aspectos no han podido ser neutralizados por los defensores del constructivismo: la aproximación tratada de manera científica al conocimiento y la definición de objetivos observables, medibles y comprobables. La gran desventaja del conductivismo, sin embargo, está relacionada con la forma en que esta teoría explica lo que sucede durante el proceso de aprendizaje. Al considerar el aprendizaje como un proceso desligado del ser humano, el conductivismo asume el conocimiento como algo objetivo, singular y fragmentable; es decir, que puede ser dividido en pequeñas secciones para ser transmitido de instructor a estudiante. Precisamente ésa es la deficiencia que el constructivismo intenta resolver cuando se considera el aprendizaje como un proceso en que el conocimiento es integrado socialmente a través de la interacción de los estudiantes. En este proceso las experiencias previas de cada persona son fundamentales para interpretar y construir el conocimiento que el profesor pone a disposición del estudiante a manera de guía. A diferencia del proceso lineal del conductivismo, el constructivismo se desarrolla de manera negociada entre profesores y estudiantes. A pesar de su reciente popularidad, el constructivismo no ha logrado impactar de manera eficaz el proceso de aprendizaje porque en el intento por diferenciarse totalmente del conductivismo negó la

9 David W. Johnson, Roger T. Johnson y Karl A. Smith, 1991. "Cooperative Learning: Increasing College Faculty Instructional Productivity”. En: ASHE-ERIC Higher Education Report 4, 1991. Association for the Study of Higher Education, ERIC Clearinghouse on Higher Education, Washington, DC. 
Sociedad de la información, sociedad del conocimiento y bibliotecas...

posibilidad de aproximarse al conocimiento de manera científica y con objetivos claros. El énfasis ha estado en permitir la búsqueda individual del conocimiento pero no en estrategias para evaluar si efectivamente se han logrado los objetivos propuestos. Las ventajas y desventajas de estas teorías deben ser analizadas al momento de definir la implementación y el diseño de cursos virtuales (Núñez, 2001).

Otro de los autores que más ha influido en la elaboración y divulgación de las ideas del llamado constructivismo pedagógico es Ausubel. ${ }^{10}$ Se considera como su aportación fundamental el concepto de que el aprendizaje debe ser una actividad significativa para el alumno y dicha significancia está directamente relacionada con la existencia de relaciones entre el conocimiento nuevo y el que ya posee. La crítica fundamental de Ausubel a la enseñanza tradicional consiste en la idea de que el aprendizaje resulta muy poco eficaz si se basa simplemente en la repetición mecánica de elementos que el alumno no puede estructurar formando un todo relacionado. Esto sólo será posible si el estudiante utiliza los conocimientos que ya posee, aunque éstos no sean totalmente correctos. Evidentemente, una visión de este tipo no sólo supone una concepción diferente sobre la formación del conocimiento, sino también una formulación distinta de los objetivos de la enseñanza. Para Ausubel, aprender es sinónimo de comprender. Por ello, lo que se comprenda será lo que se aprenderá y recordará mejor porque quedará integrado en nuestra estructura de conocimientos. Benjamín Franklin lo expresaba de una forma semejante: "dímelo y lo olvidaré; enséñamelo y lo recordaré; involúcrame y lo aprenderé".

A continuación, conviene analizar un poco cuáles son las características de la enseñanza actual, de acuerdo con este modelo proveniente de la Revolución Industrial. De acuerdo con Núñez (2001), las características de este tipo de educación son:

10 David Ausubel, Joseph Novak y Helen Hanesian, 1983. Psicología educativa. Un punto de vista cognoscitivo. México: Trillas, 623 pp. 
- Transmisión y memorización de información.

- Se centra en la enseñanza.

- No se respetan diferentes estilos de aprendizaje.

- Educación terminal dividida en semestres o años.

- Se centra en el profesor; exposición del profesor como estrategia didáctica predominante.

- El profesor es portador del conocimiento crítico. Se inhibe el pensamiento crítico de los alumnos.

- Uso limitado y/o ineficiente de la tecnología.

En la nueva sociedad de la información y el conocimiento es necesario ir superando este modelo industrial de educación que ha caracterizado los sistemas educativos de los últimos dos siglos y debemos replantear la enseñanza, tanto presencial como a distancia, desde una nueva perspectiva donde el maestro deja de ser el dueño y transmisor del conocimiento para convertirse en guía y facilitador del proceso de aprendizaje de sus alumnos. Esta nueva función del profesor es válida dentro del aula de clase de forma presencial, así como a través del uso de tecnologías digitales en la educación a distancia. Este tipo de educación se ha definido a menudo como aquella en la que estudiantes y profesores están separados geográficamente. En esta definición destacan dos elementos esenciales: primero, la educación a distancia está orientada hacia una población geográficamente dispersa, y segundo, se realiza a través de una comunicación no presencial. ${ }^{11}$ Estas características han llevado a separar las metodologías de educación presencial de las metodologías de educación a distancia. Sin embargo, la característica esencial de aislamiento y separación entre el profesor y el estudiante tiende a desaparecer cada vez más rápidamente con el uso de tecnologías de educación digital. Hoy en día un estudiante puede estar registrado simultáneamente en cursos a distancia y en cursos presenciales dentro de una misma institución educativa. De esta manera desaparecen tanto el factor de dispersión geográfica

11 Michael G. Moore y Greg Kearsley, 1996. Distance Education: a System's View. Belmont, Ca.: Wadsworth Pub. Co. 
como el de comunicación no presencial. La educación a distancia ha madurado lo suficiente a lo largo del siglo pasado como para intentar pasos más trascendentales.

El establecimiento de la "Open University" en la Gran Bretaña en 1969 definió de dos formas las principales vertientes en el desarrollo de la educación a distancia a este nivel. No sólo fue la primera institución diseñada única y específicamente para la educación superior a distancia, sino que también fue diseñada como una institución de enseñanza que utilizaría diversos medios para el efecto, y combina así en forma integrada los textos impresos, la teletransmisión y la enseñanza en vivo. Su presupuesto anual de operación es de casi 100 millones de libras esterlinas -150 millones de dólares-, y produce cada año $9 \%$ de los estudiantes de licenciatura en la Gran Bretaña, a un costo que representa aproximadamente 5\% del presupuesto de operación para otras universidades de tipo presencial, lo cual refleja el potencial de una inversión relativamente baja basada en este tipo de educación con apoyos tecnológicos respecto de otras. Desde 1997 esta institución ofrece además un programa de maestría a distancia. No es de sorprender esto; según los expertos Kaufman ${ }^{12}$ y Nipper ${ }^{13}$ nos encontramos en la tercera generación de la tecnología de la educación a distancia. De acuerdo con ellos, las características más destacadas de cada una son:

- En la primera generación se observaba el uso predominante de una sola tecnología para todo el programa; había nula interacción entre el instructor y los alumnos. Un ejemplo típico son las clases por correspondencia.

12 David Kaufman, 1989. "Post-secondary Distance Education in Canada: Policies, Practices, and priorities”. En: R. Sweet (ed.). Athabasca, Alberta: Athabasca University/Canadian Society for Studies in Education.

13 Søren Nipper, 1989. “Third Generation Distance Learning and Computer Conferencing”. En: R. Mason y A. Kaye (eds.), Mindweave: Communication, Computers, and Distance Education, Oxford: Pergamon, capítulo 5, pp. 63-73. 
- En la segunda generación se observa el uso deliberado de métodos multimedia y diseñados para educación a distancia. La comunicación es mayormente en una vía. Un ejemplo de ello son los cursos por televisión.

- La educación en la tercera generación se basa en comunicación en dos vías con interacción directa entre instructor y alumnos, y entre éstos. Materiales multimediales, acceso a otras fuentes documentales externas al curso y materiales personalizados o editables por el alumno.

A su vez, existen tres "familias" o agrupamientos de tecnologías de comunicación audiovisual para la enseñanza sobre redes digitales. De acuerdo con Fabián Romo ${ }^{14}$ son las siguientes:

- Síncrona unidireccional. Consiste en transmisión de video y/ o audio en una sola dirección -emisor hacia receptor-. Por lo general se cuenta con una sola fuente y múltiples receptores. Dentro de esta modalidad las tecnologías más típicas son: para el audio, radio AM, FM, onda corta, UHF, audio por la Web; para el video, la televisión en cualquiera de sus modalidades: VHF, UHF, HDTV, DTH, satelital y video por la Web.

- Síncrona bidireccional. Consiste en algo semejante a la anterior, con la diferencia de que incluye un medio en que el receptor y el emisor pueden establecer una comunicación en ambas direcciones, facilitando la retroalimentación. El término síncrona significa que todos los participantes deben coincidir en el tiempo - no así en el espacio- para que la comunicación se logre. Entre las tecnologías más utilizadas en esta modalidad distinguimos: para el audio, la telefonía, telefonía sobre IP, audioconferencia, audioconferencia sobre IP; para el video lo son la videoconferencia, la videoconferencia sobre IP, y la televisión interactiva de alta definición, HDTV.

14 Fabián Romo Z., 2004. "Audiovisual Technologies in Education”. Documento Interno. México: UnAM, Dirección General de Servicios de Cómputo Académico. Subdirección de Tecnologías para la Educación. 
Sociedad de la información, sociedad del conocimiento y bibliotecas...

- Asíncrona unidireccional. A diferencia de las tecnologías anteriores, ésta no requiere una coincidencia en el tiempo de emisor/receptor. Se le conoce también con el nombre de audio o video por demanda, ya que en este caso el receptor activa la comunicación hacia un servidor Web en el momento en que él lo desea y comienza a obtener su información. En este caso también puede haber más de un receptor a la vez accediendo al emisor. No se considera la retroalimentación bidireccional en el momento.

En redes de información y enseñanza más complejas puede usarse -y de hecho así se hace- una combinación de más de una de estas tecnologías a la vez para mayor penetración del servicio. Estas modalidades de enseñanza han probado tener ingredientes relevantes y potencialmente viables para la educación en el futuro. Verduin y Clark (1991), tratan muy detalladamente estos aspectos. Resumiendo, las cuatro mayores ventajas de este tipo de educación y que sin duda serán contempladas en el futuro, son:

- Permite el aprendizaje a lo largo de toda la vida. Lo cual es muy útil para adultos que desean continuar su educación u obtener entrenamientos para mayor competitividad y que por su trabajo o compromisos familiares no pueden dedicarse de lleno a la escuela.

- Mayores entornos geográficos. En regiones muy apartadas o con mucha densidad demográfica en donde es difícil proveer una completa oferta de servicios educativos escolarizados este tipo de enseñanza ha probado ser muy útil.

- Impulsa la igualdad social. Muchas personas son incapaces de acceder o terminar en sistemas escolarizados de enseñanza superior y este tipo de educación brinda oportunidades más similares a todos y ha sido un factor de movilidad social.

- Costo-beneficio adecuado. En países o regiones en donde se ha utilizado este tipo de enseñanza se ha comprobado que a ciertos volúmenes los beneficios obtenidos son atractivos respecto de las inversiones. 
Como ya se ha mencionado, la tecnología no es una panacea en sí misma, mas su valor radica en su capacidad de llegar a poblaciones desatendidas por las instituciones de educación convencional; se integra mejor con las necesidades educativas de una sociedad informatizada, y mejora la calidad de la enseñanza. Puede llegar tanto a la población económicamente activa como a la población joven en formación. Como puede observarse, no puede consistir en una simple adaptación de los modelos convencionales con nuevas modalidades. Esa mezcla funciona con muy poca eficiencia y la sociedad actual no está como para desperdiciar recursos. Por ello los nuevos modelos educativos deben ser cuidadosamente analizados y replanteados. No es cuestión simplemente de anatematizar al conductivismo presencial renegando de él y considerando a todos y cada uno de sus elementos como nocivos. Es necesario hacer profundos estudios acerca de cuáles son las mejores teorías pedagógicas y su relación con las tecnologías a utilizarse, y cuáles son los elementos educativos que deben ser conservados y cuáles los que deben ser innovados; ¿qué tanto puede una enseñanza basada en máquinas aproximarse correctamente a la diversidad y diferencias entre las distintas vivencias de las personas? No son sólo decisiones de tipo técnico; hay juicios de valores sociales que deben ser tomados en cuenta a la hora de rediseñar la educación que queremos en el futuro. Al prepararnos para estas decisiones acerca del uso de la tecnología en la educación, es muy útil hacer una diferencia entre conocimientos y habilidades. Olson y Bruner ${ }^{15}$ establecieron que el aprendizaje involucra dos distintos aspectos: primero, la adquisición del conocimiento de hechos, principios, ideas, conceptos, eventos, relaciones, leyes y reglas. Segundo, el uso de ese conocimiento para desarrollar una habilidad. El medio de representación en que se distribuye también tiene que ver con su diversidad y con el hecho de que utilizan un sistema simbólico diferente para codificar la información. Los textos, audios, imágenes fijas y en movi-

15 David R. Olson y Jerome Bruner, 1974. "Learning Through Experience and Learning Through Media". Media and Symbols: The Forms of Expression. Chicago: The University of Chicago Press (The $73^{\text {rd }}$ NSSE Yearbook). 
Sociedad de la información, sociedad del conocimiento y bibliotecas...

miento tienen códigos simbólicos diferentes para el educando, así como sus posibles mezclas. Los libros por ejemplo, pueden representar información a través de textos e imágenes fijas, pero no sonido o video. La televisión puede tener todos pero el texto no puede ser excesivo, y ha sido usada sólo en una vía, lo cual demerita sus capacidades. Recientemente, las computadoras, con sus características multimediales, han empezado a incursionar en este ambiente. No hay medio mejor o peor por sí mismo, cada uno tiene su propio código simbólico de representación. Basta comparar una novela impresa y su versión cinematográfica. Por muy apegadas que sean a la trama, es obvio que cada una tiene su propia capacidad de representación. Distintas disciplinas del conocimiento se acoplan mejor a ciertos medios; consideremos el arte, la historia y las matemáticas. Cada una tiene diferentes requerimientos para la representación de su conocimiento o más bien dicho, ponen distintos énfasis en la importancia de usar diferentes maneras de representar el conocimiento. Tienen también diferentes secuencias en las que el conocimiento pide ser presentado para estructurarlo adecuadamente.

Carol Twigg y Michael Miloff (1998) han analizado esta situación del cambio en la enseñanza para Estados Unidos, pero no es muy diferente de lo que sucede en Europa y está comenzando a suceder en México. Por medio de correlaciones de tendencias y desarrollos tecnológicos, ellos visualizaron una "infraestructura global de la enseñanza", en la que los roles de la escuela y la universidad serán drásticamente cambiados; esto es, se avecina una transformación radical del sistema educativo. Entre las tendencias estos autores observan las siguientes:

- El número de estudiantes es siempre creciente.

- Diferentes tipos de estudiantes están demandando educación; la participación de mujeres, estudiantes de mayor edad, discapacitados, minorías étnicas, inmigrantes, etc., va en aumento.

- Cada vez más, la necesidad de estudiar y trabajar a la vez se hace presente, lo que lleva a presiones de enseñanza con horarios más flexibles y/o extendidos. El edificio escolar no es ya siempre central a este proceso. 
- Las personas estudian cada vez más a lo largo de su vida.

- Este aprendizaje a lo largo de la vida conlleva un énfasis en "aprender a aprender". El conocimiento se vuelve obsoleto rápidamente a una tasa de velocidad siempre creciente, y los trabajadores dependientes del conocimiento deben por ello refrescar y actualizar sus conocimientos en forma regular.

- Debido a las diferencias entre estudiantes, hay necesidad de acomodar diferentes estilos, ritmos y alternativas de aprendizaje; los cursos deben tomar cada vez más en cuenta la diferente experiencia y bagajes previos de los estudiantes.

- Las instituciones de enseñanza superior han tenido por largo tiempo el monopolio en proveer educación a alto nivel, pero cada vez más las instituciones públicas y empresas privadas poseen conocimiento que puede ser reutilizado para fines educacionales; un poco para entrenamiento interno, pero también útil a mercados externos.

- La educación siempre se encuentra bajo constantes presiones presupuestales, lo cual lleva a una búsqueda incesante de métodos de educación más eficientes y eficaces.

- Los estudiantes se comportan cada vez más como consumidores y quieren tener opciones acerca de cómo y dónde van a ser educados, lo cual significa no comprometerse previamente con ninguna institución.

- Hay demasiadas deserciones en el sistema educativo actual.

Siguiendo a estos mismos autores, las TIC tienen el potencial para ofrecer una solución a algunas de las necesidades presentadas en las tendencias; éstas son:

- A través de las redes, puede ser ofrecido el material de cursos casi independientemente de tiempo y lugar. La modularización posibilita la oferta de diferentes y flexibles rutas de aprendizaje.

- Un número de estudiantes cada vez mayor tiene acceso a la Internet, ya sea en casa o en un campus; los costos de este servicio tienden a disminuir. 
Sociedad de la información, sociedad del conocimiento y bibliotecas...

- Más y más información se encuentra disponible en la Internet. Los motores de búsqueda cada vez más potentes aseguran la accesibilidad a este material. Nuevas aplicaciones de cómputo aseguran la comunicación entre profesores y alumnos en todo el mundo.

- La investigación de mercados en línea es rápida y fácil, y esta información puede ser combinada con datos de transacciones permitiendo a las instituciones educativas monitorear a corto plazo la respuesta de los estudiantes a sus ofertas.

- En principio, una competencia mundial por educación es posible y se puede observar ya en cursos para maestrías en negocios (MBA). Carol Hughes ${ }^{16}$ afirma que cada vez habrá mayor competencia entre los servicios de información de las bibliotecas para enseñanza superior, implicando que las bibliotecas pueden perder terreno en este campo. La compañía de Hughes para libros electrónicos, Questa Media, es un ejemplo de un nuevo competidor.

Hans Roes ${ }^{17}$ hace un estudio muy completo de lo que él considera que será el medio ambiente del aprendizaje del futuro, del cual presento un resumen:

- Estará centrado en las características, perfiles y necesidades del alumno.

- Será interactivo y dinámico.

- Permitirá el trabajo en grupo en torno a problemas mundiales reales.

- Permitirá a los estudiantes trazar sus propias rutas de aprendizaje.

16 Carol A. Hughes, 2000. "Information Services for Higher Education. A New Competitive Space”. D-Lib Magazine (diciembre 2000). Disponible noviembre 3, 2005 en: http://www.dlib.org/dlib/december00/hughes/12hughes.html

17 Hans Roes, 2001. "Digital Libraries and Education". D-Lib Magazine. 7:7/8 (julio/agosto 2001). Disponible noviembre 3, 2005 en: http://www.dlib.org/ dlib/july01/roes/07roes.html 
- Hace énfasis en competitividades, como cultura informática, y apoyará la educación continua.

Bates $^{18}$ establece que las siguientes pueden considerarse las doce características a observar para crear "buenos materiales" en tecnologías de enseñanza remotas. He aquí un resumen de las mismas:

- Calidad en los materiales de enseñanza. Objetivos claros, materiales de enseñanza bien estructurados, relevancia para las necesidades del alumno, etc., son indispensables para cualquier tecnología de este tipo. Las bondades inherentes a la tecnología no pueden sustituir la calidad de los contenidos.

- Cada medio tiene su personalidad. Diseño y producción profesional son importantes. Cada medio requiere de habilidades especiales para producirlo adecuadamente, así como cada medio tiene sus propias características que deben ser explotadas con propiedad.

- Las tecnologías educacionales son flexibles. La flexibilidad y por lo mismo la intercambiabilidad de la tecnología permite diseñar programas aun si alguna tecnología en particular no está disponible para nosotros.

- No hay ninguna "super tecnología". Toda tecnología tiene sus ventajas y desventajas. Por tanto lo mejor es la combinación de las mismas.

- Deben ponerse a disposición de maestros y alumnos todos los medios. Dado que el conjunto de alumnos no es homogéneo en su bagaje educacional, experiencia o preferencia de materiales, es necesario tener materiales en los diversos medios existentes: texto, audio, video, computadora.

- Deben balancearse variedad y economía. Entre mayor sea el número de tecnologías utilizadas, el diseño y la producción se hacen más complejos. Debe evitarse la redundancia y los gastos superfluos.

18 Anthony W. Bates, 1995. Technology, Open Learning..., op. cit. 
Sociedad de la información, sociedad del conocimiento y bibliotecas...

- La interacción es esencial. La interacción de alta calidad entre los materiales de enseñanza, instructores y otros alumnos es necesaria para un correcto proceso de aprendizaje. Aun a distancia debe cuidarse y lograrse este aspecto social.

- El número de estudiantes es crítico. El número total de alumnos que utilizará un cierto material a lo largo de todo el ciclo de vida del mismo es un factor crítico para la selección de esa tecnología. Algunas requieren de grandes cantidades para ser rentables y viceversa.

- Las nuevas tecnologías no son necesariamente mejores que las anteriores. En enseñanza, debe usarse siempre la tecnología adecuada, y no la más nueva. El buen juicio y una correcta evaluación deben ser utilizados con las tecnologías emergentes. Muchos de los principios y lecciones aprendidos en tecnologías anteriores pueden ser aplicados a las nuevas.

- Los maestros necesitan entrenamiento para explotar adecuadamente la tecnología. Los maestros e instructores necesitan entrenarse no sólo en el uso de la tecnología que utilizan para enseñar, sino en cómo los alumnos aprenden de ella y en cómo diseñar materiales para ésta. Se ha afirmado que la falta de entrenamiento a maestros es la barrera más grande a vencer para el uso de las tecnologías en la educación.

- El trabajo en equipo es esencial. Nadie puede ser experto en todo. Expertos en un tema dado, especialistas en medios (su distribución y acceso) y en pedagogía, así como diseñadores instruccionales son indispensables.

- La tecnología no es el centro. El centro es: ¿cómo y qué quiero que aprendan los alumnos? ¿En dónde podrán hacerlo? El esfuerzo debe centrarse en diseñar la experiencia de aprendizaje, y no en demostrar que la tecnología funciona. Hay suficiente tecnología para poder enseñar lo que se desee.

No obstante estas doce características deseables, es necesario tener muy presente las ventajas y desventajas de este tipo de cursos y sus materiales. La Universidad Estatal de Florida (FSU) firmó en 1998 un convenio con la Open University británica para adaptar y 
utilizar sus materiales y cursos de educación a distancia. La Estatal de Florida maneja un tipo de educación eminentemente conductivista a diferencia de la universidad británica, la cual ha utilizado una perspectiva predominantemente constructivista. He aquí dos tablas resumen de las estrategias utilizadas por cada una y los resultados obtenidos:

OPEN UNIVERSITY de GRAN BRETAÑA

\begin{tabular}{|l|l|}
\hline \multicolumn{1}{|c|}{ Estrategias } & \multicolumn{1}{c|}{ Resultados } \\
\hline $\begin{array}{l}\text { El material de estudio se desarrolló a manera } \\
\text { de guía por expertos en cada tema. }\end{array}$ & $\begin{array}{l}\text { Puerta de entrada a la motivación individual para } \\
\text { aumentar el conocimiento en temas de interés } \\
\text { personal. }\end{array}$ \\
\hline $\begin{array}{l}\text { Énfasis en la búsqueda individual del conoci- } \\
\text { miento para ser compartido posteriormente en } \\
\text { grupos de trabajo. }\end{array}$ & $\begin{array}{l}\text { Motivación para aumentar el conocimiento a tra- } \\
\text { vés de lecturas y búsquedas de información in- } \\
\text { dividual. }\end{array}$ \\
\hline $\begin{array}{l}\text { Flexibilidad en el desarrollo de actividades indi- } \\
\text { viduales que deben ser enviadas al área de con- } \\
\text { ferencia. }\end{array}$ & $\begin{array}{l}\text { Escasos mensajes enviados al área de confe- } \\
\text { rencia. }\end{array}$ \\
\hline $\begin{array}{l}\text { Estructura flexible en el desarrollo de las activi- } \\
\text { dades en grupo. }\end{array}$ & Baja participación en las actividades en grupo \\
\hline $\begin{array}{l}\text { Rigidez en las fechas de entrega de las evalua- } \\
\text { ciones finales de cada unidad. }\end{array}$ & $\begin{array}{l}\text { Aumento de las discusiones y la participación en } \\
\text { etapas previas al envío de las evaluaciones finales. }\end{array}$ \\
\hline
\end{tabular}

Núñez, 2000. 
Sociedad de la información, sociedad del conocimiento y bibliotecas...

UNIVERSIDAD ESTATAL DE FLORIDA

\begin{tabular}{|l|l|}
\hline \multicolumn{1}{|c|}{ Estrategias } & \multicolumn{1}{|c|}{ Resultados } \\
\hline $\begin{array}{l}\text { Material de estudio desarrollado como un "paque- } \\
\text { te completo de conocimiento" por expertos en } \\
\text { cada tema. }\end{array}$ & $\begin{array}{l}\text { Desmotivación para la búsqueda adicional de } \\
\text { conocimiento. }\end{array}$ \\
\hline $\begin{array}{l}\text { Énfasis en la memorización de los contenidos } \\
\text { del paquete. }\end{array}$ & $\begin{array}{l}\text { Concentración de los esfuerzos de los participan- } \\
\text { tes en "aprender" el conocimiento transmitido. }\end{array}$ \\
\hline $\begin{array}{l}\text { Estructura rígida en el desarrollo de actividades } \\
\text { individuales a ser enviadas alárea de conferencia. }\end{array}$ & Amplia participación. \\
\hline $\begin{array}{l}\text { Estructura rígida en el desarrollo de las activi- } \\
\text { dades en grupo. }\end{array}$ & $\begin{array}{l}\text { Amplia participación y distribución equitativa de } \\
\text { las responsabilidades. }\end{array}$ \\
\hline $\begin{array}{l}\text { Rigidez en las fechas de entrega de las evalua- } \\
\text { ciones finales de cada unidad. }\end{array}$ & $\begin{array}{l}\text { Aumento de las discusiones y la participación en } \\
\text { etapas previas al envío de las evaluaciones finales. }\end{array}$ \\
\hline
\end{tabular}

Núñez, 2000.

Como puede observarse, no existe una aproximación pedagógica ideal para el diseño metodológico de cursos virtuales. Tanto la aproximación tradicional de tipo conductivista, como la nueva aproximación constructivista presentan ventajas y desventajas, las cuales deberán ser ponderadas por cada educador tomando las decisiones que considere pertinentes. Pero ello no tiene nada de malo; al contrario: desde mi punto de vista expande las posibilidades. Teniendo en cuenta esta situación, lo que han estado sugiriendo los expertos últimamente es utilizar una estrategia mixta en la que se utilicen las ventajas de ambas perspectivas. La perspectiva conductivista debe ser utilizada fundamentalmente para el manejo de los aspectos de tipo organizativo como la definición de la estructura del curso, la enunciación de objetivos y el manejo de las evaluaciones. La perspectiva constructivista se debe utilizar para el manejo de los aspectos eminentemente académicos como la definición 
de estrategias de interacción y para definir las actividades individuales y grupales que contribuirán al logro de los objetivos.

Como un ejemplo, he aquí un esquema mixto que podría ser útil para el desarrollo de cursos virtuales con características tanto conductivistas como constructivistas. Con este diseño se logra una amplia participación debido al rigor en la estructura administrativa del curso, pero también se logra la formación de una comunidad que construye conocimiento a través de la negociación social, el trabajo colaborativo, la reflexión crítica, la revisión de pares y la creación de escenarios virtuales y microambientes en donde los participantes pueden aplicar los conocimientos adquiridos de manera colaborativa.

\begin{tabular}{|c|c|c|}
\hline $\begin{array}{c}\text { Etapa del diseño } \\
\text { instruccional }\end{array}$ & Perspectiva & Estrategia \\
\hline Análisis & Constructivista & $\begin{array}{l}\text { - Elaboración e implementación de un cuestionario para in- } \\
\text { vestigar las características y motivaciones de los partici- } \\
\text { pantes. Los resultados se utilizan para orientar los objeti- } \\
\text { vos del curso hacia las necesidades de los participantes. }\end{array}$ \\
\hline Diseño & Conductivista & $\begin{array}{l}\text { - Manejo administrativo por semanas, secciones y temas } \\
\text { de acuerdo con las limitantes de tiempo y recursos. } \\
\text { - División del conocimiento en fragmentos de fácil distribución. } \\
\text { - Diseño de los objetivos del curso siguiendo criterios es- } \\
\text { pecíficos según las competencias que se desea generar } \\
\text { en los estudiantes. }\end{array}$ \\
\hline Desarrollo & Constructivista & $\begin{array}{l}\text { Desarrollo del material de estudio a manera de guía y sin } \\
\text { exceso de contenido para que el estudiante desarrolle su } \\
\text { propia aproximación al tema. } \\
\text { - Uso de enlaces para facilitar al estudiante la profundiza- } \\
\text { ción en los temas de mayor interés personal. } \\
\text { - Énfasis en el desarrollo de actividades en grupo para fa- } \\
\text { cilitar la negociación social del conocimiento. } \\
\text { Desarrollo de actividades de revisión de pares para pro- } \\
\text { mover la reflexión crítica. } \\
\text { Desarrollo del curso como un micromundo que permite la } \\
\text { simulación de las competencias que tendrán que realizar } \\
\text { los estudiantes al aplicar su conocimiento en la vida real. }\end{array}$ \\
\hline
\end{tabular}


Sociedad de la información, sociedad del conocimiento y bibliotecas...

\begin{tabular}{|c|c|c|}
\hline $\begin{array}{c}\text { Etapa del diseño } \\
\text { instruccional }\end{array}$ & Perspectiva & Estrategia \\
\hline Implementación & Constructivista & $\begin{array}{l}\text { - Durante el proceso de implementación se debe realizar } \\
\text { una aproximación constructivista a través de actividades } \\
\text { que inviten a la participación, al desarrollo de trabajos en } \\
\text { grupo y a la reflexión crítica a través de conferencias } \\
\text { virtuales. }\end{array}$ \\
\hline Evaluación & Conductivista y & $\begin{array}{l}\text { constructivista } \\
\text { La evaluación debe buscar medir el logro de competen- } \\
\text { cias y objopuestos para el curso a través de exá- } \\
\text { menes tradicionales, pero también debe tomar en cuenta } \\
\text { la creación de conocimiento individual a través de la par- } \\
\text { ticipación en trabajos grupales y los aportes a las confe- } \\
\text { rencias virtuales. }\end{array}$ \\
\hline
\end{tabular}

Núñez, 2000.

A lo largo de esos elementos existe un hilo conductor: la adopción de estilos de aprendizaje más activos en los que los estudiantes tomen más responsabilidades para con sus metas de aprendizaje y con la manera de llevarlas a cabo. El aprendizaje activo implica también que los estudiantes no se limiten a ver sólo recursos proporcionados por sus instructores, sino que busquen nuevos materiales que les ayuden a resolver problemas y a desarrollar su competitividad continuamente. Independientemente de las preferencias pedagógicas de cada quien, se pueden intentar nuevas cosas alrededor de educación, Tic, etcétera.

De aquí se concluye que la búsqueda de nuevos modelos de enseñanza basados en tecnologías de información y comunicación es una condición inaplazable en la educación del siglo XXI.

Estela Morales lo resume de una manera espléndida al afirmar:

La educación superior tiene que ofrecer soluciones y opciones a los jóvenes que viven en una sociedad donde la información es el elemento de cambio más codiciado, las oportunidades de trabajo se hacen más específicas y el ciclo productivo ya no es lineal, 
porque se distribuye ampliamente en la globalidad, a partir del más bajo costo y la más alta calidad, además de integrar todos los procesos, las ideas, los diseños, la comercialización y el almacenamiento [Morales, 2001].

Con todo lo anteriormente revisado, podemos empezar a unir los dos elementos en pos de un fin común que es de nuestro interés: educación y bibliotecas. Para ello, podemos utilizar, además de lo ya presentado, las interrogantes planteadas en el documento de la Academia de Ciencias Mexicana (Academia..., 1999, p. 25):

- ¿Cómo podemos elevar la calidad de la educación aprovechando las tecnologías de información?

- ¿Cómo podemos reeducar, capacitar y adiestrar al mayor número posible de mexicanos en edad de trabajar, que están fuera de la educación formal y que tienen sólo educación básica o media básica?

- ¿Cómo podemos acercar a la población de escasos recursos, los beneficios de la disponiblidad de información de toda índole?

- ¿Cómo podemos sacar mayor provecho de los recursos que el país ha invertido hasta la fecha en estas tecnologías?

El mismo documento nos da una respuesta general, afirmando que es necesario crear una base nacional de comunicación y de conocimientos, la cual sería lograda a través de tres grandes estrategias:

- Apoyar la modernización del país, poniendo al alcance de maestros y alumnos de todos los niveles, las herramientas necesarias para acceder a nuevos métodos educativos y al cúmulo de información y conocimientos disponibles globalmente a través de los medios electrónicos.

- Extender el acceso a las tecnologías de información a los sectores que están fuera del ámbito de acción del sistema educativo 
Sociedad de la información, sociedad del conocimiento y bibliotecas...

formal, poniendo a su alcance programas de capacitación y actualización de conocimientos a lo largo de la vida así como información de toda índole.

- Integrar en un marco coherente la información y el conocimiento producidos por el país, para organizarlos y hacerlos llegar ágilmente al mayor número posible de personas, así como complementarlos con información y conocimientos actualizados generados en otras partes del mundo, indispensables para asegurar una posición competitiva de México en esta nueva era que inicia [Academia..., 1999, pp. 26-27].

Finalmente, este documento nos dice que habría cinco componentes básicos para la construcción de esa base nacional de información y conocimiento:

1. Una plataforma de equipamiento de cómputo y telecomunicaciones.

2. Capacidad suficiente de conectividad y acceso a la Internet en todo el país en condiciones de calidad y precio.

3. Capacidad de creación de contenidos y materiales nacionales en formato digital.

4. Capacidad de organización y administración de esa información para su distribución de manera ágil.

5. Una organización, un marco institucional y mecanismos de financiamiento que den viabilidad.

Para la segunda estrategia enunciada en ese documento, "extender el acceso a las tecnologías de información a los sectores que están fuera del ámbito de acción del sistema educativo formal", será necesario considerar algunos elementos con los que hemos trabajado anteriormente, es decir, nuevos modelos de enseñanza auxiliados por las TIC, lo que hoy en día se conoce como "educación digital”. En forma resumida, estos elementos serían: 
CARACTERÍSTICAS DE LA EDUCACIÓN DIGITAL

- La diferenciación entre educación a distancia y educación presencial desaparece en la educación digital.

- La educación digital representa un cambio de paradigmas. De la era industrial a la era del conocimiento; de la inflexibilidad al hipertexto, de la transmisión de información al objetivo último de aprender a aprender.

- El rol del profesor transmisor de conocimiento se transforma en la educación digital para asumir el rol de mentor y guía del proceso de aprendizaje.

- La educación digital no tiene restricciones de tiempo ni espacio. Es permanente, está disponible a toda hora, en cualquier momento y en cualquier lugar.

- Las tecnologías digitales son un medio, y no un fin, para lograr el desarrollo de competencias y habilidades.

Núñez, 2001.

Estos componentes básicos serán utilizados a la hora de alinear el modelo de biblioteca digital con las propuestas nacionales e internacionales como base para lo que denominaremos las "ocho líneas de acción".

\section{4 ÁREAS ESTRATÉGICAS ENTRE BIBLIOTECAS Y EDUCACIÓN}

El destino de un país reside en la educación de sus individuos.

BENJAMIN DisRaeLI

El educando de este futuro cercano, según Bates necesitará poder trabajar desde su casa, desde su escuela o trabajo, o en tránsito, y requerirá de las siguientes herramientas (Bates, 1995):

- Búsqueda y descarga de múltiples fuentes en variados formatos.

- Selección, almacenamiento y recreación de información.

- Conexión directa con instructores, colegas y otros educandos. 
Sociedad de la información, sociedad del conocimiento y bibliotecas...

- Capacidad de integrar documentos, información, proyectos, etcétera, con otros.

- Acceso, combinación, creación y transmisión de texto, audio, video y datos.

Como puede verse, en estas actividades se requiere de servicios de información consistentes, integrados y completos. Y es precisamente allí donde se intersecan los objetivos de la educación y los de las bibliotecas. Para abundar en ello, revisemos lo que presentó Hans Roes ${ }^{19}$ acerca de lo que considera las cinco áreas estratégicas con las cuales las bibliotecas podrán en un futuro enfrentar el reto de asumir los cambios en el modelo educativo:

- Bibliotecas digitales y ambientes de aprendizaje digitales.

- Portafolios digitales.

- Alfabetización en información.

- Diseño multidisciplinario de cursos.

- La relación entre ambientes de aprendizaje físicos y virtuales.

\subsubsection{Bibliotecas digitales y ambientes de aprendizaje}

Las bibliotecas digitales son complementos naturales a los ambientes de aprendizaje digitales. Pueden integrar la información libre esparcida en la Internet con la literatura más formal para la cual son pactadas licencias de uso de sitios electrónicos con editores tradicionales. Dichas licencias optimizan y remplazan las políticas tradicionales de desarrollo de colecciones. Las bibliotecas digitales facilitan servicios de información para los estudiantes o trabajadores de la información, independientes de tiempo y espacio, necesarios sobre todo si los mencionados estilos de aprendizaje activo serán cada vez más usuales. Mucho del trabajo hecho en la última década para el desarrollo de bibliotecas digitales redituará notablemente en innovaciones educativas.

19 Hans Roes, 2001. "Digital Libraries...", op. cit. 
Los cursos ofrecidos en la manera tradicional consisten por lo general en temarios autocontenidos en los cuales el profesor presenta su programa, textos básicos y de apoyo, y una manera de obtener guía y asesoría para transitar a través de ellos. Mucho del éxito del estudiante en estos cursos consiste en que él pueda reproducir y, por ende, leer esos textos. El centro del nuevo análisis de estos elementos es el poder conciliar el hecho de que entre más estudiantes utilicen estos estilos proactivos de aprendizaje, los cursos al estilo actual autocontenidos dejarán de ser utilizados y otros textos y rutas de tránsito deberán ser contemplados.

Al efecto, podemos observar dos tendencias: la primera, la europea - por su origen en el Reino Unido- toma las necesidades de los cursos específicos tratando de ligar virtualmente los ambientes de aprendizaje con las bibliotecas digitales. Se basa en las necesidades y características de la institución de enseñanza y del usuario y parte del hecho de que los profesores pueden ser ayudados por medio de ambientes digitales de aprendizaje específicos, enriqueciendo esos ambientes con recursos ad hoc puestos en bibliotecas digitales. Dos proyectos notables al efecto en el Reino Unido iniciaron estas actividades: INSPIR AL y ResIDe (INSPIRAL, 2001). Este último evolucionó en un proyecto más elaborado, denominado NLSF (Networked Learning Support Framework), operado principalmente por la Universidad del Oeste de Inglaterra (UWE, 2002).

La segunda tendencia es la norteamericana; su principal característica es una aproximación macro al problema. Pretende crear colecciones de amplio espectro temático y cobertura de nivel como apoyo a los ambientes digitales de aprendizaje; es decir, se concentra en recursos de aprendizaje en general y no para un curso específico. Un ejemplo típico de este modelo puede verse en la Biblioteca Nacional Digital de Educación en Ciencia, Matemáticas, Ingeniería y Tecnología de la NSF (National Science Foundation), conocida como el programa NSDL (National Science Digital Library) (Wattenberg, 1998, Zia, 2000). Este proyecto busca concentrar una enorme colección de recursos para aprendizaje en esa temática apoyando todo tipo de educación, desde la básica hasta educación continua, 
Sociedad de la información, sociedad del conocimiento y bibliotecas...

pasando por la superior. Esta aproximación es consistente con otros proyectos de gran envergadura para otras bibliotecas digitales de la NSF. Un análisis más detallado acerca de las diferencias entre las conceptualizaciones europea, estadounidense e inclusive china de las bibliotecas digitales ha sido establecido por (Zeng y Zhang, 2002).

\subsubsection{Portafolios digitales}

Los portafolios digitales son nuevas herramientas para tutoría de estudiantes. Originalmente, fueron desarrollados simplemente como una manera de monitorear el progreso de un estudiante a lo largo de un curso, haciendo énfasis en el proceso de aprendizaje y en los resultados cuantificables que el estudiante obtuviese. En la actualidad, además de seguir cumpliendo con esos objetivos básicos, un portafolios permite certificar ciertas habilidades adquiridas a lo largo de un curso mostrando resultados medibles. Del mismo modo, el portafolios se convierte en una herramienta personal del estudiante para observar su propio progreso y establecer metas nuevas y/o más profundas en el desarrollo planeado de su educación. Adicionalmente, el portafolios, el cual puede ir creciendo a lo largo de un entrenamiento, puede ser mostrado como comprobante de habilidades o experiencia para un posible empleador. Los portafolios digitales funcionan admirablemente bien en ambientes donde los estudiantes trabajan con tareas en las que deben resolver problemas de la vida real y en las que pueden buscar y proponer diversas soluciones.

Como los portafolios pueden ser almacenados y consultados en las intranets de una institución, las bibliotecas pueden administrar e indizar estos portafolios de tal forma que al ser integrados con otros recursos de información proporcionados por la misma biblioteca, consoliden todavía más el ambiente de aprendizaje con la biblioteca digital. La sinergia de conocimientos con recursos de información es muy interesante y atractiva para ser manejada por una biblioteca y es un filón que no debe ser ignorado. 


\subsubsection{Alfabetización en información}

Al ir agregando los portafolios digitales a la siempre creciente cantidad de información disponible entramos al tercer dominio en el cual las bibliotecas pueden jugar un rol importante en innovación educativa: la alfabetización en información. De acuerdo con la Association of College and Research Libraries, según su definición:

Las personas alfabetizadas en información pueden no sólo reconocer cuándo se requiere información, sino son capaces de identificar, localizar, evaluar y usar efectivamente la información requerida para una particular decisión o asunto a la mano. La persona alfabetizada en información, por lo tanto, está capacitada para una toma efectiva de decisiones, con libertad y opciones de éstas, y por ende con plena participación en una sociedad democrática.

Hay por supuesto más definiciones de alfabetización en información; tienen que ver con el ambiente en que son utilizadas, y por ello hablan de competencias personales, capacidad de análisis y síntesis, estrategias de búsqueda, etcétera. No obstante, todas se relacionan con la capacidad de aprender y marcan la necesidad de desarrollar esta capacidad. Hannelone $\operatorname{Rader}^{20}$ remarca que "los bibliotecarios están singularmente calificados para asumir un papel activo en el nuevo ambiente de enseñanza dadas sus habilidades para compilar, evaluar, organizar y proveer acceso a la información". La alfabetización en información puede verse como la capacitación tradicional del estudiante en el uso de las bibliotecas, pero llevada a fronteras mucho más ambiciosas. Pueden observarse ya algunos grupos de académicos bibliotecarios desarrollando módulos de instrucción a distancia basados en la Internet. Un ejemplo claro de ello puede verse en el tutorial de la Universidad de Texas para alfabetización en información, conocido como TILT, el cual tiene amplio reconocimiento en el medio (University of Texas, 2002).

${ }^{20}$ Hannelore B. Rader, 1997. "Educating Students for the Information Age: The Role of the Librarian". Reference Services Review, 25:2 (verano, 1997). 
Sociedad de la información, sociedad del conocimiento y bibliotecas...

Abundando más acerca de estas nuevas tareas de los bibliotecarios en un futuro cercano dentro de la producción de materiales para la educación, en la definición que da Bates puede observarse lo que es un equipo típico de producción de materiales para educación:

1. Un experto en un tema (autor, académico, consultor, etcétera).

2. Diseñador instruccional (desarrollador de cursos, pedagogo, etcétera).

3. Editor.

4. Bibliotecario.

5. Diseñador gráfico (ilustrador, diseñador de páginas Web, html, etcétera).

6. Corrector.

7. Distribuidor (impresor, en el caso de que se requiera), emisor de radio o televisión, o proveedor de servicios de Internet.

\subsubsection{Diseño multidisciplinario de cursos}

El diseño multidisciplinario de cursos es otra de las estrategias a desarrollar. En un ambiente educativo tradicional, el profesor diseña su curso bajo su casi total albedrío; escoge la manera en que va a enseñar y en la que supervisará el avance de sus alumnos (magister dixit). En los ambientes de aprendizaje digitales la tendencia es que los materiales son diseñados por grupos multidisciplinarios de expertos; pedagogos, programadores, diseñadores gráficos y, por supuesto, bibliotecarios, entre otros, acompañan ahora al experto académico en un tema dado para el desarrollo de un curso de aprendizaje en un ambiente digital con variados materiales de apoyo y diversas rutas de navegación para diferentes tipos y necesidades de educandos. Originalmente, estos cursos fueron diseñados siguiendo los patrones de la educación tradicional, agregando simplemente el elemento electrónico o a distancia, pero como cursos autocontenidos en los que la ruta de navegación es lineal y única y el material bibliográfico rígido y prácticamente el mismo que el utilizado en una biblioteca tradicional. En un enfoque más actual, el 
énfasis en ir desarrollando competitividades con miras a ir produciendo empleados del conocimiento, así como la mayor imbricación entre trabajo y aprendizaje, conduce a ambientes de aprendizaje con cursos y materiales cada vez más y más abiertos. Ahora las expectativas son que los estudiantes vayan más allá de los materiales de un aprendizaje básico y que exploren de manera independiente fuentes alternativas de información.

Igualmente, si los ambientes proactivos de aprendizaje proliferan, sin duda la función de los bibliotecarios en esos equipos multidisciplinarios es desarrollar ambientes de aprendizaje digitales. Los bibliotecarios pueden, a guisa de ejemplo, agregar ligas a los recursos, impresos o digitales, que posean en sus colecciones. Pueden explicar al estudiante cómo es que los recursos de información están organizados en un tema en particular y cómo pueden encontrar las rutas a los materiales en áreas que les sean nuevas a los estudiantes o en las que por ser numerosas sea fácil perderse o divagar. Pueden crear antologías de sitios y colecciones electrónicas con diversos niveles y enfoques, etcétera.

\subsection{AMBIENTES DE APRENDIZAJE}

Dímelo y lo olvidaré; enséñamelo y lo recordaré; involúcrame y lo aprenderé.

BENJAMIN FRANKLIN

La relación entre ambientes de aprendizaje físicos y virtuales tiene que ver con un adecuado balance de ambos para un óptimo aprovechamiento del estudiante. Si bien se ha preconizado que una persona puede aprender todo por sí misma frente a su computadora y que todo ambiente de estudio o de trabajo puede ser reproducido con aplicaciones de grupo en la red, esto no es del todo real. Ello se contrapone a los importantes aspectos sociales del trabajo y el estudio. John Brown y Paul Duguid hacen una reflexión acerca 
Sociedad de la información, sociedad del conocimiento y bibliotecas...

de la importancia del contexto social en el que las personas dan sentido a la información. Noriko Hara y Rob Kling realizaron un estudio de los problemas y frustraciones a los que se enfrentan los estudiantes en ambientes de aprendizaje puramente basados en la Internet. Los estudiantes requieren de alguna manera la retroalimentación propia de un salón de clases proporcionada por compañeros y por el profesor, y probablemente ambos ambientes, el virtual y el físico coexistirán por un buen tiempo (Brown y Duguid, 2000, Hara y Kling, 1999).

Si se planea adecuadamente el ambiente físico de la biblioteca, esto es, sus instalaciones, puede ser utilizado como apoyo a ambientes de aprendizaje más efectivos. Los edificios para bibliotecas se construyen hoy en día orientados al usuario y no a la colección, como antaño se hacía. Cada vez es más común ver pequeños gabinetes para lectura o para seminarios grupales, donde se observa un pizarrón (como en el salón de clase) y computadoras o al menos conexiones a la Internet (como en los laboratorios), con el fin de que los alumnos, por sí mismos o con ayuda de su instructor, reproduzcan ambientes de aprendizaje ya conocidos. Por si fuera poco, la colección ya existente en medios impresos se encuentra cerca en caso de ser requerida. El espacio físico de la biblioteca se reconvierte así en lo que ahora se denomina "ambiente de aprendizaje" o "centro de aprendizaje". Bajo este esquema tenemos una unión física entre aula, laboratorio y biblioteca. No es un mal destino evolutivo el del noble edificio de la biblioteca; pensándolo bien, nunca había estado la biblioteca apoyando tan de cerca y tan directamente el aprendizaje del estudiante.

Como puede verse claramente, las bibliotecas representan un importante papel en estas cinco áreas estratégicas relacionadas con los nuevos ambientes de aprendizaje. Sin lugar a dudas, los bibliotecarios no pueden estar ajenos a este proceso. Muchas son las facetas, vertientes y actividades que pueden y deben ser desarrolladas por ellos. Es obvio también que nuevas aptitudes y actitudes les serán requeridas a esos bibliotecarios para desempeñarse plenamente en este nuevo ambiente; más adelante abundaré en ello. Debe quedar claro que las bibliotecas tienen una oportunidad y una res- 
ponsabilidad enormes en esta sociedad de la información que se está reconformando y que hace evolucionar además sus esquemas educativos. Al fin y al cabo es natural que una sociedad de la información esté creando la "educación de la sociedad de la información" y que para apoyarla necesite crear también las "bibliotecas para la educación de la sociedad de la información”. Éste es el núcleo, esencia y razón de ser de las bibliotecas de nuestro futuro cercano. He ahí el paradigma sobre el cual deben construirse. No obstante, y como esta denominación es muy extensa, sigamos denominándolas, por comodidad, bibliotecas digitales, pero no olvidemos que dichas bibliotecas son necesarias para apoyar la educación propia de esa sociedad de la información y hacia ese contexto van evolucionando. Más adelante habrá que agregar un elemento de suma importancia para el modelo: la producción. Por el momento, respecto a la educación y particularizando ese contexto a nuestro país y a este momento, lo que debemos imaginar, diseñar y planear entonces son las "bibliotecas para la educación de la sociedad de la información mexicana del siglo XXI". Ampliaremos este concepto más adelante.

En este punto cabe hacer una sinopsis de lo que Bates ${ }^{21}$ pronostica que serán los cambios más significativos en las tecnologías de cómputo, telecomunicaciones, enseñanza, así como el entorno en que se moverán los educandos dentro de una década:

- La integración de televisión, telecomunicaciones y cómputo, en dipositivos únicos al alcance de un considerable número de personas.

- Costos más reducidos y mejores aplicaciones en telecomunicaciones en todo nivel, como ISDN, fibra óptica, telefonía celular, radio módems, redes inalámbricas.

- Miniaturización de componentes: cámaras, micrófonos, pantallas, etcétera.

- Mayor portabilidad, con el uso de palms, tablet PC, redes inalámbricas.

21 Anthony W. Bates, 1995. Technology, Open Learning..., op. cit. 
Sociedad de la información, sociedad del conocimiento y bibliotecas...

- Mayor poder de procesamiento, con la evolución de los microprocesadores.

- Programas más potentes y amigables.

- Más y mejores sitios en los cuales obtener información, desde la casa, trabajo, aula, etc., disponibles en todo momento.

- Instituciones educativas remotas, electrónicas, accesibles para muchos, a cualquier hora.

- Mayor cantidad de alumnos y usuarios a quienes atender, dada la reducción de costos de mantenimiento de instalaciones.

Para finalizar esta parte, he aquí un resumen del papel que de acuerdo con la IFLA las bibliotecas del futuro cercano desempeñan en pos del ideal del desarrollo sostenido:

- La biblioteca internacional y la comunidad de información forman una red que une países desarrollados y en desarrollo, apoya el progreso de servicios bibliotecarios y de información a lo largo de todo el mundo, y asegura que estos servicios respeten la equidad, así como la calidad general de vida para toda la gente y el medio ambiente natural.

- Los profesionales de las bibliotecas y de la información reconocen la importancia de la educación en sus varias formas para todos. Los servicios bibliotecarios y de información actúan como entradas a conocimiento y cultura; proporcionan el acceso a información, ideas y creaciones en varios formatos, apoyando el desarrollo personal en todas las edades, así como la participación activa en procesos sociales y de toma de decisiones.

- Los servicios bibliotecarios y de información proporcionan el apoyo esencial al aprendizaje a lo largo de toda la vida, toma de decisiones independiente y desarrollo cultural para todos. A través de sus vastas colecciones y variedad de medios, ofrecen guía y oportunidades para el aprendizaje. Los servicios bibliotecarios y de información ayudan a la gente a mejorar sus habilidades educativas y sociales, indispensables en una sociedad de la información y con miras a una participación sostenida en la democracia. Las bibliotecas impulsan el hábito de lectura y la 
alfabetización en información y promueven la educación, la conciencia pública y el entrenamiento.

- Los servicios bibliotecarios y de información contribuyen al desarrollo y salvaguarda de la libertad intelectual y ayudan a proteger los valores básicos de la democracia y de los derechos civiles universales. Por lo mismo respetan la identidad, la opción independiente, la toma de decisiones y la privacía de sus usuarios sin discriminación.

- Hoy en día, los servicios bibliotecarios y de información adquieren, conservan y ponen a disposición de todos los usuarios sin distinción la variedad más amplia de materiales, reflejando la pluralidad y la diversidad cultural de la sociedad, así como la riqueza de nuestros medios ambientes.

- Los servicios bibliotecarios y de información están contribuyendo a reducir la desigualdad de la información detectada como una creciente brecha de información, así como la división producida por el mundo digital. A través de su red de servicios, la información sobre investigación e innovación es puesta a disposición para promover el desarrollo sostenible y el bienestar de los pueblos de todo el mundo.

Nuevamente cito a Manuel Castells, el sociólogo erudito de la era de la información:

Una diferencia importante atañe a lo que denomino trabajador genérico frente a trabajador autoprogramable. La cualidad crucial para diferenciar a estos dos tipos de trabajador es la educación y la capacidad de acceder a niveles superiores de educación. El concepto de educación debe distinguirse del de cualificación. Ésta puede quedarse obsoleta rápidamente por el cambio tecnológico y organizativo. La educación -que no es un almacén de niños y estudiantes- es el proceso mediante el cual las personas -oyeron, personas, con vocaciones, preferencias y valores propios, se remarca aquí-, es decir, los trabajadores, adquieren la capacidad para redefinir constantemente la cualificación necesaria para una tarea determinada y acceder a las fuentes y métodos para adquirir dicha cualificación [Castells, 1999. La era...]. 
Sociedad de la información, sociedad del conocimiento y bibliotecas...

2.6 ÁREAS ESTRATÉGICAS DE DESARROLLO EN UN SISTEMA MICRO DE BIBLIOTECAS DIGITALES

Ya hemos analizado las áreas estratégicas que deben ser estudiadas entre las bibliotecas y el sector educativo. El siguiente paso es analizar las áreas internas de la biblioteca que deben estudiarse y en su momento convertirse en proyectos de desarrollo con el objeto de planear una adecuada instrumentación. En una biblioteca o sistema pequeño de bibliotecas reales probablemente no existan todas las áreas, ya que la presencia de ellas depende del tipo de biblioteca. No obstante, conviene que analicemos todas las áreas ya que eso nos brinda una visión global que deberá instrumentarse en un sistema de bibliotecas digitales de ciertas dimensiones. Para el caso individual de una biblioteca siempre pueden suprimirse las áreas que no existan en ella.

Curiosamente, a través de una extensa búsqueda a lo largo de iniciativas de diversos países, muchos de ellos desarrollados en la primera mitad de la década de 1990, se tiene como común denominador que fueron creadas como iniciativas nacionales de "biblioteca digital" y sin embargo son sumamente puntuales. En esencia, la mayoría se refiere a digitalización de archivos o colecciones locales, de mayor o menor relevancia, con algunas variantes. Los planes realmente a nivel nacional existieron poco en esa época y menos los planes de región o zona. Por ejemplo, los cinco países nórdicos tenían cada uno su plan antes de presentarse el e-Europe, a pesar de su cercanía y semejanza y sólo bajo su influencia crearon finalmente un plan para la región nórdica. Por lo mismo cada plan hacía énfasis en elementos que casi parecían surgir al azar de tan disímbolos que eran. Apenas en años recientes es que empezaron a surgir los verdaderos planes y estrategias. Por ende, las áreas a desarrollarse en esos sistemas de bibliotecas digitales coinciden poco. Una ojeada a las iniciativas europeas en la página Computers in Libraries permite corroborar esto casi inmediatamente (Raitt, 2000).

Como punto de partida, podemos mencionar el conjunto de áreas de desarrollo establecido por la Digital Libraries Initiative 2 
(DLI 2, 1998) de la Federación Digital de Bibliotecas norteamericana. No es muy útil para una planeación de sistemas de bibliotecas digitales, ya que su enfoque más bien está orientado a esbozar grandes áreas en las que la federación desea que se creen desarrollos dentro de la Unión Americana y no un método de desarrollo en sí. En esencia, es un proyecto que convoca a su vez a otros proyectos de investigación orientados a tres grandes rubros: el ser humano, contenidos y colecciones, y sistemas.

Recientemente los científicos de las principales universidades de Holanda pusieron en servicio un sitio Web, en el que se puede acceder a todo su material documental de investigación en forma libre y gratuita. Los lectores interesados pueden consultar así un total de 47000 documentos de los depósitos digitales académicos de las 16 instituciones involucradas. Hasta el momento, ninguna otra nación en el mundo ofrece tal cobertura de acceso a sus productos documentales de investigación académica en forma digital (DARE, 2005).

El proyecto, llamado DAREnet es una iniciativa conjunta de 16 universidades holandesas, la Biblioteca Nacional de Holanda, la Academia Real Holandesa de Artes y Ciencias (KNAw) y la Organización Holandesa para la Investigación Científica (NWO). Gracias a esta iniciativa y a un ambicioso proyecto de minería de datos se relaciona todo el material existente en los repositorios digitales de las instituciones participantes haciéndolo totalmente recuperable. El material abarca catálogos y bibliografías, libros y artículos en texto completo y hasta archivos de audio y video. Este proyecto nació, según los participantes, debido a los cada vez más altos costos de las revistas científicas, que de esta forma pueden ser distribuidas a las bibliotecas y a sus usuarios a un costo mucho menor. Por supuesto, la iniciativa no ha hecho nada felices a los editores comerciales en Holanda, tales como el gigante Elsevier Science.

Otro proyecto también muy interesante es el denominado programa eLib del Reino Unido. Concebido a través de una organización creada ad hoc llamada JISC (Joint Information Systems Comitee) para el impulso de estas iniciativas en instituciones de enseñanza 
superior en esa región. El grupo dividió las primeras dos fases de estudio del proyecto en ocho grandes áreas estrátegicas de análisis e investigación, asignando una considerable cantidad de recursos a cada una. En orden decreciente los recursos invertidos a cada área se establecieron así (eLib Programme, 2000):

- Revistas electrónicas.

- Entrenamiento y sensibilización.

- Entrega de documentos y/o contenidos electrónicos.

- Acceso a recursos de red.

- Publicación sobre demanda.

- Digitalización.

- Préstamos electrónicos, preimpresos, control de calidad, etcétera.

- Otros elementos de apoyo a infraestructura.

Ésta no es una lista exhaustiva, pero nos brinda una idea de cuáles son las áreas que despertaron interés para desarrollarse en un sistema de bibliotecas digitales en esa región.

En Canadá, el Comité Técnico para Bibliotecas Digitales (DLTC) planteó las siguientes áreas como las más importantes para ser estudiadas y desarrolladas con el fin de establecer el sistema canadiense de bibliotecas digitales (DLTC, 1997):

- Almacenamiento electrónico.

- Interfases al usuario.

- Clasificación e indización.

- Herramientas para recuperación de información.

- Entrega de documentos y/o contenidos electrónicos.

- Presentación alternativa de documentos.

- Privacidad y seguridad.

El proyecto de bibliotecas digitales de Australia planteó una serie de áreas de desarrollo para las cuales trabajarían sus diversas bibliotecas (Ianella, 1996): 
1. Registro y distribución electrónica de materiales australianos (WORLD 1).

2. Digitalización de artículos y capítulos de libros escolares (Electronic Reserve Project).

3. Edición de revistas electrónicas y suscripciones electrónicas (Electronic Journal Project y UNILINC Project).

4. Entrega de documentos electrónicos (REDD: An Electronic Document Delivery Project).

5. Digitalización de dos acervos fotográficos (Hume Image Collection Project y DIGILIB: Queensland Country Towns Image Project).

6. Digitalización de artículos de diarios (NSW Parliaments Newspaper Clippings and Press Releases Imaging Project).

7. Digitalización de archivos de grabaciones (Preserving Oral History Recordings Project).

8. Digitalización de archivos del parlamento (The Information Storage \& Retrieval Project).

9. Herramientas de acceso a la información (Scholarly Electronic Text and Image Service).

10. Digitalización de archivos de imágenes de artes plásticas (The Documentary Images Project).

11. Digitalización de acervos de museos (Australian Museums On Line).

Como los ejemplos anteriores podemos encontrar muchos otros en los que al final pueden trazarse las áreas que se presentan concurrentemente en un buen número de estos proyectos. De lo anterior se desprende el tema siguiente. 
Sociedad de la información, sociedad del conocimiento y bibliotecas...

2.7 RESUMEN DE ÁREAS ESTR ATÉGICAS DE DESARROLLO

EN SISTEMAS MICRO DE BIBLIOTECAS DIGITALES

Hoy en día lo que se aprende, dentro de pocos años ya no va a ser válido o suficiente, sino que hay que volver a aprender y hay que seguir aprendiendo prácticamente durante toda la vida: El aprender tiene que transformarse en un hábito.

D. WERNER

Para finalizar este capítulo presento un resumen de las áreas de oportunidad estratégica que las bibliotecas pueden trabajar en proyectos conjuntos con el objetivo de mejorar la educación.

- Digitalización de acervos relevantes, raros o antiguos. En este rubro podemos considerar una enorme variedad de materiales: libros, revistas, mapas, diarios, grabaciones, fotografías, manuscritos, museográficos, etcétera, que se encuentren en poder de la biblioteca o al alcance de ella y que de acuerdo con los criterios de digitalización como los ya mencionados (Harvard o Columbia, por ejemplo) valga la pena procesar (Columbia University, 2001 y Harvard University 2001).

- Digitalización parcial de materiales con copyright (capítulos de libros, artículos de revistas, etc.) previo convenio con los titulares de ese derecho.

- Desarrollo de colecciones con materiales adquiridos externamente (compra, canje o donación) en diversos medios, como libros, revistas, mapas, etcétera, en dos vertientes: buscando una amplia cobertura en temas o títulos de materiales o buscando una amplia cobertura en el tiempo inclusive la retrospectiva, previo acuerdo de derechos.

- Desarrollo de colecciones digitales propias de la biblioteca por medio de publicación sobre demanda con material propio de la institución a que pertenece la biblioteca (copyright propio o asequible). En este caso la biblioteca tiene acceso fácil a un 
sistema de publicación sobre demanda de material relativo a ella o a su institución asociada y por este medio incide en la publicación de documentos y el desarrollo de colecciones digitales con materiales propios y con poco o ningún problema de copyright.

- Entrega de documentos y/o contenido electrónicos. Con cuáles medios, herramientas, controles, etcétera, entregará la biblioteca a sus distintos grupos de usuarios copias electrónicas controladas de sus documentos.

- Acceso de la biblioteca a recursos de la Internet para ofrecer servicios a los usuarios. Por cuáles medios la biblioteca tendrá acceso a servidores, ancho de banda, personal técnico, almacenamiento electrónico, etcétera, para poder ofrecer sus servicios.

- Acceso de los usuarios: rápido, remoto, garantizado, seguro, a toda hora.

- Catalogación, indización, vínculos, metadatos e inventarios adecuados por parte de la biblioteca. Cuáles serán los estándares aceptados por las bibliotecas para registrar y ofrecer su material.

- Oferta de acceso a los usuarios a potentes buscadores por múltiple llaves y ligas. Esto es, contar con acceso a buscadores, interfases, etcétera, potentes y económicamente rentables para poder ofrecerlos a la comunidad usuaria.

- Integración de acervos distintos en pocos buscadores. Esto es, una adecuada integración de colecciones y materiales en conjuntos más lógicos de búsqueda para los usuarios, evitando la repetición de búsquedas en innumerables colecciones.

- Capacitación de usuarios, con el fin de lograr una adecuada explotación de los recursos por parte de ellos.

- Almacenamiento electrónico amplio y eficiente. Dónde, cómo y por cuánto dinero almacenar los materiales para lograr un buen acceso con un óptimo rendimiento económico.

- Preservación de materiales para mantener el conocimiento para futuras generaciones de usuarios.

Por supuesto, es imposible que una sola biblioteca desarrolle proyectos en todas y cada una de estas áreas, no obstante es importante que se tenga en mente estos dos puntos: 
1. En un sistema de bibliotecas digitales, todos estos proyectos deben ser desarrollados, compartiendo entre todas las bibliotecas miembros del proyecto la asignación de prioridades, responsabilidades y beneficios, con objeto de lograr un adecuado balance entre desarrollo y recursos invertidos.

2. Todos estos proyectos significan áreas estratégicas de desarrollo para un sistema de bibliotecas digitales, pero deben además estar puestos en contexto por un gran objetivo de perspectiva del desarrollo de este sistema. De otro modo se tendrán sistemas de bibliotecas desarrollados adecuada y exitosamente desde el punto de vista de funcionamiento y efectividad a corto plazo, pero sin obedecer a un objetivo estratégico de largo aliento.

En suma, un objetivo educativo de largo plazo sin desarrollo estratégico del sistema de bibliotecas se quedará en proyectos de "buenas intenciones". Un desarrollo estratégico del sistema de bibliotecas sin el objetivo educativo de contexto a largo plazo desperdiciará enormemente los recursos del sistema. 



\section{Capítulo 3}

La infraestructura mexicana en tecnologías de información y comunicación (TIC) 

La marca distintiva de las personas bien preparadas no es necesariamente saber todas las respuestas, sino saber dónde encontrarlas.

DOUGLAS EVERETT

\subsection{LAS CIFRAS DE LA INFRAESTRUCTURA}

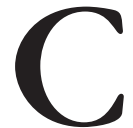

uando hablamos de infraestructura de cómputo y telecomunicaciones nos referimos, en principio, a la capacidad del Estado para proporcionar estos servicios, ya sea de manera directa o indirecta; es decir, los servicios que ofrece directamente y los que de algún modo propicia por medio de concesiones, regulaciones, normatividades, entre otros; y en segundo plano, al total de recursos con los que cuenta el país en este rubro, sin importar si son públicos o privados.

Haciendo un poco de historia, los proyectos de infraestructura gubernamental que más huella han dejado en el desarrollo de nuestro país han sido los de acceso a redes satelitales de telecomunicaciones y posteriormente a las redes terrestres en la última década del siglo Xx. Durante 45 años el marco jurídico de las telecomunicaciones estuvo basado en la Ley de vías generales de comunicación publicada el 19 de febrero de 1940. Dicha ley promovió la organización de las telecomunicaciones del país bajo un régimen monopólico sujeto a una estricta regulación estatal. Teléfonos de México, el principal agente del sector, pasó a ser, en el año de 1946, una empresa de propiedad estatal mayoritaria. Dentro del ámbito de la administración pública y sujeta a las restricciones presupuestales existentes, esa empresa no pudo desarrollar la infraestructura telefónica del país al acelerado ritmo que la sociedad mexicana demandaba. El sistema telefónico se convir- 
tió en un cuello de botella para el desarrollo, ya que para suministrar una línea, aun en las zonas más ricas del país, se tenían tiempos de espera de entre dos y cinco años. Las telecomunicaciones adolecían por tanto del mismo rezago. El reto de modernizar aceleradamente la infraestructura de telecomunicaciones implicó adoptar un modelo de desarrollo, basado en la propiedad privada de la principal empresa prestadora de servicios de telecomunicaciones.

En ese sentido, las acciones más importantes tomadas en la década de 1990 fueron en primer lugar, la modificación del Título de Concesión de Teléfonos de México en agosto de 1990; en segundo lugar, la publicación de la Ley federal de telecomunicaciones, en junio de 1995 y, por último, la creación de una entidad independiente que fuese la promotora y reguladora de las telecomunicaciones, en agosto de 1996, denominada Comisión Federal de Telecomunicaciones, COFETEL.

En lo relativo a iniciativas de infraestructura para acceso a la Internet el primer antecedente gubernamental se remonta a 1997 , donde un proyecto piloto bajo la responsabilidad de la Secretaría de Medio Ambiente, Recursos Naturales y Pesca (SEMARNAP) tuvo el objetivo de crear "telecentros" en algunas delegaciones de la Ciudad de México, así como en algunos municipios de los estados de México y Michoacán. Estos telecentros, que llegaron a ser alrededor de dos docenas, eran pequeños lugares de acceso público que ofrecían conexión a la Internet y otras redes a través de una PC con módem, línea y cuenta de algún proveedor de ese servicio. El propósito básico de esa iniciativa era ampliar la información disponible a nivel local y regional con el fin de ofrecer datos para análisis a los sectores locales que participarían cada vez con mayor empeño en la planeación del desarrollo. Como propósito secundario, los telecentros también significarían una herramienta ágil y económica para extender los frutos de la llamada sociedad del conocimiento e impulsar el desarrollo. Si bien los telecentros no proliferaron, sentaron las bases de lo que hoy serían los Centros Comunitarios Digitales (CCD) del proyecto eMéxico. 
En el Programa de las Naciones Unidas para el Desarrollo (PNUD) se presentan oficialmente las carencias tecnológicas mundiales desde 1999, y se destaca en su informe de 2001 la importancia del desarrollo tecnológico para la superación de la pobreza. Uno de los factores interesantes es la inclusión de un Índice de desarrollo tecnológico, relacionado con el conocido Índice de desarrollo humano que el PNUD divulga anualmente. El PNUD trata de dejar en claro que si bien en el mundo hay muchas necesidades, el desarrollo tecnológico sigue siendo prioritario, pues es clave para el progreso social: el énfasis en tecnología debe estar en información, en salud, en educación (Organización de las Naciones Unidas, PNUD, 2001).

Por ello, uno de los elementos que será muy importantes al momento de establecer el modelo, será conocer cuál es la infraestructura existente en México en lo relativo a tecnologías de información y comunicación (TIC). Para ello haremos una compilación de los datos más relevantes que nos permitan estimar en dónde estamos situados como país, en este aspecto, para saber qué tanto nos falta por hacer. Usaremos indicadores aceptados internacionalmente para este propósito; entre ellos, utilizaremos cinco de los más comunes: el número de usuarios de la Internet en el país, el de computadoras instaladas, el de teléfonos de línea fija, el de teléfonos celulares y el costo por hora de servicio público de la Internet.

Para obtener este tipo de datos no existe una fuente absolutamente confiable; lo más recomendable es observar varias fuentes serias y ponderar sus estimaciones.

El Instituto Nacional de Estadística, Geografía e Informática (INEGI) en su más reciente estudio de junio de 2005 reporta 16.5 millones de usuarios de la Internet en México. Para una población estimada de 105 millones de habitantes, esto da una proporción muy importante, de 15.71 usuarios de la red por cada 100 habitantes, también llamada "penetración porcentual de la Internet" en un país. Si quitamos a los menores de seis años, este factor de penetración, puede alcanzar hasta $24.9 \%$ de la población. Nueve por ciento de los hogares mexicanos tienen conexión a la Internet. 
De acuerdo con la organización especializada e'TForecasts, que presenta cifras muy actualizadas, se calcula que los usuarios de la Internet en México representan 1.49\% a nivel mundial. No obstante su cálculo conservador, esta empresa sitúa a México como el país número 16 a nivel mundial de usuarios de la Internet, dentro de su lista de los top 20 (Internet World Stats, 2004).

Estas cifras, como todas las estadísticas, no tienen valor si no se les compara con algo para tratar de ponderar su valor relativo real. Seleccionaremos algunos países representativos para darnos una idea de su verdadera dimensión.

eTForcasts informa que para fines de 2004, existen en Estados Unidos 202.45 millones de usuarios de la Internet. Esto representa $19.86 \%$ del total de usuarios de la red a nivel mundial y $69.0 \%$ de su población; esto es, el "factor de penetración" de la Internet en el país. Este último número, el factor, es de capital importancia, tal vez más aun que el número total de usuarios, toda vez que nos dice qué tanto es usado este recurso de manera porcentual entre la población.

Para la Unión Europea como conjunto, los números estimados para fines de 2004 son los siguientes: 217852995 usuarios de la Internet en Europa. Ello representa alrededor de $27.7 \%$ del total mundial y $29.9 \%$ de la población total europea como "factor de penetración". No obstante, estas cifras son en promedio; a su vez deben ser consideradas dentro del contexto de Europa Oriental y Occidental. Países como Suecia, Francia o Alemania tienen un alto nivel de penetración, mientras que Bulgaria o Rusia no. 
La infraestructura mexicana en tecnologías de información y...

Cuadro 1

TABLA EUROPEA DE USUARIOS DE LA INTERNET Y FACTOR DE PENETRACIÓN

\begin{tabular}{|lccc|}
\hline País & $\begin{array}{c}\text { Número de usuarios de } \\
\text { la Internet (millones) }\end{array}$ & $\begin{array}{c}\text { Población del país } \\
\text { (millones) }\end{array}$ & $\begin{array}{c}\text { \% de la población } \\
\text { (penetración) }\end{array}$ \\
\hline Alemania & 47.18 & 82.6 & 57.1 \\
Bulgaria & 1.16 & 7.6 & 15.3 \\
España & 13.07 & 41.5 & 31.5 \\
Francia & 24.70 & 60.2 & 41.0 \\
Holanda & 10.80 & 16.2 & 66.5 \\
Polonia & 8.00 & 38.6 & 20.7 \\
Reino Unido & 34.87 & 59.6 & 58.5 \\
Rumania & 3.00 & 22.4 & 13.4 \\
Rusia & 25.00 & 144.5 & 17.3 \\
Suecia & 6.72 & 9.0 & 74.6 \\
Turquía & 4.90 & 68.1 & 7.2 \\
\hline
\end{tabular}

Fuente: European Travel Comission. New Media Review, 2004.

Para el continente asiático y Oceanía, los números más importantes en relación con el uso de la Internet son los siguientes:

Cuadro 2

TABLA ORIENTE DE USUARIOS DE LA INTERNET Y FACTOR DE PENETRACIÓN

\begin{tabular}{|lccc|}
\hline País & $\begin{array}{c}\text { Número de usuarios de } \\
\text { la Internet (millones) }\end{array}$ & $\begin{array}{c}\text { Población del país } \\
\text { (millones) }\end{array}$ & $\begin{array}{c}\text { \% de la población } \\
\text { (penetración) }\end{array}$ \\
\hline Australia & 13.1 & 19.9 & 66.0 \\
Corea del Sur & 31.67 & 51.7 & 61.2 \\
China & 79.5 & 1200.0 & 6.6 \\
Hong Kong & 4.58 & 6.6 & 70.0 \\
Japón & 78.05 & 127.3 & 61.3 \\
Singapur & 2.75 & 4.6 & 60.0 \\
\hline
\end{tabular}

Fuente: European Travel Comission. New Media Review, 2004. 
No obstante estos números y que representan 31\% de los usuarios de la Internet a nivel mundial, el porcentaje de penetración en Asia y Oceanía es muy bajo como región, ya que la inmensa mayoría de esos países tiene condiciones socioeconómicas muy precarias. El factor de penetración es de apenas 6.9\% para el total de la población Asia-Oceanía.

Finalmente, para la región de América Latina, el total de usuarios de la Internet es de 51.18 millones a fines de 2004. Ello representa alrededor de $6.5 \%$ del total mundial de usuarios de la Internet con un factor de penetración de $9.4 \%$ del total de los habitantes de la región. Un poco más detalladamente tenemos las siguientes muestras:

Cuadro 3

TABLA LATINOÁMERICA DE USUARIOS DE LA INTERNET Y FACTOR DE PENETRACIÓN

\begin{tabular}{|lccc|}
\hline País & $\begin{array}{c}\text { Número de usuarios de } \\
\text { la Internet (millones) }\end{array}$ & $\begin{array}{c}\text { Población del país } \\
\text { (millones) }\end{array}$ & $\begin{array}{c}\text { \% de la población } \\
\text { (penetración) }\end{array}$ \\
\hline Argentina & 4.65 & 37.8 & 12.3 \\
Brasil & 22.32 & 201.1 & 11.1 \\
Chile & 5.04 & 16.7 & 30.1 \\
México & 13.88 & 105.0 & 13.2 \\
Uruguay & 1.19 & 3.4 & 34.7 \\
Venezuela & 2.31 & 28.2 & 8.2 \\
\hline
\end{tabular}

Fuente: European Travel Comission. New Media Review. 2004.

De la comparación de estas cifras podemos extraer alguna información relevante para nuestro propósito. Es importante comparar siempre los números absolutos con los números porcentuales, el mencionado "factor de penetración". De ahí podemos observar que los países con mayor índice a nivel mundial, andan cerca o por encima de $70 \%$ de su población; esto es cierto y notorio, pero también debe observarse que son países con poblaciones relativamente pequeñas. Suecia, el mejor del mundo en ese senti- 
do, sólo tiene nueve millones de habitantes para su $74 \%$ de penetración. Hong Kong, el segundo mundial, sólo posee 6.6 millones de habitantes para su 70\% de penetración. He ahí parte de la explicación de su avance en este rubro.

Lo mismo puede decirse de Holanda, con 16 millones de habitantes; Australia con 20, Singapur con 3.5 millones, Uruguay con 3.4 millones, Argentina con 37.8 millones, Chile con 16.7 millones, etcétera.

Mención aparte merecen Estados Unidos y Japón, ya que con poblaciones numéricamente considerables, 292 millones y 127 millones de habitantes, han logrado una penetración de la Internet de 69 y $61.3 \%$ respectivamente. Estos dos países en particular han logrado muy altos porcentajes de penetración en sus sociedades a pesar del enorme tamaño de las mismas.

Finalmente, es interesante hacer la comparación de México con otros países; nuestro país, a pesar de que tiene casi nueve millones de usuarios de la Internet menos que Brasil, tiene un mejor factor de penetración porcentual en su sociedad, 13.2 contra 11.1 dado el tamaño de las respectivas poblaciones. México, con una población casi tres veces mayor, tiene un factor de penetración porcentual semejante al de Argentina; sin embargo, tiene mucho menor porcentaje de penetración que Chile o Uruguay, aunque estos países tienen sólo 16.7 y 3.4 millones de habitantes; y tiene el mismo número de usuarios de la Internet que España, pero el índice de penetración es mucho mejor en este país (31\%) dado su menor número de habitantes.

Finalmente en este rubro, recalquemos que México ocupa la posición 16 entre los 20 países con mayor número de usuarios de la Internet, pero no está entre los 50 países con mejor factor de penetración; para eso estamos todavía muy lejos. México es el tercer país de América Latina en cuanto a factor de penetración de la Internet entre su población, y es el segundo en número absoluto de usuarios, pero está muy lejos de Estados Unidos con 69\% de penetración, de Canadá con 65 y de Uruguay con 34.7\%.

Luego de ponderar de manera relativa los números, podemos concluir que México no se encuentra en una situación privilegia- 
da, pero no es poco lo que ha logrado hasta el momento y tenemos un posicionamiento nada despreciable como plataforma de despegue para intentar de manera seria un proyecto de bibliotecas digitales a nivel nacional.

Cuadro 4

DOMINIOS .MX REGISTRADOS EN MÉXICO, 1991 A 2005

(UNIDADES)

\begin{tabular}{|rrrrrrrr|}
\hline Año & Total & .com.mx & .gob.mx & .net.mx & .edu.mx & .org.mx &.$m x$ \\
\hline 1991 & 1 & 0 & 0 & 0 & 0 & 0 & 1 \\
1992 & 1 & 1 & 0 & 0 & 0 & 0 & 0 \\
1994 & 50 & 5 & 1 & 0 & 0 & 0 & 44 \\
1995 & 326 & 180 & 12 & 20 & 0 & 13 & 101 \\
1996 & 2838 & 2286 & 75 & 143 & 13 & 142 & 179 \\
1997 & 7251 & 6043 & 201 & 262 & 168 & 389 & 188 \\
1998 & 12576 & 10661 & 350 & 395 & 359 & 622 & 189 \\
1999 & 28130 & 25026 & 510 & 639 & 557 & 1221 & 177 \\
2000 & 61896 & 56769 & 935 & 761 & 855 & 2399 & 177 \\
2001 & 67617 & 61496 & 1278 & 662 & 1245 & 2759 & 177 \\
2002 & 73802 & 66545 & 1687 & 621 & 1692 & 3085 & 172 \\
2003 & 82950 & 74885 & 2074 & 557 & 2114 & 3148 & 172 \\
2004 & 110431 & 100353 & 2446 & 509 & 2580 & 4370 & 173 \\
$2005^{\mathrm{a}}$ & 132446 & 120731 & 2671 & 503 & 2837 & 5532 & 172 \\
\hline
\end{tabular}

a Sólo se considera hasta el mes de mayo.

Fuente: NIC-México.

El siguiente aspecto que, como mencionamos, es necesario analizar dentro de los indicadores internacionales es el número de computadoras personales instaladas en el país. Nuevamente de acuerdo con el INEGI, las cifras de hogares con equipo de tecnología de información y comunicaciones por tipo de equipo, 2001 a 2005 son las siguientes: 
La infraestructura mexicana en tecnologías de información y...

Cuadro 5

HOGARES CON EQUIPO DE TECNOLOGÍA E INFORMACIÓN Y COMUNICACIONES

\begin{tabular}{|c|c|c|c|c|c|c|c|c|}
\hline \multirow[b]{2}{*}{ Tipo } & \multicolumn{2}{|c|}{$2001^{a}$} & \multicolumn{2}{|c|}{$2002^{a}$} & \multicolumn{2}{|c|}{$2004^{b}$} & \multicolumn{2}{|c|}{$2005^{c}$} \\
\hline & Absolutos & $\%$ & Absolutos & $\%$ & Absolutos & $\%$ & Absolutos & $\%$ \\
\hline Con computadora & 2743749 & 11.7 & 3742824 & 15.2 & 4744184 & 18.0 & 4765669 & 18.4 \\
\hline Con conexión a la Internet & 1440399 & 6.1 & 1833504 & 7.4 & 2301720 & 8.7 & 2318243 & 9.0 \\
\hline Con televisión & 21602234 & 91.8 & 23092909 & 93.6 & 24131830 & 91.7 & 23919829 & 92.7 \\
\hline Con televisión de paga & 3181370 & 13.5 & 3785962 & 15.3 & 5064252 & 19.2 & 4992830 & 19.3 \\
\hline Con línea telefónica fija ${ }^{d}$ & 9419825 & 40.0 & 11171798 & 45.3 & 12614295 & 47.9 & 12603633 & 48.8 \\
\hline Con telefonía celulard & ND & ND & ND & ND & 9285284 & 35.3 & 10843428 & 42.0 \\
\hline
\end{tabular}

Nota: Proporciones respecto del total de hogares.

${ }^{a}$ Cifras correspondientes a diciembre.

${ }^{b}$ Cifras correspondientes a junio.

${ }^{c}$ Cifras preliminares correspondientes a junio.

${ }^{d}$ A partir de 2004 incluye hogares que de manera simultánea tienen telefonía celular y fija.

ND: No disponible.

Fuente: INEGI. Encuesta Nacional sobre Disponibilidad y Uso de Tecnologías de la Información en los Hogares. http://www.inegi.gob.mx/est/contenidos/espanol/rutinas/ept.asp?t=tinf196\&c=5585

Calculando este factor de otra forma; es decir, no por hogares sino por personas, de acuerdo con las cifras de la empresa Nationmaster, México se encuentra en el lugar número 15 a nivel mundial, con una proporción de 5.43 computadoras personales por cada 100 habitantes. Nuevamente, éste es un indicador porcentual sumamente importante que debe ser contrastado con el número de habitantes del país para dar una idea real de lo que representa. México tiene más computadoras que Suecia, por ejemplo, pero el índice de ese país (50.6) es diez veces mejor que el de México ya que sólo tiene nueve millones de habitantes (Nationmaster, 2004).

Si analizamos las cifras en este rubro por país, observamos una relación semejante a la de los indicadores de usuarios de la Internet: los países desarrollados y con una población relativamente pequena tienen índices muy altos de computadoras per capita, sea en Asia-Pacífico o en Europa. Los países del antiguo bloque soviético 
tienen índices más modestos, pero no malos. En términos generales los mismos países que se observan en la primera relación, la de usuarios de la Internet, se observan en esta relación de número de computadoras, con algunas variantes en su posición. Del mismo modo, los dos países con poblaciones grandes y sin embargo altas relaciones de computadoras por habitante, son Estados Unidos y Japón. Los únicos países latinoamericanos que se encuentran entre los primeros 50 en esta relación son: Brasil en el lugar 8, México, en el 15, Argentina en el 23, Colombia en el 34, Chile en el 37, Venezuela en el 42 y Perú en el 43. He aquí una pequeña tabla al respecto con algunos datos interesantes:

Cuadro 6

TABLA CON NÚMERO DE PC Y FACTOR DE PENETRACIÓN

\begin{tabular}{|lccc|}
\hline País & $\begin{array}{c}\text { Número total de } P C \\
\text { (millones) }\end{array}$ & $\begin{array}{c}\text { Población del país } \\
\text { (millones) }\end{array}$ & $\begin{array}{c}\text { \% de la población } \\
\text { (penetración) }\end{array}$ \\
\hline Alemania & 27.6 & 82.6 & 33.4 \\
Argentina & 2.6 & 37.8 & 6.9 \\
Australia & 9 & 19.9 & 45.2 \\
Brasil & 8.5 & 201.1 & 4.2 \\
Corea del Sur & 18.6 & 51.7 & 36.0 \\
China & 36 & 1200.0 & 3.0 \\
España & 5.8 & 41.5 & 14.0 \\
Estados Unidos & 161 & 292.0 & 55.1 \\
Japón & 40 & 127.0 & 31.5 \\
México & 5.7 & 105.0 & 5.4 \\
Rusia & 6.3 & 144.5 & 4.3 \\
Singapur & 1.9 & 4.6 & 41.3 \\
\hline
\end{tabular}

Fuente: Nationmaster, 2004.

Un tercer indicador es el número de líneas telefónicas instaladas por habitante. En este rubro la mezcla es muy distinta si bien los países desarrollados aparecen en algún lugar relevante. Entre 
los primeros 100 a nivel mundial aparecen curiosamente algunos países del Caribe, con cortes eminentemente turísticos: las Bahamas, Martinica, San Vicente, Aruba, Barbados, Dominica, etcétera. Entre los países continentales aparecen, aunque abajo en la tabla, Puerto Rico y Argentina. México no aparece entre los primeros 100, tiene una densidad de cerca de 17 líneas telefónicas fijas por cada 100 habitantes, mientras que los países "desarrollados": Estados Unidos, los de Europa, Japón, etc., están por encima de las 60 líneas por cada 100 habitantes.

Respecto a teléfonos celulares por habitante, la distribución también es distinta, aunque los países desarrollados están en términos generales bien posicionados. Aquí aparecen algunos países latinoamericanos entre los primeros 100, como Argentina, Venezuela, Costa Rica, Guatemala y Paraguay. México se encuentra en el último tercio de esa tabla con poco menos de 40 teléfonos celulares por cada 100 habitantes. Aunque su dato no está actualizado, nos da una idea del rezago en este sentido, a pesar de la enorme cantidad de teléfonos celulares que se han adquirido recientemente.

CUADRO 7

USUARIOS DE TELEFONÍA MÓVIL 1998-2005

(MILES DE USUARIOS)

\begin{tabular}{|lc|}
\hline Año & Usuarios \\
\hline 1998 & 3350 \\
1999 & 7732 \\
2000 & 14078 \\
2001 & 21758 \\
2002 & 25928 \\
$2003^{\mathrm{P}}$ & 30098 \\
2004 & 38450 \\
$2005^{\mathrm{a}}$ & 40096 \\
\hline
\end{tabular}

Nota: A partir de 1999, incluye a los nuevos concesionarios de PC.

a Sólo se considera hasta febrero.

${ }^{P}$ Cifras preliminares a partir de la fecha en que se indica.

Fuente: COFETEL. Dirección General de Tarifas e Integración Estadística. http://www.inegi.gob.mx/est/contenidos/ espanol/rutinas/ept.asp?t=tinf $127 \& c=3558$ 
Otro indicador interesante es el costo de la Internet por hora. Por supuesto, existen múltiples indicadores en este sentido, pero uno muy ilustrativo es el costo promedio en un cibercafé. Observamos, por ejemplo, que hay países donde este servicio es muy caro, curiosamente son países con alto uso de la Internet; es el caso de Australia y Japón donde la hora vale 7.50 dólares en promedio. En Estados Unidos es de cinco dólares la hora. En Canadá 4.30, en Brasil 3.45, en Chile tres dólares; en Nicaragua dos y en México 2.25 (Foreign Policy). ${ }^{22}$

En Austria cuesta seis dólares, en Suecia 6.45, en Rusia tres, en Ghana 0.60 y en su vecina Nigeria 5.40; en Egipto y Argelia 1.50, en Kenia 2.28; en Irán tres dólares, en Pakistán 0.60, en la India 1.35. En Turquía 0.50 y en China 2.50. En Cuba cuesta 1.50 para el público, pero casi no existe este servicio; para los turistas cuesta 18 dólares la hora.

Abundando en los datos para México, conviene apuntar que el costo de un mes de uso de la Internet es alrededor de 20 dólares, siempre y cuando se tenga una línea telefónica; para los servicios de banda ancha, el costo oscila entre 40 y 100 dólares mensuales, dependiendo del ancho de banda.

Ya hemos mencionado que en términos generales, se estima que México está en el lugar 44 de entre 102 países en cuanto al aprovechamiento de las tecnologías de información, según la evaluación realizada por el Foro Económico Mundial, la Escuela de Negocios Francesa y el Banco Mundial. Dicho estudio consideró aspectos del uso de la tecnología como herramienta para el desarrollo, tales como el nivel de preparación de gobierno, empresas y personas; su uso efectivo, el ambiente macroeconómico, la normatividad, etc. Como otros puntos de referencia en la región, Chile ocupa el lugar 32 y Brasil el 39 (World Economic Forum, 2004).

22 Foreign Policy. 2004. Página web de la empresa. Disponible 3 de noviembre, 2005 en: http://w ww.foreignpolicy.com/story/cms.php?story_id=2594 


\subsection{PROPORCIONES DE LA INFRAESTRUCTURA}

Después de haber analizado los números que componen la infraestructura de las tecnologías de información y comunicaciones en nuestro país, es necesario analizar su relación proporcional. El principal indicador a contemplar es el gasto destinado a estas tecnologías, así como su importancia relativa en la economía de cada país y su composición. En este aspecto, México revela varias debilidades. Existe una brecha importante entre el tamaño de la economía mexicana y el de las inversiones y el gasto en TIC. México es la decimotercera economía del mundo, y sin embargo ocupa el lugar 42 en lo relativo a inversión en TIC. El valor económico del mercado de las TIC en nuestro país ha oscilado alrededor de 3\% respecto al PIB, una cantidad que nos coloca bastante lejos de $8 \%$ que existe a nivel mundial (gráfica 1).

Además del monto total, es necesario desglosar ese gasto en sus componentes de inversión. Si bien no existe una división única se puede establecer, de manera consensada, que son cinco los principales componentes del gasto en TIC:

1. Equipamiento.

2. Telecomunicaciones.

3. Servicios de tecnologías informáticas.

4. Software.

5. Recursos humanos para TIC internos.

La composición de estos cinco elementos en el gasto en TIC en un país es importante. Un dato relevante es que seguimos gastando más en telecomunicaciones que en aspectos relacionados con la adaptación e innovación de las TIC; así, el promedio mundial de inversión en telecomunicaciones respecto a la inversión total en TIC es de 44\%, pero en México ese indicador es de 67\%. Esto no es adecuado; obsérvense los porcentajes de otros países. Al invertir más en telecomunicaciones que en aspectos relativos al capital humano, nos posicionamos como entes primordialmente consumistas de la sociedad de la información, con el riesgo de no salir de esta etapa y 


\section{Gráfica 1}

INVERSIÓN EN TIC CONTRA PIB 2001

(EXCLUYE PRESUPUESTO INTERNO)

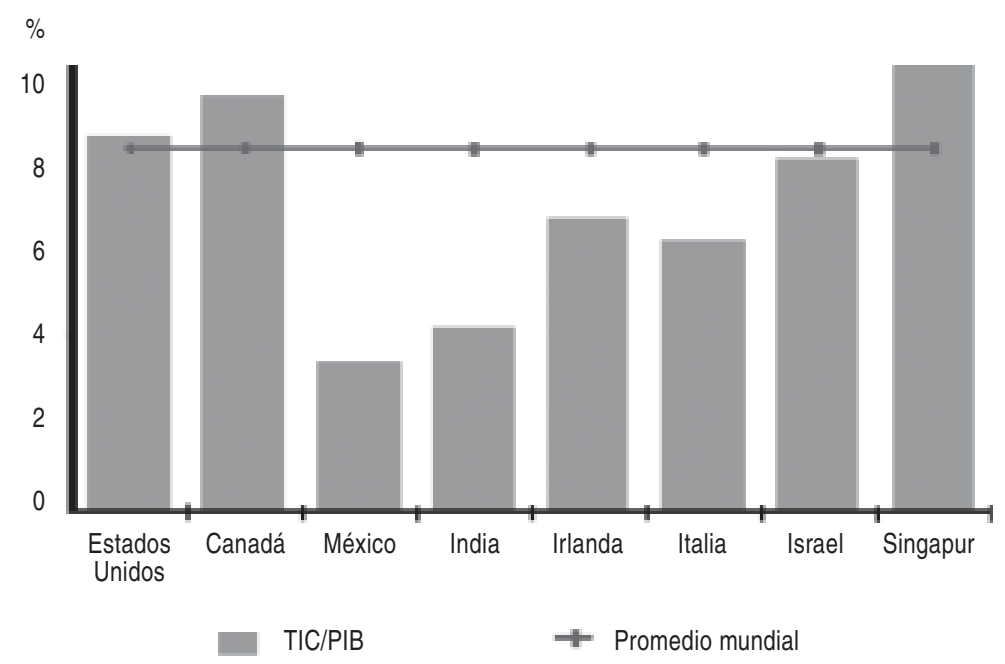

Fuente: Foro Económico Mundial.

continuar siempre como país dependiente. Como he insistido, la brecha digital, además de la conectividad, tiene que ver con el uso social, económico e innovador de las TIC, y no sólo no con nuestro consumo de artefactos digitales y de contenidos de la Internet.

Un segundo dato en este sentido es que la suma de los servicios de tecnologías de información, el mercado de software y el presupuesto empresarial destinado a las TIC -todo lo cual brinda un panorama del mercado de soluciones- representa en México 19\% del mercado total de las TIC en el país, mientras que a nivel mundial encontramos que el promedio es de $41 \%$.

Un tercer indicador de la debilidad de la adaptación tecnológica en nuestro país, es el hecho de que lo gastado por las empresas 
La infraestructura mexicana en tecnologías de información y...

Gráfica 2

COMPONENTES DE INVERSIÓN EN TIC



Fuente: Foro Económico Mundial.

mexicanas para el pago del personal interno de sistemas es sólo de $8 \%$, mientras que a nivel mundial este porcentaje llega a $15 \%$ del total del gasto en TIC (gráfica 2).

Según datos de Saúl Cruz Pantoja, ${ }^{23}$ analista de la firma Select, quien elaboró un estudio acerca de la participación del gobierno federal en las TIC partiendo del Presupuesto de Egresos de la Federación 2003, hay 26 dependencias federales que trabajarían en 189

23 Saúl Cruz P., 2003. "Composición del presupuesto asignado a TiC en el gobierno federal". Política Digital. Disponible 3 de noviembre, 2005 en: http:// www.politicadigital.com. $\mathrm{mx} / \mathrm{index}$.php? $\mathrm{id}=591$ 
proyectos asociados a tecnologías de información y comunicaciones. En conjunto esos proyectos representan una inversión mayor a los 534 millones de dólares, cifra que representa apenas $1.1 \% \mathrm{del}$ presupuesto total de egresos de las 26 dependencias, el cual asciende a 48300 millones de dólares.

Sobresale el hecho de que $40 \%$ de este monto esté destinado a la contratación de servicios de TI y software, entre los que destacan servicios de outsourcing (subcontratación), capacitación, consultoría y desarrollo de software a la medida, además del pago de licencias de software. Por otra parte, los esquemas actuales de renta de equipo y outsourcing son cada vez más demandados, incluso por las dependencias federales aquí analizadas.

Otro hallazgo, no menos significativo, es el que indica que el segundo rubro más importante (23\%) es el del presupuesto interno, es decir, lo relacionado con sueldos y prestaciones del personal que labora en los proyectos de TIC, incluyendo pagos a personal directivo, administradores, desarrolladores internos, programadores, personal de soporte técnico y mantenimiento, entre otros aspectos. El presupuesto asignado a este capítulo asciende a más de 122 millones de dólares.

El tercero en orden de importancia es el capítulo dedicado a la inversión en equipo de cómputo, donde se ubican computadoras, servidores, impresoras y otros equipos.

El Plan Nacional de Desarrollo 2001-2006 plantea el fomento a la industria y el mercado de tecnologías de la información (TI) como estrategia para aumentar la competitividad del país. Según el mismo, las TI ejercen un efecto transversal en toda la economía, razón por la cual impactan positivamente la competitividad de todos los sectores. La Secretaría de Economía, en coordinación con organismos empresariales y empresas del sector, diseñó el Programa para el Desarrollo de la Industria del Software (PROSOFT). Para alcanzar sus objetivos, se desarrollarán siete estrategias:

1. Promover las exportaciones y la atracción de inversiones.

2. Educación y formación de personal competente en el desarrollo de software, en cantidad y calidad convenientes. 
3. Contar con un marco legal promotor de la industria.

4. Desarrollar el mercado interno.

5. Fortalecer la industria local.

6. Alcanzar niveles internacionales en capacidad de procesos.

7. Promover la construcción de infraestructura básica y de telecomunicaciones.

Con estas estrategias se beneficiaría no sólo la competitividad de la industria del software, sino también la de la economía en general, puesto que las empresas mexicanas tendrían más opciones para incorporar las tecnologías de información en sus procesos productivos y de comercio. No se han visto todavía avances en este plan, pero habrá que darle tiempo, ya que no es un plan de corto plazo.

En resumen, México está posicionado de manera intermedia en cuanto a la infraestructura que permitirá que los proyectos de sociedad de la información puedan llegar a niveles masivos. Si bien se han ido planteando soluciones de visión estratégica a nivel gubernamental éstas no han estado del todo a la altura de la responsabilidad de esta situación de cambio global, donde es evidente la necesidad de una acción más decidida del Estado para construir una nueva economía del desarrollo. Como revelan las cifras, nuestra infraestructura no es despreciable, pero también debemos ver todo lo que falta por hacer para conformar un proyecto de sociedad informatizada. Estos datos nos serán sumamente útiles a la hora de plantear el modelo y por ello han sido reseñados. Para abundar más en ellos véase el anexo 3. 



\section{Capítulo 4}

\section{Diversidad cultural e integración nacional}



Recuerda que tú eres un ser humano único y grandioso; al igual que otros seis mil millones.

\subsection{DiverSiDAD CULTUR AL E INTEGR ACIÓN NACIONAL}

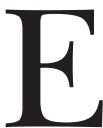
1 término "globalización" es sin duda uno de los términos más utilizados -y mal utilizados- en la actualidad. Es usado por autores en materias como comercio y economía, política, medio ambiente, arte, sociología, educación y -por supuestobibliotecas digitales. Provoca variadas reacciones en distintos grupos de habitantes del planeta: unos lo apoyan y alaban, a otros les es indiferente, hay quienes lo aborrecen y no pierden oportunidad de demostrarlo y muchos más ni lo conocen. Y es que el término significa cosas distintas para grupos distintos.

David Block ${ }^{24}$ hace algunas precisiones al respecto; para los ejecutivos de las grandes empresas, significa que sus negocios y entretenimientos no conocen fronteras. Para aquellos que trabajan en oficinas o fábricas alrededor del mundo, significa una serie de correos electrónicos o llamadas de larga distancia con colegas de otras partes del orbe y decisiones que se toman en oficinas corporativas lejanas. Para algunos jóvenes de clase acomodada, significa el dominio de MTV y el MP3 con sus mensajes consumistas asociados. Para muchos otros es una nueva forma de imperialismo, enajena-

${ }^{24}$ David Block, 2004. "Globalization, Transnational Communication and the Internet”. International Journal on Multicultural Societies (IJMS), vol. 6:1, pp. 13-28. 
ción y explotación. Para los académicos de universidades e instituciones de investigación es una oportunidad de intercambiar impresiones, datos, publicaciones, etcétera, con colegas de todo el mundo y un nuevo filón que explotar en la búsqueda de información y conocimiento. Si bien éstas no son todas las visiones de globalización nos dan una idea de las muy diversas versiones -y aversiones- que el término provoca.

La "globalización" está referida a esos procesos espacio-temporales de cambio que cimentan una de las transformaciones de las organizaciones humanas vinculándolas entre sí expandiendo la actividad humana a través de regiones y continentes. Sin este contexto de conexiones espaciales en expansión no puede haber formulación coherente ni clara del término. ${ }^{25}$

Globalización es la intensificación de las relaciones sociales a lo largo del mundo vinculando localidades distantes de tal forma que los eventos locales son conformados en buena medida por eventos que ocurren a muchos kilómetros de ditancia y viceversa. ${ }^{26}$

Una enorme parte de la preocupación y rechazo que el concepto trae, es que para muchos globalización implica homogeneización. A un buen número de personas preocupadas por la cultura, el término les hace pensar que en un futuro, a raíz del constante intercambio de fuerzas homogeneizadoras, eventualmente los habitantes del mundo se hallarán pensando, actuando y hablando de una manera muy similar. Como ejemplo, George Ritzer ${ }^{27}$ comenta la eventual homogeneización de los medios de consumo a lo largo del mundo en un concepto que él denomina la "MacDonaldización"; en él establece cómo los principios del restaurante de comida rápida han ido penetrando más y más en la sociedad norteamericana

25 David Held, Anthony McGrew, David Goldblatt y Jonathan Perraton (1999), citados por Block, D., op. cit.

26 Anthony Giddens (1990), citado por Block, D., "Globalization...", op. cit.

27 George Ritzer (1998), citado por Block, D., "Globalization...", op. cit. 
y en otras en el mundo. Los trabajos de Ritzer extrapolan la globalización económica a una globalización cultural con argumentos de cómo el consumismo forma parte importante de la vida cultural de grupos de personas. Benjamin Barber ha desarrollado trabajos en una línea similar de pensamiento, estableciendo que vamos hacia una cultura global en lo que él ha denominado el "MacMundo", definiéndolo como "una experiencia de compra y entretenimiento en la que se pone a disposición de todos un ensamble de tiendas, cinemas múltiples, parques temáticos, espectáculos deportivos, cadenas de comida rápida, TV con películas con numerosos comerciales, videos musicales e informerciales, en una única y vasta empresa...".28

Obviamente, el problema y el fenómeno existen, pero como he mencionado ya en otros capítulos el problema de fondo no subyace en el medio sino en el uso del medio. Como ya hemos recalcado, el problema es la creación de "analfabetos digitales funcionales". Éstos son los que quedan expuestos totalmente a este fenómeno sin ninguna protección. No debemos ni podemos rechazar al medio per se, sino tomar las medidas que permitan el correcto aprovechamiento del medio. Hacer otra cosa sería tanto como rechazar la imprenta porque con ella se puede tener acceso a literatura barata e insulsa, información sesgada o pornografía. El fenómeno debe enfocarse en sus elementos críticos reales: alfabetización digital funcional e impulso decidido a la diversidad cultural y a las identidades nacionales.

La relación de fondo entre la sociedad de la información y la diversidad cultural está estrechamente ligada a la evolución del marco regulatorio del comercio internacional, el cual se ha ido constituyendo como el armazón de la globalización económica, y que tiende a su vez a introducir cada vez más presiones dentro del papel de apoyo que en la actualidad desempeñan los estados y los gobiernos en materia cultural en beneficio de las poblaciones a las que se deben. El abandono de este papel que hasta ahora se ha

28 Benjamin Barber (1995), citado por Block, D., "Globalization...", op. cit. 
materializado a través de políticas culturales y diversas medidas de apoyo a la cultura, tiene como grave riesgo la asignación de prioridades basadas en la aplicación exclusiva de las reglas del mercado al sector cultural. Esta situación significaría en efecto una homogeneización de las culturas en provecho de un modelo cultural único, basado en una lógica exclusivamente económica y comercial que excluiría la expresión de las culturas "menos rentables" o carentes de los recursos y mecanismos de apoyo necesarios para su expresión.

Esta amenaza puede anularse sólo en tanto estemos conscientes de que la cultura no es una simple mercancía. Lo realmente importante, como muchos gobiernos y grupos de personas consideran, es que los bienes y servicios culturales desempeñan un papel determinante e imprescindible para muchos países y regiones del mundo respecto a la identidad de los pueblos, a la cohesión necesaria del tejido social de los mismos, a la vida democrática e inclusive retroalimenta al mismo desarrollo económico. No se trata de negar que los bienes y servicios culturales pueden ser objeto de comercio: se trata de que se reconozca que no pueden estar sometidos a las reglas usuales del comercio.

Los elementos decisivos de la diversidad cultural se sitúan, por tanto, en las presiones y tendencias que nos trae la evolución del cuadro reglamentario del comercio global, por un lado, y por otro, las políticas culturales y las diversas medidas de apoyo que los estados y los gobiernos adoptan para mantener la cultura en beneficio de sus poblaciones.

El reconocimiento de la importancia de la diversidad cultural para el desarrollo social y económico no es un tema nuevo en la escena política internacional. Esta importancia fue destacada ya en acuerdos internacionales como el Acuerdo de Florencia de 1950 y su Protocolo de Nairobi de 1976; la Convención Universal sobre Derechos de Autor de 1952; la Declaración de los Principios de Cooperación Cultural Internacional de 1966; la Convención sobre las Medidas que Deben Adoptarse para Prohibir e Impedir la Importación, la Exportación y la Transferencia de Propiedad Ilícitas de Bienes Culturales de 1970; la Convención para la Pro- 
tección del Patrimonio Mundial Cultural y Natural de 1972; la Declaración de la UNESCO sobre la Raza y los Prejuicios Raciales de 1978; la Recomendación Relativa a la Condición del Artista de 1980; la Recomendación sobre la Salvaguardia de la Cultura Tradicional y Popular de 1989; el Informe de la Comisión Mundial de Cultura y Desarrollo de la UNESCO, Nuestra Diversidad Creativa de 1995. En 1998, el Plan de Acción de Estocolmo de la UNESCO caracterizaba "la política cultural como uno de los componentes principales de un desarrollo endógeno y durable". Además de ser reconocido en las tribunas culturales tradicionales, el concepto de diversidad cultural ha penetrado en tribunas no culturales tales como el G8, el Banco Mundial, el Consejo Europeo, la OEA y la Organización Internacional de la Francofonía, donde es considerado un importante componente de la calidad de vida, la solución de conflictos y la seguridad humana. Finalmente, en 2002 la UNESCO emitió la Declaración Universal sobre la Diversidad Cultural (2002). He aquí un resumen de lo más importante de ella en torno a diversidad cultural e identidades:

La cultura adquiere formas diversas a través del tiempo y del espacio. Esta diversidad se manifiesta en la originalidad y la pluralidad de las identidades que caracterizan los grupos y las sociedades que componen la humanidad. Fuente de intercambios, de innovación y de creatividad, la diversidad cultural es, para el género humano, tan necesaria como la diversidad biológica para los organismos vivos. En este sentido, constituye el patrimonio común de la humanidad y debe ser reconocida y consolidada en beneficio de las generaciones presentes y futuras. En nuestras sociedades cada vez más diversificadas, resulta indispensable garantizar una interacción armoniosa y una voluntad de convivir de personas y grupos con identidades culturales a un tiempo plurales, variadas y dinámicas. Las políticas que favorecen la inclusión y la participación de todos los ciudadanos garantizan la cohesión social, la vitalidad de la sociedad civil y la paz. Definido de esta manera, el pluralismo cultural constituye la respuesta política al hecho de la diversidad cultural. Inseparable de un contexto democrático, el pluralismo cultural es propicio a los intercambios 
culturales y al desarrollo de las capacidades creadoras que alimentan la vida pública.

La diversidad cultural amplía las posibilidades de elección que se brindan a todos; es una de las fuentes del desarrollo, entendido no solamente en términos de crecimiento económico, sino también como medio de acceso a una existencia intelectual, afectiva, moral y espiritual satisfactoria. La defensa de la diversidad cultural es un imperativo ético, inseparable del respeto de la dignidad de la persona humana. Ella supone el compromiso de respetar los derechos humanos y las libertades fundamentales, en particular los derechos de las personas que pertenecen a minorías y los de los pueblos autóctonos. Toda persona debe, así, poder expresarse, crear y difundir sus obras en la lengua que desee y en particular en su lengua materna; toda persona tiene derecho a una educación y una formación de calidad que respete plenamente su identidad cultural; toda persona debe poder participar en la vida cultural que elija y ejercer sus propias prácticas culturales, dentro de los límites que impone el respeto a los derechos humanos y a las libertades fundamentales.

Al tiempo que se garantiza la libre circulación de las ideas mediante la palabra y la imagen, hay que procurar que todas las culturas puedan expresarse y darse a conocer a través de la infodiversidad. La libertad de expresión, el pluralismo de los medios de comunicación, el multilingüismo, la igualdad de acceso a las expresiones artísticas, al saber científico y tecnológico -comprendida su forma electrónica- y la posibilidad, para todas las culturas, de estar presentes en los medios de expresión y de difusión, son los garantes de la diversidad cultural. Frente a los cambios económicos y tecnológicos actuales, que abren vastas perspectivas para la creación y la innovación, se debe prestar una atención particular a la diversidad de la oferta creativa, a la justa consideración de los derechos de los autores y de los artistas, así como al carácter específico de los bienes y servicios culturales que, en la medida en que son portadores de identidad, de valores y sentido, no deben ser considerados como mercancías o bienes de consumo como los demás.

Las políticas culturales, en tanto que garantizan la libre circulación de las ideas y las obras, deben crear condiciones propicias para la producción y difusión de bienes y servicios culturales 
diversificados, gracias a industrias culturales que dispongan de medios para desarrollarse en los planos local y mundial. Cada Estado debe, respetando sus obligaciones internacionales, definir su política cultural y aplicarla utilizando para ello los medios de acción que juzgue más adecuados, ya se trate de apoyos concretos o de marcos reglamentarios apropiados.

Entre las acciones que los gobiernos deben desarrollar, establecidas en la declaración de la UNESCO, extraemos algunas muy importantes, y que sin duda tienen estrecha relación con la creación de la sociedad del conocimiento (Maxwell, 2000):

- Alentar, a través de la educación, una toma de conciencia del valor positivo de la diversidad cultural y mejorar, a este efecto, tanto la formulación de los programas escolares como la formación de los docentes.

- Fomentar la "alfabetización electrónica" y acrecentar el dominio de las nuevas tecnologías de la información y de la comunicación, que deben considerarse al mismo tiempo como disciplinas de enseñanza y como instrumentos pedagógicos capaces de reforzar la eficacia de los servicios educativos.

- Promover la diversidad lingüística en el espacio digital y fomentar el acceso gratuito y universal, a través de las redes mundiales, a todas las informaciones que pertenecen al dominio público.

- Luchar contra las desigualdades en materia de electrónica -en estrecha cooperación con los organismos competentes del sistema de las Naciones Unidas- favoreciendo el acceso de los países en desarrollo a las nuevas tecnologías, ayudándolos a dominar las tecnologías de la información y facilitando a la vez la circulación electrónica de los productos culturales endógenos y el acceso de dichos países a los recursos numéricos de orden educativo, cultural y científico, disponibles a escala mundial.

- Estimular la producción, la salvaguardia y la difusión de contenidos diversificados en los medios de comunicación y las redes 
mundiales de información naturales, y favorecer las sinergias entre la ciencia moderna y los conocimientos locales.

La IFLA (Federación Internacional de Bibliotecas e Instituciones) también se pronunció en este sentido. En los debates de la Reunión Intergubernamental previa a la Convención para la Protección de la Diversidad Cultural y Expresiones Artísticas de la UNESCO la IFLA estableció: "Entre los valores fundamentales de IFLA está el de creer que las personas, las comunidades y las organizaciones del mundo requieren acceso universal y equitativo a la creación, producción y diseminación de información, ideas y obras intelectuales y artísticas para su bienestar social, educacional, cultural, democrático y económico".

De acuerdo con las estadísticas mundiales, las páginas en español ocupan el sexto lugar en número en la Web, con algo así como 2.5\% del total mundial, lo cual es poco considerando que el español es el tercer idioma del mundo ya que lo habla $6 \%$ del planeta. Por otra parte, dentro de los usuarios de la red a nivel mundial los hispanoparlantes ocupan el cuarto sitio con aproximadamente $7.5 \%$ del total de usuarios. Cifra notable si consideramos que el segundo y el tercer lugar son usuarios del hemisferio oriental, lo que nos coloca como el segundo conglomerado de usuarios en el lado occidental, sólo después de los angloparlantes, pero aún poco en comparación con este grupo (36.5 por ciento).

Por todo lo anterior, es de capital importancia que el modelo de bibliotecas digitales contemple estos aspectos y acciones relativas a la identidad nacional basada a su vez, como expresa la UNESCO, en el pluralismo cultural. Como se ha establecido, es sumamente importante que nuestros modelos culturales no sean regidos sólo por modelos de globalización económica y eficiencia taylorista. Si México tiene hoy en día la riqueza cultural que ostenta es precisamente debido a su diversidad y pluralismo culturales, en las más variadas y ricas formas: lenguas, acentos, música, cocina, arte, leyendas y tradiciones, fiestas, expresiones, artesanías, folklor, etc., etc. Cuán poco de lo que somos seríamos si todos estos elementos culturales tuviesen una expresión uniforme y homogénea en todo el país. Por 
supuesto y por fortuna, lo mismo puede afirmarse del resto de los países de Iberoamérica.

Como una muestra respecto al idioma español y a la vez como un ejemplo de los muchos elementos que conforman nuestra identidad cultural y que son también preocupación en este y en otros ámbitos, se dio este debate en el III Congreso Internacional de la Lengua Española, celebrado en Argentina en noviembre de 2004. En este foro precisamente se estableció de antemano que los principales temas a debatir serían unidad, diversidad, identidad e internacionalización del idioma. Bajo el lema "identidad lingüística y globalización" se llevaron a cabo los trabajos con la presencia de 160 escritores, ensayistas, semiólogos, críticos y académicos, todos ellos compartiendo estas preocupaciones. Entre ellos, cabe destacar la exquisita intervención de nuestro compatriota Carlos Fuentes, ${ }^{29}$ quien en el discurso inaugural comentó:

Posiblemente el inglés sea más práctico que el castellano, el alemán más profundo, el francés más elegante, el italiano más gracioso y el ruso más angustioso. Pero yo creo profundamente que es la lengua española la que con mayor elocuencia y belleza nos da el repertorio más amplio del alma humana, de la personalidad individual y de su proyección social. No hay lengua más constante y más vocal: escribimos como decimos y decimos como escribimos.

Obviamente, el castellano es sólo uno de nuestros numerosísimos elementos de identidad cultural a cuidar en nuestra sociedad del conocimiento, en donde habrá que agregar muchos otros: lenguas indígenas, arte, costumbres, tradiciones, expresiones, cocina y recetas, folklor, valores, formas de vida, etc.; toda una pléyade adicional de elementos que forman la idiosincracia mexicana y que

29 Carlos Fuentes, 2004. "Texto completo del discurso inaugural del III Congreso Internacional de la Lengua Española”. Rosario, Argentina, noviembre 17, 2004. Disponible 3 de noviembre, 2005 en: http://cvc.cervantes.es/obref/congresos/rosario/inauguracion/fuentes_c.htm 
deben ser registrados, protegidos e impulsados en un proyecto de esta naturaleza so pena de, efectivamente, ir uniformando todo en un afán globalizador en el que "integrador" signifique "homogeneizador". Las mejores expresiones culturales se han dado en aquellos lugares y momentos donde el intercambio cultural ha sido "además de" y no "en vez de". Como mexicanos deseamos ser integrados al ciberespacio, no homogeneizados en él; son dos cosas muy distintas. 


\section{Capítulo 5}

El modelo de planeación de bibliotecas digitales para México 

No salgas al camino dependiendo de otros; lleva siempre tu propio mapa.

\subsection{CONTEXTO DEL MODELO}



on el análisis efectuado en el capítulo 2 se trató de establecer ante todo una definición de la relación sociedad-educación-bibliotecas, contextualizando la sociedad de la información y la educación para esa sociedad de la información. No cabe duda ya de que las bibliotecas tienen una oportunidad y una responsabilidad enorme ante esta sociedad de la información que se está reconformando y que hace evolucionar además sus modelos educativos. Creo que ha quedado establecido que una sociedad de la información está creando la educación de la sociedad de la información y para apoyarla necesita crear también las bibliotecas para la educación de la sociedad de la información o, más propiamente dicho, como ya se subrayó también, queremos crear la educación de la sociedad del conocimiento y para apoyarla necesitamos crear también las bibliotecas para la educación de la sociedad del conocimiento. He planteado que ésta es la parte toral y por tanto el marco básico de conceptualización de las bibliotecas de nuestro futuro cercano; he ahí el primer paradigma sobre el cual deben construirse. He planteado también, dado que esa denominación es muy larga, que sigamos llamándolas por comodidad bibliotecas digitales, sin olvidar nunca y menos en este momento que esas bibliotecas se requieren para apoyar la educación propia de esa sociedad del conocimiento y hacia ese contexto van evolucionando. 
De acuerdo con los postulados de los principales proyectos, el de Sociedad de la Información que hemos revisado, nacional e internacionalmente, así como con los de la Cumbre de la Sociedad del Conocimiento, los de la IFLA, etcétera, se observan dos vertientes muy importantes: la de la "educación", que ya hemos analizado, y la de la "producción", entendiéndose ésta como el hecho de que la sociedad de la información tenga efecto diario y relevante en el mejoramiento del nivel de vida, del trabajo, de la capacitación, de la economía de las personas, de las organizaciones, empresas, comunidades y naciones; tiene que ver con la productividad, con la información que, además de las personas, los gobiernos y las empresas requieren para el desarrollo de un país. Particularizando ese contexto de tiempo y momento a nuestro país y a este instante, se plantea entonces que el ámbito de acción de esta parte del trabajo es imaginar, diseñar y planear "las bibliotecas digitales para la educación y la producción de la sociedad del conocimiento mexicana del siglo XXI". Como ya se ha mencionado antes, debe entenderse aquí el término "educación” en su sentido más ecuménico, no sólo de enseñanza, ya que las bibliotecas de esta sociedad de la información deben ayudar también en la investigación, la cultura y la educación continua; deben ayudar a aprender, a trabajar en redes y a fomentar el concepto de colaboración colectiva por encima del de competencia individual. Pero las bibliotecas de esta sociedad deben ayudar además a personas, empresas y organizaciones a obtener la información para la capacitación, la cualificación, la producción y el desarrollo económico, industrial, gubernamental, etc., y en ese sentido debe entenderse aquí el término producción. Este segundo componente, que fue enunciado en el tema acerca de bibliotecas digitales y educación, es de suma importancia ya que los dos enfoques son de capital importancia en el modelo y se complementan mutuamente.

Se plantearon ya en la obra Bibliotecas y publicaciones digitales estrategias y líneas de acción útiles para microsistemas de bibliotecas digitales; es decir, sistemas locales de bibliotecas aisladas o correspondientes a una institución o grupo de instituciones. Con esos conceptos "propedéuticos" y esas estrategias de desarrollo, cual- 
quier profesional de la bibliotecología encargado de una biblioteca o sistema bibliotecario institucional puede concebir un plan de acción bien planeado, estructurado, con rumbo y con idea para el establecimiento de una o un conjunto de bibliotecas digitales en su ámbito de acción.

Pero el objeto de estudio en esta segunda obra, como fue esbozado desde el principio, es establecer un marco de referencia de la conceptualización de las bibliotecas digitales a nivel de país, tratando de establecer las diversas capas que debe tener una organización nacional. Por supuesto esta tarea no es fácil. El concepto de organización de las bibliotecas digitales en nuestro país, como en cualquier otro, no es monolítico. Es obvio que se trata de un sistema de bibliotecas digitales a lo largo de todo el territorio nacional con el concurso de muchos sectores y capas de nuestra sociedad, y siendo un sistema de bibliotecas nacional, lo mejor será utilizar el enfoque de sistemas el cual por cierto, nada tiene que ver con la construcción de programas ni con computadoras o telecomunicaciones. Como ya se mencionó en la introducción, el problema puede ser explicado desde varios enfoques, pero me he decidido por el enfoque sistémico como el idóneo a aplicar en esta segunda parte, debido a la metodología misma.

De algún modo ya hemos hecho un análisis reduccionista en la primera parte de este trabajo, estudiando cada una de las partes que pueden intervenir en la construcción de una biblioteca digital y explicando cómo trabaja cada una dentro de un todo. Como ya mencioné, esto ayuda mucho a quien trate de diseñar su biblioteca digital o un pequeño conjunto de bibliotecas digitales; el entorno "micro", por tanto, ha quedado definido. Pero eso no puede ser simplemente extrapolado a nivel nacional para concebir una estrategia de desarrollo en México. Para esta segunda parte a nivel macro, es decir, a nivel país, no me parece que el planteamiento de bibliotecas digitales pueda establecerse a través de un conjunto de leyes o principios fundamentales que expliquen el comportamiento y permitan la predicción fenomenológica relativa a las bibliotecas y a la educación. El método del pensamiento o enfoque de sistemas es integrador en vez de reduccionista tanto en el análisis de las 
situaciones como en las conclusiones a partir de él y puede proponer soluciones globales en donde hay que tener en consideración diversos elementos y relaciones que conforman la estructura de lo que se define como sistema, así como también de todo aquello que conforme el entorno del sistema definido. La metodología holista implicada en este enfoque funcionará mejor en el análisis macro y servirá como complemento lógico al análisis reduccionista de la otra obra.

Debe añadirse también que el enfoque de sistemas, en su proceso de desarrollo reciente, ha evolucionado al incluir en la visión sistémica tradicional nuevas corrientes filosóficas que proclaman no una realidad objetiva y externa al sujeto que observa esa realidad (como ocurre en la visión científica) sino que bajo esta posición se define una relación muy estrecha entre el sujeto que observa y el objeto observado, de manera que la realidad ya no resulta extraña al sujeto e igual para todos, como lo propugna el positivismo científico, sino que se construye conjuntamente entre el sujeto y el objeto, en un espacio-tiempo determinado. Las filosofías que enriquecen el pensamiento sistémico contemporáneo son la fenomenología de Husserl y la hermenéutica de Gadamer, que a su vez se nutren del existencialismo de Heidegger, del historicismo de Dilthey y de la propia fenomenología de Husserl. Además, a pesar de sus posturas a veces opuestas, adopto algunas de las interpretaciones filosóficas de Piaget.

La consecuencia de esta perspectiva sistémica, fenomenológica y hermenéutica es que hace posible ver a la organización ya no con un fin predeterminado, sino que dicha organización puede tener diversos fines en función de la forma en que los involucrados en su destino la vean, surgiendo la variedad interpretativa. Esta visión estaría condicionada por los intereses y valores de dichos involucrados, existiendo solamente un interés común centrado en la prevalencia de la misma, a lo cual hay que agregarle la trayectoria histórica de la organización que condiciona su situación actual, además de la experiencia del pasado y las aspiraciones futuras de sus miembros, quienes influirán en su comportamiento. Como afirma Pablo González Casanova: "en vez de llevar el conocimiento al 
objeto de estudio obtengamos el conocimiento a partir del objeto de estudio...." ${ }^{30}$

Esta nueva visión de la organización es mucho más rica y dinámica que la científica e interpreta mejor lo que sucede en el mundo real al establecer un modelo organizacional que es construido colectiva y permanentemente por los miembros de la organización a partir de las interpretaciones evolutivas que existen de la misma. Bajo este punto de vista constructivista estaremos, por tanto, haciendo mención de un conjunto de conceptos, elaboraciones teóricas, interpretaciones y prácticas -esperemos que sean buenas prácticas-, que al mismo tiempo que poseen un cierto acuerdo y contexto entre sí, poseen también un conjunto de perspectivas, interpretaciones y prácticas bastante diversas y que por lo mismo es difícil considerarlas como un solo ente. Bajo este punto de vista común en las actuales elaboraciones constructivistas trataremos de tener presente que el conocimiento no es el resultado de una mera copia de la realidad preexistente, sino de un proceso dinámico e interactivo a través del cual la información externa es interpretada y reinterpretada por la mente al ir construyendo progresivamente modelos explicativos cada vez más complejos y sofisticados. Esto significa que trataremos de conocer la realidad a través de los modelos que construimos para explicarla, y que estos modelos siempre son susceptibles de ser mejorados o cambiados.

En consecuencia, bajo la perspectiva científica obtendríamos un modelo organizacional cuyos fines están predeterminados, mientras que bajo la perspectiva sistémica-fenomenológica-hermenéutica obtendremos un modelo organizacional en el que los fines del mismo son producto de la construcción conjunta de los involucrados. Esto contribuirá de mejor forma para un futuro a mediano plazo, ya que no querría yo que este modelo quedase grabado en piedra, sino que fuese reconstruido y complementado por la acción de los distintos sectores actores involucrados en el esfuerzo.

30 Pablo González Casanova, 2004. Las nuevas ciencias y las humanidades: De la academia a la política. Barcelona: Anthropos. 
Usando un enfoque constructivista, un modelo es una herramienta de identificación y no debe tener carácter absoluto; debe entenderse como un elemento provisional de acercamiento al entorno. El verdadero encanto de un modelo radica en la posibilidad de combinarlo con otros, recreando, de acuerdo con la necesidad, escenarios de ambientación. Lo interesante de los modelos está en que permiten definir criterios de mediación entre el ser y su entorno por medio de la identificación de características, patrones e interacciones, creando y recreando, interpretando y reinterpretando el conocimiento. Termino esta reflexión con los señalamientos de Karl Popper $^{31}$ al respecto:

[...] la racionalidad de la ciencia no reside en su hábito de apelar a datos empíricos en apoyo de sus dogmas - pues eso lo hacen también los astrólogos- sino exclusivamente en el enfoque crítico, en una actitud que supone, por supuesto, el uso crítico, entre otros argumentos, de datos empíricos (especialmente en las refutaciones) [...] no tiene nada que ver con la búsqueda de la certeza, de la probabilidad o de la confiabilidad [...] conscientes de nuestra falibilidad, sólo nos interesa criticar o probar las teorías científicas, con la esperanza de descubrir en qué estamos equivocados, de aprender de nuestros errores y, si tenemos suerte y talento, de lograr teorías mejores.

\subsection{PREMISAS DEL MODELO}

El primer paso es establecer el alcance del modelo; esto es, su cobertura. Recordemos que un modelo es la representación de una realidad y destaca las características que deseamos estudiar. En este caso el objeto de estudio es lo primero a definir.

31 Karl R. Popper, 1983. Conjeturas y refutaciones: El desarrollo del conocimiento científico. Buenos Aires, p. 280. 
Es importante establecer muy claramente de qué estamos hablando cuando pensamos en una solución de colecciones y servicios de información documentales digitales para México. Si es para México, estamos estableciendo entonces que éste es un modelo de alcance nacional y aun más allá, dado que existen muchos mexicanos fuera de nuestras fronteras que podrían verse beneficiados de un sistema de tales características. Cuando decimos "modelo de biblioteca digital" es pertinente aclarar: ¿estamos hablando de una biblioteca digital o de varias bibliotecas digitales? Si el modelo representa a una biblioteca ¿es un modelo único o es un modelo que representa a una de ellas para que sea replicado muchas veces?; si se trata de varias bibliotecas, ¿de cuántas estamos hablando? Hipotéticamente podríamos partir asumiendo tres posibilidades básicas:

1. Una gran superbiblioteca digital que concentre enormes colecciones y servicios de todo tipo para todo el país.

2. Un selecto conjunto de bibliotecas digitales especializadas por tipo o colección con esa función.

3. Un gran grupo de bibliotecas de diversas índoles, capacidades, comunidades y características funcionando articuladamente para todo el país.

Como lo establecimos en el apartado 2.2.2 existen dos tendencias o estrategias a nivel mundial: la de los países con una alta infraestructura de telecomunicaciones y cómputo ya instalada, donde el énfasis está en la integración de sistemas, telecomunicaciones, redes, etc., dejando que las aplicaciones, contenidos y servicios tomen su lugar por su propia fuerza, con el ejemplo de la National Information Infraestructure de la Unión Americana (NII, Relationship..., 1998) que ha logrado arrancar el proyecto ya mencionado anteriormente de la Biblioteca Digital Nacional de Ciencia y Tecnología (NSDL, 2001). La segunda tendencia como ya comentamos se observa en otros países, principalmente la Unión Europea, en donde el énfasis ha estado en el desarrollo de contenidos, aplicaciones y servicios, dejando que la infraestructura se vaya desarrollando por sí misma. 
Del análisis cuidadoso y detallado de las estrategias y estructuras desarrolladas a nivel mundial, el modelo de desarrollo de nuestras bibliotecas se parece más al de la segunda estrategia. La estrategia adecuada para México consiste en el desarrollo de contenidos, aplicaciones y servicios pensando en que la infraestructura se va a ir desarrollando, pero con el apoyo de una adecuada catalización del Estado. Continuando en esta línea de pensamiento y de acuerdo con las iniciativas planteadas y analizadas, la solución de base para la primera aproximación al modelo de estudio de nuestras bibliotecas digitales no es la creación de una superbiblioteca digital con inmensas colecciones que se encargue de servir a todo el país; tampoco es un conjunto selecto de bibliotecas digitales cumpliendo esa función. Las principales razones para esta primera aproximación son las siguientes:

1. Nuestro modelo de desarrollo sociopolítico no contempla ya la excesiva centralización de recursos y oportunidades; la misma premisa se establece para el ámbito documental.

2. Nuestro esquema de desarrollo de tecnologías de información y comunicación no corresponde al de los países con una alta infraestructura de telecomunicaciones y cómputo ya instalada, donde el énfasis está en la integración de sistemas, telecomunicaciones, redes, etc., dejando que las aplicaciones, contenidos y servicios tomen su lugar por su propia fuerza.

3. La tecnología actual de cómputo y telecomunicaciones permite considerar un modelo integrador a nivel país el cual era muy difícil de implementar en una estructura "tradicional".

4. México no parte de la nada en cuanto al desarrollo bibliotecario. Existe ya un sistema de bibliotecas públicas, así como un buen número de bibliotecas y colecciones especializadas a nivel universitario o de investigación que ya empezaron o están listas en el desarrollo de colecciones digitales y cuyo total asciende a más de 10 000; existe además un considerable acervo en instituciones privadas y gubernamentales.

5. Existe una buena cantidad de información con valor documental, en poder de diversos sectores productivos, que bien organi- 
zada puede formar parte de acervos documentales nacionales y que a la fecha no se ha explotado.

6. Existe una enorme cantidad de recursos documentales no digitalizados en múltiples repositorios que, procesados en forma compartida y colaborativa por muchas bibliotecas, podrán formar un enorme y rico acervo mexicano en un plazo y a un costo razonables.

Esto queda reforzado por lo planteado en el documento de la Academia de Ciencias Mexicana (1999, p. 32) en la tabla de acciones por componente. En el renglón de servicios se propone:

$\begin{array}{lllll}\text { Diseñar las bases } & \text { Crear la RNBD enla- } & \text { Consolidar un siste- } & \text { Consolidar una red } & \text { Consolidar una pla- } \\ \text { para la creación y } & \text { zando la Biblioteca } & \text { ma federado de bi- } & \text { nacional de educa- } & \text { taforma de produc- } \\ \text { operación de una } & \text { Nacional, la red de } & \text { bliotecas digitales } & \text { ción y capacitacióna } & \text { ción y distribución } \\ \text { red de bibliotecas } & \text { bibliotecas públicas, } & \text { para la educación, la } & \text { distancia apoyada electrónica masiva } \\ \text { digitales (RNBD). } & \text { las universitarias, } & \text { capacitación y el en la RNBD y en los de información de } \\ & \text { las de investigación } & \text { adiestramiento. Con- } & \text { sistemas federados toda índole para to- } \\ & \text { y las escolares. } & \text { solidar un sistema de bibliotecas digi- dos los ámbitos. } \\ & \text { federado de bibliote- tales. } \\ & \text { cas digitales para la } \\ & \text { investigación. }\end{array}$

Por estas razones se concluye que nuestra primera aproximación al modelo de desarrollo de bibliotecas digitales mexicano debe ser un sistema articulado de numerosas bibliotecas digitales de muy diversas índoles y características donde se conforma de manera integral un organismo con una sola función general, y en donde todas y cada una de ellas cumplen una función particular preestablecida, armónica y aditiva. Para representarlo de otra manera, una especie de "federación" de bibliotecas digitales de muchos tipos y características alcanzando a todos los usuarios del país y más allá. Como todo sistema orgánico, debe tener entonces subsistemas y "tejidos" especializados con funciones específicas. Recordemos además que se ha preestablecido en la metodología una visión holística y por ello debemos plantear un modelo organizacional cuyos fines sean producto de la construcción conjunta de todos los involu- 
crados. Para lograr esto indudablemente tendrán que crearse o impulsarse ciertas bibliotecas y colecciones digitales estratégicas para un adecuado funcionamiento, pero el modelo no debe basarse en el desarrollo de apenas un selecto grupo de bibliotecas digitales.

De este planteamiento establecemos entonces las primeras premisas y precisiones: cuando hablamos del modelo de construcción de biblioteca digital para México, vamos más allá de los planteamientos micro que se refieren a una sola biblioteca y que son replicables muchas veces; estamos en el entendido de que nos estamos refiriendo siempre a un sistema nacional y organizado de bibliotecas digitales y nunca a una superbiblioteca o selecto club de ellas.

Cuando hablamos entonces del modelo de planeación y organización de esa biblioteca digital, dado que es un sistema nacional debemos entonces ir estableciendo la interacción de las partes que la integran. Debemos organizarnos y planear a nivel federal, estatal, municipal y regional con planos geográficos por nivel, por sector, por comunidades de usuarios, etc. Requerimos y tendremos como seguros participantes bibliotecas públicas, escolares, universitarias, especializadas, industriales, privadas, etc. Como ya se ha establecido, la sociedad de la información del futuro cercano no contempla únicamente al sector educativo. Se tienen necesidades y recursos de sectores productivos muy definidos que deben ser integrados adicional e indispensablemente a este esfuerzo bibliotecario.

Para establecer la premisa del alcance de contenido hemos mencionado ya la creación de un conjunto de recursos, sistemas, servicios y acervos de información documental. Como analizamos en los primeros capítulos de esta obra, el concepto de información es muy amplio y conviene precisarlo. De acuerdo con las premisas de información aceptadas universalmente para este tipo de iniciativas, la premisa fundamental de este tipo de sistemas y servicios de información es que nuestro sistema educativo, económico, político y social operará con más eficiencia si se establece un mecanismo que garantice que los responsables, planificadores, gerentes, ejecutivos, directivos, profesionales, etc., del sector público y de los sectores privados así como del sistema educativo, incluyendo a maestros, 
investigadores, académicos y alumnos, tengan acceso puntual a datos e informaciones actualizadas, suficientes, pertinentes, oportunas y fiables. Por ello, la materia prima y en consecuencia la premisa del contenido de un proyecto nacional de bibliotecas digitales e información es el acceso y la utilización óptima de los conocimientos a través de los materiales documentales generales, especializados y profesionales, la información científica, técnica, política, cultural, social y económica y las técnicas y habilidades desarrolladas o disponibles en el país y en otras partes del mundo, como recurso destinado a resolver problemas y para el desarrollo.

Se ha mencionado ya varias veces la participación de "varios sectores" en el proyecto. Conviene ir aclarando ese concepto. Una primera imagen conceptual del modelo en cuanto a los sectores que lo conformarían puede visualizarse en la figura 5.1.

Figura 5.1

ESQUEMA BÁSICO DE ORGANIZACIÓN SECTORIAL PARA UN SISTEMA NACIONAL DE BIBLIOTECAS DIGITALES

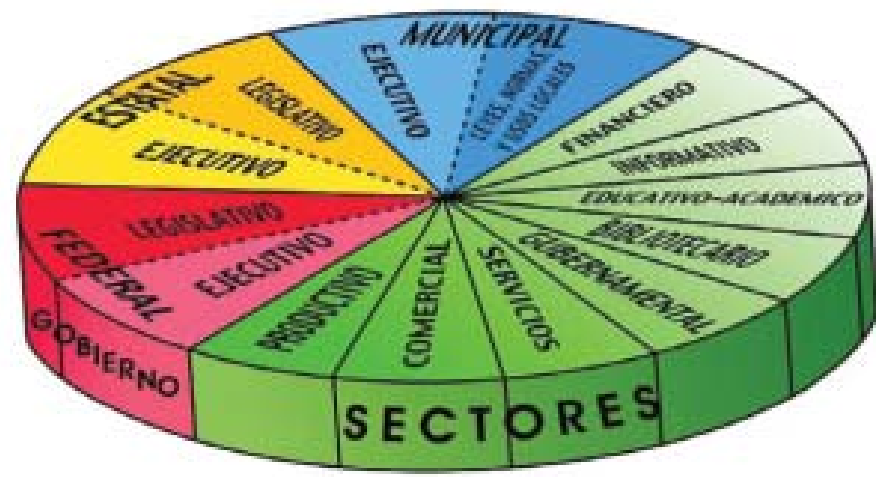

¿Por qué sectores no gubernamentales deben ser incluidos en este modelo? ¿No es responsabilidad del gobierno de manera primordial crear, organizar y sustentar las bibliotecas de un país? 
Recordemos que estamos estableciendo el modelo para el futuro del país. En forma tradicional, como en otros países, el gobierno mexicano ha tenido casi exclusivamente la responsabilidad de crear, organizar y sostener la inmensa mayoría de las bibliotecas del país; pero eso no se contempla más en los modelos de países más avanzados y por avanzados no me refiero a su desarrollo económico, sino a sus conceptos de la sociedad de la información, los cuales funcionan independientemente de su etapa de desarrollo económico. Partiendo del hecho incuestionable de que la información documental no es ya más un insumo exclusivo del sector educativo o de investigación académica, podemos establecer sin duda que la información es un insumo valiosísimo e insustituible para el desarrollo de nuestro país y forma parte de las preocupaciones y necesidades de sectores productivos del mismo: comercial, industrial, financiero, energético, de servicios, etc. Todo sector estratégico del desarrollo de un país la requiere, la consume y paga por ella. Por supuesto, el gobierno deberá seguir sosteniendo buena parte de esa responsabilidad, pero no puede seguir siendo su exclusiva responsabilidad. Por tanto, el modelo futuro ideal de desarrollo de bibliotecas digitales es un proyecto de Estado y por ello conlleva el concurso gobiernosector educativo-sectores productivos. A este hecho lo hemos denominado "bibliotecas para la educación y la producción". De este análisis pueden resaltarse las siguientes nuevas premisas:

- El sistema nacional de bibliotecas digitales es una concurrencia armónica entre el gobierno mexicano, los principales sectores del desarrollo y la misma sociedad civil. No es responsabilidad única del gobierno; es un proyecto de Estado, mitad gobierno, mitad sociedad civil.

- El gobierno mexicano es responsable de su mitad del desarrollo de manera integral; hay responsabilidades federales, estatales y municipales, tanto de los poderes ejecutivos como de los legislativos. Debe llegar a involucrar incluso legislaciones y usos y costumbres regionales y locales. Cada una de las partes y niveles del gobierno mexicano debe establecer claramente sus responsabilidades y asumirlas. 
- Los principales sectores del desarrollo del país también son responsables de su mitad. Deben establecerse claramente en el ámbito del proyecto nacional. Hay que definir quiénes son responsables de organizar cada uno. Cuáles son además sus necesidades de información, sus recursos, características, organización, subsectores; quién va a operar el proyecto. En este documento se establece una primera propuesta.

- Como puede verse y era de esperarse, los sectores educativoacadémico y bibliotecario están en esta estructura. Al igual que los demás deben establecer cuidadosamente sus responsabilidades, recursos, características, subsectores, niveles, necesidades, operadores, fortalezas, retos, amenazas, etcétera, dentro del proyecto.

- En este diagrama, la mitad izquierda contempla al gobierno en su función rectora. En la mitad derecha se repite el sector gubernamental ya que éste a su vez es un área "productiva" en el proceso de la información documental. En esta parte debe verse al gobierno no en su función rectora, sino como actor del proceso de desarrollo socio-económico nacional: el sector cuenta con importantes recursos de colecciones y/o servicios documentales para aportar al proyecto y es a la vez un ávido consumidor de información. Tiene características, subsistemas, necesidades, servicios, etc., que van mucho más allá de la función rectora. Por ello se repite en el esquema; por un lado es el gobierno como ejecutivo y legislador, el que participa en el proyecto; por otro, es una parte muy importante del proceso de producción y consumo de información documental y por lo mismo se inserta en el mismo nivel que los demás sectores con sendas responsabilidades. Resumiendo, el gobierno tiene a la vez los papeles de "director" y "actor" en esta obra y es conveniente diferenciarlos.

Una vez establecido lo anterior, continuemos definiendo las características organizacionales con más detalle; para ello analicemos con más profundidad las responsabilidades que competen al gobierno en su función rectora. De acuerdo con varios autores la 
función gubernamental en las décadas venideras tenderá a ser más reguladora y menos realizadora. Turner y Corbacho ${ }^{32}$ presentan un resumen de esas "nuevas" funciones del Estado en el futuro cercano, el cual cito textualmente:

Como los ciudadanos desean numerosos servicios de las autoridades de los estados-nación en los decenios venideros, en vez de disminuir, la función del Estado cambiará. Las autoridades se esforzarán en hallar maneras de desempeñar con más eficacia sus funciones tradicionales, entre ellas la regulación del sector privado, la determinación de políticas que fomenten el crecimiento económico y la equidad, el asegurar un nivel de vida mínimo a los más necesitados, velar por la defensa nacional y la aplicación de la legislación interna y conformar un conjunto de valores sociales.

Existen muchos otros autores que comparten este punto de vista. De acuerdo con esta tendencia, el Estado deberá cada vez más crear las condiciones para que la sociedad civil realice cosas en vez de pretender hacer todo por sus propias fuerzas. Por supuesto, esto no debe interpretarse como que el Estado ya no es responsable de emprender proyectos de estrategia nacional. Nada más lejos de la realidad; debe entenderse que el Estado propicia, fomenta, regula, supervisa. Es decir, el Estado debe ver que las cosas se den, sin realizarlas él mismo y sin acabar teniendo el control absoluto de ellas, ya que en ese caso se vuelve el dueño, el patrón, con una serie de inconveniencias que la historia se ha encargado de probar que no llevan a buen puerto. Dicen que la función ideal del Estado es la de catalizador, en el más puro sentido químico de esta acepción: aquel agente que acelera una reacción sin intervenir en ella. Bajo esta acepción moderna debemos definir entonces cuáles son las funciones del gobierno dentro de un proyecto de esta naturaleza. En la figura 5.2 presento un mapa conceptual con estas responsabilidades.

32 Frederick Turner y Alejandro Corbacho, 2000. Las nuevas funciones del estado. Disponible 3 de noviembre, 2005 en: http://www.unesco.org/issj/rics163/ abstracts $163 . \mathrm{htm}$ 
Figura 5.2

MAPA CONCEPTUAL DE RESPONSABILIDADES A NIVEL GOBIERNO EN TORNO A UN SISTEMA NACIONAL DE BIBLIOTECAS DIGITALES. PARA LEERLO DEBE UBICARSE PRIMERO LA ACCIÓN EN LA LÍNEA SUPERIOR, LUEGO UBICAR EL CONCEPTO EN LA COLUMNA

DE LA IZQUIERDA Y CERRAR CON LA CASILLA QUE LOS INTERSECTA

\begin{tabular}{|c|c|c|c|c|c|c|c|c|}
\hline & Promover & Legislar & Instalar & Coordinar & $\begin{array}{l}\text { Financiar } \\
\text { (semilla) }\end{array}$ & Catalizar & Extender & Preservar \\
\hline Infraestructura en & & & $\begin{array}{l}\text { cómputo } \\
\text { telecom. }\end{array}$ & $\begin{array}{l}\text { cómputo; } \\
\text { telecom. }\end{array}$ & & & & \\
\hline Estandarización en & & $\begin{array}{l}\text { telecom.; } \\
\text { protocolos }\end{array}$ & & $\begin{array}{l}\text { telecom:; } \\
\text { protocolos }\end{array}$ & & $\begin{array}{l}\text { telecom:; } \\
\text { protocolos }\end{array}$ & & \\
\hline Normalización de & & $\begin{array}{l}\text { publ.electr. } \\
\text { Registro y } \\
\text { marcado } \\
\text { bibliográfico }\end{array}$ & & & & $\begin{array}{l}\text { publ. electr. } \\
\text { Registro y } \\
\text { marcado } \\
\text { bibliográfico }\end{array}$ & $\begin{array}{l}\text { aplicaciones } \\
\text { de acceso }\end{array}$ & \\
\hline $\begin{array}{l}\text { No redundancia } \\
\text { inútil de } \\
\text { colecciones }\end{array}$ & voluminosas & & & voluminosas & & & & voluminosas \\
\hline $\begin{array}{l}\text { Creación de } \\
\text { colecciones } \\
\text { nacionales para } \\
\text { educación y } \\
\text { capacitación } \\
\text { estratégicas }\end{array}$ & $\begin{array}{l}\text { de volumen; } \\
\text { estratégica }\end{array}$ & & & & $\begin{array}{l}\text { de volumen; } \\
\text { estratégica }\end{array}$ & & & \\
\hline $\begin{array}{l}\text { Innovación } \\
\text { tecnológica en }\end{array}$ & $\begin{array}{l}\text { aplicaciones } \\
\text { y uso de } \\
\text { cómputo }\end{array}$ & & & & $\begin{array}{l}\text { aplicaciones } \\
\text { y uso de } \\
\text { cómputo }\end{array}$ & $\begin{array}{l}\text { aplicaciones } \\
\text { y uso de } \\
\text { cómputo }\end{array}$ & & \\
\hline $\begin{array}{l}\text { Acceso libre y/o } \\
\text { económico a }\end{array}$ & $\begin{array}{l}\text { base mínima } \\
\text { de información }\end{array}$ & $\begin{array}{l}\text { base mínima } \\
\text { de información }\end{array}$ & & & & $\begin{array}{l}\text { base mínima } \\
\text { de información }\end{array}$ & & $\begin{array}{l}\text { base mínima } \\
\text { de información }\end{array}$ \\
\hline $\begin{array}{l}\text { Derechos de } \\
\text { propiedad }\end{array}$ & respeto a & respeto a & & & & & & respeto a \\
\hline $\begin{array}{l}\text { Inversión } \\
\text { privada en }\end{array}$ & $\begin{array}{l}\text { cómputo;. } \\
\text { telecom. }\end{array}$ & & & & & $\begin{array}{l}\text { aplicaciones } \\
\text { de acceso }\end{array}$ & $\begin{array}{l}\text { cómputo } \\
\text { telecom }\end{array}$ & \\
\hline $\begin{array}{l}\text { Formación de } \\
\text { personal } \\
\text { calificado en }\end{array}$ & $\begin{array}{l}\text { cómputo; } \\
\text { telecom. }\end{array}$ & & & & & & $\begin{array}{l}\text { cómputo; } \\
\text { telecom. }\end{array}$ & $\begin{array}{l}\text { cómputo; } \\
\text { telecom. }\end{array}$ \\
\hline $\begin{array}{l}\text { Formación de } \\
\text { especialistas en }\end{array}$ & $\begin{array}{l}\text { tecnologías y } \\
\text { modelos educ. } \\
\text { Bib. digitales }\end{array}$ & & & $\begin{array}{l}\text { tecnologías y } \\
\text { modelos educ. } \\
\text { Bib. digitales }\end{array}$ & & $\begin{array}{l}\text { tecnologías y } \\
\text { modelos educ. } \\
\text { Bib. digitales }\end{array}$ & & \\
\hline $\begin{array}{l}\text { Identidad, cultura } \\
\text { y valores }\end{array}$ & $\begin{array}{l}\text { nacionaly } \\
\text { regional }\end{array}$ & & & & & & & \begin{tabular}{|l} 
nacional y \\
regional
\end{tabular} \\
\hline $\begin{array}{l}\text { Creación de texto y } \\
\text { materiales digitales }\end{array}$ & $\begin{array}{l}\text { contenidos } \\
\text { básicos }\end{array}$ & & & $\begin{array}{l}\text { contenidos } \\
\text { básicos }\end{array}$ & $\begin{array}{l}\text { contenidos } \\
\text { básicos }\end{array}$ & & $\begin{array}{l}\text { contenidos } \\
\text { básicos }\end{array}$ & \\
\hline $\begin{array}{l}\text { Servicios de } \\
\text { información } \\
\text { documental a }\end{array}$ & & & & gran público & gran público & gran público & gran público & \\
\hline $\begin{array}{l}\text { Seguridad y } \\
\text { privacidad }\end{array}$ & de usuarios & de usuarios & & & & & & de usuarios \\
\hline $\begin{array}{l}\text { Organización } \\
\text { sectorial }\end{array}$ & en todo sector & & arranque & a todo sector & & cooperación & cooperación & participación \\
\hline
\end{tabular}


Alineación a marcos de referencia: Como paso previo a su definición, es necesario "alinear" el modelo dentro del contexto internacional y nacional. He aquí mi propuesta de un marco de referencia para el modelo de bibliotecas digitales para México. Me pareció lo más conveniente que el marco rector para este alineamiento fuese una unión de la última declaración de la Sociedad del Conocimiento de la UNESCO, la Declaración de Libertad Intelectual del IFLA y las cinco prioridades de e-Europe como referente internacional, así como el proyecto e-México, el documento de la Academia de Ciencias Mexicana y el Programa Nacional de Educación 2001-2006 en el ámbito nacional (World Summit...,2003), (IFLA, 1999), (European Comission..., 1997), (e-México, 2001), (Secretaría de Educación Pública, 2001), (Academia..., 1999). Así, de esos seis documentos, he aquí en seguida mi propuesta de marco de referencia del modelo de biblioteca digital para México, ya alineado.

\subsection{MARCO DE REFERENCIA PROPUESTO PARA EL MODELO}

El género humano está entrando de lleno a la sociedad de la información y del conocimiento. Tal sociedad está relacionada con las capacidades para identificar, producir, procesar, transformar, difundir y utilizar información destinada a crear conocimientos y aplicarlos en beneficio del desarrollo humano. La sociedad mexicana, como muchas otras del orbe, está experimentando un cambio radical en las formas en que genera, integra y utiliza el conocimiento. Ésta es, sin duda, una de las transformaciones sociales de mayor trascendencia y determinará las oportunidades y desafíos de la educación, la erradicación de la pobreza y otros objetivos del desarrollo socioeconómico en las próximas décadas. Los cambios abarcan no sólo el ámbito de las capacidades de la educación, sino que afectan todos los campos de la vida intelectual, cultural y social, dando expresión concreta a los múltiples tipos de inteligencia humana y, en conjunto, están dando origen a una nueva sociedad caracterizada por el predominio de la información y el conocimiento. Esta 
nueva sociedad se ha impulsado en el cambio acelerado y sin precedente de las tecnologías de la información y la comunicación, así como en la acumulación y diversificación del conocimiento. En el campo tecnológico se observa una clara tendencia hacia la convergencia global de los medios masivos de comunicación, las telecomunicaciones y los sistemas de proceso de datos, determinando el surgimiento de nuevas oportunidades para la producción y difusión de contenidos culturales, educativos, informativos y de esparcimiento.

La conectividad es uno de los importantes factores habilitadores para crear la sociedad del conocimiento. El acceso universal, ubicuo, equitativo y asequible a infraestructuras y servicios de tecnologías de información es una de las ambiciones de esta sociedad, es un objetivo de todos los que participan en su creación y tratamos de garantizarla de conformidad con las posibilidades económicas y tecnológicas de nuestro país. Un buen desarrollo de infraestructuras de red y aplicaciones de comunicación e información adaptadas a las condiciones nacionales y locales, fácilmente accesibles y asequibles, con adecuado ancho de banda y con otras tecnologías innovadoras, será sin duda factor para acelerar el progreso económico y social y mejorar el bienestar de todas las personas, comunidades y poblaciones en México; por ello, los proyectos e iniciativas en este sentido irán preparando el camino del modelo de bibliotecas digitales.

La utilización y despliegue de las tecnologías de información y comunicación en México debe orientarse a la creación de beneficios en todos los ámbitos de la vida cotidiana. Varios ejes estratégicos en este sentido han sido identificados e iniciados: la información y servicios gubernamentales, la atención y la información sanitaria, la actividad económica y generación de empleos, la agricultura, el transporte, la protección del medio ambiente y la gestión de los recursos naturales, la prevención de catástrofes, son algunas de las líneas de acción establecidas ya en el proyecto de sociedad de la información e-México.

Un eje o conjunto de ejes de acción de especial importancia para el desarrollo nacional y también enunciado en e-México es el 
relacionado con la educación, la capacitación para el empleo y la vida e identidad cultural. Se vislumbra ya el advenimiento de un nuevo modelo educativo a nivel mundial más allá de nuevas modalidades educativas basadas en tecnologías de información y comunicación, más como un desarrollo de contenidos e igualdad de acceso que de tecnología. Este nuevo modelo abarcará tanto la educación para el conocimiento como la educación para la capacitación. Las instituciones educativas tienen que realizar esfuerzos extraordinarios de apertura para proporcionar nuevos espacios de aprendizaje que aseguren esas oportunidades de educación para todos a lo largo de la vida. Las tecnologías de información y comunicación siguen abriendo nuevas perspectivas para la educación a distancia, y seguramente permitirán atender de manera más amplia y más eficiente las necesidades educativas, cada día más urgentes y diversas, tanto de quienes no han podido terminar su educación básica como de los egresados de niveles superiores. Esto supone respetar un conjunto de principios y prioridades: educación de buena calidad para todos, acceso universal y permanente a las fuentes y métodos de información para el conocimiento, respeto a la dignidad humana, a la libertad de expresión y a la diversidad cultural y lingüística, a través del entendimiento e incorporación de los sistemas de conocimiento autóctonos; integración masiva de grupos o minorías marginadas; capacitación para el trabajo; inversión en ciencia y tecnología; balance entre el desarrollo de contenidos educativos, científicos, tecnológicos, culturales y recreativos de carácter nacional y la adecuada integración de los correspondientes internacionales.

Ningún nuevo modelo educativo puede desarrollarse adecuadamente en nuestro país sin el desarrollo paralelo y consistente de un sistema de bibliotecas digitales que lo apoye en todo momento. Las bibliotecas digitales son potencialmente importantes y deben articularse perfectamente y complementarse con el eje educacióncapacitación-vida e identidad cultural, así como con los otros ejes de la sociedad del conocimiento.

Dada su capital importancia, su alcance, su complejidad, su inversión y su trascendencia, no puede ser un proyecto de gobierno, 
sino un proyecto del Estado mexicano. Por ello, los gobiernos federal y estatales, los poderes legislativos federal y estatales, el sector educativo, el sector privado y la sociedad civil, tienen una función y una responsabilidad importantes en el desarrollo de las bibliotecas digitales para la educación de la sociedad del conocimiento mexicana del siglo XXI y en su caso, en el proceso de adopción de decisiones al efecto. Crear una sociedad del conocimiento con una adecuada educación e información con prioridad humanista supone un esfuerzo conjunto que necesita la cooperación y la asociación de todas las partes interesadas.

Se integrarán y vigilarán las políticas que creen un clima favorable de estabilidad, previsibilidad y competencia leal a todos los niveles, de tal forma que se atraiga más inversión privada para el desarrollo de infraestructura de las tecnologías de información y comunicación y que ésta sirva también para cumplir las obligaciones del servicio universal en regiones en las cuales las condiciones tradicionales del mercado no lo permiten. En las zonas menos aventajadas el establecimiento de puntos de acceso público a estas tecnologías en oficinas de correos, escuelas, bibliotecas y archivos serán garantía eficaz del acceso universal a los servicios y a la infraestructura de la sociedad de la información.

Es indispensable que todos puedan acceder y contribuir a la información, a las ideas y al conocimiento en una sociedad del conocimiento incluyente. Es posible mejorar el intercambio y el incremento de los conocimientos mundiales y nacionales para favorecer el desarrollo y eliminar las barreras que impiden un acceso equitativo a la información para realizar actividades económicas, sociales, políticas, sanitarias, culturales, educativas y científicas, si se facilita el acceso a la información de dominio público, lo que puede lograrse, entre otras cosas, mediante el diseño y el acceso a contenidos adecuados. Un dominio público rico es un factor capital del crecimiento de la sociedad de la información, ya que genera ventajas tales como un público informado, nuevos empleos, innovación, oportunidades comerciales y el avance de las ciencias. El acceso sin dificultad a la información de dominio público es esencial en la sociedad de la información, dentro de un marco de abso- 
luto respeto contra toda apropiación indebida de la información. Este esquema debe fortalecerse sobre todo en las entidades públicas tales como bibliotecas y archivos, museos, colecciones culturales y otros puntos de acceso comunitario para promover la preservación de los registros de documentos y el acceso libre y equitativo a la información. Será su prioridad impulsar el acceso universal y equitativo al conocimiento científico y la creación y divulgación de información científica y técnica, con inclusión de las iniciativas encaminadas al acceso abierto en el campo de las publicaciones científicas.

Hay que ofrecer a cada persona la posibilidad de adquirir las competencias y los conocimientos necesarios para comprender, participar activamente y beneficiarse plenamente de la sociedad de la información y la economía del conocimiento. La alfabetización y la educación primaria universal son factores esenciales para crear una sociedad de la información integradora para todos, teniendo en cuenta en particular las necesidades especiales de grupos minoritarios, en general marginados y vulnerables: las niñas y las mujeres, personas de la tercera edad, discapacitados, grupos indígenas, etcétera. A la vista de la amplia gama de especialistas en tecnologías e información que serán necesarios a todos los niveles, debe prestarse particular atención a la creación de capacidades institucionales y promoverse el empleo de las bibliotecas digitales en todos los niveles en la educación, la formación y el perfeccionamiento de los recursos humanos. La formación continua y de adultos, la capacitación para el trabajo y el aprendizaje continuo, la enseñanza a distancia y otros servicios especiales, pueden ser claves a la hora de beneficiarse de las nuevas posibilidades ofrecidas por las tecnologías de información y comunicación para los empleos tradicionales, los profesionistas independientes y las nuevas profesiones. A este respecto, la conciencia acerca de la importancia que revisten estas tecnologías, la adquisición de conocimientos y los acervos digitales en este ámbito son un cimiento fundamental para individuos y grupos.

Los creadores, editores y productores de contenido, así como los profesores, instructores, bibliotecarios, archivistas y alumnos 
deben desempeñar una función activa en la promoción de la sociedad de la información, particularmente en los sectores menos favorecidos de la sociedad. Para alcanzar un desarrollo sostenible de la sociedad del conocimiento, deben reforzarse las capacidades nacionales en materia de investigación y desarrollo de tecnologías de información y bibliotecas digitales. La fabricación de contenidos y productos para estos acervos representa una oportunidad importante e impostergable de creación de riqueza. El logro de nuestras aspiraciones compartidas para que nuestro país se convierta en miembro eficaz y exitoso de la sociedad de la información y se integre definitivamente en la economía del conocimiento, depende en gran parte de la mayor creación de capacidad en las esferas de la educación, los conocimientos técnicos y el acceso a la información, elementos todos ellos determinantes para el desarrollo y la capacidad de competencia. Las tecnologías de información y comunicación son un importante factor habilitador del crecimiento, ya que mejoran la eficacia e incrementan la productividad, especialmente en las pequeñas y medianas empresas (PyMEs). Por esta razón, el desarrollo de la sociedad de la información es importante para lograr un crecimiento económico general y armónico en nuestro país. Se debe fomentar la mejora de la productividad por medio de las tecnologías y acervos de información y la aplicación de la innovación en todos los sectores económicos. La distribución equitativa de los beneficios, no sólo económicos, contribuye a la erradicación de la pobreza y al desarrollo social.

Debe reforzarse el marco de confianza que abarca, entre otras cosas, la seguridad de la información y de las redes, la autenticación, la privacidad y la protección de los usuarios, como requisito imprescindible para que se desarrolle la sociedad de la información y se promueva la confianza de usuarios en las tecnologías de información y comunicación. Los programas y aplicaciones deben ser fáciles de utilizar, asequibles y accesibles para todos, adaptados a las necesidades nacionales respecto a idioma y cultura, y favorables al desarrollo sostenible.

Conviene recomendar especialmente la preparación y adopción de normas internacionales, tanto bibliotecológicas como tecnoló- 
gicas. La concepción y el empleo de normas abiertas, compatibles e impulsadas por la demanda, en las que se tenga en cuenta las necesidades de los editores, bibliotecarios y usuarios, son factor básico del desarrollo y facilitará la propagación de las tecnologías de información y acervos digitales.

La diversidad cultural es el patrimonio común de la humanidad y particularmente de nuestro país; el modelo de bibliotecas digitales debe contemplar y estimular insoslayablemente el respeto de las identidades y diversidades culturales y lingüísticas, las tradiciones y las religiones, además de promover un diálogo entre las culturas. El fomento, la afirmación, el rescate y la preservación de los diversos idiomas e identidades culturales indígenas contribuirán a enriquecer aún más a la sociedad de la información mexicana. Es esencial promover la producción de contenidos y la accesibilidad a los mismos, sea con propósitos educativos, científicos o culturales o con fines recreativos en diferentes idiomas y formatos. La creación de contenidos que se ajusten a las necesidades nacionales o regionales fomentará el desarrollo socioeconómico y estimulará la participación de todas las partes interesadas, incluyendo a los habitantes de zonas rurales distantes o marginadas. La preservación del patrimonio cultural es un elemento crucial de nuestra identidad personal y el conocimiento de nosotros mismos, los que a su vez son el enlace de nuestras comunidades con su pasado. La sociedad de la información mexicana y, por ende, las bibliotecas digitales mexicanas deben aprovechar y preservar el patrimonio cultural y heredarlo a las futuras generaciones, para lo cual utilizarán todos los medios convenientes al efecto.

La libre circulación de las ideas es el postulado esencial de las sociedades del conocimiento. Las bibliotecas digitales deben respetar los principios de libertad de pensamiento, de información y de prensa, así como los de independencia, pluralismo y diversidad de los acervos y de los medios de comunicación, como pilares esenciales para la sociedad de la información. De igual importancia es la libertad intelectual de buscar, recibir, divulgar y utilizar la información para la creación, recopilación y divulgación de conocimiento. La selección y disponibilidad de los materiales y servi- 
cios bibliotecarios deberá regirse siempre por consideraciones profesionales y no por puntos de vista políticos, morales o religiosos. Deben regirse también por los valores fundamentales de paz, libertad, igualdad, solidaridad, tolerancia, responsabilidad compartida y respeto a la naturaleza. Reconocemos la importancia de la ética y la autocensura para la sociedad de la información, quien debe promover la justicia, la dignidad y el valor del ser humano. Al utilizar las tecnologías de información y los acervos digitales de las bibliotecas deben respetarse los derechos humanos y las libertades fundamentales de otros, lo que da igual valor tanto a la privacidad personal como al derecho a la libertad de opinión, conciencia y religión. Las bibliotecas y los servicios de información deberán poner a disposición de todos los usuarios por igual sus materiales, instalaciones y servicios. No deberán discriminar el acceso o distribución por ninguna razón como raza, origen nacional o étnico, género, edad, discapacidad, religión o ideología. Todos los actores de los poderes gubernamentales y de la sociedad civil deben adoptar las medidas preventivas y las acciones necesarias con arreglo a la legislación para que este marco se extienda y se consolide como el cimiento para las bibliotecas digitales de la sociedad mexicana del conocimiento del siglo XXI.

\subsection{DEFINIENDO EL MODELO}

Una vez establecido nuestro marco de referencia, es pertinente establecer los elementos básicos para la planeación del modelo: definición y objetivos, misión, visión, políticas, estrategias y factores de éxito.

Definición y objetivo: El sistema nacional de bibliotecas digitales es un conjunto de capacidades técnicas, organizativas, recursos electrónicos, redes distribuidas y personal calificado integrados para la creación, búsqueda y distribución de acervos y servicios de información documental multimedios cuya función es la de satisfacer en lo posible todas las necesidades de información de múltiples comunidades específicas de usuarios, procurando hacer llegar sus 
colecciones y servicios a aulas, oficinas, laboratorios, industrias, hogares, áreas públicas, etcétera, a todo el país y más allá.

Misión: Ser la principal herramienta de tecnologías de información para hacer accesible el conocimiento a través de la información documental para la enseñanza, el estudio, el trabajo, la investigación, la capacitación y el esparcimiento de personas y comunidades escolares, académicas, profesionales, gremiales, sectoriales, artísticas, a lo largo de todo el territorio nacional extendiéndose a la comunidad global.

Visión: El sistema nacional de bibliotecas digitales debe conformarse como una herramienta primordial de un nuevo modelo educativo. Debe ser un mecanismo de igualdad y movilidad social brindando oportunidades equitativas de acceso a la información y enseñanza adecuada, oportuna y en lo posible gratuita a todo tipo de comunidades. Debe ayudar a preservar, junto con los valores científicos, artísticos y culturales universales la identidad, los valores, la lengua y la cultura nacionales así como las regionales. Debe convertirse en el principal apoyo de los proyectos para la integración adecuada de las tecnologías de información para la construcción de una sociedad del conocimiento en México. Debe ayudar a la integración y vínculo con comunidades de mexicanos fuera del territorio nacional. Debe ser elemento clave en un modelo de capacitación de aptitudes para el trabajo en forma permanente bajo nuevos paradigmas de trabajo en red, colaborativo más que competitivo, etcétera.

Políticas: El sistema nacional de bibliotecas digitales es un proyecto de importancia nacional y estratégica para el país y no es reponsabilidad única del gobierno; es un proyecto del Estado mexicano. Por lo mismo, debe construirse sobre un modelo nacional de organización participativa de los sectores gubernamental, educativo y productivo del país, tomando cada uno su responsabilidad en la producción, organización y distribución del material documental de manera integral y armónica; debe poder articularse desde los niveles más altos de los sectores involucrados hasta los niveles más elementales de participación. Debe evitar redundancias innecesarias. 
Este sistema de bibliotecas debe priorizar que la distribución y consumo de información documental no es simplemente una tarea de asistencia social que deba ser otorgada bajo el esquema de los programas de esa índole. Es un factor indispensable para un incremento y desarrollo sostenido igualitario y visible del bienestar económico, social, político, educativo, etcétera, de todos los sectores de nuestro país. Por lo mismo, debe establecerse una serie de estrategias para su desarrollo y sustento económico.

Estrategias: Como se ha señalado, y reiterando la visión holística del mismo, el sistema de bibliotecas digitales es "un modelo nacional de organización participativa". Dado que es un proyecto de alcance nacional que no depende únicamente del sector gubernamental debe establecerse una perfecta articulación del sistema en una estructura confederada de sectores, niveles, programas, etcétera.

El sector gubernamental mexicano es responsable de su parte del desarrollo de manera integral en su función rectora; debe tenerse siempre en cuenta que hay responsabilidades federales, estatales y municipales, tanto del poder ejecutivo como del legislativo. Ninguna parte puede ser soslayada; debe involucrar inclusive a autoridades y legislaciones regionales y locales. Cada una de las partes y niveles del gobierno mexicano debe establecer claramente sus responsabilidades y asumirlas. El sector gubernamental es también importante productor y consumidor de información, por lo que debe contemplarse en esta faceta del desarrollo, sin confundir nunca ambas vertientes.

El sector gubernamental debe solicitar, organizar y poner en marcha iniciativas "detonadoras" de esta estructura nacional, sin volverse su administrador en el proceso. Debe poder iniciar proyectos "semilla" en distintas instancias en forma estratégica para que esas instancias se vuelvan a su vez eficaces motores del cambio. Debe proveer el sustento legal. Para ello, lo primero debe ser la organización y la coordinación de los sectores.

Factores de éxito: Para la definición del modelo he tratado de no pasar por alto las premisas esenciales de los modelos de desarrollo de la sociedad del conocimiento y bibliotecas digitales más rele- 
vantes provenientes de otros países y que han sido ya analizados. Si bien nuestro modelo no puede ser igual a ninguno de ellos, dadas nuestras características nacionales y dado que debe contener una personalidad y contexto propios, he tratado de integrar todas las premisas consideradas indispensables y las "buenas prácticas" de los modelos norteamericano, europeo, canadiense y brasileño entre otros.

Deben establecerse claramente en el ámbito del proyecto nacional los principales sectores del desarrollo nacional y, por tanto, participantes en el proyecto. Debe definirse quiénes son responsables de organizar cada uno de los sectores, cuáles son las necesidades de información del sector, sus recursos, insumos, características, organización, subsectores, operadores ejecutivos.

Se debe tener especial cuidado al establecer las definiciones ya mencionadas para los sectores educativo-académico y bibliotecario; dado su papel estratégico en el proyecto, deben definirse con absoluto detalle y precisión sus responsabilidades, recursos, necesidades, fortalezas, etcétera.

El gobierno es también un importante sector "productivo" en el proceso de la información documental y como tal debe formar parte del conjunto de sectores actores del desarrollo. Cuenta con importantes recursos de colecciones y/o servicios documentales para aportar al proyecto y es un ávido e importante consumidor de información; visto como productor y consumidor, el gobierno tiene características, subsistemas, necesidades, servicios, etc., que le son propios y deben ser definidos con detalle y precisión al margen de su función rectora.

Para comenzar a estructurar las estrategias sería conveniente organizar un comité directivo -steering commitee- y dos grupos o "fuerzas de tarea". Esta estructura se ha denominado así a propósito en otros países para ésta y otras iniciativas de planeación e implica que dicha instancia se crea sólo para sentar las bases de organización de una estructura más permanente. La experiencia es que en este tipo de iniciativas no debe crearse una estructura organizativa muy grande con toda la parafernalia de organigrama, puestos, plazas, oficinas, edificios, etc. Si bien hay varias maneras de crear- 
la, una aproximación muy conveniente podría ser un cuerpo colegiado o comité directivo formado por un muy pequeño y selecto grupo de funcionarios de alto nivel y miembros destacados de la sociedad civil, ayudados por una mínima infraestructura o secretariado de tiempo completo. Si al inicio la comisión es muy grande y con carácter representativo de todos los sectores, corre el riesgo de perderse en sus objetivos, crear estructuras de poder y/o pertenencia o burocratizarse. Se crearán también dos grupos operativos, las mencionadas "fuerzas de tarea". De acuerdo con la experiencia, las seis funciones críticas de estos dos grupos serían:

- La definición de roles, responsabilidades y estructura de apoyo dentro del comité y dentro de ambos grupos de trabajo.

- El establecimiento de los grupos de trabajo intersecretariales e intersectoriales, cada uno con una misión específica de organización. Cada grupo deberá contar con expertos técnicos, políticos, etc., apropiados a su tarea y deberá establecer claramente sus metas, tiempos, programas, productos y agentes responsables.

- La búsqueda y asignación de personas clave a cargo de cada uno de los grupos de trabajo.

- La definición de estrategias de fondos económicos primarios y secundarios para el proyecto.

- El establecimiento de recomendaciones generales y adopción de las "mejores prácticas".

- La definición de mecanismos para la instrumentación coordinada, evaluación de avances y retroalimentación hacia ellos mismos y hacia el comité directivo.

Una vez que entran en funciones, coordinados siempre por el cuerpo colegiado directivo, estos dos grupos de trabajo deben emprender acciones estratégicas encaminadas al desarrollo del modelo. Del mapa conceptual de responsabilidades a nivel gobierno podemos obtener estas primeras acciones a desarrollar:

- Definición detallada y organización de los sectores que conformarán el modelo. 
- Evaluación del entorno nacional de bibliotecas y bibliotecas digitales; esto es:

1. Inventario de recursos, acervos y servicios documentales, digitales o no.

2. Inventario de legislaciones, políticas, programas, normalización, etcétera.

Estos mecanismos de arranque son absolutamente estratégicos, ya que su logro sustenta la base de acción del modelo y aporta la estructura y la información necesarias para desarrollar la parte operativa del mismo (figura 5.3 ).

Figura 5.3

ETAPA DE INICIO DEL MODELO




5.5 DESARROLLANDO EL MODELO: ACCIONES Y GRUPOS

5.5.1 Definición detallada y organización de los sectores que conformarán el modelo

Retomando nuestro diagrama básico de organización del modelo de bibliotecas digitales observamos que el sistema sectorial se encuentra conformado en primera instancia por los sectores gubernamentales -mitad izquierda-, y en segunda instancia por los sectores productivos junto con el académico-educativo - mitad derecha.

Como metodología para la primera mitad, la del sector gubernamental, una primera aproximación, no definitiva podría ser la propia dada por los poderes de la Unión en cuanto a sus secretarías y organismos; para el caso de México, a nivel federal, serían (Instituto de Investigaciones Jurídicas, UNAM, 2000):

- Secretaría de Gobernación (SEGOB), Centro Nacional de Prevención de Desastres (CENAPRED), Servicio Sismológico Nacional (SSN), Sistema Nacional de Protección Civil (SINAPROC).

- Secretaría de Hacienda y Crédito Público (SHCP), Comisión Nacional Bancaria y de Valores (CNBV).

- Secretaría de Relaciones Exteriores (SRE).

- Secretaría del Trabajo y Previsión Social (STPS).

- Secretaría de Salud (SSA), Instituto Mexicano del Seguro Social (IMSS), Instituto de Seguridad y Servicios Sociales de los Trabajadores del Estado (ISSSTE), Instituto Nacional de Salud Pública (INSP).

- Secretaría de Agricultura, Ganadería, Desarrollo Rural, Pesca y Alimentación (SAGARPA).

- Secretaría del Medio Ambiente y Recursos Naturales (SEMARNAT), Comisión Nacional del Agua (CNA), Servicio Meteorológico Nacional (SMN), Instituto Nacional de Ecología (INE).

- Secretaría de Economía (SE), Banco de México (BM), Instituto Nacional de Estadística, Geografía e Informática (INEGI). 
- Secretaría de Comunicaciones y Transportes (SCT), Instituto Mexicano del Transporte (IMT), Comisión Federal de Telecomunicaciones (COFETEL).

- Secretaría de Educación Pública (SEP), Consejo Nacional de Ciencia y Tecnología (CONACYT), Consejo Nacional para la Cultura y las Artes (CONACULTA), Instituto Nacional de Antropología e Historia (INAH).

- Secretaría de Desarrollo Social (SEDESOL), Desarrollo Integral de la Familia (DIF), Confederación Deportiva Mexicana (CODEME).

- Secretaría de Energía (SENER), Petróleos Mexicanos (PEMEX), Instituto Mexicano del Petróleo (IMP), Comisión Federal de Electricidad (CFE), Comisión Nacional Reguladora de Energía (CNE).

- Secretaría de la Función Pública (SEFUPU).

- Secretaría de la Reforma Agraria (SRA).

- Secretaría de Turismo (SECTUR).

- Secretaría de la Defensa Nacional (SEDENA).

- Secretaría de Marina Armada de México (SEMAR).

- Secretaría de Seguridad Pública (SSP).

- Congreso de la Unión, Cámara de Diputados y Cámara de Senadores.

- Suprema Corte de Justicia de la Nación, Tribunal Electoral, Tribunales Colegiados, Tribunales Unitarios de Circuito, juzgados de distrito, Consejo de la Judicatura Federal, Comisión Nacional de los Derechos Humanos.

Esta estructura respondería a una división lógica desde el punto de vista de la delegación de responsabilidades del gobierno mexicano en el nivel federal, pero está integrada por 20 sectores, 18 del poder ejecutivo, uno del poder legislativo y uno del poder judicial. Cuando tratemos de sincronizar esto con los sectores estatales o regionales correspondientes, correremos el riesgo de crear una estructura demasiado grande e inoperante. Además, es necesaria una integración coherente con los sectores privados de producción. Una división de esos sectores comúnmente utilizada por organismos de cálculo de indicadores económicos, tales como el Instituto Nacional de Estadística, Geografía e Informática (INEGI) es la siguiente: 
- Administración pública, servicios médicos, esparcimiento y defensa.

- Servicios financieros, seguros, bursátiles e inmobiliarias.

- Agropecuario, silvicultura, pesca, alimentos y agua.

- Minería.

- Industria manufacturera y maquiladora.

- Construcción.

- Comunicaciones y transporte.

- Servicios comerciales.

- Servicios comunales, sociales, asistenciales, profesionales y personales.

- Energía.

- Servicios turísticos.

Integrando los correspondientes al sector gubernamental que no se encuentren ahí, más los correspondientes a los sectores productivos -mitad derecha del diagrama- así como los correspondientes a los poderes legislativo y judicial, el conjunto de sectores propuesto podría quedar conformado por 12 de ellos de acuerdo con la siguiente lista. Detallaré las secretarías y organismos gubernamentales que se propone involucrar en cada sector, así como los sectores civiles correspondientes.

Los 12 sectores integrados que conforman el modelo son los siguientes:

- Administración pública, servicio exterior, defensa, seguridad y protección civil (SEGOB, SEFUPU, SRE, SEDENA, SEMAR, SSP), procuradurías: generales, del Consumidor, etc., CENAPRED, Servicio Sismológico Nacional (SSN), Sistema Nacional de Protección Civil (SINAPROC), poderes ejecutivos federal, estatales y municipales.

- Agropecuario, silvicultura, pesca, alimentos, desarrollo rural, medio ambiente, recursos naturales y agua (SAGARPA, SEMARNAT, SRA, CNA, SMN, INE, PROFEPA).

- Servicios médicos y sanitarios (SSA, IMSS, ISSSTE, INSP, sistemas de salud privados).

- Energía (SENER, PEMEX, IMP, CFE, CNE). 
- Servicios comunales, sociales, asistenciales, del trabajo, de esparcimiento, profesionales y personales (SEDESOL, DIF, STPS, SEMAR, CONADEPI), aduanas, INPI, sociedades de beneficiencia privadas, iglesias, CODEME, organizaciones deportivas y recreativas, notarías.

- Industria manufacturera, maquiladora, minera y de la construcción (SE, CANACINTRA y sus agremiados, constructoras).

- Establecimientos y servicios comerciales y turísticos (SECTUR, CONCANACO y sus agremiados, cámaras nacionales de la industria hotelera y restaurantera, industria cinematográfica, editorial, alimentaria, de espectáculos).

- Servicios tributarios, financieros, seguros, bursátiles e inmobiliarias (SHCP, SAT, SE, Banco de México, CNBV, BMV, sector bancario, aseguradoras).

- Sector académico-educativo y bibliotecario (SEP, CONACyT, CONACULTA, INAH, UNAM -en especial Biblioteca y Hemeroteca nacionales-, IPN, UAM, universidades y otras instituciones educativas estatales públicas, sistema educativo privado).

- Comunicaciones, transporte y servicios informativos (SCT, INEGI, IMT, COFETEL, SEMAR, transportistas terrestres, aéreos y marítimos, FFCC, diarios, empresas de radio y televisión, de telefonía y telecomunicaciones).

- Poder legislativo: Congreso de la Unión, congresos estatales, cámaras legislativas, tanto federales como estatales.

- Poder judicial: Suprema Corte de Justicia de la Nación, tribunales electorales colegiados, unitarios de circuito, juzgados de distrito y Consejo de la Judicatura Federal, Comisión Nacional de los Derechos Humanos y sus correspondientes estatales.

Como puede observarse, esta propuesta de agrupamiento sectorial cubre (o al menos eso pretende), a todos los sectores gubernamentales de los tres poderes, así como a los sectores productivos más representativos de la sociedad civil y, por supuesto, al muy importante sector académico-educativo y bibliotecario. Cumple pues con la premisa del diagrama básico con sólo 12 sectores. Por supuesto, ésta es sólo una de las posibles divisiones, y es totalmen- 
te arbitraria; puede ser subdividida o integrada de muchas otras formas, pero ilustra sin duda el concepto de integración coherente de prácticamente todos los sectores públicos y privados del país involucrados con recursos y necesidades de información para la educación, el trabajo, el desarrollo y el esparcimiento, en un número razonable de sectores.

Una vez definidos los sectores, así como los organismos que formarán parte de cada uno de ellos, ya sea que se utilice esta división o cualquier otra seleccionada, será necesario organizarlos. Pero primero analizaremos la tarea del segundo grupo de trabajo, el encargado del inventario de recursos.

Nuevamente, el segundo grupo de trabajo, el encargado del inventario formado de manera semejante que el primero, intersecretarial e intersectorial, debe repetir el proceso de conformación de las "seis acciones básicas" para llevar a cabo su cometido.

5.5.2 Evaluación del entorno nacional de bibliotecas tradicionales y digitales

La tarea de este segundo grupo de trabajo, una vez establecido como fuerza de tarea y con sus seis acciones básicas consiste en evaluar el entorno nacional de bibliotecas digitales o no, llegando a una exhaustividad y nivel de detalle mucho mayores de los que existen actualmente en las cifras del INEGI y que son demasiado escuetas y desactualizadas. En este estudio es sumamente importante, a diferencia de la situación actual, incluir tanto instituciones públicas como privadas e integrar una serie de colecciones documentales de diversa índole; todas aquellas que tengan valor bibliográfico, tales como colecciones musicales, cinematográficas, videográficas, etc. Esta tarea se divide en dos partes principales:

1. Realizar el inventario de recursos, acervos y servicios documentales, digitales y no.

2. Realizar el inventario de legislaciones, políticas, programas, normalización, etcétera. 
Inventario de recursos.

A) Bibliotecas, archivos documentales, centros de información y documentación.

- Serie actualizada anual de número de bibliotecas en el país, con cortes por estado, municipio, tipo, nivel, superficie, capacidad, etcétera.

- Serie actualizada anual de número de archivos documentales con valor bibliográfico en el país, con cortes por estado, municipio, tipo, nivel, etcétera.

- Serie actualizada anual de número de documentos en el país, con cortes por colecciones, tipo, estado, nivel, edad de colecciones, etc., totales, por estado, por municipio, por nivel, etcétera.

- Serie actualizada anual de usuarios y préstamos, con cortes por tipo de usuario, nivel, edad, tipo de servicio, etc., por sector, estado, municipio.

- Tasas anualizadas de crecimiento de bibliotecas, colecciones y usuarios, con cortes por tipo, nivel, estado, municipio, sector, etcétera.

- Serie actualizada anual de inversión en bibliotecas y desarrollo de colecciones, con cortes por nivel, tipo, sector, fuente de financiamiento, por habitantes, etcétera.

B) Personal bibliotecario.

- Serie anualizada del personal dedicado al servicio de bibliotecas, archivos, etc., con cortes por tipo, nivel, escolaridad; por tipo y nivel de biblioteca, actividad, por estado, municipio, sector, etcétera.

- Personal profesional bibliotecario existente por estado, municipio, actividad, sector, etcétera.

- Inversión anualizada por rubros para este personal, por estado, municipio, sector, etcétera.

- Escuelas de bibliotecología, carreras y posgrados, programas 
de capacitación, personas involucradas por estado, municipio, etcétera.

C) Servicios bibliotecarios y de información.

- Serie anualizada de tipo de servicios, número de ellos, público atendido, inversión por sector, valor comercial de los servicios, etc., por estado y municipio.

D) Recursos tecnológicos.

- Inventario de servidores, computadoras, estaciones de trabajo, impresoras, escáneres, etc., dedicados al servicio documental.

- Inventario de programas para bibliotecas, licencias, etcétera.

- Inventario de red e infraestructura de telecomunicaciones para bibliotecas por nivel, tipo, estado, municipio, sector, antigüedad del equipo, etcétera.

Todo este inventario debe realizarse por partida doble, considerando por un lado las bibliotecas con materiales en soportes tradicionales y por otro, obviamente, lo ya realizado en soportes digitales.

Inventario de legislaciones, políticas y programas.

- Legislaciones federal, estatales, municipales, sectoriales acerca de:

- Bibliotecas y centros de información y documentación.

- Archivos documentales.

- Protección a patrimonio cultural documental.

- Protección a propiedad intelectual.

- Capacitación e inversión en bibliotecas.

- Sus equivalentes en cuanto a programas, planes, políticas, normatividades, etcétera.

- Inventario de estándares, políticas, normas, acerca de sistemas de registro y normalización de información documental, por sectores, tipo, bibliotecas, etcétera. 
La compilación detallada en lo posible de esta información y su difusión y actualización adecuada serán un factor indispensable para el acierto en la toma de decisiones por todos los planeadores y operadores del proyecto. Una vez que este segundo grupo ha terminado su tarea y publicado sus resultados, puede concluir sus actividades no sin antes establecer los mecanismos y los agentes responsables que aseguren la actualización y difusión anual del inventario.

Como resultado, estos dos grupos de trabajo deben aportar, por un lado, la estructura de organización de los 12 sectores y por el otro la información básica que esta estructura necesita para la planeación.

\subsection{CONSOLIDANDO EL MODELO}

El "comité directivo de arranque" estaría listo para transformarse en el "comité directivo de los doce sectores", reconformándose e integrando personas clave provenientes de esos 12 sectores. Nuevamente debe respetarse la premisa de un "comité directivo" formado por un muy pequeño y selecto grupo de funcionarios de alto nivel así como miembros de los distintos sectores y de la sociedad civil, con el apoyo de una mínima infraestructura o secretariado de tiempo completo.

Los países en desarrollo necesitan inversiones y capital, infraestructura, tecnología, expertos y equipos. Y necesitan todo eso simultáneamente; de lo contrario, cualquier proyecto estará destinado al fracaso. Se pueden emprender proyectos locales, impulsados por gobiernos, organizaciones no gubernamentales (ONG), empresarios, pero su alcance será siempre demasiado limitado si no es concurrente. Por tanto, una vez que se han logrado las acciones estratégicas de arranque y partiendo de las iniciativas nacionales e internacionales acerca de sociedad de la información y bibliotecas digitales, he extraído y propongo las que considero las "ocho líneas de acción” operativas más relevantes para el adecuado desarrollo del proyecto: 
- Creación, desarrollo y no redundancia de colecciones y servicios documentales digitales nacionales, en particular:

- Textos y material digital básico para cada nivel educativo.

- Servicios de información documental para el gran público.

- Estrategias de adquisición y desarrollo de materiales originalmente digitales, así como estrategias de digitalización de materiales.

- Normalización y estandarización de registros digitales desde el punto de vista bibliográfico.

- Revisión y actualización de la legislación acerca del acceso a la información, derechos de propiedad electrónica y privacidad, así como de otros entornos legales relevantes para el proyecto.

- Desarrollo de especialistas y personal calificado en tecnologías y servicios de información y modelos educativos.

- Promoción del uso efectivo de la información; acceso gratuito o económico.

- Desarrollo de infraestructura de cómputo y telecomunicaciones, así como en innovaciones tecnológicas que impulsen el proyecto.

- Impulso a la inversión privada en tecnologías de información y comunicaciones.

- Integración del proyecto a la identidad, valores y cultura nacionales.

En este punto, es conveniente recapitular qué es lo que ya tenemos antes de entrar de lleno a la fase operativa del modelo:

- Un comité directivo adecuado, con personas clave provenientes de los sectores público y privado, y con funciones preestablecidas para coordinar esa fase operativa con el apoyo de una mínima infraestructura secretarial de tiempo completo.

- Una organización claramente definida de 12 sectores básicos del país, con personas clave que pueden incidir sobre múltiples instituciones.

- Un estudio estadístico muy completo de los recursos y potencial documental, humano, legal, normativo, tecnológico, etc., 
acerca de las bibliotecas e instituciones semejantes de todos los sectores públicos y privados.

- Ocho líneas de acción claramente establecidas en las que cada sector deberá trabajar.

Con estos cuatro elementos logrados: el comité, los 12 sectores organizados, el estudio estadístico y las ocho líneas de acción operativas definidas, estamos en posibilidad de establecer la estrategia central del modelo: "Los 12 sectores trabajarán y desarrollarán las ocho líneas de acción operativas para definir cuál es la incidencia, recursos, necesidades, oportunidades, retos, debilidades, etc., de cada uno al respecto".

Esto significa que cada uno de los sectores analizará y desarrollará todos los enfoques que el comité haya establecido en cada una de las ocho líneas de acción, entregando una propuesta de acción específica para cada sector y línea. Al final deberíamos contar con una matriz de $12 \times 8=96$ análisis-propuestas. Será responsabilidad del comité directivo sentar las bases y reglas de operación para que todas sean homogéneas en alcance, forma y contenido.

Por supuesto, el grado de incidencia de cada sector en cada línea de acción no es homogéneo; en algunas líneas de acción habrá mayor o menor incidencia. No obstante es muy importante establecer el grado de incidencia y de responsabilidad de cada sector en cada caso, por mínimo que sea. Así, la matriz conceptual de esta estructura con cierto grado de incidencia esperada se vería de la siguiente forma: 


\section{El modelo de planeación de bibliotecas digitales para México}

\section{MATRIZ CONCEPTUAL DEL GRADO DE INCIDENCIA DE LOS 12 SECTORES CON LAS OCHO LÍNEAS \\ DE ACCIÓN DEL PROYECTO NACIONAL DE BIBLIOTECAS DIGITALES}

\begin{tabular}{|c|c|c|c|c|c|c|c|c|}
\hline & $\begin{array}{c}\text { Creación de } \\
\text { colecciones } \\
\text { y servicios } \\
\text { digitales }\end{array}$ & $\begin{array}{l}\text { Normalización } \\
\text { de registros } \\
\text { documentales }\end{array}$ & $\begin{array}{l}\text { Legislación } \\
\text { acerca de } \\
\text { acceso y } \\
\text { propiedad }\end{array}$ & $\begin{array}{c}\text { Desarrollo } \\
\text { de personal } \\
\text { en Bibl. } \\
\text { Dig., TIC y } \\
\text { modelos } \\
\text { educativos }\end{array}$ & $\begin{array}{c}\text { Promoción } \\
\text { de acceso } \\
\text { y uso } \\
\text { efectivo de } \\
\text { información }\end{array}$ & $\begin{array}{c}\text { Desarrollo } \\
\text { de } \\
\text { infraestructura } \\
e \\
\text { innovaciones } \\
\text { de TIC }\end{array}$ & $\begin{array}{l}\text { Impulso } \\
\text { a la } \\
\text { inversión } \\
\text { privada } \\
\text { en TIC }\end{array}$ & $\begin{array}{c}\text { Integración } \\
\text { a identidad } \\
\text { y cultura } \\
\text { nacionales }\end{array}$ \\
\hline $\begin{array}{l}\text { Admón. pública, exterior, } \\
\text { seguridad, ejecutivo }\end{array}$ & alto & básico & medio & alto & medio & alto & alto & alto \\
\hline $\begin{array}{l}\text { Agropecuario, pesca, } \\
\text { alimentos, agua, naturales }\end{array}$ & alto & básico & básico & básico & medio & básico & básico & medio \\
\hline Médico sanitario & medio & básico & alto & básico & alto & alto & medio & básico \\
\hline Energía & medio & básico & básico & básico & básico & medio & alto & básico \\
\hline $\begin{array}{l}\text { Servicios comunales, } \\
\text { sociales, trabajo, deporte }\end{array}$ & medio & básico & básico & medio & alto & básico & básico & alto \\
\hline $\begin{array}{l}\text { Industria manufacturera, } \\
\text { maquila, construcción }\end{array}$ & alto & básico & básico & básico & básico & medio & alto & básico \\
\hline $\begin{array}{l}\text { Servicios comerciales, } \\
\text { turísticos, cine, editores }\end{array}$ & alto & medio & alto & básico & medio & alto & alto & medio \\
\hline $\begin{array}{l}\text { Servicios tributarios, } \\
\text { financieros, seguros, bolsa }\end{array}$ & medio & básico & medio & básico & medio & medio & alto & básico \\
\hline $\begin{array}{l}\text { Sector académico } \\
\text { educativo bibliotecario }\end{array}$ & alto & alto & alto & alto & alto & alto & básico & alto \\
\hline $\begin{array}{l}\text { Comunicaciones transportes, } \\
\text { servicios informativos }\end{array}$ & alto & medio & medio & medio & alto & alto & alto & alto \\
\hline Poder legislativo & medio & básico & alto & medio & medio & medio & básico & medio \\
\hline Poder judicial & medio & básico & medio & básico & básico & básico & básico & básico \\
\hline
\end{tabular}


Para este cometido, cada uno de los 12 sectores se convierte a su vez en un grupo de trabajo y debe organizarse internamente bajo la guía y dirección del comité directivo. Sería útil que cada sector aplicara las seis funciones básicas mencionadas para los primeros dos grupos que se encargaron de las acciones de infraestructura:

- Búsqueda y asignación de personas clave a cargo de cada uno de los subsectores, así como la definición de representantes, roles, responsabilidades y estructura de apoyo dentro de cada sector.

- Establecimiento de grupos de trabajo intersectoriales, cada uno con una misión específica de organización. Cada grupo deberá contar con los expertos técnicos y políticos apropiados y deberá definir claramente sus metas, tiempos, programas, productos y responsables.

- Definición de estrategias de fondeos para el proyecto dentro del sector.

- Establecimiento de recomendaciones generales para las necesidades de información típicas de ese sector.

- Definición de mecanismos para la planeación, instrumentación coordinada, evaluación de avances y retroalimentación del sector.

- Establecimientos de mecanismos de interacción con grupos de trabajo en los niveles superiores e inferiores y en cada uno de los estados.

Como hemos mencionado, el comité directivo debe establecer claramente las características y expectativas de cada una de las líneas de acción; para ello será conveniente que presente un conjunto de "condiciones estratégicas de inicio" deseadas, a partir de las cuales debe ser elaborada la propuesta de cada sector. Por ello, es conveniente detallar más en qué debería consistir cada una de esas ocho líneas de acción establecidas y una propuesta de "condiciones estratégicas de inicio” tentativas para cada línea de acción. 
5.7 DeTAlle DE LAS OCHO LÍNEAS DE ACCIÓN

5.7.1 Creación, desarrollo y no redundancia de colecciones y servicios documentales digitales nacionales

Los programas nacionales y regionales de contenidos o eContent, como son denominados generalmente a nivel mundial, se centran en que las empresas y los ciudadanos puedan acceder a múltiples contenidos digitales de alta calidad, ajustados a sus necesidades y hacer uso de ellos. Estos programas por lo general han tenido dos grandes vertientes: por un lado tienen que ver con el desarrollo de contenidos para un concepto general y de amplio alcance de la sociedad de la información; por lo mismo estos programas tienen objetivos muy amplios y contemplan variados intereses de la sociedad en general e incluyen planes para fomentar múltiples ámbitos de acción de esa sociedad, tales como desarrollo de contenidos de información amplios y variados: datos jurídicos, administrativos, financieros y económicos; datos del catastro y la propiedad, datos geográficos, estadísticos, meteorológicos, oceanográficos y otros sobre medio ambiente; material informativo de entretenimiento o servicios comerciales; datos relativos a la salud, la seguridad y la protección del consumidor; información sobre turismo, tráfico, clima; información sobre normas y patentes; información sobre servicios y trámites a nivel local, entre muchos otros. Como puede verse, existe una gran variedad de contenido que puede desarrollarse para una sociedad de la información al margen de los contenidos típicos para educación y bibliotecas que, por supuesto, están incluidos.

Por otro lado existen planes tendientes a posicionar o impulsar al sector productivo de contenidos informáticos de una región o país dentro del mercado mundial. Estos planes obviamente están ligados a objetivos económicos y predominantemente comerciales de impulso a un sector de bienes y servicios específicos de un país, en un intento de desarrollar una "industria de la información" como elemento de la economía de un país o región dados.

No es objeto de este trabajo presentar un plan de desarrollo de contenidos para todos los campos de la sociedad de la información 
mexicana, el cual por cierto no existe a la fecha; en todo caso, eso correspondería al proyecto nacional de sociedad de la información e-México. Nuestro objetivo es presentar un plan para las bibliotecas digitales y su entorno de acción, la educación y la capacitación, en el entendido de que debería estar sustentado e inscrito en ese plan nacional más general. No obstante, la parte toral de contenidos es la relacionada a bibliotecas y centros de información, y muchos de los principios y estrategias de los planes más generales son extrapolables a este ámbito más particular y en ellos nos basamos para desarrollar este apartado.

Éste es uno de los aspectos en que la función rectora del gobierno es estratégica. No es responsabilidad básica del gobierno crear y desarrollar por sí mismo los contenidos educativos para toda la educación del país, pero sí que sea un gestor y organizador de la tarea y abone el terreno en ese sentido.

De acuerdo con la dinámica establecida en el apartado anterior respecto a los grupos de trabajo, el gobierno debe introducir "objetivos estratégicos de inicio”. He aquí una propuesta tentativa:

- Creación de grandes repositorios nacionales de información digital a través de dos grandes vertientes:

- La adquisición y desarrollo de materiales originalmente digitales.

- La digitalización de materiales ya existentes en soportes tradicionales. Esto deberá contar con una política perfectamente establecida de cuáles materiales deben priorizarse en la digitalización.

- Estrategia de desarrollo de materiales de texto digital básicos para los niveles de enseñanza básica, media y media superior.

- Estrategia de desarrollo de la información para la enseñanza superior y la investigación científica.

- Estrategia para el impulso de la información para el desarrollo tecnológico, comercial, industrial, etcétera, de los sectores productivos.

- Estrategia de servicios de información documental para el gran público. 
- Estrategia de recomendación de estándares para formatos de datos: ya sea texto, imagen fija, imagen en movimiento, sonido, etcétera.

Partiendo de estos puntos, cada sector debe hacer una propuesta para cada línea de acción. Uniendo las 12 propuestas que resulten de los 12 sectores podríamos establecer la línea de acción final, la cual debe reflejarse en planes de acción específicos para el desarrollo de esa línea de acción. En este caso, integrando y considerando todas las necesidades, propuestas y características que los 12 sectores hayan presentado en su grupo de trabajo respecto a esta primera línea de acción relativa a la creación y desarrollo de contenidos digitales, a partir de las "condiciones estratégicas de inicio", la matriz conceptual de incidencia nos dirá de cuáles sectores se esperan propuestas más incidentes hacia el plan.

Este plan deberá tener en cuenta importantes aspectos contemplados en proyectos de este tipo tales como:

1. Amplia variedad de los contenidos a ser desarrollados: libros y revistas electrónicos, metadatos, índices y resúmenes; datos estadísticos, imágenes fijas y en movimiento; sonido, catálogos, datos geoespaciales, bibliografías, sitios web, tutoriales, realidad virtual, etcétera.

2. Los cinco criterios fundamentales de la accesibilidad:

Estándares abiertos de metadatos y de interoperabilidad: es decir, considerar el intercambio de datos, búsqueda de información entre sistemas, así como la información misma; la interfaz con los usuarios y plataformas de cómputo.

Preservabilidad: usar estándares que garanticen larga vida de los documentos, a pesar de cambios tecnológicos, con objeto de crear colecciones no perecederas.

Sostenibilidad: coordinar que las organizaciones tengan la infraestructura y recursos para mantener la creación de sus colecciones y servicios.

Usabilidad: que los sistemas e interfaces sean amigables; que exista un buen soporte a usuarios, que los materiales sirvan 
Un modelo de planeación de bibliotecas digitales para México

para enseñar y aprender, que tengan elementos de valor agregado sobre materiales tradicionales.

Modularidad: que un buen número de materiales sean unidades de dimensiones adecuadas como para ser reutilizados por otros textos; es decir, usar ampliamente el concepto de "objetos de aprendizaje".

5.7.2 Normalización y estandarización de registros digitales desde el punto de vista bibliográfico

Hemos tratado ya la importancia equivalente tanto de la creación y desarrollo de colecciones digitales como del desarrollo de mecanismos que permitan su recuperación y distribución. De poco sirve crear copiosos conjuntos de información si ésta no puede ser localizada cuando se requiere o si se deben invertir enormes cantidades de tiempo en decantar información no relevante para nuestra actividad. La información para el estudio, la investigación, el trabajo o la capacitación debe estar a unos cuantos golpes de tecla cuando se requiera. Debe ser veraz, oportuna, pertinente y suficiente. De hecho, ésa es la diferencia esencial entre una colección y una masa amorfa de información. En algún lugar leí la que se afirmaba era la más simple definición de biblioteca y que sin embargo conservaba su esencia: "Biblioteca es una colección documental con un sistema de recuperación sirviendo a cierta comunidad de usuarios”. El que la hizo era un genio. Yo la llamo el Miró de las definiciones de biblioteca: en tres pinceladas la describe sin perder su esencia. Por supuesto, faltan elementos formales de una biblioteca: en realidad es un conjunto de colecciones, sirve para preservar y distribuir la información; cuenta con personal y recursos especializados, brinda un conjunto de servicios especializados, etc. Conocemos las características de una biblioteca "formal" y son la organización, la recuperabilidad, la autenticidad y la invariabilidad. Detalles todos que la describen de una manera más completa. Pero lo valioso de esta definición es que rescata su esencia con tres detalles irreductibles: la colección, los sistemas de recuperación y los usuarios. Sin esos tres elementos mínimos, no puede existir la biblio- 
teca. Para todos pueden sonar lógicos los elementos de colección y usuarios, pero muchas veces no se pondera en todo su valor la importancia de los sistemas de recuperación, siendo elementos indispensables para la existencia de una biblioteca. Las bibliotecas digitales no son la excepción.

En la actualidad, existen distintas tendencias y herramientas en lo tocante a los mecanismos de recuperación de la información documental, en especial los relativos a la información digital. Como puede suponerse, en el nivel mundial estamos en una etapa de transición del registro documental tratando de adaptarnos al nuevo auge de las publicaciones electrónicas a través de la red. A propósito evito calificar a alguna de ellas como la mejor o única, pues mi conclusión es que no existe, a la fecha, ninguna "bala de plata" que permita realizar el registro de manera definitiva para todos los materiales cumpliendo con todos los requerimientos de todas las bibliotecas para todos sus usuarios. Como en muchas otras actividades del quehacer humano, lo mejor será usar cada herramienta para sus mejores capacidades de acuerdo con cada necesidad específica. Lo que debe quedar claro es que resulta absolutamente necesario establecer los mecanismos de recuperación adecuados para que las colecciones digitales lleguen a los usuarios de manera eficiente.

Dado que en el punto anterior hemos establecido un plan para desarrollar colecciones digitales para nuestras bibliotecas a nivel nacional, es evidente que requerimos también de un plan para crear un sistema nacional de registro de esos materiales. Como ya hemos mencionado, no se trata simplemente de recomendar tal o cual herramienta como única solución nacional, sino de establecer un mecanismo coordinado de creación armónica de esos mecanismos de recuperación. Como hemos mencionado la función rectora del gobierno es estratégica, pero tampoco es su total responsabilidad crear y desarrollar por sí mismo los mecanismos de recuperación de información para el país, sin embargo, como ya lo dijimos sí debe ser un gestor y un organizador de la tarea.

Nuevamente de acuerdo con la dinámica establecida en el apartado anterior respecto a los grupos de trabajo, el gobierno debe 
introducir "condiciones estratégicas de inicio". He aquí una propuesta tentativa, con algunas premisas incluidas:

- Toda colección digital debe ser desarrollada siempre contemplando un serio mecanismo de registro y acceso.

- Cada tipo de material debe tener sus herramientas típicas de recuperación recomendables, libros, video, textos escolares, etcétera.

- Todo material nuevo digital que se cree debería ya traer sus metadatos de origen.

- Crear estrategias para reconvertir todos los catálogos, bibliografías, índices, etc., existentes en formatos manuales en el nivel nacional, a formato digital.

- Crear estrategias de interoperabilidad de los registros digitales creados; es decir, que puedan ser fácilmente intercambiables entre sistemas.

- Crear estrategias para desarrollar sistemas de "minería de datos" que permitan hacer búsquedas a lo largo de múltiples catálogos disímbolos.

Si se observa la matriz de incidencia se percibe que en este rubro el sector que llevaría prácticamente todo el peso es el académico-educativo-bibliotecario, con apoyo de los sectores editorial y de información. En efecto, los más indicados para decidir cuáles mecanismos de recuperación usar para qué materiales, son estos sectores. Lo que hace falta aquí en esencia es organización y método. El gobierno debe usar su poder de convocatoria y de organización de todos los sectores educativos públicos y privados, a nivel federal y estatal, utilizando el talento académico y bibliotecario del país para coordinar el plan detallado. Recuerdo que hubo una época en la que el CONACyT impulsaba la ciencia y la tecnología de la información y documentación con proyectos nacionales de amplio espectro multinstitucionales y multisectores que obtuvieron cierto éxito en sus objetivos y que sin duda marcaron un hito en la manera de organizar dicho sector, por lo general muy disgregado. Hace muchos años que ni el CONACyT ni ninguna otra organización 
gubernamental lanza un proyecto de coordinación con alcance nacional multisectorial relacionado con sistemas y/o acervos documentales. Ésta sería sin duda una buena oportunidad.

5.7.3 Revisión y actualización de la legislación acerca del acceso a la información, derechos de propiedad electrónica y privacidad

Como hemos ya revisado, los aspectos legales también son de vital importancia para un adecuado desarrollo de los proyectos tendientes a apoyar las bibliotecas digitales.

En términos generales, tres son las grandes vertientes en que el poder legislativo, tanto el de la federación como los de los estados, puede hacer la diferencia:

a) Acceso a la información.

b) Privacidad.

c) Derechos de propiedad electrónica.

Las dos primeras tienen que ver en mayor medida con el proyecto mexicano de "sociedad de la información" en términos generales y la tercera, además de poseer esta característica, es de capital importancia para el proyecto de bibliotecas digitales.

En efecto, es necesario crear una legislación que propicie y norme el "derecho al acceso a la información" que todos los mexicanos debemos tener. Esto debe entenderse en el contexto ya explicado, como uno de nuestros derechos humanos en esta nueva sociedad informatizada, para consolidarse como un mecanismo de justicia social. Es el derecho nato que los mexicanos tenemos como ciudadanos de este país y del mundo y que debe estar consagrado en las leyes para poder acceder a información para nuestra educación, cultura y bienestar. No debe confundirse con la legislación reciente en nuestro país acerca del "derecho a la información" que fue creada con el interés de hacer pública y transparente la información del ejercicio gubernamental. Si bien ésta fue una iniciativa loable y necesaria en nuestro país, es tan sólo una mínima parte de 
la información a la que debemos tener derecho todos los mexicanos. Ahora hace falta legislar acerca del "derecho al acceso a la información" en ese otro aspecto, más general, contemplando el derecho que deben tener los mexicanos de acceder a múltiples clases de información que les permitan elevar su nivel de educación, capacitación y que incidan directamente sobre su bienestar y su nivel de vida. Esta legislación sentará las bases sobre las cuales debe construirse nuestra "sociedad de la información" mexicana y por supuesto, como parte importante de ella, las bibliotecas digitales mexicanas.

La segunda vertiente es la del derecho a la privacidad. Como se ha mencionado ya, uno de los aspectos importantes en esta sociedad informatizada es la de crear confianza en las herramientas tecnológicas. Parte importante de ello es legislar acerca de la privacidad de la información. Esto no es un tema trivial; ha sido y es un elemento de profundo debate en otras sociedades más avanzadas; no se trata sólo de definir si mi nombre, dirección y teléfono deban o no ser proporcionados a terceros, sino de algo mucho más profundo, conforme múltiples datos de cada persona se acumulan en sistemas nacionales e internacionales. Nótese el grave problema que el fenómeno llamado spam o distribución masiva de mensajes de correo electrónico está causando ya a nivel mundial. ¿Quién tiene derecho a mandar qué a quién? Éste es un problema de privacidad: la de quien puede desear o no recibir estos mensajes y la de quien tiene derecho a hacer envíos por la internet sin necesidad de ser controlado puntualmente. Las dos situaciones se contraponen y es necesario, como en muchos otros aspectos, balancear los derechos. ¿Quién tiene derecho a usar la información financiera de una persona, o su historial y propensiones médicas, o información acerca de sus preferencias políticas, religiosas o sexuales? Sin duda hay un derecho a la información hoy en día, pero es necesario balancearlo con el natural derecho a la privacidad de las personas. Nuestro país no ha iniciado muchos debates o estudios en ese sentido, siendo vital legislar para una adecuada construcción de la sociedad de la información mexicana. 
La tercera y no menos importante vertiente es aquella que, además de ser necesaria para la construcción de la sociedad de la información mexicana, es de vital importancia para el desarrollo del proyecto de bibliotecas digitales: los derechos de propiedad en el entorno digital. Como hemos ya tratado exhaustivamente en el capítulo 5, "Bibliotecas y publicaciones digitales", es un problema de delicado balance entre distintos derechos que se contraponen, y que debe ser reestructurado de una forma vanguardista visionaria y no sólo respondiendo a las exigencias del momento de acuerdo con los tratados internacionales de moda o los intereses de tal o cual sector. Es necesario crear en este sentido una legislación de largo aliento que propicie tanto el desarrollo de legítimas ganacias de los editores como el legítimo derecho del acceso a la información por parte de usuarios y bibliotecas. No es tan simple como extender o reducir tales o cuales derechos de algún sector como se va a lograr esto. Tiene que ser una visión de la sociedad en su conjunto, en la que los cuerpos legislativos sean asesorados por diversos grupos sociales con el objeto de ver las necesidades y características de cada uno de ellos buscando siempre ese equilibrio donde se encuentran la equidad, la justicia y donde haya ganancia para todos; de otra forma saldrán entuertos como el de la modificación de la ley autoral mexicana de 2003 que va en detrimento de la ley de 1996, la cual, sin ser perfecta, no era mala para su época, y sin duda era mejor que la ahora ya modificada. El peligro es ir hacia atrás en vez de hacia adelante, todo por legislar con visiones parciales sectoriales. No hay que olvidar que la Ley Federal del Derecho de Autor es al fin y al cabo una ley reglamentaria del artículo 28 constitucional, y “...tiene por objeto la salvaguarda y promoción del acervo cultural de la nación; protección de los derechos de los autores...". Hago énfasis nuevamente: debe salvaguardar y promover el acervo cultural de la nación, así como proteger los derechos de los autores; nunca dice que debe hacerse una cosa en detrimento de la otra, ni que es más importante lo uno que lo otro. Ambos objetivos deben estar siempre balanceados.

Por lo mismo, en este aspecto también es estratégica la función rectora del gobierno en particular la del poder legislativo. Como 
sucede con muchas otras leyes y disposiciones normativas, son el marco propicio para que ciertas condiciones de la sociedad fluyan en armonía y balance y logren su cometido.

Así como con la dinámica establecida en el apartado anterior respecto a los grupos de trabajo, el sector legislativo debe introducir "condiciones estratégicas de inicio". He aquí una propuesta:

- Declaración de principios del "derecho a la información de la sociedad mexicana”, más allá de las cuestiones de transparencia. A este efecto he presentado tentativamente el marco contextual del modelo en el apartado 5.3, el cual está alineado con la última declaración de la "sociedad del conocimiento" de la UNESCO, la Declaración de Libertad Intelectual de la IFLA y las cinco prioridades de e-Europe como marcos de referencia internacionales, así como el proyecto e-México y el Programa Nacional de Educación 2001-2006, como marcos de referencia en el ámbito nacional.

- Establecer las propuestas estratégicas que se consideren pertinentes para los aspectos de seguridad y privacidad de la red, lo cual no es objeto directo de este trabajo.

- La adopción a nivel de ley o al menos de recomendación por parte del poder legislativo, de las reglas del "uso ético" (fair use).

- Establecer una estrategia para contemplar adecuados mecanismos de propiedad industrial, primera copia, la remuneración por copia privada, etc., que son inherentes a las publicaciones digitales y que no pueden ser simplemente extensiones de las disposiciones legales de los otros medios de edición. Estos aspectos de legislación o al menos conceptualización específica para los materiales electrónicos que así lo ameriten deben estar claramente contemplados en la legislación y normatividad, sin ninguna ambigüedad.

- Estrategias para el desarrollo de una nueva ley autoral o al menos una reforma profunda que nuevamente equilibre los dos grandes objetivos establecidos en la ley: "la salvaguarda y promoción del acervo cultural de la nación; protección de los de- 
rechos de los autores" que a su vez emanan de los principios establecidos en el artículo 28 de la Constitución Mexicana:

[...] la ley castigará severamente y las autoridades perseguirán con eficacia, toda concentración o acaparamiento en una o pocas manos de artículos de consumo necesario y que tenga por objeto obtener el alza de los precios; todo acuerdo, procedimiento o combinación de los productores, industriales, comerciantes o empresarios de servicios, que de cualquier manera hagan, para evitar la libre concurrencia o la competencia entre sí y obligar a los consumidores a pagar precios exagerados y, en general, todo lo que constituya una ventaja exclusiva indebida a favor de una $o$ varias personas determinadas y con perjuicio del público en general o de alguna clase social [...] tampoco constituyen monopolios los privilegios que por determinado tiempo se concedan a los autores y artistas para la producción de sus obras [...]

El éxito para medir esta nueva legislación o al menos una reforma a la existente será el grado en que pueda equilibrar los dos objetivos que existen en la ley actual, así como los dos principios de nuestra carta magna que como puede observarse, se contraponen unos a los otros.

Al observar nuevamente nuestra matriz de incidencia se percibe que en este rubro el sector que lleva prácticamente todo el peso es el legislativo, y como en muchos otros quehaceres de ese sector, es imprescindible y por ello recomendable que en este caso recoja las necesidades y puntos de vista que todos y cada uno de los otros once sectores tengan que hacerle, para lograr en efecto un plan legislativo que contemple a todos los sectores de la sociedad pertinentes al proyecto, buscando ese equilibrio y esa situación de "todos-ganan" enunciada desde el apartado de derechos de propiedad. 
5.7.4 Desarrollo de especialistas y personal calificado en modelos educativos, tecnologías y servicios de información

Para el adecuado desarrollo del proyecto y con el fin de que pueda ser sostenido por un lapso razonable para su posterior consolidación, se necesitan recursos humanos calificados. La pregunta obligada entonces es ¿tenemos los recursos humanos adecuados y suficientes para tal proyecto? Si no es el caso ¿cómo deberemos formarlos? De acuerdo con lo establecido en capítulos anteriores, distinguimos tres tipos de especialistas necesarios:

1. Especialistas en modelos educativos.

2. Especialistas en tecnologías de información.

3. Especialistas en servicios documentales y de información.

La acción primordial en este punto debe centrarse en la elaboración de un censo o inventario de este tipo de recursos a nivel de país y con base en ello elaborar un plan específico que genere la formación y/o capacitación. Respecto a este tipo de especialistas, me atrevo a vaticinar los siguientes resultados generales del censo.

En cuanto a los especialistas en modelos educativos, supongo que, independientemente del número obtenido, el resultado será que desearíamos tener más y al nivel adecuado que se requiere, pero que existe un número suficiente y capacitado para ser una "masa crítica" que genere la idea central alrededor de esos modelos educativos y elabore un plan de formación de recursos humanos en diversos niveles.

Respecto a los especialistas en tecnologías de información, supongo que el resultado será que existe abundancia relativa de estos recursos, ya que en las últimas dos décadas estas carreras se han posicionado fuertemente en el currículum de gran cantidad de escuelas y por ello no debe ser escaso su número. No me atrevería a calificar la calidad obtenida de esos recursos pero estoy seguro de que igualmente podría encontrarse un buen número de personal profesional y técnico altamente calificado que diseñe fácilmente programas de educación continua relativos al proyecto. De todos mo- 
dos será necesario dar capacitación en la temática alineada al modelo de bibliotecas, ya que poco personal especializado en tecnologías de información conoce de bibliotecas y menos de bibliotecas digitales.

Respecto al personal especializado en servicios documentales y de información, el panorama esperado es distinto. En esencia, éste es el personal profesional bibliotecario y de archivos. En este aspecto, el país tiene un serio déficit. Las escuelas de bibliotecología, como es sabido en el medio, son escasas y sus poblaciones pequeñas. Sólo entregan unos pocos cientos de egresados cada año. Ello es suficiente a duras penas para ir atendiendo las necesidades más perentorias de las bibliotecas en el país, pero no es suficiente para detonar y sostener un proyecto de esta envergadura. Y aquí no hay sucedáneos ni similares. Por tanto será necesario establecer un plan inteligente de formación de recursos humanos idóneos al respecto.

Por su misma naturaleza, la responsabilidad principal de esto será del sector educativo, en su acepción más amplia: secretarías de educación federal y estatales, universidades, organismos académicos, y por supuesto, escuelas de bibliotecología y archivonomía. La responsabilidad de este sector será la de diseñar un plan de formación de recursos humanos perfectamente alineada con un proyecto de esta naturaleza. Ya vimos las caracterizaciones del bibliotecario digital en Norteamérica, Europa y Latinoamérica que nos ayudan a conceptualizar las competencias de lo que deseamos. El plan deberá alinear tanto el plan de formación profesional en las escuelas de bibliotecología - el cual rendirá frutos a mediano plazo-, como el de capacitación y educación continua de un gran número de personal profesional y técnico que deberá irse integrando poco a poco al proyecto y que debe rendir frutos a corto plazo. El segundo sector en importancia de responsabilidad dentro del proyecto es el gubernamental, en especial el ejecutivo, el cual deberá proveer el soporte para organizar al sector educativo, así como el dinero semilla para iniciar esa capacitación continua.

¿Cuáles deberán ser las principales temáticas que deben impartirse en esta educación y capacitación continua? Esta pregunta puede ser respondida con el resumen que hicimos en el apar- 
tado 2.5 acerca de las áreas estratégicas de desarrollo de sistemas micro de bibliotecas digitales; he aquí un sumario del mismo. Para más detalle véanse los apartados 2.5 y 2.5.1.

- Digitalización de acervos relevantes, raros o antiguos.

- Digitalización parcial de materiales con copyright -capítulos de libros, artículos de revistas, etc.- previo convenio con los titulares de ese derecho.

- Desarrollo de colecciones con materiales adquiridos externamente -compra, canje o donación- en diversos medios como libros, revistas, mapas, etc., tanto actual como retrospectiva, previo acuerdo de derechos.

- Desarrollo de colecciones digitales propias de la biblioteca por medio de publicación sobre demanda del material propio de la institución a que pertenece la biblioteca -copyright propio o asequible.

- Entrega de documentos y/o contenido electrónicos. Con cuáles medios, herramientas, controles, entregará la biblioteca a sus distintos grupos de usuarios copias electrónicas controladas de sus documentos.

- Acceso de la biblioteca a recursos de internet para ofrecer servicios a los usuarios. Por cuáles medios la biblioteca tendrá acceso a servidores, ancho de banda, personal técnico, almacenamiento electrónico, para poder ofrecer sus servicios. Acceso de los usuarios: rápido, remoto, garantizado, seguro, a toda hora.

- Catalogación, indización, vínculos, metadatos e inventarios adecuados por parte de la biblioteca. Cuáles serán los estándares aceptados por las bibliotecas para registrar y ofrecer su material digital.

- Integración de acervos distintos en pocos buscadores. Esto es, una adecuada integración de colecciones y materiales en conjuntos más lógicos de búsqueda para los usuarios, evitando la repetición de búsquedas en innumerables colecciones.

- Capacitación de usuarios, con el fin de lograr una adecuada explotación de los recursos por parte de ellos. 
- Almacenamiento electrónico amplio y eficiente. Dónde, cómo y por cuánto dinero almacenar los materiales para lograr un buen acceso con un óptimo rendimiento económico.

- Preservación de materiales para mantener el conocimiento para futuras generaciones de usuarios.

La problemática para este propósito ya ha sido discutida en el capítulo 2; así, podemos resumir los rasgos más definitivos de nuestro objetivo:

- Existe un pequeño número de instructores y/o capacitadores, por lo que éstos deberán ser aprovechados al máximo.

- Debe capacitarse a un considerable número de personal bibliotecario y técnico en todo el país, así como al personal de tecnologías de información y en un abanico muy amplio de instituciones.

- Sólo existen escuelas de bibliotecología en unas cuantas entidades federativas del país y con matrículas muy pequeñas.

Por lo mismo, es adecuado un proyecto de capacitación continua a través de educación a distancia, luego de lo enunciado en el capítulo 2. Por supuesto, deberán prepararse los materiales necesarios para este proyecto de acuerdo con lo establecido en los apartados correspondientes.

Con el diseño y puesta en marcha de este plan específico de formación de recursos humanos se asegurará que el proyecto cuente con esa "masa crítica" de detonación sin la cual nada podrá ser llevado a feliz término. No hay plan, por perfecto que sea, que pueda ser realizado sin un mínimo de personal calificado que vaya desarrollándolo; por esta razón forma parte de las ocho líneas de acción primordiales.

5.7.5 Promoción del uso efectivo de la información; acceso gratuito o económico

Para el desarrollo de esta acción, es conveniente comenzar recordando el Manifiesto de la biblioteca pública de la IFLA/UNESCO de 1994. En él se establece: 
La libertad, prosperidad y el desarrollo de la sociedad y sus individuos son fundamentos de los valores humanos. Los cuales serán adquiridos a través de la habilidad de ciudadanos bien informados para ejercer sus derechos democráticos y jugar un rol activo en la sociedad. La participación constructiva y el desarrollo de la democracia dependen de una educación satisfactoria así como de un acceso gratuito e ilimitado al conocimiento, hechos democráticos y jugar un rol activo en la sociedad. La participación constructiva y el desarrollo de la democracia dependen de una educación satisfactoria así como de un acceso gratuito e ilimitado al conocimiento, enseñanza, cultura e información. Las bibliotecas públicas, la puerta local al conocimiento, proveen las condiciones básicas para el aprendizaje duradero, su desarrollo cultural y la toma de decisiones independientes de individuos y grupos sociales [IFLA, 1994].

Como ya hemos establecido, un proyecto de bibliotecas digitales en México no está conformado exclusivamente por bibliotecas públicas, para quien ese documento fue hecho, pero es sumamente importante recoger el espíritu que lo anima y que está muy bien definido en el párrafo citado.

Uno de los objetivos principales del proyecto es la reducción de la brecha digital en los ciudadanos de este país. Por supuesto, la brecha está allí en donde las tecnologías de información y comunicación no están disponibles para la gente. Pero como ya hemos dicho, aun estando disponible, la simple conexión no hace de la información lo que socialmente no era. La sociedad del conocimiento es aquella en la cual las tecnologías digitales de comunicación están crecientemente integradas al desarrollo y superación personal a través del aprovechamiento de esa información para generar conocimientos y habilidades nuevas. La verdadera brecha digital no es carecer de acceso a la internet; es no poseer la capacidad de aprovechar la internet para mejorar el nivel de vida. Por ello es de primordial importancia promover el uso, pero sobre todo, el aprovechamiento de la información en las bibliotecas digitales. 
5.7.6 Desarrollo de infraestructuras de cómputo y telecomunicaciones; desarrollo en innovaciones tecnológicas que impulsen el proyecto

Para el adecuado desarrollo de esta línea de acción, debemos partir de la información presentada en el apartado 2.2.3 y el capítulo 3, es decir, la información relativa a la infraestructura mexicana en lo relativo a tecnologías de información. ¿Por qué es importante este rubro?

Como ha sido analizado a lo largo de toda esta obra, un proyecto de bibliotecas de la sociedad de la información es más que nada un proyecto de contenidos, educación, capacitación, calidad de vida. Un error grave, ha sido el pensar que es sólo un proyecto de conectividad y acceso a la tecnología, y abordarlo únicamente con ese enfoque. No obstante, es preciso reconocer que sin el acceso a esa tecnología y sin la infraestructura adecuada al respecto, no puede implementarse con éxito un proyecto de este tipo, por más contenidos de los que se disponga. Del análisis de capítulos anteriores, hemos podido establecer la importancia de la "brecha digital" y, más aún, la importancia de disminuirla en nuestro país.

Ya hemos mencionado que cuando hablamos de infraestructura de cómputo y telecomunicaciones nos referimos, en principio, a la capacidad que el Estado tiene para proporcionar estos servicios, ya sea de manera directa o indirecta; es decir, los servicios que el Estado ofrece y los que de algún modo propicia por medio de concesiones, regulaciones, normatividades, etcétera.

En épocas recientes, quien ha tenido la responsabilidad principal, en lo relativo a infraestructura de acceso por parte de los sectores e iniciativas gubernamentales, ha sido la Secretaría de Comunicaciones y Transportes (SCT); para revisar lo más relevante obtenido hasta el momento, lo pertinente es asomarse a los programas de desarrollo anuales de esta secretaría, los cuales en lo tocante a infraestructura para conectividad incluyen las siguientes acciones.

El programa de desarrollo 2003 de la SCT en lo tocante a e-México, en su apartado de conectividad propuso las siguientes acciones (la numeración es la propia del programa): 
6. Proporcionar conectividad digital de alta velocidad a través de las redes públicas de telecomunicaciones y las satelitales, con objeto de integrar la red de centros comunitarios digitales.

7. Negociar con las diferentes instituciones que a la fecha hayan instalado y/o que planeen instalar locales con acceso a Internet para el público en general, para que se transformen en centros comunitarios digitales e-México -CCD's e-México.

8. Instalar en el primer cuatrimestre del año los primeros 3200 CCD's para dar cobertura a las 2445 cabeceras municipales del país y otras poblaciones.

9. Licitar en el segundo semestre del año la segunda red satelital e-México y la primera red de conectividad alámbrica e inalámbrica terrestre.

10. Promover conectividad adicional a más CCD's , mediante acuerdos de programas de cobertura social, entre la SCT y los concesionarios de redes públicas de telecomunicaciones [Secretaría de Comunicaciones y Transportes, 2003].

El programa de desarrollo 2004 de la SCT en lo tocante a eMéxico, en su apartado de conectividad propuso las siguientes acciones:

7. Continuar la negociación con las diferentes instituciones que a la fecha hayan instalado y/o que planeen instalar centros con acceso a Internet para el público en general, para invitarlas a que dichos centros se transformen a Centros Comunitarios Digitales e-México -CCD's e-México-, de acuerdo a los lineamientos establecidos en el Manual de Implantación.

8. Licitar e instalar la segunda red de conectividad satelital para otros dos mil CCD's, donde la SCT estará a cargo de la conectividad, y otras dependencias y entidades del Gobierno Federal proveerán el equipamiento de cómputo, proporcionarán los locales, capacitación, personal para los CCD's, puesta en marcha, operación y mantenimiento de los mismos.

9. Ofrecer conectividad adicional a más CCD's a partir del segundo semestre del año, por medio de acuerdos derivados de los programas de cobertura social entre la SCT y las empresas de televisión por cable, considerando que la cobertura dependerá de las 
localidades donde los operadores de redes públicas de telecomunicaciones ofrezcan el servicio.

10. Llevar conectividad a CCD's adicionales, a partir del segundo semestre del año, a través del servicio de conectividad alámbrica e inalámbrica terrestre que se convenga con operadores de redes públicas, considerando que la cobertura dependerá de las localidades donde los operadores de redes públicas de telecomunicaciones ofrezcan el servicio [Secretaría de Comunicaciones y Transportes, 2004].

El "Programa de acceso a servicios digitales en bibliotecas públicas", coordinado por la Dirección General de Bibliotecas de Conaculta informa en su último reporte que en el año 2004 las bibliotecas públicas con computadoras y acceso a la Internet, pasaron de 249 a 675 con 4077 computadoras y sus accesorios. Afirma que para 2006 llegarán a 1700 bibliotecas. En sus planes se incluye un programa de capacitación para operarios de esas bibliotecas. No queda claro de las cifras oficiales si esos centros están contabilizados en los 3200 CCD o son aparte.

- Los 3200 centros comunitarios digitales (CCD) en operación más los 4000 programados próximamente.

- El "Programa de acceso a servicios digitales en bibliotecas públicas", con sus 675 bibliotecas con un total de 1700 programadas.

- Primera red satelital de conectividad del proyecto e-México, operada por Internet Direct para los 3200 CCD desde junio de 2003.

- Segunda y tercera redes satelitales de conectividad para los CCD, licitada y ganada recientemente por Telmex y que tentativamente entrará en servicio en 2005.

Como pudimos observar en el capítulo 3, en estos aspectos de conectividad no se trata sólo de una cuestión de números absolutos, sino del "factor de penetración" en la población. Ésas son las cifras trascendentales y que están faltando urgentemente en los 
proyectos de infraestructura gubernamentales y son vitales; por ejemplo, no es lo mismo afirmar que se atenderá a tres millones de personas que decir que se otorgarán tres millones de sesiones-persona. Son dos cifras totalmente distintas cuando se habla de usuarios. Más que el número total de computadoras es necesario saber con precisión la relación de cuántas computadoras en red estarán disponibles para cuántos usuarios y por cuántas horas, con objeto de detectar ese factor, establecerlo claramente y por supuesto, incrementarlo bajo un plan articulado.

Por ello, el plan de acción en este rubro debe comenzar con una investigación que permita conocer con precisión los números absolutos, pero sobre todo los números relativos que nos permitan establecer el tamaño de la brecha digital actual en lo tocante a conectividad y las proyecciones anuales que muestren que ésta se va a ir cerrando. Las cifras que es urgente determinar serían las siguientes en primera instancia:

- Número de CCD y/o bibliotecas públicas conectadas a la red.

- Número de computadoras en servicio en red para el público.

- Número de usuarios distintos, es decir, personas, que atienden.

- Número de sesiones-persona otorgadas, es decir, de cuántas sesiones disfruta una persona en un periodo dado.

- Ancho de banda promedio otorgado.

- Horas de servicio otorgadas por centro, por computadora, por persona.

Estas cifras, calculadas y proyectadas por año, el actual y los siguientes, sí permitirán de manera efectiva obtener el "factor de penetración" del proyecto en lo tocante a conectividad y acceso. Con ello se podrá estimar correctamente el dato que es en realidad relevante: cuántas personas están logrando el acceso a la red, durante cuántas horas y en cuántas sesiones, como resultado de esta infraestructura gubernamental, y con ello el impacto de la misma. Las proyecciones y comparaciones anuales permitirán establecer también si la "brecha digital" se va abriendo o cerrando y la tasa a la que ésta lo hace. Ésas son las cifras realmente relevantes que es 
necesario obtener en primera instancia, y que por supuesto retroalimentarán a estos proyectos a fin de asignar prioridades, inversiones, etc. Todos los proyectos en este sentido deben tender articuladamente al cierre de esa brecha. La acción en realidad en este rubro consiste en retroalimentar, articular e impulsar los proyectos actuales, simplemente partiendo de otras cifras, las que realmente harán la diferencia en nuestra sociedad. Debemos recordar nuevamente que esto sólo nos habla de conectividad, de la cantidad de acceso, y no garantiza el éxito final de nuestra sociedad de la información mexicana. Será necesario establecer además el impacto cualitativo, los logros o frutos de ese acceso, que al final es lo que importa. Pero los aspectos de cantidad son condición sine qua non y por tanto imprescindibles también en este tipo de esfuerzos, y por ahí debemos comenzar.

Por supuesto, dado que aquí se habla de infraestructura gubernamental, es precisamente ese sector el que tiene la responsabilidad primaria de implementar esta línea de acción, como la ha tenido tradicionalmente. Aquí se requiere el concurso de muchos integrantes de ese sector: los del ejecutivo federal, estatales y municipales, los del legislativo federal y sus correspondientes estatales y municipales; la Secretaría de Comunicaciones y Transportes y sus organismos auxiliares; el Conaculta, la Secretaría de Educación Pública y sus correspondientes estatales. El sector académico y bibliotecario tiene también una responsabilidad secundaria que permite sumar sus recursos de conectividad y de capital humano para incidir favorablemente e impulsar esa conectividad de la mayor y mejor manera posible.

Si lo analizamos con cuidado, no es que haya falta de infraestructura en nuestro país; el sector gubernamental se ha preocupado y ocupado al respecto. Tampoco carecemos de proyectos en este sentido y no son malos proyectos; todo lo contrario: son ambiciosos, visionarios, oportunos y pertinentes. Lo que ha faltado desde mi punto de vista como se ha tratado de establecer a lo largo de todo este trabajo, es articulación y método, de acuerdo con las "buenas prácticas" internacionales. Esta acción, simple en su planteamiento, podría significar un giro interesante. Habiendo concierto, 
Un modelo de planeación de bibliotecas digitales para México

nuestra infraestructura podría rendir pingües resultados a corto plazo.

5.7.7 Impulso a la inversión privada en tecnologías de información y comunicaciones

En esencia, esta acción es una extensión de la anterior, sólo que involucra al sector privado. Como hemos mencionado, éste no debería ser sólo un proyecto del gobierno; es un proyecto de Estado. Si vamos a impulsar la industria, la banca, las PYMEs, etc., requeriremos de información oportuna, pertinente, adecuada. El sector privado necesita la información para el desarrollo, tanto como las personas y el sector público. No puede depender de que toda la información que se requiera, genere y consuma provenga siempre del sector público o de que el mercado la genere. Véase el anexo 2, "Proceso evolutivo de la Internet en las PyMEs".

En el capítulo 3 se presentó una compilación del estado del arte de la infraestructura mexicana en tecnologías de información y telecomunicaciones, para darnos una idea del punto en el que nos encontramos en este rubro respecto a otros países y lo que falta por hacer. En una buena medida, lo que ahí se refleja son las acciones que el gobierno mexicano está realizando para incidir en la penetración de los CCD, las bibliotecas con acceso a servicios digitales, etc. No obstante, en un proyecto de bibliotecas digitales a nivel nacional es importante hacer una reflexión adicional y generar acciones que tiendan a ampliar la "penetración" del recurso también al sector privado del país. En este sentido, y como ya se ha establecido en el capítulo 3, es necesario definir los números de los indicadores de las TIC que corresponden al sector privado para tener una idea del estado que guardan respecto al sector público, y en seguida definir un plan de acción que permita por un lado incrementar esos números de los indicadores en el sector privado y por otro lado, y más importante, incrementar la "penetración" de las tecnologías en ese sector.

En esencia, podríamos resumir lo anterior en dos importantes preguntas: ¿cómo invertir para incrementar la penetración de las 
TIC en el sector privado? y ¿cómo crear más bibliotecas, contenidos y usuarios en ese mismo sector?

Recordemos que ya teníamos una propuesta en este sentido, consignada en el documento de la Academia de Ciencias Mexicana, en que se proponía la creación de una "base nacional de comunicación y de conocimientos", la cual sería lograda a través de tres grandes estrategias:

- Apoyar la modernización del país.

- Extender el acceso a las tecnologías de información a los sectores que están fuera del ámbito de acción del sistema educativo formal.

- Integrar en un marco coherente la información y el conocimiento producidos por el país, para organizarlos y hacerlos llegar ágilmente al mayor número de posible de personas (Academia..., 1999, pp. 26-27).

Si bien esta propuesta y sus correspondientes estrategias no estaban dirigidas al sector privado, sino al educativo, me parece que pueden ser tomadas tal cual para extrapolarlas como la acción principal en este sentido y las estrategias al respecto, simplemente agregando que el énfasis en esta acción se encuentra precisamente en el sector privado.

Éste es otro de los aspectos en que la función rectora del gobierno es estratégica, no obstante tampoco es su responsabilidad total crear y desarrollar por sí mismo los mecanismos de infraestructura de tecnologías de información y comunicaciones para el sector público pero sí lo es que, una vez que instala su parte, gestione que la otra parte se desarrolle, organice la tarea dentro del sector privado y abone el terreno en ese sentido.

De nuevo y de acuerdo con la dinámica establecida en el apartado anterior respecto a los grupos de trabajo, el gobierno podría introducir "condiciones estratégicas de inicio". He aquí una propuesta tentativa: 
- Definir y planear la plataforma de equipamiento de cómputo y telecomunicaciones necesaria para el sector público.

- Establecer cuál es el "factor de penetración" actual de las TiC en el sector privado, así como la capacidad necesaria de conectividad y de acceso a la Internet para todo el sector en condiciones de calidad y precio.

- Crear la capacidad de elaboración de contenidos y materiales nacionales en formato digital por parte del sector.

- Crear la capacidad de organización y administración por parte del sector de esa información para su distribución de manera ágil.

- Crear una organización, un marco institucional y los mecanismos de financiamiento que den viabilidad al proyecto.

Los primeros dos aspectos deberían ser responsabilidad compartida del sector gubernamental y el sector privado. Los tres restantes deben ser responsabilidad del sector privado, mismo que deberá utilizar sus mecanismos de organización con este propósito.

De la "Matriz conceptual del grado de incidencia de los $12 \mathrm{sec}$ tores con las ocho líneas de acción del proyecto nacional de bibliotecas digitales", podemos inferir que los sectores de los cuales se esperaría mayor número de propuestas y con mayor alcance serían: los sectores ejecutivo, de administración pública; energía; manufacturero, maquila y construcción; servicios comerciales, turísticos, editores; servicios financieros y de banca, seguros, bolsa; comunicaciones y transportes, servicios informativos.

Independientemente de la intensidad esperada, como en las otras acciones, cada sector debe hacer una propuesta en esta línea de acción. Uniendo las 12 propuestas que resulten de los 12 sectores con las "condiciones estratégicas de inicio" podríamos establecer la línea de acción definitiva respecto a esta séptima línea de acción la cual deberá reflejarse en el "plan de acción específico para el desarrollo de esa línea de acción”. 
5.7.8 Integración del proyecto a la identidad, valores y cultura nacionales

La ciencia genética moderna ha confirmado lo que las antiguas creencias han afirmado por siglos: el hecho más relevante de nuestra vida como especie es que pertenecemos a una única y común especie humana. Por tanto, deberíamos hacer más que sólo tolerar nuestra diversidad, deberíamos honrarla y celebrarla.

WiLLIAM CLINTON

Como hemos establecido en el capítulo 4, una enorme parte de la preocupación y rechazo que el fenómeno de la globalización trae dentro de la sociedad de la información, sobre todo en el entorno cultural, es que para muchos globalización implica homogeneización. A un buen número de personas preocupadas por la cultura, el término les hace pensar que en un futuro, a raíz del constante intercambio de fuerzas homogeneizadoras, eventualmente los habitantes del mundo se hallarán pensando, actuando y hablando de una manera muy similar. Hemos destacado también que el riesgo y el fenómeno existen pero, como ya hemos tratado en otros capítulos, el problema mayor subyace no en el medio sino en el uso del medio. Como ya hemos recalcado, el problema es que se propicie la existencia de "analfabetos digitales funcionales". Ellos son los que pueden quedar expuestos totalmente a este fenómeno sin protección alguna. No se trata de estigmatizar al medio, sino de tomar las medidas que permitan el correcto aprovechamiento del mismo. El fenómeno debe enfocarse en sus elementos críticos reales: alfabetización digital funcional e impulso decidido a la diversidad cultural y a la identidad nacional.

Hemos comentado también que se puede contrarrestar esta amenaza sólo en tanto nos mantengamos conscientes de que la cultura no es una simple mercancía. Lo realmente importante, como muchas personas y grupos comprenden, es que los bienes y servi- 
cios culturales desempeñan un papel determinante para nuestro país y nuestras regiones respecto a la identidad de los habitantes, a la cohesión necesaria del tejido social de los mismos, a la vida democrática e inclusive retroalimenta al mismo desarrollo económico. No se trata de negar que los bienes y servicios culturales puedan ser objeto de comercio: se trata de que se reconozca que no pueden estar sometidos a las reglas usuales del comercio.

De entre las acciones que los gobiernos deben desarrollar, establecidas en la declaración de la UNESCO, hago un extracto y una "alineación" al modelo de bibliotecas digitales, respecto a este tema de las acciones relativas a la identidad, valores y cultura nacionales.

Las múltiples formas de la cultura universal se manifiestan en la originalidad y la pluralidad de las identidades que caracterizan a los grupos y las sociedades que componen la humanidad. En particular, como nación mexicana, constituyen nuestro patrimonio común y por tanto debe ser reconocidas y consolidadas en beneficio de las generaciones presentes y futuras. En una sociedad cada vez más globalizada, resulta indispensable garantizar una interacción armoniosa y una voluntad de convivir de personas y grupos con identidades culturales a un tiempo plurales, variadas y dinámicas, tanto al interior de nuestra nación como hacia el resto del mundo. El pluralismo cultural constituye por tanto la respuesta política al hecho de la diversidad cultural. Inseparable de un contexto democrático, el pluralismo cultural debe propiciar los intercambios culturales y el desarrollo de las capacidades creadoras que alimentan nuestra vida cotidiana como individuos y como nación.

Nuestra diversidad cultural amplía las posibilidades de elección que se brindan a todos; es una de las fuentes del desarrollo, no solamente en términos económicos, sino también como medio de acceso a una existencia intelectual, afectiva, moral y espiritual satisfactoria. La defensa de la diversidad cultural es inseparable del respeto de la dignidad de las personas, en particular la de las personas que pertenecen a minorías y a pueblos autóctonos. Debe cuidarse que todos puedan crear y expresarse en su lengua materna. Toda persona tiene derecho a una educación y a una formación de calidad que respete y permita expresar plenamente 
su identidad y valores culturales, con el único límite que impone a su vez el respeto a los derechos humanos y a las libertades fundamentales y culturales de otros.

Contando con la garantía de la libre circulación de las ideas mediante el intercambio documental, hay que procurar que todas nuestras culturas puedan expresarse y darse a conocer. La libertad de expresión, el pluralismo de los medios de comunicación, el multilingüismo, la igualdad de acceso a las expresiones literarias y artísticas, al saber científico y tecnológico por parte de todas nuestras culturas -comprendida su forma electrónica-, son los garantes de la diversidad cultural. Junto con las presiones hacia el Estado derivadas del cambio económico y tecnológico actual, a la vez que se abren amplias perspectivas para la creación y la innovación, debe cuidarse con especial atención a la diversidad de la oferta creativa. Debe considerarse siempre el carácter específico de los bienes y servicios culturales que, en la medida en que son portadores de identidad, de valores y sentido, no deben ser considerados sólo como mercancías o bienes de consumo como los demás. La asignación de prioridades y evaluaciones nunca debe estar basada en la aplicación exclusiva de las reglas del mercado al sector cultural.

A la vez que se fomenta y cuida el pluralismo cultural, debe procurarse siempre que éste mantenga también una identidad y unos valores como nación. Debemos estar conscientes siempre de que formamos parte de una nación inmensamente rica en lo cultural, plural, cósmica, en el significado de Vasconcelos. Deberá cuidarse que se vea esta pluralidad multicultural como la suma de lo que somos y de lo que nos une, nunca de lo que nos divide. La identidad dentro de la diversidad, la unión dentro de las diferencias, la riqueza que da al todo la variedad de las partes, el orgullo de la pertenencia como individuos a una nación deben ser siempre el hilo conductor que dé cohesión al tejido social y el valor supremo que nos dé forma como nación mexicana y a la vez cosmopolita.

Las acciones de impulso a las bibliotecas digitales deben contemplar y estimular insoslayablemente este respeto de las identidades y diversidades culturales y lingüísticas, a las tradiciones y los valores, además de promover un diálogo entre las culturas y una identidad nacional. El fomento, la afirmación, el rescate y preser- 
vación de los diversos idiomas e identidades culturales indígenas contribuirán a enriquecer aún más a la sociedad del conocimiento mexicana. Es esencial promover a la vez la producción de contenidos y la accesibilidad a los mismos, sea con propósitos educativos, científicos, culturales o recreativos, en diferentes idiomas y formatos. La creación de contenido nacional que se ajuste a las necesidades nacionales o regionales fomentará el desarrollo socioeconómico y estimulará la participación de todas las partes interesadas, incluyendo a los habitantes de zonas rurales, distantes o marginadas. La preservación del patrimonio cultural es un elemento crucial de la identidad personal y del conocimiento de nosotros mismos, los que son a su vez enlace con nuestras comunidades y con nuestro pasado. La sociedad del conocimiento mexicana y por tanto las bibliotecas digitales mexicanas deben aprovechar y preservar nuestro patrimonio cultural y heredarlo a las futuras generaciones.

Reiterando y de acuerdo con la dinámica establecida anteriormente respecto a los grupos de trabajo, proponemos las "condiciones estratégicas de inicio" al grupo:

- Elaborar una estrategia para impulsar, a través de la educación, una toma de conciencia del valor positivo de la diversidad cultural mexicana y mejorar, a este efecto, tanto la formulación de los programas escolares como la formación de los docentes.

- Impulsar el conocimiento y dominio de las tecnologías de información y comunicación, las que deben considerarse al mismo tiempo como disciplinas a enseñarse y como instrumentos pedagógicos capaces de reforzar la eficacia de los servicios educativos en general.

- Promover la diversidad lingüística en el espacio digital y fomentar el acceso gratuito y universal, a través de las redes mundiales, a toda la información del dominio público.

- Reducir las desigualdades en materia de la brecha digital, tanto en acceso como en uso adecuado, fomentando la "alfabetización funcional digital", impulsando el uso adecuado de las nuevas tecnologías de información y comunicación por parte de 
mayor número de personas, ayudándolos a asimilar y sacar provecho de ellas y facilitando a la vez la circulación electrónica de los productos culturales, educativos y científicos tanto en el plano regional y nacional como los disponibles a escala mundial.

- Crear las condiciones propicias para la producción y difusión de bienes y servicios culturales diversificados, gracias a industrias e iniciativas culturales que dispongan de medios para desarrollarse en los planos local y nacional.

- Estimular la producción, la salvaguardia y la difusión de contenidos diversificados en los medios de comunicación y las redes mundiales de información, y favorecer las sinergias entre la ciencia moderna y los conocimientos locales.

De la matriz conceptual del grado de incidencia podemos inferir que los sectores de los cuales se esperaría mayor número de propuestas y con mayor alcance serían: el ejecutivo, de administración pública; energía; manufacturero, maquila y construcción; servicios comunales, sociales, de trabajo y deporte; académico-educativo-bibliotecario; servicios informativos. En un grado medio serían los sectores agropecuario, de alimentos y agua; el sector de servicios comerciales, turísticos, cine y editorial; sector legislativo.

Independientemente de su intensidad esperada, como en las otras acciones, cada sector debe hacer una propuesta en esta línea de acción. Uniendo las 12 propuestas que resulten de los 12 sectores con las "condiciones estratégicas de inicio" ya propuestas, podríamos establecer la línea de acción definitiva respecto a esta séptima línea de acción la cual deberá reflejarse en el "plan de acción específico para el desarrollo de esa línea de acción”.

Finalmente, una vez que se tengan los planes detallados para cada línea de acción el comité deberá darles forma, cuerpo y articulación para volverlos un todo coherente. Como todo plan, deberá tener elmentos adicionales como tiempos de ejecución, mecanismos y vías de finacimiento, definición de agentes responsables y acciones de inicio. Deberán ser también especificados los mecanismos detallados de seguimiento, evaluación y retroalimentación 
del plan. Deberán ser tomadas las medidas alternativas en caso de que alguno de los sectores o de los resultados no estén funcionando de acuerdo con lo esperado.

Figura 5.4

DIAGRAMA SISTÉMICO DEL MODELO DE BILIOTECAS




Dado que ha sido planteada una perspectiva sistémica y fenomenológica, la organización que define y opera el plan no debe verse nunca como un fin predeterminado, sino que dicha organización puede tener diversos fines en función de la forma en que los involucrados en su destino la vean, surgiendo la variedad interpretativa. Esta visión deberá estar condicionada por los intereses y valores que posean los participantes, existiendo solamente un interés común centrado en la prevalencia de la misma. A esta visión habrá que agregarle la trayectoria histórica que la organización vaya acumulando, la cual irá condicionando su situación del momento, adicionándole además de la experiencia del pasado las aspiraciones futuras de los miembros de la misma, quienes influirán por ende en su comportamiento. El modelo organizacional podrá y deberá ser construido permanente y colectivamente por los miembros de la organización, a partir de las interpretaciones evolutivas que existan de la misma. Esto contribuirá de mucho mejor forma para un futuro a mediano y largo plazos, ya que como mencioné, deliberadamente no he grabado este modelo en piedra pensando en que puede ser reconstruido, complementado y enriquecido por la acción de las distintas personas, organizaciones y sectores que puedan verse involucrados en el esfuerzo. Puesto que no se trata de un plan de corto plazo, tomará un tiempo desarrollarlo y mucho más llevarlo a cabo. Pero creo que uno de sus principales atractivos es precisamente ése: que una vez desarrollado es un plan con visión de largo alcance que puede servir como un horizonte de referencia lejano en el tiempo para que pueda seguir siendo un plan estratégico de desarrollo nacional a lo largo de muchos años y, sin embargo, vigente. Concluyo con esta reflexión de John F. Kennedy: "el cambio es la ley de la vida; quienes sólo miran al presente y al pasado seguramente se van a perder el futuro". 

Investigar es entrar en callejones oscuros y estrechos, con el único fin de averiguar si tienen salida o no.

MARSTON BATES

\section{Resumen y conclusiones}

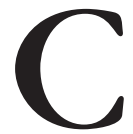

omo fue enunciado desde el prólogo, el tratamiento de la biblioteca digital fue hecho desde dos enfoques sustancialmente distintos y mutuamente complementarios uno del otro: en el primer capítulo, y como resumen de la obra Bibliotecas y publicaciones digitales se estudió y explicó a la biblioteca digital desde un enfoque reduccionista, como un ente aislado o cuando mucho, como un grupo de ellas dentro de una organización. El siguiente paso consistía en estudiar a las bibliotecas digitales a través de un enfoque holístico y bajo éste se planteó al modelo de bibliotecas digitales como el total de ellas, es decir un inmenso conjunto o sistema o una enorme organización a nivel de todo el país, y por tanto sus partes fueron sus sectores, componentes y relaciones funcionales a nivel nacional. Dado que el primer capítulo de esta obra consiste en las conclusiones del primer enfoque, no es necesario volver a establecer un resumen y conclusiones del mismo, en el cual y teniendo como centro la biblioteca digital, hemos tratado de analizar minuciosamente todas y cada una de sus partes principales, con la idea de explicar sus interrelaciones y descubrir sus características, pensando en un lector profesional de la bibliotecología, para ayudarle a comprender de la manera más precisa posible el origen, evolución, estado del arte y tendencias de la biblioteca digital; cómo concebir, diseñar y construir una biblioteca digital, disectando cada una de sus partes y sus interrelaciones. 
Cómo se va construyendo una colección digital, con material digital original o digitalizado. Hemos tratado de explicar cuándo, cómo y por qué debe digitalizarse tal o cual material y las ventajas y desventajas de hacerlo; qué implicaciones legales tiene el uso o copia de estos materiales y cómo el bibliotecario actual puede desenvolverse adecuadamente en ese entorno. Como hemos mencionado también, ese enfoque no ha cuestionado en sí la naturaleza social de la biblioteca ni la necesidad o pertinencia de su existencia, consolidados por más de cuatro milenios de historia.

La segunda aproximación o enfoque de las bibliotecas digitales, que se presenta en esta obra y como ya se ha mencionado, fue el holístico. En este caso el objeto de estudio son todas las posibles bibliotecas digitales existentes o potencialmente creables en nuestro país. Las preguntas, por tanto, fueron otras: en primer lugar, era necesario replantear la función misma de las bibliotecas a nivel nacional. Para ello era indispensable abrir mucho más el horizonte y comenzar con un objeto de estudio mucho más amplio. De ahí, y dado que la biblioteca es una institución de servicio para la sociedad se requiere entonces analizar detalladamente esa sociedad en la que se inserta: sus características, sus necesidades, su problemática; por supuesto, hablamos de la sociedad mexicana actual. Pero esta sociedad no es una isla en el planeta; es necesario entonces analizar primero a la sociedad mundial para contextualizar dentro de ella a la sociedad mexicana. Se dice que actualmente la sociedad en la que vivimos a nivel mundial es la denominada "sociedad de la información", era necesario entonces empezar a estudiar y definir a esta así llamada sociedad actual. ¿Qué rasgos la definen? ¿en qué es nueva y en qué es igual a otras predecesoras? ¿desde cuándo existe? ¿cuál es su contexto? ¿cuáles son sus tendencias, fortalezas y problemática? ¿cuáles son sus riesgos, injusticias y omisiones?

¿Por qué nuestra sociedad se autoadjudica este nombre para definirse? Las respuestas son muchas y complejas, pero muy probablemente la introducción de nuevas organizaciones y tecnologías específicas de información se encuentren entre las principales. En efecto, en las últimas décadas vimos florecer organizaciones y empresas que ofrecían específicamente "productos de informa- 
ción" a diferencia de las empresas que originalmente vendían bienes y servicios. Ahora tenemos la especialización de "sólo servicios”, más aún: sólo servicios de información. Las tecnologías de información vinieron a reafirmar este concepto. Las computadoras y los sistemas de telecomunicaciones evolucionaron a pasos agigantados cambiando muchas cosas acerca del procesamiento y envío de información. En la segunda mitad del siglo xx el desarrollo de esas organizaciones y tecnologías fue sobresaliente, marcando a nuestra sociedad y haciendo más notoria esa "sociedad de la información", tanto que se decidió empezar a denominarla con ese nombre. Finalmente, en las postrimerías del siglo $\mathrm{xx}$, el desarrollo acelerado de esas organizaciones y tecnologías de información se incrementó de forma tal, que ha marcado ya de modo casi absoluto a nuestra sociedad de los albores del siglo XXI.

Es importante recalcar aquí que aunque esta caracterización sólo define a una parte de la sociedad mundial y esos rasgos y características existen sólo en ciertos segmentos del conglomerado humano, debemos estar conscientes de que conforman rasgos típicos de lo que podríamos denominar "el estadio más avanzado de la civilización humana" -que no de su cultura- aunque no todos los habitantes del planeta se encuentren en él. Esto no descalifica a la caracterización. Presento la caracterización consciente de que hoy en día convivimos en el mundo desde sociedades neolíticas de recolectores-cazadores, pasando por sociedades agrícolas y sociedades industriales, hasta sociedad de la información. Más de la mitad del planeta no ha llegado a la sociedad industrial, pero ello no quiere decir que no haya existido o no exista tal sociedad. No es el punto de juzgar lo bueno o malo de que coexistan varias sociedades en el planeta, sino de caracterizarlas, aunque obviamente tendremos que llegar en este trabajo al momento de debatir brechas y desigualdades. Lo que está fuera de discusión es el hecho de que las organizaciones y las tecnologías de información están moldeando y reconformando sensiblemente la manera en que la vida se desarrolla en la actualidad y cómo lo hará en los próximos años en buena parte del mundo y por ello es importante que sean analizadas y sobre todo, planeadas. También es importante resaltar que 
existe la tendencia a tratar de explicar la sociedad actual a través de su icono más representativo, la internet, mezclando a veces ambos conceptos, lo cual sin duda es igualmente riesgoso e impreciso.

Las principales características que definen a la "sociedad de la información" son:

1. Posee organizaciones con uso intensivo de información.

2. Posee un sector de información significativo.

3. Hay uso social de la información.

4. Hay una sociedad del aprendizaje.

En la última cumbre de la UNESCO alrededor de este tópico el énfasis consistió en establecer que

el acceso a la información es esencial para la creación de sociedades del conocimiento; la utilización de las tecnologías de la información y la comunicación debe guiarse por un conjunto de principios, comprendidos el del acceso universal a información y el de la libertad de prensa, a fin de optimizar su eficacia en beneficio de los individuos, las comunidades y el desarrollo de cada país. Los ministros participantes hacen un llamamiento a los gobiernos para que "reexaminen sus prioridades de desarrollo, a fin de efectuar las inversiones que necesita la edificación de las sociedades del conocimiento" que, según recalcan, "comprenden muchos más aspectos que los de la tecnología y la conectividad" [World Summit on the Information Society (WSIS), 2003].

Esta última proposición adquiere singular importancia, dado que la propia uNESCO, a través de la International Telecommunication Union (ITU) decide privilegiar ahora el uso del término "sociedad del conocimiento" en lugar de "sociedad de la información" precisamente para comenzar a hacer una distinción entre el concepto que ha hecho énfasis alrededor de la tecnología y la conectividad con el nuevo que contempla también contenidos y derecho al acceso, así como nuevos paradigmas. Ninguna política de trabajo y educación basada en las TIC será posible si se le remite sencillamente al problema del acceso a la infraestructura y la conectividad. 
Dada su importancia, he elaborado un resumen de los once principios fundamentales que, de acuerdo con la cumbre mundial, deben regir la construcción de una "sociedad del conocimiento":

1. La función de los gobiernos y de todas las partes interesadas en la promoción de las TIC para el desarrollo.

2. Infraestructura de la información y la comunicación: fundamento básico de una sociedad de la información para todos.

3. Acceso a la información y al conocimiento.

4. Creación de capacidades.

5. Crear confianza y seguridad en la utilización de las TIC.

6. Entorno habilitador.

7. Aplicaciones de las tic: ventajas en todos los aspectos de la vida.

8. Diversidad e identidad culturales, diversidad lingüística y contenido local.

9. Medios de información.

10. Dimensiones éticas de la sociedad de la información.

11. Cooperación internacional y regional.

Estos once principios me parecen de capital importancia. Sin ellos, toda la cuestión de la sociedad de la información pierde su rumbo. ¿Para qué queremos una sociedad informatizada? ¿El simple acceso a las TIC y a las redes pone a sus beneficiarios en un plano superior? Si las personas no pueden obtener de ello los mecanismos para propiciar el desarrollo de cada individuo informatizado y de su entorno social todo habrá sido en vano. Hay que ofrecer a cada persona la posibilidad de adquirir las competencias y conocimientos necesarios para comprender, participar activamente y beneficiarse plenamente de la sociedad de la información y de la economía del conocimiento; los miembros de esta sociedad deben poder estar informados y ser creativos. La utilización y despliegue de las TIC debe orientarse a la creación de beneficios en todos los ámbitos de la vida cotidiana; de otra forma tendremos cada vez más millones y millones de personas que tienen acceso a la red mundial y que saben conectarse y utilizar las herramientas más elementales 
de conexión, como navegador y correo, pero que simplemente lo hacen para cuestiones sin relevancia, sin incorporarlo realmente a una mejora en su nivel de vida y, para colmo, quedando expuestos a grandes volúmenes de mediatización sin desarrollar mecanismos de defensa. Es decir, tendremos millones de personas "alfabetizadas" digitalmente pero dentro de las cuales la inmensa mayoría será "analfabeta digital funcional". Esto sería tanto como afirmar en la actualidad que simplemente con enseñar a leer y escribir a todos los individuos están ya listos para iniciar su educación y desarrollo por sus propios medios sin mayor esfuerzo adicional. Peor aún, es como pretender que simplemente con llevar a los alumnos a la escuela y mostrarles los libros de texto los hemos puesto en el camino del saber.

Concluyendo: no es sólo un problema de conectividad y acceso. El riesgo mayor que enfrenta la sociedad de la información es el de alfabetizar digitalmente en masa a millones de personas, creando a la vez en masa millones de "analfabetas digitales funcionales". Sería la más cruel de las paradojas respecto a lo que promete. Los 11 principios de la sociedad del conocimiento sin duda alguna hacen la diferencia y cierran realmente la "brecha digital". Serrano y Martínez definen la "brecha digital" como

[...] la separación que existe entre las personas, comunidades, estados, países, etc., que utilizan las nuevas tecnologías de la información como una parte rutinaria de su vida diaria y aquellas que no tienen acceso a las mismas y que aunque las tengan no saben cómo utilizarlas. La "brecha digital" puede ser definida en términos de la desigualdad de posibilidades que existen para accesar a la información, al conocimiento y la educación mediante las tecnologías de información. La brecha digital no se relaciona solamente con aspectos exclusivamente de carácter tecnológico, es un reflejo de una combinación de factores socioeconómicos y en particular de limitaciones y falta de infraestructura de telecomunicaciones e informática.

Es de capital importancia recalcar esto, ya que es lo que define la principal diferencia entre "sociedad de la información" y "socie- 
dad del conocimiento": la "brecha digital" tiene dos componentes primordiales y distintos: uno es la posibilidad de acceder a la tecnología de información, y otro es un factor socieconómico relativo a la capacidad de aprovechar esta tecnología en favor del propio desarrollo. Se observa entonces que en este aspecto de la marginación digital, deberemos cuidar tanto la posibilidad de ofrecer el acceso a las tecnologías de información y comunicación, como la creación de un entorno que elimine las barreras socioeconómicas y culturales que limitan la capacidad de aprovechar estas tecnología en favor del propio desarrollo para la comprensión receptiva, circunstancia que en consecuencia, incrementa la habilidad para contextualizar estructuradamente lo que acontece y crear conocimiento. La verdadera brecha digital no es carecer de acceso a la Internet; es no poseer la capacidad de aprovecharla para mejorar el nivel de vida.

Existen múltiples iniciativas en una enorme variedad de países y regiones alrededor de la sociedad de la información o del conocimiento. Se realizó un análisis detallado de ellas para contextualizar la iniciativa mexicana al respecto, la denominada e-México. En el "Plan Nacional de Desarrollo 2001-2006" se estableció:

En México, buena parte de la población no tiene acceso a una educación de calidad, competitiva en las nuevas posibilidades que el desarrollo tecnológico ofrece. Es necesario adoptar una estrategia que permita a los trabajadores mexicanos contar con una capacitación continua que fortalezca el uso y aprovechamiento de las nuevas tecnologías. En el mundo moderno, la capacitación continua constituye la mejor garantía de seguridad y progreso para el trabajador... Es imprescindible promover acciones para el uso y aprovechamiento de las tecnologías como recursos estratégicos que contribuyan a la satisfacción de las necesidades de la sociedad mexicana y adoptar los mejores estándares tecnológicos y medidas que protejan la propiedad intelectual. El ejecutivo federal fortalecerá el sistema nacional de metrología, normalización y evaluación de la conformidad.

El proyecto e-México se definió como: 
Un proyecto integrador, que articula los intereses de los distintos niveles de gobierno, de diversas entidades y dependencias públicas, de los operadores de redes de telecomunicaciones, de las cámaras y asociaciones vinculadas a las tecnologías de la información y las comunicaciones, así como de diversas instituciones, a fin de ampliar la cobertura de servicios básicos como educación, salud, economía, gobierno y ciencia, tecnología e industria, así como de otros servicios a la comunidad.

Como puede observarse, la iniciativa mexicana, si bien no es original, fue ambiciosa, como debía ser. Sigue la línea de la iniciativa brasileña la cual a su vez fue adaptada a un contexto latinoamericano a partir de la línea básica de la iniciativa europea, lo cual desde mi punto de vista fue un enfoque acertado. Ahora bien, es conveniente hacer notar que después de la iniciativa federal para la sociedad mexicana de información, el único documento de planeación con cierto grado de detalle para estrategias y líneas de acción relacionando e-México y la educación, es el "Plan Nacional de Educación 2001-2006", de la SEP, entre los cuales no parece haber la articulación deseada en dos proyectos tan cercanos entre sí. No existió tampoco una propuesta para bibliotecas digitales por parte de ninguna entidad federal o de cobertura nacional sino hasta mayo de 2002 en que el ejecutivo lanzó una iniciativa nacional de impulso a las bibliotecas, aunque no detallada y mínimamente articulada con el proyecto e-México. En resumen: en México hay iniciativas alrededor de la sociedad de la información-educación-bibliotecas, sin embargo, parecen carecer de organización y articulación entre ellas. Desde mi punto de vista hay una "brecha" en el proyecto mexicano, la cual después de un arranque en cierta forma rápida y consistente con las otras propuestas semejantes a nivel mundial se ha estancado en los últimos dos años.

El siguiente proyecto surgió hasta 2002, con el "Programa de acceso a servicios digitales en bibliotecas públicas" derivado a su vez del programa "Hacia un país de lectores". Nuevamente, este proyecto hace énfasis en los aspectos de conectividad y accesibilidad tecnológica pero soslaya otros puntos importantes como los 
contenidos si bien, muy atinadamente según mi punto de vista, rescata ya aspectos de formación de recursos humanos. De hecho, la meta central de este proyecto es la de dotar a poco más de 1700 bibliotecas públicas de infraestructura de TIC para el año 2006.

Mucho se insiste en que la tecnología nos ofrece la oportunidad de enseñar diferente, y que es una forma de contender con los retos que plantea la cambiante sociedad actual. En efecto, hay evidencia clara de que la tecnología nos permite cambiar el modelo educativo y no sólo las formas y llegar a nuevas poblaciones poco o nulamente atendidas, y con costos menores que los obtenidos en modelos más convencionales. Esto requiere de nuevas aproximaciones a los paradigmas de la enseñanza-aprendizaje. No se trata sólo de utilizar la tecnología como una nueva manera de realizar el mismo proceso, sino de actualizar el proceso en sí. En suma, debe crearse un nuevo modelo de enseñanza, y no sólo nuevas modalidades de enseñanza. Es necesario inventar o replantear métodos para enseñar y aprender acordes con el número de personas que requieren ser instruidas hoy en día, con el inmenso número de conocimientos que deben ser enseñados, así como con los diferentes objetivos de la enseñanza y las distintas y cambiantes necesidades de estos educandos del siglo XXI.

De acuerdo con los expertos, en un futuro cercano los papeles de la escuela y la universidad serán drásticamente cambiados; esto es, se avecina una transformación radical del sistema educativo. Entre las tendencias se observan las siguientes (Twigg y Miloff, 1998): un número de estudiantes siempre creciente está demandando educación; mujeres, gente de la tercera edad, discapacitados, etc.; la necesidad de estudiar y trabajar a la vez; estudio a lo largo de toda la vida; obsolescencia de conocimientos; presiones presupuestales a la educación, etcétera.

De acuerdo con Hans Roes (2001) el medio ambiente del aprendizaje del futuro:

- Estará centrado en las características, perfiles y necesidades del alumno.

- Será interactivo y dinámico. 
- Permitirá el trabajo en grupo en problemas mundiales reales.

- Permitirá a los estudiantes trazar sus propias rutas de aprendizaje.

- Hace énfasis en competitividades informáticas y apoyará la educación continua.

Puede observarse en todo esto un hilo conductor: la adopción de estilos de aprendizaje más activos en los cuales los estudiantes tomen más responsabilidades para con sus metas de aprendizaje y con la manera de llevarlas a cabo. El aprendizaje activo implica también que los estudiantes no se limiten a ver sólo recursos proporcionados por sus instructores, sino que busquen nuevos materiales que les ayuden a resolver problemas y a desarrollar su competitividad continuamente. Independientemente de las preferencias pedagógicas de cada quien, estos elementos ilustran con claridad que se pueden intentar nuevas cosas alrededor de la educación, las TIC, etcétera.

Puede concluirse entonces que la búsqueda de nuevos modelos de enseñanza basados en tecnologías de información y comunicaciones es una condición inaplazable en la educación del siglo XXI, y que estos modelos pueden integrar perfectamente bien los enfoques previos o nuevos, inclusive híbridos, de las aproximaciones pedagógicas actuales.

Estela Morales lo resume de una manera espléndida:

La educación superior tiene que ofrecer soluciones y opciones a los jóvenes que viven en una sociedad, donde la información es el elemento de cambio más codiciado, las oportunidades de trabajo se hacen más específicas y el ciclo productivo ya no es lineal, porque se distribuye ampliamente en la globalidad, a partir del más bajo costo y la más alta calidad, además de integrar todos los procesos, las ideas, los diseños, la comercialización y el almacenamiento [Morales, 2001].

Uniendo entonces los elementos de educación y tecnologías, la Academia de Ciencias Mexicana ha establecido tres estrategias: 
1) Apoyar la modernización del país. 2) Extender el acceso a las tecnologías de información a los sectores que están fuera del ámbito de de acción del sistema educativo formal. 3) Integrar en un marco coherente la información y el conocimiento producidos por el país (Academia..., 1999, pp. 26-27). Como puede verse, en estas actividades se requiere de servicios de información consistentes, integrados y completos. Y es precisamente allí donde se intersecan los objetivos de la educación y los de las bibliotecas. De acuerdo con Roes (2001) éstas son las cinco áreas estratégicas con las cuales las bibliotecas podrán en un futuro enfrentar el reto de asumir los cambios en el modelo educativo:

- Bibliotecas digitales y ambientes de aprendizaje digitales.

- Portafolios digitales.

- Alfabetización en información.

- Diseño multidisciplinario de cursos.

- La relación entre ambientes de aprendizaje físicos y virtuales.

Como puede verse claramente, las bibliotecas deben jugar un importante papel en estas cinco áreas estratégicas relacionadas con los nuevos ambientes de aprendizaje. Sin lugar a dudas los bibliotecarios no pueden estar ajenos a este proceso. Muchas son las facetas, vertientes y actividades que pueden y deben ser desarrolladas por ellos. Es obvio también que nuevas aptitudes y actitudes serán requeridas a esos bibliotecarios para desempeñarse plenamente en este nuevo ambiente. Pero debe quedar claro que las bibliotecas tienen una oportunidad y una responsabilidad enorme en esta sociedad de la información que se está reconformando y que hace evolucionar además sus esquemas educativos. Al fin y al cabo es natural que una "sociedad de la información" esté creando la "educación de la sociedad de la información" y para apoyarla necesite crear también las "bibliotecas para la educación y la producción de la sociedad de la información". Éste es el núcleo, esencia y razón de ser de las bibliotecas de nuestro futuro cercano. He ahí el paradigma, cimiento y pegamento sobre los cuales deben construirse. Tales bibliotecas se requieren para apoyar la educación propia de 
esa sociedad de la información, y hacia ese contexto van evolucionando. Pero las bibliotecas de esta sociedad deben ayudar además a personas, empresas y organizaciones a obtener la información para la capacitación, la cualificación, la producción y el desarrollo económico, industrial, gubernamental, etcétera, y en ese sentido debe entenderse producción. Esta segunda componente, que fue enunciada en el apartado de "Bibliotecas digitales y educación", es de suma importancia, ya que los dos enfoques son de capital importancia en el modelo y se complementan mutuamente.

De acuerdo con la visión de la IFLA acerca de las bibliotecas del futuro:

Los servicios bibliotecarios y de información proporcionan el apoyo esencial al aprendizaje a lo largo de toda la vida, toma de decisiones independiente y desarrollo cultural para todos. A través de sus vastas colecciones y variedad de medios, ofrecen guía y oportunidades para el aprendizaje. Los servicios bibliotecarios y de información ayudan a la gente a mejorar sus habilidades educativas y sociales, indispensables en una sociedad de la información y con miras a una participación sostenida en la democracia. Las bibliotecas impulsan el hábito de lectura y la alfabetización en información y promueven la educación, la conciencia pública y el entrenamiento.

Respecto al perfil del bibliotecario profesional para las bibliotecas digitales, podemos recapitular lo siguiente: las bibliotecas digitales requieren de bibliotecarios digitales. Las colecciones digitales deben ser planeadas, seleccionadas, adquiridas, organizadas, distribuidas y preservadas. Los servicios digitales deben ser diseñados, construidos, operados y mantenidos. Si bien en términos generales, los requerimientos para crear y operar una biblioteca digital son básicamente los mismos que para una biblioteca tradicional, las semejanzas terminan allí. Organizar un conjunto de colecciones y servicios digitales representa una serie de acciones y habilidades cotidianas que difieren de las requeridas para hacerlo con sus correspondientes tradicionales. Los bibliotecarios profesionales que dirigen bibliotecas digitales deben tomar decisiones y realizar ac- 
ciones para las cuales probablemente no fueron entrenados a fondo durante su carrera profesional. Si a esto sumamos el rápido cambio en los aspectos tecnológicos, resulta que lo que se aprendió recientemente queda rebasado en poco tiempo. El perfil entonces es "saber ser y saber hacer, puesto de manifiesto en actitudes, conductas o comportamientos en situaciones en las cuales pueda encontrarse un profesional". Existen varios tipos de perfiles: ocupacional, de competencia, de personalidad, teórico o ideal y profesional.

El perfil profesional del bibliotecario debe involucrar no sólo el perfil ocupacional sino también expectativas de desempeño acordes con las necesidades del medio y una visión acertada de los cambios tecnológicos y sociales que estamos viviendo. En los estudios relativos a perfiles profesionales, hay varias maneras de dividirlos; una de ellas ha sido dividir en dos grandes vertientes la caracterización del personal, estableciendo por un lado un enfoque hacia los atributos personales, es decir, las características innatas de un profesional y por otro los atributos profesionales, o sea las características aprendidas durante su formación. Existen por supuesto subdivisiones o agrupamientos de las características según el enfoque de los que han realizado estos estudios.

Existen definiciones de perfiles deseados para el profesional actual de la bibliotecología en diversas regiones del mundo; entre las más importantes, tenemos los perfiles establecidos por la Special Libraries Association de la Unión Americana, el de la Unión Europea, y en particular el de países como España y Francia. En el cono sur, en Latinoamérica, hay también muy interesantes definiciones al respecto que pueden servirnos como ejemplos a seguir. En el fondo, no difieren mucho unas de otras. Lo importante de todas ellas es comprender que con estas distintas visiones y caracterizaciones de lo que se espera que sea un bibliotecario profesional en la actualidad, sea suficiente para poder entender la responsabilidad del perfil que los bibliotecarios digitales deben presentar ante la sociedad; en particular ante las organizaciones que los contratan y ante los usuarios a los que atienden; los bibliotecarios profesionales mexicanos no son la excepción. 
Por supuesto, esto implica una reflexión conjunta entre los profesionales de la bibliotecología actuales en el campo del ejercicio profesional y los que tienen a su cargo la formación curricular de los futuros bibliotecológos en las escuelas correspondientes. Ello implica que los planes de estudio, balance de cargas curriculares académicas, etc., deberán ser replanteados en algún momento y cada vez más con mayor frecuencia a fin de responder a estos perfiles profesionales.

Muy vigente queda por tanto la reflexión de Jesse Shera ${ }^{33}$ acerca del estado del arte de la profesión bibliotecaria; a pesar de tener ya 15 años me parece que se encuentra cada día más vigente dentro del contexto actual:

[...] De todas las profesiones la del bibliotecario es seguramente la más derivativa y sintética, dependiente sobremanera de las disciplinas más formales para la derivación de su propia estructura teórica y cuerpo de práctica [...] esta calidad le ha dado a la bibliotecología una posición estratégica única de liderazgo en la integración del conocimiento humano y podría hacer de la bibliotecología una gran fuerza unificadora, no sólo en el mundo del saber sino en el de toda la vida humana...

En otro tema, uno de los elementos que será muy importante al momento de establecer el modelo, será conocer cuál es la infraestructura existente en México en lo relativo a tecnologías de información y comunicaciones. Para ello se ha presentado en el capítulo 3 una compilación de los datos más relevantes que nos permiten estimar en dónde estamos situados como país en este aspecto para saber qué tanto nos falta por hacer. Se usaron indicadores aceptados mundialmente para este propósito; entre ellos se distinguen cinco de los más comunes: el número de usuarios de la Internet en el país, el número de computadoras instaladas, el número de teléfonos de línea fija, de celulares y el costo por hora de la Internet.

33 Jesse H. Shera, 1990. "Lo que el bibliotecario...”. Op. cit., pp. 201-231. 
De los números presentados en el capítulo 3, se determina que las cifras deben ser tratadas con cuidado. Dependiendo del número tomado, puede concluirse sin faltar a la verdad que estamos muy bien o que estamos muy mal. Esto pasa cuando se usan números absolutos al respecto, lo que muchos hacen. Como pudo observarse, lo mejor es tomar números relativos porcentuales: el llamado "factor de penetración" de las cifras relativas a la Internet, PC, líneas, etc. Y siempre usar esos números dentro de un contexto: mundial, de región, etc., pues de otra forma puede llegarse a la conclusión que uno desee, óptima o pésima, pero siempre será sesgada.

Como conclusión que pretende ser objetiva, México está posicionado de manera intermedia en cuanto a la infraestructura que permitirá que los proyectos de sociedad de la información puedan llegar a niveles masivos. Si bien se han ido planteando soluciones de visión estratégica a nivel gubernamental, éstas no han estado del todo a la altura de la situación de cambio global, donde es evidente la necesidad de acciones estratégicas más decididas del Estado para construir una nueva economía del desarrollo. Como puede observarse en cuanto a las cifras, nuestra infraestructura no es nada despreciable, pero también puede verse todo lo que falta por hacer con miras a un proyecto de sociedad informatizada. Debemos estar muy conscientes de que en este rubro el ritmo del país no puede detenerse, pues es un factor vital para cualquier proyecto de educación o desarrollo.

Respecto a la diversidad cultural e integración nacional procedimos primero a definir y explicar "globalización cultural". Una enorme parte de la preocupación y rechazo que el concepto trae, es que para muchos globalización implica homogeneización. Para un buen número de personas preocupadas por la cultura, el término les hace pensar que en un futuro, a raíz del constante intercambio de fuerzas homogeneizadoras, eventualmente los habitantes del mundo se hallarán pensando, actuando y hablando de una manera muy similar. Obviamente el problema y el fenómeno existen, pero como fue establecido, el problema de fondo no subyace en el medio sino en el uso del medio. Como ya hemos recalcado, el proble- 
ma es la creación de "analfabetos digitales funcionales". Éstos son los que quedan expuestos totalmente a dicho fenómeno sin ninguna protección. No debemos ni podemos rechazar al medio per se, sino tomar las medidas que permitan el correcto aprovechamiento del medio. Hacer otra cosa sería tanto como rechazar la imprenta porque con ella se puede tener acceso a literatura barata e insulsa, información sesgada o pornografía. El fenómeno debe enfocarse en sus elementos críticos reales: alfabetización digital funcional e impulso decidido a la diversidad cultural y a las identidades nacionales.

Como pudo observarse, el elemento crítico entre la sociedad de la información y la diversidad cultural está estrechamente ligado a la evolución del marco regulatorio del comercio internacional, que se ha ido constituyendo como el armazón de la globalización económica, y que tiende a su vez a introducir más presiones dentro del papel de apoyo que en la actualidad desempeñan los estados y los gobiernos en materia cultural en beneficio de las poblaciones a las que se deben. El abandono de este papel que hasta ahora se ha materializado a través de políticas culturales y diversas medidas de apoyo a la cultura, tiene como grave riesgo la asignación de prioridades basadas en la aplicación exclusiva de las reglas del mercado al sector cultural. Esta situación significaría, en efecto, una homogeneización de las culturas en provecho de un modelo cultural único, basado en una lógica exclusivamente económica y comercial, que excluiría la expresión de las culturas "menos rentables" o carentes de los recursos y mecanismos de apoyo necesarios para su expresión.

Esta amenaza puede anularse sólo en tanto estemos conscientes de que la cultura no es una simple mercancía. Lo realmente importante, como muchos gobiernos y grupos de personas consideran, es que los bienes y servicios culturales desempeñan un papel determinante e imprescindible para muchos países y regiones del mundo respecto a la identidad de los pueblos, a la cohesión necesaria del tejido social de los mismos, a la vida democrática e inclusive retroalimenta al mismo desarrollo económico. No se trata de negar que los bienes y servicios culturales puedan ser objeto 
de comercio: se trata de que se reconozca que no pueden estar sometidos a las reglas usuales del comercio. Los elementos decisivos de la diversidad cultural se sitúan por tanto, en las presiones y tendencias que nos trae la evolución del cuadro reglamentario del comercio global, por un lado, y por otro, las políticas culturales y las diversas medidas de apoyo que los estados y los gobiernos adoptan para mantener la cultura en beneficio de sus poblaciones.

Por todo lo anterior, como pudo observarse, es de capital importancia que el modelo de bibliotecas digitales contemple estos aspectos y acciones relativas a la identidad nacional basada, a su vez, en el pluralismo cultural. Como fue establecido, es sumamente importante que nuestros modelos culturales no sean regidos sólo por modelos de globalización económica y eficiencia taylorista. Si México tiene hoy en día la riqueza cultural que ostenta es precisamente debido a su diversidad y pluralismo culturales, en las más variadas y ricas formas: lenguas, acentos, música, cocina, arte, leyendas y tradiciones, fiestas, expresiones, artesanías, folklor, etc., etc. Cuán poco de lo que somos seríamos si todos estos elementos culturales tuviesen una expresión uniforme y homogénea en todo el país. Por supuesto, lo mismo puede afirmarse del resto de los países de Iberoamérica. Hay de sobra elementos de identidad cultural nacionales a desarrollar en nuestra sociedad del conocimiento, que forman nuestra idiosincracia mexicana, latina e hispana y que deben ser registrados, protegidos e impulsados en un proyecto de esta naturaleza, so pena de efectivamente ir uniformando todo en un afán globalizador en donde "integrador" signifique "homogeneizador". Las mejores expresiones culturales se han dado en aquellos lugares y momentos donde el intercambio cultural ha sido además de y no en vez de. Como mexicanos deseamos ser integrados al ciberespacio, no homogeneizados en él; son dos cosas muy distintas.

Entrando ya al planteamiento del modelo a nivel nacional, hemos establecido que una "sociedad de la información" está creando la "educación de la sociedad de la información" y la "producción de la sociedad de la información" y para apoyarla necesita crear también las bibliotecas para la educación de la sociedad de la 
información o más propiamente dicho, como ya se subrayó también, queremos crear la "educación de la sociedad del conocimiento" y para apoyarla necesitamos crear también las bibliotecas para la educación de la sociedad del conocimiento como marco básico de conceptualización de las bibliotecas de nuestro futuro cercano. Se estableció también, dado que esa denominación es muy larga, que las llamáramos por comodidad bibliotecas digitales, sin olvidar nunca, y menos en este momento, que esas bibliotecas se requieren para apoyar la educación propia de esa sociedad del conocimiento y hacia ese contexto van evolucionando. Como fue establecido, debe entenderse aquí el término "educación" en su sentido más ecuménico, no sólo de enseñanza, ya que las bibliotecas de esta sociedad de la información deben ayudar, aparte de esa tarea, en la investigación, la cultura y la educación continua; deben ayudar a aprender a aprender, a trabajar en redes y a fomentar el concepto de colaboración colectiva por encima del concepto de competencia individual.

El objeto de estudio de este trabajo en su segunda parte, fue establecer un marco de referencia de la conceptualización de las bibliotecas digitales a nivel de país, tratando de establecer las diversas capas que una organización nacional debe tener; tarea nada fácil. El concepto de organización de las bibliotecas digitales en nuestro país, como en cualquier otro, no puede ser monolítico. Siendo un sistema de bibliotecas digitales a lo largo de todo el territorio nacional con el concurso de muchos sectores y capas de nuestra sociedad, y siendo un sistema de bibliotecas nacional, se optó por utilizar el enfoque de sistemas, que nada tiene que ver con la construcción de programas ni con computadoras o telecomunicaciones. Como ya se mencionó en la introducción, el problema puede ser explicado desde varios enfoques, pero me decidí por el enfoque sistémico como el mejor posible a aplicar en la segunda parte.

La razón fundamental de ello obedeció a la metodología misma. De algún modo ya hemos hecho un análisis reduccionista en la primera parte de este trabajo, analizando cada una de las partes que pueden intervenir en la construcción de una biblioteca digital y explicando cómo trabaja cada parte dentro de un todo. Como se 
mencionó, eso ayuda mucho a aquel que está tratando de diseñar su biblioteca digital o pequeño conjunto de bibliotecas digitales; el entorno "micro" por tanto ha quedado definido. Pero eso no podía ser simplemente extrapolado a nivel nacional para concebir una estrategia de desarrollo en México. Para esta segunda parte a nivel "macro", es decir, a nivel país, no me pareció que el planteamiento de bibliotecas digitales pueda establecerse a través de un conjunto de leyes o principios fundamentales que expliquen el comportamiento y permitan la predicción fenomenológica relativa a las bibliotecas y a la educación.

El enfoque holístico bajo el pensamiento o enfoque de sistemas es integrador en vez de reduccionista, tanto en el análisis de las situaciones como en las conclusiones que nacen a partir de él, y puede proponer soluciones globales en donde hay que tener en consideración diversos elementos y relaciones que conforman la estructura de lo que se define como "sistema", así como también de todo aquello que conforme el entorno del sistema definido. La consecuencia de esta perspectiva sistémica, fenomenológica y hermenéutica es que hace posible ver a la organización ya no como que tiene un fin predeterminado, sino que dicha organización puede tener diversos fines en función de la forma en que los involucrados en su destino la vean, surgiendo la variedad interpretativa. Esta visión estaría condicionada por los intereses y valores que posean dichos involucrados, existiendo solamente un interés común centrado en la prevalencia de la misma. A esta visión hay que agregarle la trayectoria histórica de la organización, que condiciona su situación actual; adicionándole el pasado y las aspiraciones futuras de los miembros de la misma, quienes influirán en su comportamiento. Esta nueva visión de la organización pretende ser mucho más rica y dinámica que la científica e interpreta mejor lo que sucede en el mundo real, estableciéndose un modelo organizacional que es construido colectiva y permanentemente por sus miembros a partir de las interpretaciones evolutivas que existan de la misma. Bajo este punto de vista de elaboración constructivista hemos procurado tener presente siempre que el conocimiento no es el resultado de una mera copia de la realidad preexistente, sino de un pro- 
ceso dinámico e interactivo a través del cual la información externa es interpretada y reinterpretada por la mente al ir construyendo progresivamente modelos explicativos cada vez más complejos y sofisticados. Esto significa que hemos tratado de conocer la realidad a través del modelo que construimos para explicarla, y que este modelo es siempre susceptible de ser mejorado o cambiado. En palabras de Pablo González Casanova: "en vez de llevar el conocimiento al objeto de estudio obtengamos el conocimiento a partir del objeto de estudio...".

Entrando a las premisas del modelo, el primer paso fue establecer el alcance del mismo; esto es, su ámbito de cobertura, recordando que un modelo viene siendo la representación de una realidad que destaca las características que deseamos estudiar. En este caso el objeto de estudio fue lo primero a definir. Por ello era muy importante establecer con toda claridad de qué estábamos hablando cuando pensamos en una solución de colecciones y servicios de información documentales digitales para México. Si es para México, estamos estableciendo entonces que éste es un modelo de alcance nacional, a lo largo y ancho de todo el territorio nacional y aun más allá, dado que existen muchos mexicanos fuera de nuestras fronteras que podrían verse beneficiados de un sistema de tales características.

Como lo establecimos en el apartado 2.2.2 existen dos tendencias o estrategias a nivel mundial: la de los países con una alta infraestructura TIC ya instalada, donde el énfasis está en la integración de sistemas, telecomunicaciones, redes, etc., dejando que las aplicaciones, contenidos y servicios tomen su lugar por su propia fuerza, con el ejemplo de la National Information Infraestructure (NII) de la Unión Americana (NII. Relationship..., 1998) que ha logrado arrancar el proyecto ya mencionado anteriormente de la Biblioteca digital nacional de ciencia y tecnología (NSDL, 2001). La segunda tendencia, como ya comentamos, se observa en otros países, principalmente de la Unión Europea y otros semejantes, en donde el énfasis ha estado en el desarrollo de contenidos, aplicaciones y servicios, dejando que la infraestructura se vaya desarrollando por su propia fuerza. Del análisis cuidadoso y detallado de las estrategias y 
estructuras desarrolladas a nivel mundial, se decidió que el modelo de desarrollo de nuestras bibliotecas se parece más al de la segunda estrategia. Y digo "se parece más" porque no es idéntico al de esa segunda estrategia. Creo que la estrategia adecuada para México en lo tocante a bibliotecas digitales consiste en el desarrollo de contenidos, aplicaciones y servicios como primer énfasis, pensando en que la infraestructura se va a ir adecuando con una acertada catalización del Estado.

Continuando en esta línea de pensamiento y de acuerdo con las iniciativas planteadas y analizadas se concluyó que la solución de base para la primera aproximación al modelo de estudio de nuestras bibliotecas digitales no es la creación de una superbiblioteca digital con inmensas colecciones que se encargue de servir a todo el país; tampoco un conjunto selecto de bibliotecas digitales cumpliendo esa función. Las principales razones para llegar a concluir esta primera aproximación fueron las siguientes:

- Nuestro modelo de desarrollo sociopolítico no contempla ya la excesiva centralización de recursos y oportunidades; la misma premisa se establece para el ámbito documental.

- Nuestro esquema de desarrollo de tecnologías de información y comunicación no corresponde al de los países con una alta infraestructura de telecomunicaciones y cómputo ya instalada, donde el énfasis está en la integración de sistemas, telecomunicaciones, redes, etc., dejando que las aplicaciones, contenidos y servicios tomen su lugar por su propia fuerza.

- La tecnología actual de cómputo y telecomunicaciones permite considerar un modelo integrador a nivel país el cual era muy difícil de implementar en una estructura "tradicional" sin esas herramientas.

- México no parte de la nada en cuanto al desarrollo bibliotecario. Existe ya un sistema de bibliotecas públicas, así como un buen número de bibliotecas y colecciones especializadas a nivel universitario o de investigación quienes ya empezaron o están listas en el desarrollo de colecciones digitales y cuyo total asciende a más de 10000 sin contar las de instituciones privadas. 
- Existe una buena cantidad de información con valor documental dispersa en poder de los sectores productivos y bien organizada puede formar parte considerable de acervos documentales nacionales que a la fecha no se han explotado.

- Existe una enorme cantidad de recursos documentales no digitalizados en múltiples repositorios que procesada en forma compartida y colaborativa por muchas bibliotecas podrá formar un enorme y rico acervo mexicano en un plazo y a un costo razonables.

Por estas razones se concluyó que nuestra primera aproximación al modelo de desarrollo de bibliotecas digitales mexicano debe ser un sistema articulado de numerosas bibliotecas digitales de muy diversas índoles y características donde se conforma de manera integral un organismo con una sola función general, y en donde todas y cada una de ellas cumplen una función particular preestablecida, armónica y aditiva. Dicho de otra manera, una especie de "federación" de bibliotecas digitales de muchos tipos y características alcanzando a todos los usuarios del país y más allá. Como todo sistema orgánico debe tener entonces subsistemas y tejidos especializados con funciones específicas. Recordemos además que se ha preestablecido en la metodología una visión holística, y por ello debemos plantear un modelo organizacional en el que los fines del mismo son producto de la construcción cooperativa de todos los involucrados en él. Para lograr este objetivo, indudablemente tendrán que crearse o impulsarse ciertas bibliotecas y colecciones digitales estratégicas para un adecuado funcionamiento del todo, pero el modelo no debe basarse en el desarrollo de sólo un selecto grupo de bibliotecas digitales.

De este planteamiento se establecieron entonces las primeras premisas y precisiones: cuando hablamos del modelo de construcción de biblioteca digital para México, vamos más allá de los planteamientos micro que se refieren a una sola biblioteca y que son replicables muchas veces; estamos en el entendido de que nos estamos refiriendo siempre a un sistema nacional organizado de bibliotecas digitales, y nunca a una superbiblioteca o selecto club de ellas. Hablamos entonces de un modelo de planeación y organiza- 
ción de esa biblioteca digital como un sistema nacional y debemos entonces ir estableciendo la interacción de las partes que la integran. Debemos organizarnos y planear a nivel federal, estatal, municipal y regional y además con planos geográficos, por sector, por comunidades de usuarios, etc. Requerimos de ellas y tendremos como seguros participantes a bibliotecas públicas, escolares, universitarias, especializadas, industriales, privadas, etc. Como fue establecido, la sociedad de la información del futuro cercano no contempla sólo al sector educativo. Se tienen necesidades y recursos de sectores productivos muy definidos que van más allá de su propio ámbito; por ello, otros sectores deben ser integrados adicional e indispensablemente a este esfuerzo bibliotecario.

Para establecer la premisa del alcance de contenido hemos mencionado varias veces la creación de un conjunto de recursos, sistemas, servicios y acervos de información documental. Como analizamos en los primeros capítulos de esta obra, el concepto de información es muy amplio y conviene precisarlo. De acuerdo con las premisas de información aceptadas universalmente para este tipo de iniciativas, la premisa fundamental de este tipo de sistemas y servicios de información es que nuestro sistema educativo, económico, político y social operará con más eficiencia si se establece un mecanismo que garantice que los responsables, planificadores, gerentes, ejecutivos, directivos, profesionales, etc., del sector público y de los sectores privados, así como del sistema educativo, incluyendo a todos los maestros, investigadores, académicos y alumnos, tengan acceso puntual a datos e informaciones actualizadas, suficientes, pertinentes, oportunas y fiables. Por ello, la materia prima y en consecuencia la premisa del contenido de un proyecto nacional de bibliotecas digitales e información, es el acceso y la utilización óptima de los conocimientos a través de los materiales documentales generales, especializados y profesionales; la información científica, técnica, política, cultural, social y económica; y a través también de las técnicas y habilidades desarrolladas o disponibles en el país y en otras partes del mundo, como recurso destinado a resolver problemas y para el desarrollo en todos los sectores de la sociedad. 
Se concluyó también que la función del Estado en un futuro cercano será cada vez más la de fomentar y regular y menos la de realizar. De acuerdo con esta tendencia, el Estado deberá crear las condiciones para que la sociedad civil participe en vez de pretender realizarlo todo por sus propios medios. Por supuesto, esto no debe interpretarse como que el Estado ya no es responsable de la realización de proyectos de estrategia nacional. Nada más lejos de la realidad; debe entenderse que el Estado propicia, fomenta, regula, supervisa, etc. Es decir, el Estado debe ver que las cosas se den, sin realizarlas él mismo y sin acabar teniendo el control absoluto de ellas. Bajo esta acepción moderna se definió cuáles son las funciones del gobierno dentro de un proyecto de esta naturaleza. Para ello véase el mapa conceptual de responsabilidades a nivel gobierno acerca de un sistema nacional de bibliotecas digitales (figura 5.2).

Como paso previo a su definición, fue necesario "alinear" el modelo dentro del contexto internacional y nacional. Me pareció lo más conveniente que el marco rector para este alineamiento fuese una unión de la última declaración de la Sociedad del Conocimiento de la UNESCO, la Declaración de Libertad Intelectual de la IFLA y las cinco prioridades de e-Europe como referencia internacional, así como el proyecto e-México, el documento de la Academia de Ciencias Mexicana y el Programa Nacional de Educación 2001-2006 en cuanto al ámbito nacional (World Summit..., 2003, IFLA, 1999, European Comission..., 1997, e-México, 2001, Secretaría de Educación Pública, 2001, Academia..., 1999). El marco de referencia, ya alineado, puede verse en el apartado 5.3. Una vez establecido el marco de referencia, se definieron los elementos básicos para la planeación del modelo:

Definición y objetivo: El sistema nacional de bibliotecas digitales es un conjunto de capacidades técnicas, organizativas, recursos electrónicos, redes distribuidas y personal calificado integrados para la creación, búsqueda y distribución de acervos y servicios de información documental multimedios cuya función es la de satisfacer en lo posible todas las necesidades de información de múltiples 
comunidades específicas de usuarios, procurando hacer llegar sus colecciones y servicios a aulas, oficinas, laboratorios, industrias, hogares, áreas públicas, etc., a todo el país y más allá.

Misión: Ser la principal herramienta de tecnologías de información para hacer accesible el conocimiento a través de la información documental para la enseñanza, el estudio, el trabajo, la investigación, la capacitación y el esparcimiento de personas y comunidades escolares, académicas, profesionales, gremiales, sectoriales, artísticas, etc., de todo nivel y a lo largo de todo el territorio nacional extendiéndose a la comunidad global.

Visión: El sistema nacional de bibliotecas digitales debe conformarse como una herramienta primordial de un nuevo modelo educativo. Debe ser un mecanismo de igualdad y movilidad social brindando oportunidades equitativas de acceso a la información y enseñanza adecuada, oportuna y en lo posible gratuita a todo tipo de comunidades. Debe ayudar a preservar, junto con los valores científicos, artísticos y culturales universales la identidad, los valores, la lengua y la cultura nacionales así como las regionales. Debe convertirse en el principal apoyo de los proyectos para la integración adecuada de las tecnologías de información para la construcción de una sociedad del conocimiento en México. Debe ayudar a la integración y vínculo con comunidades de mexicanos fuera del territorio nacional. Debe ser elemento clave en un modelo de capacitación de aptitudes para el trabajo en forma permanente bajo nuevos paradigmas de trabajo en red, colaborativo más que competitivo, etcétera.

Políticas: El sistema nacional de bibliotecas digitales es un proyecto de importancia nacional y estratégica para el país y no es responsabilidad única del gobierno; es un proyecto del Estado mexicano. Por lo mismo, debe construirse sobre un modelo nacional de organización participativa de los sectores gubernamental, educativo y productivo del país, tomando cada uno su responsabilidad en la producción, organización y distribución del material documental de manera integral y armónica; debe poder articularse desde los niveles más altos de los sectores involucrados hasta los niveles más elementales de participación. Debe evitar redundancias innecesarias.

Este sistema de bibliotecas debe priorizar que la distribución y consumo de información documental no es simplemente una tarea de asistencia social que deba ser otorgada bajo el esquema 
de los programas de esa índole. Es un factor indispensable para un incremento y desarrollo sostenido igualitario y visible del bienestar económico, social, político, educativo, etc., de todos los sectores de nuestro país. Por lo mismo, debe establecerse una serie de estrategias para su desarrollo y sustento económico.

Estrategias: Como se ha establecido, y reiterando la visión holística del mismo, el sistema de bibliotecas digitales es "un modelo nacional de organización participativa". Dado que es un proyecto de alcance nacional que no depende únicamente del sector gubernamental debe establecerse una perfecta articulación del sistema en una estructura confederada de sectores, niveles, programas, etcétera.

Factores de éxito: Para la definición del modelo he tratado de no pasar por alto las premisas esenciales de los modelos de desarrollo de la sociedad del conocimiento y bibliotecas digitales más relevantes, que han sido ya analizados, provenientes de otros países. Si bien nuestro modelo no puede ser igual a ninguno de los ahí presentados dadas nuestras características nacionales y puesto que debe contener una personalidad y contexto propios, se trató de integrar todas las premisas consideradas indispensables y las "buenas prácticas" de los modelos norteamericano, europeo, canadiense y brasileño, entre otros.

Deben establecerse claramente en el ámbito del proyecto nacional los principales sectores del desarrollo nacional y por tanto participantes en el proyecto. Debe definirse quiénes son responsables de organizar a cada uno de los sectores, cuáles son las necesidades de información del sector, sus recursos, insumos, características, organización, subsectores, operadores ejecutivos, etc. Especial cuidado debe tenerse al establecer las definiciones mencionadas para los sectores educativo-académico y bibliotecario. Dado su papel estratégico en el proyecto, deben definirse con absoluto detalle y precisión sus responsabilidades, recursos, necesidades, fortalezas, etc. El gobierno es también un importante sector "productivo" en el proceso de la información documental y como tal debe formar parte del conjunto de sectores actores del desarrollo. Como sector cuenta con importantes recursos de colecciones y/o servicios documentales para aportar al proyecto y es un ávido e importante 
consumidor de información; visto como sector de producción y consumo, el gobierno tiene características, subsistemas, necesidades, servicios, etc., que le son propios y por tanto también deben ser definidos con detalle y precisión al margen de su función rectora.

Por ello, para comenzar a estructurar las estrategias, sería conveniente organizar un comité directvo (steering commitee) y dos "fuerzas de tarea". Esta estructura ha sido denominada así a propósito en otros países para ésta y otras iniciativas de planeación e implica que dicha instancia sólo se crea para sentar las bases de organización de una estructura más permanente. La experiencia es que en este tipo de iniciativas no debe crearse una estructura organizativa muy grande con toda la parafernalia de organigrama, puestos, plazas, oficinas, edificios, etc. Si bien hay varias maneras de crearla, una aproximación muy conveniente podría ser un cuerpo colegiado o comité directivo formado por un muy pequeño y selecto grupo de funcionarios de alto nivel y miembros de la sociedad civil, ayudados por una mínima infraestructura o secretariado de tiempo completo. Si la comisión original es muy grande y de carácter representativo de todos los sectores al inicio, corre el riesgo de perderse en sus objetivos, de crear estructuras de poder o pertenencia o de burocratizarse. Dos grupos operativos, las mencionadas "fuerzas de tarea" se crean también al efecto; de acuerdo con la experiencia, las seis funciones críticas de estos dos grupos serían:

- La definición de roles, responsabilidades y estructura de apoyo dentro del comité y los dos grupos de trabajo.

- El establecimiento de los dos grupos de trabajo intersecretariales e intersectoriales, cada uno con una misión específica de organización. Cada grupo deberá contar con expertos técnicos, políticos, etc., apropiados a su tarea y deberá establecer claramente sus metas, tiempos, programas, productos y agentes responsables.

- La búsqueda y asignación de personas clave a cargo de cada uno de los grupos de trabajo.

- La definición de estrategias de fondeos primario y secundario para el proyecto. 
- El establecimiento de recomendaciones generales y adopción de las "mejores prácticas".

- La definición de mecanismos para la instrumentación coordinada, evaluación de avances y retroalimentación hacia ellos mismos y hacia el comité directivo.

Una vez que estos dos grupos de trabajo entren en funciones, coordinados siempre por el cuerpo colegiado directivo, deben emprender las siguientes acciones estratégicas encaminadas al desarrollo del modelo. Del mapa conceptual de responsabilidades a nivel gobierno se obtuvieron las acciones que serían desarrolladas por sendos grupos:

- Definición detallada y organización de los sectores que conformarán el modelo.

- Evaluación del entorno nacional de bibliotecas y bibliotecas digitales; esto es:

- Inventario de recursos, acervos y servicios documentales, digitales y no.

- Inventario de legislaciones, políticas, programas, normalización, etcétera.

Estos mecanismos de arranque son absolutamente estratégicos, ya que su logro sustenta la base de acción del modelo. Los sectores organizados con ella y con el inventario de recursos permite tener la estructura y la información para desarrollar las siguientes acciones operativas del modelo.

Desarrollando el modelo: acciones y grupos. Definición detallada de los sectores que conformarán el modelo

Retomando nuestro diagrama básico de organización del modelo de bibliotecas digitales observamos que el sistema sectorial se encuentra conformado en primera instancia por los sectores gubernamentales -mitad izquierda-, y en segunda instancia por los productivos junto con el académico-educativo - mitad derecha-. Como 
metodología, uniendo las dos mitades, y después de varias aproximaciones, establecimos una propuesta de conformación de 12 sectores, lo cual puede verse con detalle en el apartado 5.5.1. Esta propuesta de agrupamiento sectorial cubre, o al menos eso pretende, a todos los sectores gubernamentales de los tres poderes así como a los sectores productivos más representativos de la sociedad civil y, por supuesto, al muy importante sector académico-educativo y bibliotecario; cumple pues con la premisa del diagrama básico con sólo 12 sectores. Por supuesto, ésta es sólo una de las posibles divisiones, y es totalmente arbitraria; puede ser subdividida o integrada en muchas otras formas, pero ilustra sin duda el concepto de integración coherente de prácticamente todos los sectores públicos y privados del país, involucrados con recursos y necesidades de información para la educación, el trabajo, el desarrollo y el esparcimiento, en un número razonable de sectores.

La tarea de este segundo grupo de trabajo, una vez establecido como fuerza de tarea y con sus seis acciones básicas, consiste en realizar la evaluación del entorno nacional de bibliotecas digitales o no, llegando a una exhaustividad y nivel de detalle mucho mayores de los que existen actualmente en las cifras del INEGI, ya que ellas en particular son demasiado escuetas y desactualizadas. En este estudio es sumamente importante, a diferencia de la situación actual, incluir tanto instituciones públicas como privadas e integrar al mismo una serie de colecciones documentales de muy diversa índole, todas aquellas que tengan valor bibliográfico, tales como colecciones musicales, cinematográficas, videográficas, etc. Esta tarea se divide en dos partes principales:

1. Inventario de recursos, acervos y servicios documentales, digitales y tradicionales: a) bibliotecas, archivos documentales, centros de información y documentación, etc. b) Personal bibliotecario. c) Servicios bibliotecarios y de información. d) Recursos tecnológicos.

2. Inventario de legislaciones, políticas, programas, normalización, etc. El detalle de este inventario se encuentra en el apartado 5.5.2. 
La compilación detallada en lo posible de esta información y su difusión y actualización adecuada serán un factor indispensable para la acertada toma de decisiones por todos los planeadores y operadores del proyecto. Una vez que este segundo grupo haya terminado su tarea y publicado sus resultados, puede concluir sus actividades no sin antes establecer los mecanismos y agentes responsables que aseguren que el proyecto sea actualizado y difundido anualmente.

Estos dos grupos de trabajo deben obtener como resultado, por un lado la estructura de organización de los 12 sectores y por el otro la información básica que esta estructura necesita para la planeación.

Consolidando el modelo: El "comité directivo de arranque" estaría listo para transformarse en el "comité directivo de los 12 sectores", reconformándose e integrando personas clave provenientes de esos 12 sectores. Nuevamente debe respetarse la premisa de un "comité directivo" formado por un muy pequeño y selecto grupo de funcionarios de alto nivel y miembros de la sociedad civil, ayudados por una mínima infraestructura o secretariado de tiempo completo.

Los países como el nuestro necesitan inversiones y capital, infraestructura, tecnología, expertos y equipos. Y necesitan todo eso simultáneamente; de lo contrario, cualquier proyecto estará destinado al fracaso. Se pueden emprender proyectos locales, impulsados por gobiernos, organizaciones no gubernamentales (ONG), empresarios, etc., pero su alcance será siempre demasiado limitado si no es concurrente. Por tanto, una vez que se han logrado las acciones estratégicas de arranque, y partiendo de las iniciativas nacionales e internacionales acerca de sociedad de la información y bibliotecas digitales, propuse "ocho líneas de acción" operativas para el adecuado desarrollo del proyecto:

- Creación, desarrollo y no redundancia de colecciones y servicios documentales digitales nacionales. En particular:

- Textos y material digital básico para cada nivel educativo.

- Servicios de información documental para el gran público. 
- Estrategias de adquisición y desarrollo de materiales originalmente digitales, así como estrategias de digitalización de materiales.

- Normalización y estandarización de registros digitales desde el punto de vista bibliográfico.

- Revisión y actualización de la legislación acerca de acceso a la información, derechos de propiedad electrónica y privacidad, así como de otros entornos legales relevantes al proyecto.

- Desarrollo de especialistas y personal calificado en tecnologías y servicios de información y modelos educativos.

- Promoción del uso efectivo de la información; acceso gratuito o económico.

- Desarrollo de infraestructura de cómputo y telecomunicaciones; desarrollo en innovaciones tecnológicas que impulsen el proyecto.

- Impulso a la inversión privada en tecnologías de información y comunicaciones.

- Integración del proyecto a la identidad, valores y cultura nacionales.

En este punto, es conveniente recapitular qué es lo que ya tenemos antes de entrar de lleno a la fase operativa del modelo:

- Un comité directivo, de tamaño adecuado, con personas clave provenientes de varios sectores, tanto públicos y privados, y con funciones adecuadas preestablecidas, para coordinar esa fase operativa apoyado en una mínima infraestructura secretarial de tiempo completo.

- Una organización claramente definida de 12 sectores básicos del país, con personas clave que pueden incidir sobre múltiples instituciones.

- Un estudio estadístico muy completo de los recursos y potencial documental, humano, legal, normativo, tecnológico, etc., acerca de las bibliotecas e instituciones semejantes de todos los sectores públicos y privados.

- Ocho líneas de acción claramente establecidas en las que cada sector deberá trabajar. 
Con estos cuatro elementos logrados; comité, los 12 sectores organizados, estudio estadístico y las ocho líneas de acción operativas definidas, estamos en posibilidad de establecer la estrategia central del modelo: "Los 12 sectores trabajarán y desarrollarán cada uno las ocho líneas de acción operativas, para definir cuál es la incidencia, recursos, necesidades, oportunidades, retos, debilidades, etc., de cada sector respecto a cada una de las ocho líneas".

Esto significa que cada uno de los sectores analizará y desarrollará todos los enfoques que el comité haya establecido en cada una de las ocho líneas de acción, entregando una propuesta de acción específica para cada sector y línea. Esto quiere decir que al final deberíamos contar con una matriz de $12 \times 8=96$ análisis-propuestas. Será responsabilidad del comité directivo sentar las bases y reglas de operación para que todas sean homogéneas en alcance, forma y contenido. Por supuesto, el grado de incidencia de cada sector en cada línea de acción no es homogéneo; en algunas líneas de acción habrá mayor o menor incidencia de parte de cada sector. Pero es muy importante establecer el grado de incidencia y responsabilidad de cada sector en cada caso, por mínimo que sea. Véase la matriz conceptual del grado de incidencia de los 12 sectores con las ocho líneas de acción.

Para cumplir con este cometido, cada uno de los 12 sectores se convierte a su vez en un grupo de trabajo y debe organizarse internamente, bajo la guía y dirección del mencionado comité directivo. Para esto, podría ser útil que cada sector aplique las "seis funciones básicas" para los primeros dos grupos que se encargaron de las acciones de infraestructura. Este comité debe establecer claramente las características y expectativas para cada sector de cada una de las líneas de acción; para ello, será conveniente que el comité presente un conjunto de "condiciones estratégicas de inicio" sobre las cuales debe ser elaborada la propuesta. Es conveniente también detallar más en qué debería consistir cada una de esas ocho líneas de acción establecidas y la propuesta de "condiciones estratégicas de inicio" tentativas para cada línea de acción.

Durante el desarrollo del modelo se detallaron en lo posible algunas propuestas de cómo desarrollar estas líneas de acción. 
Recordemos que la dinámica de desarrollo de estas ocho líneas de acción es que a partir de las "condiciones estratégicas de inicio" -independientemente de su intensidad esperada-cada sector debe hacer una propuesta en cada línea de acción. Uniendo las 12 propuestas que resulten de los 12 sectores con las "condiciones estratégicas de inicio" podremos establecer las línea de acción definitivas, las cuales deberán reflejarse en el plan de acción específico para el desarrollo de cada línea de acción.

Finalmente, una vez que se tengan los planes detallados para cada línea de acción el comité deberá darles forma, cuerpo y articulación para volverlos un todo coherente. Como todo buen plan, deberá tener elementos adicionales como tiempos de ejecución, mecanismos y vías de financimiento, definición de agentes responsables y acciones de inicio. Deberán ser también especificados los mecanismos detallados de seguimiento, evaluación y retroalimentación del plan. Deberán ser tomadas las medidas alternativas en caso de que alguno de los sectores o de los resultados no esté funcionando de acuerdo con lo esperado. El modelo organizacional podrá y deberá ser construido permanente y colectivamente por los miembros de la organización, a partir de las interpretaciones evolutivas que existan de la misma. Esto contribuirá de mejor forma para un futuro a mediano y largo plazos pensando en que puede ser reconstruido, complementado y enriquecido por la acción de los distintas personas, organizaciones y sectores que puedan verse involucrados en el esfuerzo. Puesto que no se trata de un plan de corto plazo, tomará un tiempo desarrollarlo y mucho más llevarlo a cabo, pero uno de sus principales atractivos es precisamente ése: que una vez desarrollado es un plan con visión de largo alcance que puede servir como horizonte de referencia lejano en el tiempo para que pueda seguir siendo un plan estratégico de desarrollo nacional durante muchos años y, no obstante, vigente. 

Los libros no se han hecho para que creamos lo que dicen, sino para que los analicemos. Cuando tomamos un libro, no debemos preguntarnos qué dice, sino qué quiere decir.

UMBERTO ECO

\section{Consideraciones finales}



omo advertí en las conclusiones de Bibliotecas y publicaciones digitales tampoco pretendo en modo alguno haber agotado todos los temas relacionados con la biblioteca digital bajo este segundo enfoque. Todo aquel que haya seguido ambos trabajos, sin duda coincidirá conmigo en ello. Como mencioné al inicio de esta obra, cada tópico que desarrollaba era una puerta que al abrirla me conducía a un corredor lleno de puertas, cada una de las cuales conducía a su vez a otro corredor en forma infinita... o quizá eran otras galerías, tal como Borges imaginaba en su Biblioteca de Babel: “... el universo -que otros llaman la Biblioteca-, se compone de un número indefinido, y tal vez infinito, de galerías hexagonales, con vastos pozos de ventilación en el medio, cercados por barandas bajísimas. Desde cualquier hexágono se ven los pisos inferiores y superiores: interminablemente...”. La biblioteca digital es sin duda una Biblioteca de Babel, infinita, complicada, cambiante, pero interesante en extremo por lo mismo y con innumerables secretos aún por descubrir y por explicar. Nuevamente tengo muchas más respuestas que cuando comencé; por consecuencia tengo muchísimas más preguntas.

No pretendo tampoco afirmar que el modelo propuesto es el mejor o el único modelo posible; jamás fue mi idea. Tampoco aspiro a que se vuelva un modelo oficial; sería muy pretencioso de mi parte. Mi única intención al respecto ha sido demostrar que me- 
diante un método de planeación adecuado, moderno, coparticipativo e integral es posible diseñar un plan articulado a nivel de todo el país, con objeto de lograr que nuestras bibliotecas, digitales por lo que se verá, se inserten realmente en un verdadero desarrollo de nuestra sociedad. Si alguien que pueda tomar decisiones al respecto encuentra algo útil en esta obra y lo aplica, por poco que sea, habrá cumplido su propósito y habrá valido la pena.

Al fin y al cabo a todos nos interesa el desarrollo social, cultural y económico de nuestro país; una educación que lleve a las personas a un mejor nivel de vida gracias a más y lectura y capacitación, y que ello sea un motor de movilidad social. Un modelo educativo que tenga presente, como Yeats decía, que "educar no es llenar un recipiente; es encender una llama”, y lograr una sociedad donde el nuevo "analfabetismo digital" y el "analfabetismo funcional" se reduzcan y cuyos miembros realmente puedan aprovechar la red para acceder a un mejor nivel de vida; una sociedad más igualitaria y participativa, donde la libre circulación de las ideas y los derechos sean las directrices y convivan con una sana responsabilidad del ejercicio de los mismos y donde los grupos marginados tiendan a desaparecer; un rescate de nuestra identidad, lengua, cultura y valores nacionales dentro de su diversidad; una sociedad que replantea sus valores humanistas y que es capaz de globalizarlos más rápidamente que sus intereses económicos; una sociedad que aprenda a valorar, apreciar, cuidar y construir su patrimonio científico, cultural, social y ecológico y que aprenda a convivir en paz con el planeta y sus habitantes. Una sociedad que logre comprender que es más importante ser que tener, y que valore tanto o más la colaboración que la competencia. Una sociedad que atesore más el conocimiento que el reconocimiento. Una sociedad que nuevamente logre equilibrar el derecho a obtener legítimas ganancias de comercializar la información con el derecho al acceso y difusión de la misma. Una sociedad que, al fin, comprenda que la tecnología sin vocación humanista no tiene sentido y no lleva a ningún lado.

Sin querer ser pretencioso, nada de lo aquí enunciado podrá ser posible sin un elemento de capital importancia: las bibliotecas para la educación y el trabajo de la sociedad mexicana del siglo XXI, 
muy probablemente bibliotecas digitales. Por supuesto, su cabal desarrollo no será condición suficiente para ese objetivo, pero sin duda será una condición necesaria, absolutamente necesaria y hasta indispensable. En las declaraciones de la IfLA leemos -y no podría estar más de acuerdo-: "las bibliotecas son un elemento crucial en cualquier tipo imaginable de educación”. Yo agregaría: "y en cualquier tipo imaginable de trabajo".

Mencioné en la otra obra que Umberto Eco explicó alguna vez el significado de su genial y misteriosa última frase de El nombre de la rosa $;{ }^{34}$ básicamente, él quiso decir: "las cosas existen cuando tienen nombre; la sustancia de las cosas proviene primordialmente del nombre, y aunque desaparezcan, queda su esencia en el nombre". Carl Gustav Jung lo dijo también de otra forma: "los nombres invocan; si se pronuncian ciertos nombres las cosas aparecen". Un poco era ésa mi idea: he tratado de lograr que el término "Bibliotecas digitales" con todo su concepto, con toda la carga que lleva asociada se fusionara en una verdadera esencia y estas bibliotecas aparecieran. Ojalá y las bibliotecas digitales tengan ahora un poco más de nombre y significado para el lector. Al menos, para mí sí.

En una posdata que apareció años después de publicada la obra, Umberto Eco explicaba el significado de esa última frase de su libro. Eco dice:

Desde la publicación de $E l$ nombre de la rosa he recibido numerosas cartas de lectores que desean saber el significado del hexámetro latino, y por qué ese hexámetro me inspiró el título de la obra. Les contesto que este verso es de la obra De Contemptu Mundi de Bernardo de Morlay, un monje benedictino del siglo XII cuyo poema es una variante del tema ubi sunt, más conocido por otra obra de Villon titulada Dónde están las nieves de antaño

34 Stat rosa pristina nomine, nomina nuda tenemus (La original rosa existió por su nombre, sólo nos quedan los nombres). Humberto Eco, 1980. Op. cit., p. 607. 
Un modelo de planeación de bibliotecas digitales para México

(Mais ou sont les neiges d'antan). Los lugares comunes tales como la grandeza del ayer, las alguna vez famosas ciudades, las adorables princesas, todo desaparece en el vacío. Bernardo agrega que esas cosas dejan siempre y al menos, sus nombres detrás de ellas. $\mathrm{Y}$ habiendo dicho esto, dejo al lector que saque sus propias conclusiones. ${ }^{35}$

35 Umberto Eco, "Postdata al Nombre de la Rosa". Disponible 3 de noviembre de 2005 en: http://www.umbertoeco.com/id-39/UmbertEco_Name_of_the_ Rose_Umberto_Eco.html 
"Cetera, desunt..."36

36 "Lo demás, falta..." 



\section{Glosario}

AACR2 (Anglo American Cataloguing Rules). Reglas Angloamericanas de Catalogación, versión 2.

ACRL Association of College and Research Libraries.

ALA American Library Association.

Alfabetización (digital, electrónica, informática o tecnológica). Término utilizado para designar el concepto de capacitación básica o mínima del individuo en tecnologías de la información y comunicación.

Alfabetización funcional. Término utilizado para designar el concepto de dominio del individuo en cuanto a la capacidad de obtener beneficios reales para escalar a un mejor nivel de vida, gracias al acceso a las tecnologías de información y comunicación.

Algoritmo. Término proveniente del nombre de un célebre matemático árabe del siglo IX, llamado Al-Juarizmi, quien escribió el Compendio para el cálculo de Al-jabr y Al-muqabala, en el cual presenta la solución de varias ecuaciones lineales y cuadráticas a través de un nuevo proceso, consistente en un método para resolver un problema numérico a través de reglas claras, en forma secuencial e iterativa. Posteriormente, a cualquier proceso que siguiera esa aproximación se le denominó en latín con el nombre de su creador, llamándolo "algoritmo", y de ahí al español.

Ancho de banda. La cantidad de información que puede ser enviada o recibida por unidad de tiempo por un dispositivo de 
Un modelo de planeación de bibliotecas digitales para México

telecomunicaciones dentro de una red, tal como módem, línea telefónica, etc. Se mide en "bytes" o caracteres por segundo y sus múltiplos, kilobytes por segundo (kbps), megabytes por segundo (mbps), etcétera.

ARL. Association of Research Libraries.

ASCII (American Standard Code for Information Interchange). Se pronuncia "aski". Código creado a fines de los cincuenta y perfeccionado durante más de una década; a fines de los sesenta tomó la forma que conocemos hoy. En un principio, las computadoras sólo manejaban internamente números. Por su construcción de naturaleza eminentemente eléctrica se utilizaron números binarios, ya que es la representación más simple de un sistema numérico al usar sólo dos componentes, " 0 " y “ 1 ”. Ideal para una máquina que tiene cables, energía y todo puede representarlo con "existe electricidad" o "no existe electricidad". Al principio, los datos eran sólo números, y las instrucciones para manejarlos se daban también con instrucciones en forma de números. Conforme las computadoras evolucionaron se hizo necesario que también pudiesen representar internamente letras, para así ir formando textos más comprensibles y después de las letras, los otros caracteres inherentes a un texto (comas, puntos, signos, etc.). Para representarlos internamente sin romper ese esquema básico binario la solución fue representarlos como una convención de números binarios, arbitraria y previamente establecida, algo así como el código morse. En un principio cada empresa de computadoras estableció su convención; pronto se hizo necesario estandarizarla y surgió una norma en ese sentido. Ése es el principio del código ASCII, el cual nació como una norma americana para homogeneizar las posibles representaciones numéricas binarias de las letras y signos de puntuación. En un principio funcionaba sólo con el alfabeto inglés. Luego fueron agregados otros caracteres con diacríticos usados en otros alfabetos occidentales (letras con acentos, tildes, diéresis, etc.), con lo que se convirtió en un código internacional más allá de la Unión Americana, derivando en versiones ISO usadas en todos los alfabetos del mundo occidental. Posteriormente se crearon otras versio- 
nes similares para alfabetos griego, cirílico, árabe, japonés, etc. Gracias a ASCII es posible que lo que tecleamos en cualquier computadora con teclado "occidental" sea legible en cualquier otra computadora, sin importar la marca de la misma o el sistema que se utilice para enviarlo de forma remota. (Véase también: UNICODE). ISO 10646. Information technology. Universal Multiple-Octet Coded Character Set (UCS). Part I. Architecture and Basic Multilingual plane. Geneve: ISO (1993-1997).

Blog. Palabra proviene de la contracción de un término de la red: Web Log (contenidos personales en la red). En esencia, un "blog" es básicamente una revista o serie de artículos que se distribuyen por la red mundial $\mathrm{wW}$, con la característica distintiva de que su información se actualiza constantemente con nuevos comentarios, datos y vínculos, inclusive diariamente; es decir, no queda estática como en una revista "típica".

BNF (Backus Naur Form). Notación para metalenguajes muy utilizada para definir lenguajes de programación desde 1959 y que toma su nombre de sus creadores John Backus y Peter Naur.

BNF. Bibliothèque Nationale de France.

Byte. Conjunto formado generalmente por ocho dígitos binarios o bits, que bajo una convención preestablecida representan un caracter de texto en código ASCII. También se le llama "octeto" o "caracter" y sirve como unidad de medida de almacenamiento como discos, CD, DVD.

Ciberespacio. Término creado en 1984 por William Gibson en su novela de ciencia ficción Neuromante (Neuromancer). Se define como el espacio de comunicación abierto por la interconexión mundial de las computadoras y por donde fluyen los datos, archivos y mensajes informáticos permitiendo su intercambio por acceso remoto.

Ciberseguridad. Término creado para definir el conjunto de leyes, normas, medidas, procedimientos, recomendaciones, sistemas, dispositivos, tendientes a evitar el uso indebido de información en la Internet, tales como distribución de virus, spam, apropiación ilegítima de información personal (phishing), acceso ilegal o malicioso a sistemas (hacking), etcétera. 
Un modelo de planeación de bibliotecas digitales para México

DLTC. (Canadiense) Digital Libraries Technical Committe.

DTH (Direct-To-Home TV). Sistema de TV enviada directamente al usuario vía satélite gracias a una pequeña antena receptora en el lugar del usuario.

Dublin core. Es un conjunto de 15 etiquetas prestablecidas para agregar metadatos a documentos en la Internet con objeto de lograr de manera muy simple la descripción de recursos documentales destinados a ese entorno de red. El Núcleo de Dublín es el resultado de una consenso internacional multidisciplinario logrado a través de los esfuerzos de una iniciativa al efecto. Ha funcionado como un cimiento para una estandarización de registro y descripción bibliográfica de un buen número de documentos disponibles vía Internet.

ECIA. European Council of Information Associations.

En-línea (On-line). Concepto que establece que existe una conexión "en vivo"; es decir, existente en ese momento entre dos computadores, o entre una terminal y una computadora, ya sea a una red local o a la Internet.

ENIAC I (Electronic Numerical Integrator and Calculator). Computadora e integrador numérico electrónico. Considerada la primera computadora electromecánica en la historia. Comenzó a funcionar en 1946, en la Universidad de Pennsylvania, EUA. Ocupaba $150 \mathrm{~m}^{2}$, tenía 18000 bulbos y pesaba 30 toneladas. Aunque tardaba casi medio segundo en multiplicar dos números de diez cifras, era mucho más rápida que cualquier otra máquina inventada hasta entonces y demostró que los procesos numéricos electrónicos eran posibles abriendo el camino a las computadoras actuales.

Esteganografía. Es el arte o ciencia de comunicar de manera oculta un mensaje, escondiendo o disfrazando la información entre otro conjunto de datos visible de forma que pase inadvertido ante cualquier inspección sin levantar sospechas. Los primeros documentos que describen el uso de estas técnicas datan de los tiempos de Herodoto en la Grecia antigua. El mensaje microfilmado hasta parecer el punto de una letra en una carta es el arquetipo extensamente conocido. Hoy en día suele utilizarse 
para esconder información en todo tipo de archivos tales como fotos, videos o audio. Se puede ocultar un mensaje dentro de contenidos multimedios, mezclando los bits del mensaje original entre los bits del archivo gráfico o de sonido. El archivo resultante será una imagen o archivo de audio totalmente funcional que a primera vista no levanta ninguna sospecha, y del que con el software adecuado es posible extraer la información oculta.

FTP (File Transfer Protocol). Protocolo de transferencia de archivos vía Internet. Como su nombre indica, fue diseñado para transferir todo tipo de archivos entre computadoras. Existen dos tipos de transferencias: la "descarga" (download), consistente en traer y alojar (bajar) un archivo a nuestra computadora desde un servidor remoto. La "carga" (upload) consiste en llevar y alojar (subir) un archivo desde nuestra computadora a un servidor remoto. Existen además dos tipos de FTP muy utilizados: el FTP anónimo, en donde se permite a cualquiera que acceda al sitio descargar un archivo; y el FTP privado; en donde es necesario conectarse al servidor utilizando un nombre y una contraseña.

G7, G8. Grupo de los 7. Denominación original de un grupo formado por los países altamente industrializados para esfuerzos cooperativos. En la actualidad son ocho países más la Unión Europea que funciona como un noveno elemento. (Estados Unidos, Inglaterra, Francia, Alemania, Japón, Italia, Canadá y Rusia). Se conoce también como G-8 o Grupo de los ocho.

Gobernanza. Arte o manera de gobernar o gobernarse que se propone como objetivo el logro de un desarrollo económico, social e institucional duradero, promoviendo un sano equilibrio entre los diversos sectores que conforman una nación, una organización, una institución, etcétera.

Gopher. Sistema desarrollado por la Universidad de Minnesota, EUA previo al advenimiento de la World Wide Web para organizar y desplegar archivos en servidores en la Internet. El servidor Gopher presentaba sus archivos como una lista jerárquicamente estructurada dentro del mismo con objeto de encontrar y trans- 
ferir esos archivos a través de la red. Fue sustituido por los "navegadores" para Web.

Handheld. Véase PDA.

HDTV (High Definition Television). Televisión de alta definición. Es un nuevo tipo de TV que provee de mucha mayor resolución de imagen (por lo general el doble) que la TV tradicional, así como pantallas más anchas. No existe un estándar único, varía con cada compañía que lo pretende utilizar.

ICANN (Internet Corporation for Assigned Names and Numbers).

La corporación internacional que se encarga de llevar el control mundial de todos los números y nombres de dominio de los sitios en la Internet.

Info-ricos. Término acuñado en 1970 por Phillip J. Tichenor, profesor de periodismo y comunicación de masas; George Donohue, profesor de sociología y Clarice N. Olien, profesora de sociología rural, todos ellos de la Universidad de Minnesota, EUA, para definir a los estratos de la sociedad que tienen amplio acceso a fuentes de información, así como el conocimiento que desarrolla el interés y la predisposición hacia una mayor riqueza informativa; además, su información previa las habilita para una contextualización estructurada de lo que acontece. Lo opuesto es el término info-pobre, aquellas personas que tienen poco acceso a fuentes de información, por lo general limitadas a radio y televisión y cuyos conocimientos limitados les dejan expuestos a la mediatización.

Infraestructura de información. Plataforma de computadoras y telecomunicaciones y los servicios genéricos sobre ellas que soportan las aplicaciones o programas puestos a disposición de los usuarios vía la red.

ISDN. Red intergubernamental establecida bajo los auspicios de la UNESCO con sede en París y cuyo objetivo es desarrollar y mantener un registro internacional de publicaciones periódicas, el cual contiene la información necesaria para identificación y control bibliográfico, inclusive el Número Internacional Estándar de la Revista (ISSN) y título clave.

JSTOR (Journal Storage Project). Organización no lucrativa creada 
en 1995, cuyo fin es aprovechar las tecnologías de información para la conversión de colecciones de revistas académicas desde soportes en papel a digitales.

KWIC. Tipo de índice permutado en el que el contenido temático de una obra se representa mediante palabras clave de su título o de otra fuente de información del documento, extraídas de listas de palabras significativas y no significativas. Las palabras clave aparecen en orden alfabético, jerarquizadas de alguna manera en una posición fija, precedidas y seguidas por el resto de las palabras del título o fuente.

KWOC. Tipo de índice permutado que varía en su presentación respecto al índice KWIC en que las palabras clave aparecen como un encabezamiento en línea separada. Bajo cada encabezamiento aparece la totalidad de los títulos, completos o truncados, que contienen la palabra clave de que se trata.

Metadato. Dato acerca de los datos. Elemento que describe el contenido, condiciones, características, de un documento con el fin de definir, identificar, organizar, indizar, filtrar, colocar, preservar, recuperar y administrar ese documento como una parte de un conjunto ordenado de recursos de información electrónicos. Los metadatos pueden crearse para describir los atributos inherentes de un recurso documental cualquiera que éste sea: objeto bibliográfico (libro, revista, tesis, etc.), registros e inventarios archivísticos, objetos geoespaciales, recursos visuales (realia) y de museos y galerías; programas de computadora, etc. Los metadatos pueden presentar diferentes niveles de especificidad, profundidad o estructura. Como ejemplo, la catalogación produce una ficha con metadatos acerca de un libro. Módem. Contracción de "modulador-demodulador". Aparato que convierte (modula) las señales de comunicación de una computadora al tipo de señal de una línea telefónica para que puedan viajar a través de ella. Del otro lado, un aparato semejante reconvierte (remodula) la señal nuevamente a su forma original para la computadora destino.

MODS (Metadata Object Description Schema). Esquema de metadatos para descripción de objetos. Consiste en un "esquema" 
Un modelo de planeación de bibliotecas digitales para México

XML preestablecido por la Biblioteca del Congreso de Estados Unidos para un tipo de documento dado.

NII (National Information Infrastructure). Iniciativa creada en Estados Unidos en 1993 cuyo objetivo es proveer la integración de hardware, software y habilidades que faciliten el acceso y conectividad masivos entre las personas de ese país, hacia las ofertas de servicios y recursos de información. Véase también: http://www.kmbook.com/nii/

NCOIT\&R (National Coordination Office for Information Technology Research and Development). Agencia coordinadora en Estados Unidos del programa de Infraestructura de Información, el HPCC.

NSF (National Science Foundation). Agencia independiente del gobierno de Estados Unidos establecida en 1950, con el objetivo de promover el progreso de la ciencia en ese país. Muchos proyectos de biblioteca digital en la Unión Americana son financiados por esta agencia.

Objeto digital. Cualquier entidad documental: texto, imagen, sonido, etc., que ha sido codificada numéricamente bajo algún formato de representación digital y ensamblada junto con algún conjunto de metadatos de tal forma que puede ser almacenado, buscado, encontrado y usado a partir de una colección en un sistema computacional.

oCDE (Organisation de Coopération et Développement Economiques). Organización mundial para favorecer intercambios y actividades hacia la globalización económica.

OEBPS 1.0 (Open eBook Forum Publications Structure Specification) Primera especificación consensada internacionalmente acerca de la estructura de publicación de un libro electrónico. En agosto de 2002 este organismo publicó la versión 1.2 de estas recomendaciones, la cual contiene mejoras.

Palm. Véase PDA.

Papel electrónico. Véase Tinta electrónica.

PDA (Portable Digital Assistant). Asistente digital portátil. Es una pequeña computadora de mano que se opera con un "lápiz" electrónico sobre una pantalla sensible. La mayoría de estos 
equipos realiza funciones sencillas, como control de agenda, directorio, calculadora, bloc de notas, memorandos, juegos, etc. Dependiendo de su capacidad y precio pueden contar con versiones simples de sistemas operativos como el Windows CE de Microsoft o PALM Os, los cuales le permiten extender sus capacidades a proceso de texto, hoja de cálculo, acceso inalámbrico a Internet, etc. Permite también la inclusión de algún programa que permita copiar partes de e-books a la máquina y leerlos a través de ella.

PyMEs. Sector económico de un país que comprende las "pequeñas y medianas empresas".

TCP/IP. Es un protocolo que permite transmisión fiable de paquetes de datos sobre redes. Un protocolo es un conjunto de reglas preestablecidas entre dos dispositivos para permitir su enlace. El nombre TCP/IP proviene de dos protocolos originales de UNIX, el Transmission Control Protocol (TCP) y el Internet Protocol (IP), si bien en la actualidad llegan a ser más de 100 protocolos diferentes definidos en este conjunto. El TCP/IP es la base de la Internet que sirve para enlazar computadoras pequeñas y grandes, provenientes de diversos fabricantes y con diferentes sistemas operativos.

TIC. Tecnologías de información y comunicación. La suma de todo el desarrollo tecnológico humano en computación, informática, redes, telecomunicaciones, etc., utilizado para crear, almacenar, intercambiar y usar información en sus múltiples formas (texto, datos, voz, imágenes, video). Abarcan equipos de cómputo, programas, servicios en la Internet, teléfonos fijos y celulares, equipos y servicios de redes, etc. Por lo general se asocian a un contexto: TIC para la educación, la salud, el desarrollo, en bibliotecas, etcétera.

Tinta electrónica. Material que es insertado dentro de una película para ser usada integrándola a dispositivos de despliegue electrónicos; la tinta electrónica es un revolucionario y complejo concepto de química, física y electrónica desarrollado para crear este nuevo material. El componente principal de la tinta electrónica consiste en millones de microcápsulas diminutas, 
aproximadamente del diámetro de un cabello humano. Básicamente, cada microcápsula contiene a su vez múltiples partículas blancas positivamente cargadas y partículas negras negativamente cargadas suspendidas en un fluido claro. Cuando un campo eléctrico positivo es aplicado en la parte inferior de la cápsula, se produce un movimiento de partículas blancas a la parte superior de la microcápsula donde se hacen visibles al usuario; esto hace parecer blanca a la superficie en aquel punto. Al mismo tiempo, el campo eléctrico envía las partículas negras al fondo de las microcápsulas donde son escondidas. Invirtiendo este proceso, las partículas negras aparecen en lo alto de la cápsula, haciendo que la superficie parezca oscura en aquel punto y viceversa. Para formar un despliegue de texto o imagen con la tinta electrónica, las microcápsulas son emparedadas dentro de una película plástica transparente tan delgada como una hoja y que funciona como una capa de circuitería. Bajo una corriente eléctrica predeterminada, esta capa forma un patrón de pixeles que pueden ser entonces controlados por ese dispositivo de despliegue. Esta película puede ser sobrepuesta a prácticamente cualquier superficie como metal, plástico, vidrio, tela, incluso papel, convirtiéndola en un dispositivo de despliegue.

UNICODE. Es el siguiente paso después de ASCII en el desarrollo de códigos binarios de caracteres para escritura o texto. Oficialmente llamado el estándar mundial de caracteres unicode, consiste en un código establecido internacionalmente para el intercambio, procesamiento y despliegue de los textos escritos en la inmensa mayoría de las diversas lenguas del mundo moderno. También apoya el tratamiento de muchos textos clásicos e históricos en varias lenguas. The Unicode Standard Version 4.0 (2003). The Unicode Consortium. Reading, MA: Addison Wesley. 1504 p. ISBN 0321185781. ISO/IEC 10646.

uSB (Universal Serial Bus). Puerto Serie Universal. Puerto de comunicación de computadoras personales con dispositivos externos. Sustituye al RS232C. 


\section{Referencias bibliográficas*}

Academia de Ciencias. 1999. México frente a la era de la información. México: Academia de Ciencias. 54 pp.

American Library Association (ALA). 1983. The ALA Glossary of Library and Information Science. American Library Association, Chicago, IL.

An Act for the Encouragement of Learning, by Vesting the Copies of Printed Books in the Author's or Purchasers of Such Copies. Queen Anne of Great Britain, c. 19 (1709). Disponible noviembre 3, 2005 en: http:// press-pubs.uchicago.edu/founders/documents/a1_8_8s2.html

Archivo de la Universidad de Salamanca (AUS). Libros de Claustros, Libro 239, marzo 11, 1776.

Arias Terry, Ana. 1999. "Demystifying the e-Book - What is it, Where Will it Lead us, and Who's in the Game?", Against the Grain. Noviembre de 1999. Disponible noviembre 3, 2005 en: http://www.against-thegrain.com/ATG_AnaEbook.html

Association of College and Research Libraries (ACRL). 1998. A Progress Report on Information Literacy. Marzo de 1998. Disponible noviembre 3, 2005 en: http://www.ala.org/ala/acrl/acrlpubs/whitepapers/ progressreport.htm

* Todas las referencias electrónicas han sido verificadas como existentes y exactas hasta el 3 de noviembre de 2005. Están incluidas las bibliografías conjuntas de Bibliotecas y publicaciones digitales y Un modelo de planeación de bibliotecas digitales para México para una referencia total. 
Association of Research Libraries (ARL). 1995. "Realizing Digital Libraries". Proceedings of the 126th Annual Meeting. Boston, Massachusetts, mayo 17-19, 1995. Appendix II. Disponible noviembre 3, 2005 en: http://www.arl.org/arl/proceedings/126/2-defn.html

Association of Research Libraries (ARL). 2000. ARL Directory of Scholarly Electronic Journals. Disponible noviembre 3, 2005 en: http:// www.arl.org/scomm/edir/

Ausubel, David, Joseph Novak y Helen Hanesian. 1983. Psicología educativa. Un punto de vista cognoscitivo. México: Trillas, $623 \mathrm{pp}$.

Baca, Murtha (ed.). 2000. Introduction to Metadata: Patways to Information. Getty Research Institute. Página Web del Instituto. Disponible enero 3, 2005 en: http://www.getty.edu/research/conducting_research/ standards/intrometadata/

Backus-Naur Form. 2000. FOLDOC: Free On-Line Dictionary of Computing. Disponible noviembre 3, 2005 en: http://foldoc.doc.ic.ac.uk/ foldoc/foldoc.cgi?query=backus-naur\&action=Search

Banner, William A. 1983. Discurse for the Dedication of the Undergraduate Library. Septiembre 23, 1983. Disponible noviembre 3, 2005 en: http://www.howard.edu/library/Special/Excellence@Howard/ bannerWA/UGL1983.htm

Baseline Focus Group. 1999. Advantages of Electronic Journals. Sumario y Reporte Total. Disponibles noviembre 3, 2005 en: http://www.mimas.ac.uk/ $\mathrm{sj} /$ baserept.htm

Bates, Anthony W. 1995. Technology, Open Learning and Distance Education. New York: Routledge.

Bawden, David y Ian Rowlands. 1999. "Digital Libraries: Assumptions and concepts”. Libri. vol. 49:4, pp. 181-202.

Beniger, James R. 1986. The control Revolution: Technological and Economic Origins of the Information Society. Cambridge, MA: Harvard University Press.

Bevis King's Video Formats. Disponible noviembre 3, 2005 en: http:// www.ee.surrey.ac.uk/Contrib/WorldTV/video.html

Bibliotheca Universalis. 2004. Página Web de la biblioteca. Disponible noviembre 3, 2005 en: http://www.culture.gouv.fr/g7/

Bibliothèque Nationale de France (BNF). 2004. Página Web de la biblioteca. Disponible noviembre 3, 2005 en: http://www.bnf.fr

Birmingham, William P. 1995. "An agent-based architechture for digital libraries”. D-Lib Magazine. (Junio, 1995.) 
Block, David. 2004. "Globalization, Transnational Communication and the Internet". International Journal on Multicultural Societies (IJMS), vol. 6:1, pp. 13-28.

Boomgaarden, Wesley (ed.). 1993. Staff Training and User Awareness in Preservation Management. Preservation Planning Program Guide 2. Washington, D.C.: Association of Research Libraries.

Borges, Jorge Luis. 1941. "La biblioteca de Babel". El jardin de senderos que se bifurcan. Incluido en Ficciones (1944). Buenos Aires, Alianza Editorial. Disponible noviembre 3 de 2005 en http://babel.webcindario.com/ Borgman, Christine L. 1999. "What are Digital Libraries?: Competing Visions". Information Processing and Management, vol. 35, pp. 227-243.

Boyce, Peter y Heather Dalterio, 1996. "Electronic publishing of Scientific Journals". Physics Today (enero). American Institute of Physics, pp. $42-47$.

Bradbury, Ray. 1981. Fahrenheit 451. Barcelona: Plaza \& Janés.

Braslavsky, Cecilia. 1994. "Una función para la escuela (...)". ¿Para qué sirve la escuela? Daniel Filmus (comp.). Buenos Aires: Norma.

Braun, Linda W. 2002. "A Librarian by Any Name". Library Journal. 127(2):46. Disponible noviembre 3, 2005 en: http://ww w.library journal.com/index.asp?layout=articleArchive\&articleId=CA191647\& display $=$ searchResults $\& s t \mathrm{t}=001$

Brazil. Ministry of Science and Technology. 2000. Information Society in Brazil: Green Book. Disponible noviembre 3, 2005 en: http:// socinfo.org.br

British Library. 2004. Página Web de la biblioteca. Disponible noviembre 3, 2005 en: http://www.bl.uk/about/policies/digital.html

Brown, John y Paul Duguid, 2000. The Social Life of Information. Harvard Bussiness School Press. 336 pp.

Bush, Vannevar. 1945. "As we may think". The Atlantic Monthly, 176:1 (julio, 1945), pp. 101-108. Disponible noviembre 3, 2005 en: http:// www.theatlantic.com/doc/194507/bush

Cano, Virginia. 1998. De bibliotecario a gestor de información: ¿cambio de nombre o nuevas competencias? III Encuentro de Directores y II de Docentes de Escuelas de Bibliotecología y Ciencias de la Información del Mercosur, octubre 29 al 31, 1998. Disponible noviembre 3, 2005 en: http://www.utem.cl/deptogestinfo/extension.htm

Caplan, Priscilla. 1995. "You Call it Corn, We Call it Syntax-independent Metadata for Document-like Objects". The Public Access Computer Systems Review, vol. 4, núm. 6. 
Castells, Manuel. 1999. La era de la información: economía, sociedad y cultura. México: Siglo XXI, p. 375.

1999. Internet y la sociedad red: lección inaugural del programa de doctorado sobre la sociedad de la información y el conocimiento. Universidad Abierta de Cataluña. Disponible noviembre 3, 2005 en: http://www.uoc.edu/web/esp/articles/castells/print.html

Chartier, Roger. 1999. Cultura escrita, literatura e historia. México. Fondo de Cultura Económica, pp. 48 y 50.

1994. El orden de los libros. Ed. Gedisa, España, pp. 3-4.

Cleveland, Gary. 1998. Digital Libraries: Definitions, Issues and Challenges. (UDT Occasional Paper \#8) IFLANET: Activities \& Services. Página Web oficial de la IFLA. Disponible noviembre 3, 2005 en: http://www.ifla.org/ VI/5/op/udtop8/udtop8.htm

Commission on Preservation and Access. (EUA). 1994. The Digital Preservation Consortium Mission and Goals. Disponible noviembre 3, 2005 en: http://www.clir.org/pubs/reports/dpcmiss/dpcmiss.html

Collier, Mel. 1997. "Towards a General Theory of the Digital Library". Proceedings of the International Symposium on Research, Development and Practice in Digital Libraries: ISDL'97. Noviembre 18-21, 1997. Disponible noviembre 3, 2005 en: http://www.dl.ulis.ac.jp/ ISDL97/proceedings/collier.html

Columbia University. 2001. Selection Criteria for Digital Imaging Projects. Disponible noviembre 3, 2005 en: http://www.columbia.edu/cu/ libraries/digital/criteria.html

Communications of the ACM (CACM). 1995. Association for Computing Machinery. Special Number for Digital Libraries, vol. 38:4. Abril, 1995. ComputerUser Dictionary. Entrada por "electronic publishing". Disponible noviembre 3, 2005 en: http://computeruser.com/resources/ dictionary/noframes/nf.definition.html?bG9va3VwPTUyNA==

Cox, Ingemar J. y Miller, Matt L. 2001. "Electronic Watermarking: The First 50 Years." Proceedings of the IEEE 2001 Int. Workshop on MultiMedia Signal Processing, 2001. Disponible noviembre 3, 2005 en: http://www.ee.ucl.ac.uk/ icox/papers/2001/mmsp01.pdf

Crawford, Timothy. 1992. Blessing and Curse in Syro-Palestinian Inscriptions of the Iron Age. American University Studies: Series VII, Theology and Religion, vol. 120. New York: Peter Lang Publishing, $259 \mathrm{pp}$.

Crawford, Walt. 2000. "Nine Models, One Name: Untangling the e-book Muddle”. American Libraries. 31:8 (Septiembre 2000), pp. 56-59. 
Cruz P., Saúl. 2003. "Composición del presupuesto asignado a TIC en el gobierno federal”. Política Digital. Disponible noviembre 3, 2005 en: http://www.politicadigital.com.mx/index.php?id=591

Cyan Worlds. 2001. Página Web de la empresa. Disponible noviembre 3, 2005 en: http://www.cyan.com

DARE. Digital Academic Repositories Een Surf-Programma. 2005. Sitio web oficial del Programa DareNet. Holanda. Disponible noviembre 3, 2005 en: http://www.darenet.nl/page/language.view/keur.page

Darnton, Robert. 1993. "Historia de la Lectura", Formas de hacer historia. Ed. Peter Burke, Madrid, p. 189.

De la Parra, Eduardo. 2004. "Comentarios a las Reformas a la Ley Federal del Derecho de Autor". Revista de Derecho Privado. Instituto de Investigaciones Jurídicas, Universidad Nacional Autónoma de México. Nueva época, año III, núm. 8, mayo-agosto 2004, pp. 95-110.

Deleuze, Gilles y Félix Guattari. 1987. A Thousand Plateaus. Mineápolis: University of Minnesota Press, p. 25.

Derrida, Jacques. 1976. Of Grammatology. Trad. Gayatri Chakravorty Spivak. Baltimore: John Hopkins University Press, p. 8.

Digital Libraries Federation. 2001. Disponible noviembre 3, 2005 en: http://www.diglib.org/dlf homepage.htm (la definición está disponible en: http://www.diglib.org/about/strategic.htm)

DLI 1. Digital Libraries Initiative 1. 1995. Digital Libraries Federation. Disponible noviembre 3, $2005 \mathrm{en:} \mathrm{http://www.dli2.nsf.gov/dlione/}$

DLI 2. Digital Libraries Initiative 2. 1998. Digital Libraries Federation. Disponible noviembre 3, 2005 en: http://www.nsf.gov/pubs/1998/ nsf9863/nsf9863.htm

DLTC. 1997. [Canadian] Digital Libraries Technical Committe. Sitio Web oficial. Disponible noviembre 3, 2005 en: http://cimic3.rutgers.edu/ ieee_dltf.html

Eco, Umberto. "Postdata al Nombre de la Rosa". Disponible 3 de noviembre de 2005 en: http://www.umbertoeco.com/id-39/UmbertEco_Name_of_the_ Rose_Umberto_Eco.html

Eco, Umberto. 1980. El nombre de la rosa. Trad. Ricardo Pochtar. Ed. Lumen.

eLib Programme. 2000. Summative Evaluation of Phases 1 and 2 of the e-Lib Initiative. JISC. Disponible noviembre 3, 2005 en: http://www.ukoln.ac.uk/ services/elib/info-projects/phase-1-and-2-evaluation/overview.pdf

Ercegovac, Zorana. 1999. "Introduction" within the Special Topic Issue, "Integrating Multiple Overlapping Metadata Standards". Journal of the American Society for Information Science, vol. 50, núm. 13, pp. 1165-1168. 
Un modelo de planeación de bibliotecas digitales para México

Esposito, Joseph. J. 2003. "The Processed Book”. First Monday. Disponible noviembre 3, 2005 en: http://w w w.firstmonday.dk/issues/ issue8_3/esposito

Esteve Botey, Francisco. 1949. "Ex-libris y ex-libristas". Madrid, Coleccionismo, núm. 170 al 181, año XVI y XVII, 1929-1930. Madrid, Aguilar.

European Comission (1997). Libro verde sobre la convergencia de los sectores de telecomunicaciones, medios de comunicación y tecnologías de la información y sobre sus consecuencias para la reglamentación. COM 623. Disponible noviembre 3, 2005 en: http://europa.eu.int/ ISPO/convergencegp/greenp.html

European Commission (1997). Propuesta para los derechos afines en la sociedad de la información [COM (97) 628 final COD97/0359]. Disponible noviembre 3, 2005 en: http://europa.eu.int/scadplus/leg/es/ lvb/124152.htm

European Council of Information Associations (ECIA). 1999. Euroréférentiel IED. Référentiel des Compétences des Professionnels Européens de l'Information et Documentation. París: ADBS Editions. Disponible noviembre 3, 2005 en: http://w w w.adbs.fr/uploads/ouvrages/ 1917_fr.pdf

European Travel Comission. 2004. New media Review. Disponible noviembre 3, 2005 en: http://www.etcnewmedia.com/review/ default.asp?SectionID $=10$

Fishman, Stephen. 2004. The Copyright Handbook: How to Protect \& Use Written Works. 8a. Edición. 512 pp.

FOLDOC. Free On-Line Dictionary of Computing. Disponible noviembre 3, 2005 en: http://foldoc.doc.ic.ac.uk/foldoc/index.html

Foreign Policy. 2004. Página Web de la empresa. Disponible noviembre 3, 2005 en: http://www.foreignpolicy.com/story/cms.php?story_id=2594

Foucault, Michel. 1977. What is an author?: Language, Counter-memory, Practice: Selected Essays and Interviews. Ithaca, NY: Cornell University Press.

Fuentes, Carlos. 2004. Texto completo del discurso inaugural del III Congreso Internacional de la Lengua Española. Rosario, Argentina, noviembre 17, 2004. Disponible noviembre 3, 2005 en: http://cvc.cervantes.es/ obref/congresos/rosario/inauguracion/fuentes_c.htm

Gallica. La Bibliothèque Numérique. 2004. Bibliothèque Nationale de France. Página Web de la biblioteca. Disponible noviembre 3, 2005 en: http://gallica.bnf.fr 
Garduño, Roberto. 2004. "La educación a distancia como elemento del desarrollo de la sociedad del conocimiento". Investigación Bibliotecológica: Archivonomía, Bibliotecología e Información. México: UNAM, Centro Universitario de Investigaciones Bibliotecológicas, vol. 37, núm. 18. Diciembre, pp. 7-8. Disponible noviembre 3, 2005 en: http://www.ejournal.unam.mx/iibiblio/vol18-37/IBI03701.pdf

Gasaway (Lolly), Laura N. 2001. When Work Pass Into Public Domain. University of North Carolina". Disponible noviembre 3, 2005 en: http:/ /www.unc.edu/ $\sim$ unclng/public-d.htm

Gesner, Konrad, 1545. Bibliotheca Universalis, Sive, Catalogus Omnium Scriptorum locupletissimus, in Tribus Linguis, Latina, Graca, \& Hebraica.... Zürich. Apud Christoph Froschauer.

Gladney, Henry M., et al. 1994. Digital Library: Gross Structure and Requirements. Proceedings of the First Annual Conference on the theory and practice of Digital Libraries.

Goldfarb, Charles F. 1996. The Roots of SGML. A Personal Recollection. Disponible noviembre 3, 2005 en: http://www.sgmlsource.com/ history/roots.htm

González Casanova, Pablo. 2004. Las nuevas ciencias y las humanidades: de la academia a la política. Barcelona: Anthropos. 478 pp.

Gorman, Michael. 1998. "What is the Internet". The One Person Library, vol. 15 , núm. $6(6 / 98)$ p. 5.

2001. Bibliographic Control or Chaos: an Agenda for National Bibliographic Services in the $21^{\text {st }}$ Century. Paper presented at the $67^{\text {th }}$ IFLA General Conference and Council. Boston, EUA, agosto 16-25.

Guimarães, José Augusto. 1998. Moderno profissional da informacão. Elementos para sua formacão e atuação no mercosul com vistas ao terceiro milênio. Tercer Encuentro de Directores y Segundo de Docentes de las escuelas de Bibliotecología del Mercosur. Octubre 29-31. Santiago de Chile. Universidad Tecnológica Metropolitana.

Gutenberg Project. 2001. Página Web oficial del proyecto. Disponible noviembre 3, 2005 en:http://promo.net/pg

Haigh, Susan. 1996. Optical Character Recognition as a Digitization Technology. Disponible noviembre 3, 2005 en: http://www.nlc-bnc.ca/9/ 1/p1-236-e.html

Hara, Noriko y Rob Kling. 1999. "Student's Frustrations with a Web-based Distance Education Course". First Monday, 4(12) (diciembre 1999). Disponible noviembre 3, 2005 en: http:/firstmonday.org/issues/ issue4_12/hara/index.html 
Un modelo de planeación de bibliotecas digitales para México

Harvard Library Preservation. 2000. Image Digitization. File Formats. Digital Still Images. Disponible noviembre 3, $2005 \mathrm{en}$ : http://preserve.harvard.edu/ resources/imageformats.html

Harvard University. 2001. Selection for Digitizing: A Decision-Making Matrix. Disponible noviembre 3, $2005 \mathrm{en:} \mathrm{http://preserve.harvard.edu/}$ bibliographies/matrix.pdf

Hughes, Carol A. 2000. "Information Services for Higher Education. A New Competitive Space". D-Lib Magazine (diciembre 2000). Disponible noviembre 3, 2005 en: http://w ww.dlib.org/dlib/december00/ hughes/12hughes.html

Iannella, Renato (ed.) 1996. "Australian Digital Libraries Initiatives". DLib Magazine (diciembre 1996). Disponible noviembre 3, 2005 en: http://w ww.dlib.org/dlib/december96/12iannella.html

Information Highway Advisory Council. 1997. "Preparing Canada for a

Digital World-Final Report of the Information Highway Advisory Council". Agosto.

IFLA. International Federation of Library Associations and Institutions. 1994. Manifesto de la IFLA/UNESCO Public Library. Disponible noviembre 3, 2005 en: http://www.ifla.org/VII/s8/unesco/span.htm

1996. Position Paper on Copyright in the Electronic Environment. Octubre 1996. Disponible noviembre 3, 2005 en: http:// www.ifla.org/V/press/pr961002.htm

1999. Declaración de la IFLA sobre las bibliotecas y la libertad intelectual. Disponible noviembre 3, 2005 en: http://www.ifla.org/ faife/policy/iflastat/iflastat_s.htm

Iglesias, Carmen. 2002. De historia y de literatura como elementos de ficción. Discurso al tomar el nombramiento como miembro de la Real Academia de la Lengua Española. Madrid, septiembre 30, 2002. Disponible noviembre 3, 2005 en: http://www.rae.es/rae/gestores/ gespub000001.nsf/(voA nexos)/arch5838FB807DBF5039C1256C7E0045FD95/\$FILE/ciglesias.htm

Indiana University Digital Library Program (IUDLP). 2004. Sitio oficial Web.

Disponible noviembre 3, 2005 en: http://www.dlib.indiana.edu/

INEGI [México, Instituto Nacional de Estadística, Geografía e Informática]. 2005. Encuesta nacional sobre disponibilidad y uso de tecnologías de la información en los hogares. Disponible noviembre 3, 2005 en: http://www.inegi.gob.mx/est/contenidos/espanol/rutinas/ ept.asp?t=tinf $196 \& c=5585$ 
INSPIR AL. 2001 [INveStigating Portals for Information Resources And Learning]. Centre for Digital Library Research [CDLR]. Disponible noviembre 3, 2005 en: http://inspiral.cdlr.strath.ac.uk/

Instituto de Investigaciones Jurídicas, Universidad Nacional Autónoma de México. 2000. Secretarías de Estado. Gobierno de México. Disponible noviembre 3, 2005 en: http://www.juridicas.unam.mx/navjus/ $\mathrm{gob} / \mathrm{mx} / \mathrm{pe} 1 . \mathrm{htm}$

Internet World Stats. 2004. Usage and Population Statistics. Disponible noviembre 3, $2005 \mathrm{en:} \mathrm{http://www.internetworldstats.com/top20.htm}$

International Organization for Standardization. 2003. The Dublin Core Metadata Element Set. Information and Documentation. Disponible noviembre 3, $2005 \mathrm{en:} \mathrm{http://www.niso.org/international/SC4/n515.pdf}$ Johnson, Doug. 2002. "Why Do We Need Libraries When We Have the Internet?". Real Questions, Good Answers, vol. 2, núm. 1. Disponible noviembre 3, 2005 en: http://www.doug-johnson.com/dougwri/ internet.html

Johnson, David W., Roger T. Johnson y Karl A. Smith. 1991. "Cooperative Learning: Increasing College Faculty Instructional Productivity", ASHE-ERIC Higher Education Report núm. 4, 1991. Association for the Study of Higher Education, ERIC Clearinghouse on Higher Education, Washington, D.C.

Johnson, Mark. 1999. XML for the Absolute Beginner. Disponible noviembre 3, 2005 en: http://www.cnn.com/TECH/computing/9904/02/ xml.idg/

Joint ICSU Press/UnesCo Expert Conference on Electronic Publishing in Science. 1996. UNESCO, París, 19-23 Febrero 1996. Recommendations. Disponible noviembre 3, 2005 en: http://gateway.library.uiuc.edu/ $\mathrm{icsu} / \mathrm{recomm} \sim 1 . \mathrm{htm}$

Joint Pothographic Experts Group. 2003. Página Web oficial del grupo de expertos. Disponible noviembre 3, 2005 en: http://www.jpeg.org

Kaufman, David. 1989. "Post-secondary Distance Education in Canada: Policies, Practices, and Priorities”. En: R. Sweet (ed.). Athabasca, Alberta: Athabasca University/Canadian Society for Studies in Education.

Kenneth, Arnold. 1995. "The Electronic Librarian Is a Verb/The Electronic Library Is Not a Sentence". Journal of Electronic Publishing. 1:95. Disponible noviembre 3, 2005 en: http://www.press.umich.edu/jep/ works/arnold.eleclib.html

Kling, Rob y Geoffrey McKim. 1997. A Typology for Electronic Journals: Characterizing Scholarly Journals by Their Distribution Forms. (Working Paper No.WP-97-07) Indiana University, Bloomington, Center 
for Social Informatics. Disponible noviembre 3, 2005 en: http:// www.slis.indiana.edu/CSI/WP/wp97-07B.html

Kominek, John. 1995. Introduction to Fractal Compression. Disponible noviembre 3, 2005 en: http://www.faqs.org/faqs/compression-faq/ part2/section-8.html

Lafuente, Ramiro. 1999. Biblioteca digital y orden documental. México: UNAM, Centro Universitario de Investigaciones Bibliotecológicas.

Lange, Holley y B. Jean Winkler. 1997. "Taming the Internet: Metadata, a Work in Progress". Advances in Librarianship, ed. Irene Godden, vol. 21, pp. 47-72. San Diego: Academic Press.

Leiner, Barry M. 1998. The Scope of the Digital Library. Draft Prepared by Barry M. Leiner for the D-Lib Working Group on Digital Library Metrics. January 16, 1998. Revised October 15, 1998. Disponible noviembre 3, 2005 en: http://www.dlib.org/metrics/public/papers/dig-lib-scope.html

Leopold's Home Video Formats page. 1999. Disponible noviembre 3, 2005 en: http://www.cs.tut.fi/ ${ }^{\sim}$ leopold/Ld/VideoFormats.html

Lessig, Lawrence. 2001. The Future of Ideas: The Fate of the Commons in a Connected World. New York: Random House.

Levy, David M. y Catherine C. Marshall. 1994. "Washington's White Horse? A look at Assumptions Underlying Digital Libraries”. Digital Libraries DL'94. Disponible noviembre 3, 2005 en: http://www.csdl.tamu.edu/DL94/ paper/levy.html

Ley Federal del Derecho de Autor. 1996. Disponible noviembre 3, 2005 en: http://info4.juridicas.unam.mx/ijure/tcfed/126.htm?s=

Library of Congress Web Site. National Digital Library Program. Disponible noviembre 3, 2005 en: http://memory.loc.gov/ammem/dli2/ html/lcndlp.html

Library of Congress Preservation Web Site. 1999. Selection Criteria for Preservation Digital Reformatting. Disponible noviembre 3, 2005 en: http://lcweb.loc.gov.preserv/prd/presdig/presselection.html

Licklider, Joseph C. R. 1965. Libraries of the Future. The MIT Press: Cambridge, MA., pp. 6-10.

Lyman, Peter y Hal Varian. 2000. "How Much Information?" Journal of Electronic Publishing. Diciembre, 2000, vol. 6:2. Disponible noviembre 3, 2005 en: http://www.press.umich.edu/jep/06-02/lyman.html 2003. "How Much Information? 2003". Sitio Web oficial de la Universidad de California en Berkeley, EUA. Disponible noviembre 3, 2005 en: http://www2.sims.berkeley.edu/research/projects/howmuch-info-2003/ 
Lynch, Clifford y Héctor García-Molina. 1995. "Interoperability, Scaling, and the Digital Libraries Research Agenda: A report on the May 18-19, 1995 IITA Digital Libraries Workshop". Disponible noviembre 3, 2005 en: http://diglib.stanford.edu/diglib/pub/reports/iita-dlw/ main.html\#2

1997. "Searching the Internet". Scientific American. Marzo. Disponible noviembre 3, 2005 en: http://www.hackvan.com/pub/stig/ articles/trusted-systems/0397lynch.html

Marcum, Deanna B. 1997. "Digital Libraries: For Whom? For What?" The Journal of Academic Librarianship, Marzo.

Matthiae, Paolo. 1980. Ebla: an Empire Rediscovered. Trad. Christopher Holme. Garden City, N.Y.: Doubleday. Citado por: Wellisch, Hans. 1981. "Ebla: the World's Oldest Library". Journal of Library History. vol. 16, núm. 3 (Verano 1981), pp. 488-499.

May, Mike. 1996. "Fractal Image Compression". Science Observer (Sept.Oct. 1996). Disponible en: http://w ww.americanscientist.org/Issues/ Sciobs96/Sciobs96-09image.html

Maxwell, Christine. 2000. Global Trends that Will Impact Universal Access. Document Submitted to UNESCO by Christine Maxwell (ed.) on behalf of the Internet Society. July $15^{\text {th }}, 2000$. Disponible noviembre 3, 2005 en: http://www.isoc.org/isoc/unesco-paper.shtml

McKiernan, Gerry. 2000. EJI: A Registry of Innovative E-Journal Features and Functionalities. Iowa State University. Disponible noviembre 3, 2005 en: http://www.public.iastate.edu/ ${ }^{\sim}$ CYBERSTACKS/EJI.htm

McLuhan, Marshall. 1964. Understanding Media: The Extensions of Man. New York: McGraw-Hill.

Messier, Paul. 2003. Video Format Identification Guide. Boston Art Conservation. Disponible noviembre 3, $2005 \mathrm{en:} \mathrm{http://www.video-id.com/}$

Millares Carlo, Agustín. 1971. Introducción a la historia del libro y de las bibliotecas, México: Fondo de Cultura Económica.

Mintzer, Fred. 1999. "Long Term Storage of Digital Media Objects for Digital Libraries", NSF Workshop on Data Archival and Information Preservation, Washington DC, Marzo.

MODS. Metadata Object Description Schema. 2004. Página Web oficial. Washington: Library of Congress, Disponible noviembre 3, 2005 en: http://www.loc.gov/standards/mods/

Mogge, Dru. 1999. "Seven Years of Tracking Electronic Publishing: The ARL Directory of Electronic Journals, Newsletters and Academic Discussion Lists". Library Hi Tech. 17:1, pp. 17-25. 
Molina, M Clemencia y Pérez, Marta. 1988. "El currrículo y los perfiles del profesional en bibliotecología y ciencias de la información". $R e$ vista Interamericana de Bibliotecología. Medellín: Colombia. 11(1). Moore, Michael G. y Greg Kearsley. 1996. Distance Education: a System's View. Belmont, Ca.: Wadsworth Pub. Co.

Morales C., Estela. 2001. "La sociedad de la información en el siglo XXI y la biblioteca universitaria”. Revista digital universitaria, vol. 2, núm. 2. Junio 30. México: Dirección General de Servicios de Cómputo Académico, Universidad Nacional Autónoma de México (UNAM). Disponible noviembre 3, $2005 \mathrm{en:} \mathrm{http://www.revista.unam.mx/vol.2/num2/art1/}$ 2004. "El hombre y la sociedad como centro de los servicios de información”. XXII Coloquio de Investigación Bibliotecológica y de la Información: Sociedad, Información y Bibliotecas. México: UNAM, Centro Universitario de Investigaciones Bibliotecológicas. Septiembre 22-24.

Morrison, Alan et al. 1998. "Creating and Documenting Electronic Texts. Chapter 3: Digitization-Scanning, OCR, and Re-keying”. AHDS Guides to Good Practice. Disponible noviembre 3, 2005 en: http://ota.ahds.ac.uk/ documents/creating/chap3.html\#1

NCOIT\&R. National Coordination Office for Information Technology Research \& Development. 1994. Disponible noviembre 3, 2005 en: http:/ /www.hpcc.gov y en: http://www.hpcc.gov/about/presentations/ furlani-nhpcc-3apr02/

Nationmaster. 2004. Massive Central Data Source. Página Web de la empresa. Disponible noviembre 3, $2005 \mathrm{en}$ : http://www.natinmaster.com. Véase también: Personal computers (top 100 countries) en: http:// www.nationmaster.com/graph-T/med_per_com e Internet users per capita (top 100 countries) en: http://www.nationmaster.com/graphT/med_per_com_cap

NII. National Information Infraestructure. 1998. Relationship Between HPCC and NII. Disponible noviembre 3, 2005 en: http://www.itrd.gov/ pubs/iita/1.1.html

NSDL. National Science, Technology, Engineering, and Mathematics Education Digital Library. 2001. Página Web de la biblioteca. Disponible noviembre 3, 2005 en: http://nsdl.org

Naur, Peter (ed.). 1963. Revised Report on the Algorithmic Language Algol 60. Communications ACM 6:1, pp. 1-17.

Nelson (Ted) Theodor H. 1974. Computer Lib/Dream Machines. Ed. orig. Mindful Press, 153 pp. Ed. revisada. Redmond, WA.: Tempus Books of Microsoft Press, 1987. 
Nipper, Søren. 1989. "Third Generation Distance Learning and Computer Conferencing”. En: Mason, R. y Kaye, A. (eds.). Mindweave: Communications, Computers and Distance Education. Oxford: Pergamon. Capítulo 5, pp. 63-73.

Núñez, Andrés. 2000. Una comparación del campus virtual de British Open University y el campus virtual de Florida StateUniversity: constructivismo vs. conductismo. Centro Virtual Cervantes. Instituto Cervantes (España). Disponible noviembre 3, 2005 en: http://cvc.cervantes.es/ obref/formacion_virtual/campus_virtual/nunez.htm

2001. "La educación digital". Congreso internacional de tecnología, educación y desarrollo sostenible. Murcia, España. Septiembre 1719. Disponible noviembre 3, $2005 \mathrm{en:} \mathrm{http://www.edutec.es/edutec01/}$ edutec/comunic/TSE16.html

Nürnberg, P.J., et al. 1995. "Digital Libraries: Issues and Architecture". The Second Annual Conference on Theory and Practice of Digital Libraries (Texas A\&M University, College Station, Texas, Junio 1995), pp. 148-154. Disponible noviembre 3, 2005 en: http://www.csdl.tamu.edu/ DL95/papers/nuernberg/nuernberg.html

Oasis Standards and Other Approved Work. 2005. Página oficial de la organización OASIS. Disponible noviembre 3, 2005 en: http://www.oasisopen.org/specs/index.php\#opendocumentv1.0

ODLIS (On-Line Dictionary of Library and Information Science). 2002. Western Connecticut State University. Disponible noviembre 3, 2005 en: http://www.wcsu.edu/library/odlis.html

O'Donnell, James J. 1994. “The Virtual Library: An Idea Whose Time Has Passed". Okerson y Mogge (eds.), Gateways, Gatekeepers, and Roles in the Information Omniverse. Washington, D. C.: Association of Research Libraries, pp. 2-5 y 19-31. Disponible noviembre 3, 2005 en: http://ccat.sas.upenn.edu/jod/virtual.html

Olson, David R. y Jerome Bruner. 1974. "Learning Through Experience and Learning Through Media". Media and Symbols: The Forms of Expression. Chicago: The University of Chicago Press. (The $73^{\text {rd }}$ NSSE Yearbook).

Open eBook Forum. 2002. Open eBook Publication Structure Specification Version 1.2. Disponible noviembre 3, $2005 \mathrm{en:} \mathrm{http://www.openebook.org/}$ oebps/oebps 1.2/index.htm

Organización de las Naciones Unidas. Programa de las Naciones Unidas para el Desarrollo (PNUD). 2001. Informe sobre desarrollo humano 2001: poner el adelanto tecnológico al servicio del desarrollo huma- 
Un modelo de planeación de bibliotecas digitales para México

no. Disponible noviembre 3, 2005 en: http://www.undp.org/hdr2001/ spanish/

Otlet, Paul M. 1934. Traité de Documentation: Le Livre Sur le Livre. Bruselas: Editiones Mundaneum Palais Mondial. Reimpreso por: Liège: Centre de Lecture Publique de la Communauté Française en Belgique, 1989. Reimpreso en español como: Otlet, Paul. 1996. El tratado de documentación: el libro sobre el libro. Teoría y práctica. (Trad. de M olores Ayuso). Murcia: Universidad de Murcia, Caja de Ahorros de Murcia.

Pérez Mazatán, Javier. 2005. "e-México National System”. Fourth India Mexico Joint Commision. Nueva Delhi, India: Octubre 21-22. Presentación Power Point. Láminas 32-35. Disponible noviembre 3, 2005 en: http:// www.e-mexico.gob.mx/wb2/eMex/eMex_the_emexico_nationa

Planning Workshop on Distributed Knowledge Work Enviroments. 1997. Final Report of the Planning Workshop: Digital Libraries [Introducción]. Disponible noviembre 3, 2005 en: http://www.si.umich.edu/SantaFe

Presidencia de la República, 2001. Plan nacional de desarrollo 20012006. Capítulo "Crecimiento con calidad". Disponible noviembre 3 , 2005 en: http://pnd.presidencia.gob.mx/index.php?idseccion=45\#

Popper, Karl R. 1983. Conjeturas y refutaciones: el desarrollo del conocimiento científico. Buenos Aires: Paidós, p. 280.

Public Communication Group, 2003. "Trends in Electronic Journal Collection: An International Perspective". Summary. Joshua Clarke (ed.). PCG Vantage, vol. 1:2, noviembre 2003. Disponible noviembre 3, 2005 en: http://www.imakenews.com/pcgplus/e_article000200562.cfm

Rader, Hannelore B. 1997. "Educating Students for the Information Age: The Role of the Librarian". Reference Services Review, 25:2.

Raitt, David. 2000. "Digital Libraries Initiatives Across Europe". Computers in Libraries. 20:10 (nov./dic.). Disponible noviembre 3, 2005 en: http://www.infotoday.com/cilmag/nov00/raitt.htm

Rangel, David. 1998. Derecho intelectual. México: McGraw-Hill, p. 111. Rice, Condoleezza. 1998. Copyright \& Fair Use. Memorandum to Faculty Members. Stanford University Libraries. Disponible noviembre 3, 2005 en: http://fairuse.stanford.edu/stanford_notices/rice.html

Roes, Hans. 2001. "Digital Libraries and Education". D-Lib Magazine. 7:7/8 (julio/agosto). Disponible noviembre 3, 2005 en: http://www.dlib.org/ dlib/july01/roes/07roes.html

Romo Z., Fabián. 2004. "Audiovisual Technologies in Education". Documento Interno. México: UNAM, Dirección General de Servicios de Cómputo Académico. Subdirección de Tecnologías para la Educación. 
Roush, Wade. 2001. "e-Book Basics: e-Book Primer". e-Book Web. Disponible noviembre 3, 2005 en: http://www.ebookweb.org/basics/ ebook.primer.htm

Rusch-Feja, Diann, y Siebeky, Uta. 1999. "Evaluation of Usage and Acceptance of Electronic Journals". D-Lib Magazine. 5:10 (1995). Disponible noviembre 3, 2005 en: http://www.dlib.org/dlib/october99/ rusch-feja/10rusch-feja-full-report.html

Sakaiya, Taichi. 1995. Historia del futuro. La sociedad del conocimiento. Santiago de Chile: Ed. Andrés Bello, 1995, 225 pp.

Sánchez, Alfredo. 1999. Programa nacional de bibliotecas digitales. México: Conacyt; Red de Desarrollo de Investigación en Informática (REDII). Disponible noviembre 3, 2005 en: http://ict.udlap.mx/dl/ dlmex/pnbd-version3.html

Sayood, Khalid. 2000. Introduction to Data Compression. 2a. ed. San Francisco: Morgan Kaufmann Publ., pp. 1-37.

Santa Fe Planning Workshop on Distributed Knowledge Work Environments. 1997. Final Report on Digital Libraries. March 9-11. Report Version: Septiembre 20. Disponible noviembre 3, 2005 en: http:// www.si.umich.edu/SantaFe/

Seamans, Nan y Gail Mcmillan. 1998. Digital Library Definition for DLI2. Disponible noviembre 3, 2005 en: http://scholar.lib.vt.edu/DLI2/ defineDL.html

Secretaría de Comunicaciones y Transportes. 2001. Programa Sectorial de Comunicaciones y Transportes 2001-2006. Sistema Nacional eMéxico. Primera Ed., pp. 253-272.

Secretaría de Comunicaciones y Transportes. 2003. Sector Comunicaciones y Transportes; Programa 2003. Disponible noviembre 3, 2005 en: http://www.sct.gob.mx/progtrab2003/10-P2003_e-MEXICO.pdf

Secretaría de Comunicaciones y Transportes. 2003. Sector Comunicaciones y Transportes; Programa 2004. Disponible noviembre 3, 2005 en: http://www.sct.gob.mx/progtrab2004/c4_e-mexico_p2004.pdf

Secretaría de Desarrollo Social. 2004. Gobierno en-línea. Disponible noviembre 3, 2005 en: http://www.sedesol.gob.mx/gobiernoenlinea/emexico.htm Secretaría de Educación Pública. 2001. Programa Nacional de Educación 2001-2006. Primera Ed. Disponible noviembre 3, 2005 en: http:// www.sep.gob.mx/wb2/sep/sep_2734_programa_nacional_de

Senso, José A. y Antonio de la Rosa Piñero. 2003. "El concepto de metadato: algo más que descripción de recursos electrónicos". Ciência da Informação. (Ci. Inf.), mayo-agosto, vol. 32, núm. 2, pp. 95-106. 
Serrano S., Arturo y Evelio Martínez M. 2003. La brecha digital: mitos y realidades. Mexicali: Universidad Autónoma de Baja California, FOECA (Fondo Editorial de Baja California), 175 pp.

Shannon, Claude. 1948. "A Mathematical Theory of Communication". The Bell System Technical Journal. Bell Laboratories, pp. 379-636.

Sharon, Taly y Frank, Ariel J. 2000. "Digital Libraries on the Internet". $6 \sigma^{\text {th }}$ IFLA Council and General Conference. Jerusalem, Agosto 13-18. Disponible noviembre 3, $2005 \mathrm{en:} \mathrm{http://www.ifla.org/IV/ifla66/papers/}$ 029-142e.htm

Shera, Jesse H. 1990. "Lo que el bibliotecario necesita saber". Los fundamentos de la educación bibliotecológica. México: UNAM, Centro Universitario de Investigaciones Bibliotecológicas, pp. 201-231.

Sistema Nacional e-México. 2001. Disponible noviembre 3, 2005 en: http:// www.e-mexico.gob.mx

Smith, Abby. 1999. Why Digitize? CLIR. Council on Library and Information Resources. Commission on Preservation and Access. 2:99. Disponible noviembre 3, 2005 en: http://www.clir.org/pubs/reports/pub80smith/pub80.html

Soules, Aline. 2002. "The Rights and Wrongs of the Doctrine of the First Sale”. Electronic Book Web. Disponible noviembre 3, 2005 en: http:// 12.108.175.91/ebookweb/stories/storyReader $\$ 1816$

Special Libraries Association (SLA). 1996. Competencies for Special Librarians of the 21st Century. Full Report. Submitted to the SLA Board of Directors by the Special Committee on Competencies for Special Librarians. May. Revised June 2003. Disponible noviembre 3, 2005 en: http://www.sla.org/content/SLA/professional/meaning/ competency.cfm

Spink, Amanda. 1995. "Digital Libraries and Sustainable Development?" Digital Libraries DL'95. Disponible noviembre 3, 2005 en: http:// www.csdl.tamu.edu/DL95/papers/spink/spink.html

Sterling, J. A. L. 2000. World Copyright Law. London: Sweet \& Maxwell. $1084 \mathrm{pp}$.

Stoker, David. 1999. "Wanted-An Innovative and Visionary Evidence Based/ Knowledge Management Librarian". Journal of Librarianship and Information Science. 31(2):67-69.

Teasdale, Guy. 1995. L'Hypertexte: Historique et Applications en Bibliothéconomie. Disponible noviembre 3, 2005 en: http://w ww.ebsi. umontreal.ca/cursus/vol1no1/teasdale.html 
Tennant, Roy. 1999. "Digital v. Electronic v. Virtual Libraries". Berkeley Digital Library SunSITE. Disponible noviembre 3, 2005 en: http:// sunsite.berkeley.edu/mydefinitions.html

Tenopir, Carol. 2003. Electronic Publishing: Research Issues for Academic Librarians and Users. Disponible noviembre 3, 2005 en: http:// www.findarticles.com/p/articles/mi_m1387/is_4_51/ai_105046543/ pg_1

The Letter of Aristeas to Philocrates. ca. 150 b.C. The Forgotten Books of Eden. Chapter I, Paragraphs 11-13. Translated in the late 1800's by Dr. S. C. Malan and Dr. E. Trumpp. Translated into King James English from both the Arabic version and the Ethiopic version which was then published in The Forgotten Books of Eden in 1927 by The World Publishing Company. Disponible noviembre 3, 2005 en: http:/ /ww w.earth-history.com/Pseudepigrapha/FB-Eden/aristeasintro.htm

Thompson, James W. 1967. The Medieval Library. New York: Hafner Publishing.

Thompson, Kim. 1998. University of California Selection Criteria for Digitization. Disponible noviembre 3, 2005 en: http://www.library.ucsb. edu/ucpag/digselec.html

Tichenor, Philip J., George Donohue y Clarice Olien. 1970. "Mass Media Flow and Differential Growth in Knowledge". Public Opinion Quarterly, 34 , pp. 159-170.

Torre Villar, Ernesto de la. 1994. Ex libris y marcas de fuego. México: UNAM, Dirección General de Publicaciones y Fomento Editorial.

Torres, Araceli. 2000. La biblioteca virtual: ¿qué es y qué promete? México: UNAM, Centro Universitario de Investigaciones Bibliotecológicas.

Tramullas, Jesús. 2002. "Las bibliotecas como sistemas multifacetados de información". Sesión en el programa de doctorado "Informática y modelización matemática”, Universidad Rey Juan Carlos, España. Disponible noviembre 3, 2005 en: http://www.tramullas.com/ presentaciones.html

Turner, Frederick y Alejandro Corbacho. 2000. Las nuevas funciones del estado. Disponible noviembre 3, 2005 en: http://www.unesco.org/ issj/rics163/abstracts163.htm

Twigg, Carol y Michael Miloff. 1998. "The Global Learning Infraestructure”. En: Don Tapscott, Alex Lowry y David Ticoll, Blueprint to the Digital Economy, McGraw-Hill, 1998. 
Un modelo de planeación de bibliotecas digitales para México

UCLA-NSF Social Aspects of Digital Libraries Workshop. 1996. Final Report. UCLA-NSF. Febrero 15-17. Disponible noviembre 3, 2005 en: http:// is.gseis.ucla.edu/research/dl/

UNESCO. 2002. Declaración universal de la UNESCO sobre la diversidad cultural. Página web de la UNESCO. Disponible noviembre 3, 2005 en: http://www.unesco.org/culture/pluralism/diversity/html_sp/ index_sp.shtml

United States of America. House of Congress. 1996. Fair Use Guidelines for Educational Multimedia established by Congress of the United States: Nonlegislative Report of the Subcommittee on Courts and Intellectual Property Committee on the Judiciary US House of Representatives. Disponible noviembre 3, 2005 en: http:// www.libraries.psu.edu/mtss/fairuse/guidelines.html

United States of America. House of Congress. 1998. Digital Millennium Copyright Act. Executive Summary. Disponible noviembre 3, 2005 en: http://www.copyright.gov/reports/studies/dmca/ dmca_executive.html

University of Cornell. Electronic Publishing Steering Committee. 1998. Electronic Publishing Strategies for Cornell University. Disponible noviembre 3, 2005 en: http://www.library.cornell.edu/ulib/pubs/ EPSCFinalReport1998.htm

University of Maryland: University College. 2000. Copyright and Fair Use in the Classroom, on the Internet, and the World Wide Web. Disponible noviembre 3, $2005 \mathrm{en:} \mathrm{http://www.umuc.edu/library/copy.html}$

University of Texas System Digital Library. 2002. "TILT: [Texas Information Literacy Tutorial]". Disponible noviembre 3, 2005 en: http:// tilt.lib.utsystem.edu

UWE [University of Western England]. 2002. Networked Learning Supported Framework. Disponible noviembre 3, 2005 en: http://www.uwe.ac.uk/ library/nlsf/

Verduin, John R. y Thomas A. Clark. 1991. Distance Education: The Foundations of Effective Practice. San Francisco: Jossey-Bass, pp. 16-42 y 81-83.

Villate, Javier. 2001. La propiedad intelectual en la nueva era digital. Archivo del Observatorio para la CiberSociedad. Disponible noviembre 3, 2005 en: http://www.cibersociedad.net/archivo/ articulo.php?art $=40$

Voutssás M., Juan. 1995. "Crónica de tres muertes anunciadas: el teatro, la radio y el libro". BIBLIOS: Revista para Especialistas en Información, vol. I, núm. 2, pp. 2-3. Marzo-abril. 
2006. Bibliotecas y publicaciones digitales. México: UnAM, Centro Universitario de Investigaciones Bibliotecológicas, $319 \mathrm{pp}$.

Watstein, Sarah, Pascal Calarco y James Ghaphery. 1999. "Digital Libraries: Keywords". RSR/Reference Services Review, 27 (4), pp. 344-352.

Wattenberg, Frank. 1998. "A National Digital Library for Science, Mathematics, Engineering and Technology Education”. D-Lib Magazine (octubre 1998). Disponible noviembre 3, 2005 en: http://www.dlib.org/dlib/ october98/wattenberg/10wattenberg.html

Weber, Hartmut y Marianne Dörr. 1997. Digitization as a Method of Preservation? CLIR. Council on Library and Information Resources. Commission on Preservation and Access. 10:97. Disponible noviembre 3, 2005 en: http://www.clir.org/pubs/reports/digpres/ digpres.html

What is MARC. 1996. Disponible noviembre 3, 2005 en: http://www.ifla. org/VI/3/p1996-1/unimarc.htm

World Economic Forum. 2004. Global Information Technology Report, 2003-2004. Oxford: Oxford University Press.

World Summit on the Information Society (WSIS). 2003. Cumbre Mundial sobre la Sociedad de la Información. Declaración de principios. Ginebra, diciembre 10-12, 2003. Disponible noviembre 3, 2005 en: http:// www.itu.int/dms_pub/itu-s/md/03/wsis/doc/S03-WSIS-DOC0004!!pdf-S.pdf

World Wide Web Consortium [W3C]. 2002. XML. Disponible noviembre 3, 2005 en: http://www.w3.org/xml

2002. PNG. Disponible noviembre 3, 2005 en:http://www.w3.org/ Graphics/PNG

Writing HTML. 1998. Disponible noviembre 3, 2005 en: http://www.mcli. dist.maricopa.edu/tut_es/

Wyner, Aaron D. The Significance of Shannon's Work. Disponible noviembre 3, 2005 en: http://cm.bell-labs.com/cm/ms/what/shannonday/ work.html

The XML Cover Pages-Home page. 2001. Disponible noviembre 3, 2005 en: http://oasis-open.org/cover/

Zeng, L. y J. Zhang. 2002. "Digital Libraries; Where to Go?: An Analysis of Definitions, Architectures and Projects of Digital Libraries".Journal of the China Society for Scientific \& Technical Information. 19:1, February, pp. 64-73.

Zia, Lee L. 2000. "The NSF National Science, Mathematics, Engineering and Technology Education Digital Library Program”. D-Lib Magazine 
Un modelo de planeación de bibliotecas digitales para México

(October, 2000). Disponible noviembre 3, 2005 en: http://www.dlib.org/ dlib/october00/zia/10zia.html

Ziv, Jacob y Abraham Lempel. 1977. "A Universal Algorithm for Sequential Data Compression". IEEE Transactions on Information Theory, IT23:3. Mayo.

\section{OTROS SITIOS DE REFERENCIA DE ESPECIAL INTERÉS} ACERCA DE BIBLIOTECAS DIGITALES

Bibliotecas del mundo. En la Biblioteca Cervantes Virtual. Directorio de enlaces a bibliotecas virtuales, catálogos en línea, proyectos de digitalización, hemerotecas, webs e instituciones relacionadas con la literatura y la cultura hispanas. Disponible 3 de noviembre, 2005 en: http://www. cervantesvirtual.com/bib_mundo/biblioteca_mundo.shtml?portal=2

Bibliothèques Numériques. Portal de cultura francesa con ligas a numerosas bibliotecas digitales del mundo francoparlante. Disponible 3 de noviembre, 2005 en: http://www.culture.fr/BibliothequesMediatheques/c391

CLIR Reports y CLIR Issues. The Council of Library and Information Resources. Reportes profesionales de numerosas investigaciones acerca de variados temas en bibliotecas digitales. Página Web. Disponible 3 de noviembre, 2005 en: http://w ww.clir.org/pubs/reports/reports.html y en: http://www.clir.org/pubs/issues/issues.html

D-Lib Magazine (Digital Library Magazine). Copyright $(2005$ Corporation for National Research Initiative (CNRI). Mensual. Sitio Web de la revista. Disponible 3 de marzo, 2005 en: http://www.dlib.org

Digital Libraries Federation. Página Web oficial. Disponible 3 de noviembre, 2005 en: http://www.diglib.org/sitemap.htm

GT. Bibliotecas Virtuais. "Exemplos de Projetos de Biblioteca Virtual no Mundo". Disponible 3 de noviembre, 2003 en: http://www.cg.org.br/ gt/gtbv/mundo.htm

II Congreso Online del Observatorio para la cibersociedad. "¿Hacia qué sociedad del conocimiento?" Barcelona, 30 de octubre al 16 de noviembre de 2004. Disponible 3 de noviembre del 2005 en: http://www. cibersociedad.net/congres2004/index_es.html

International Federation of Library Associations (IFLA). Digital Libraries: Resources and Projects. Página Web de la IFLA. Disponible 3 de noviembre, 2003 en: http://www.ifla.org/II/diglib.htm 
Librarians' Index to the Internet (lii.org). Una guía por materias construida por bibliotecarios a 6000 sitios de recursos en la Internet. Disponible 3 de noviembre, 2005 en: http://sunsite.berkeley.edu/Help/ searchdetails.html

Library Literature \& Information Science Full Text. (C) 2005 The HW Wilson Company. Disponible 3 de noviembre, 2005 en: http://www.hwwilson.com/ Databases/liblit.htm

Libweb: Library Servers Via w w w. Sitio Web. Actualizado todos los días, a la medianoche, tiempo del pacífico. Libweb contiene listas de más de 7200 páginas Web de bibliotecas en más de 125 países. Disponible 3 de noviembre, 2005 en: http://sunsite.berkeley.edu/Libweb/

Preservation: A Selected Bibliography. Amigos Library Services. Una página con una extensa bibliografía acerca de preservación, incluida la digital. Página Web. Disponible 3 de noviembre, 2005 en: http:// www.amigos.org/preservation/bibpress.html

SWIFT. Selected Digital Library Internet Resources. Columbia University. Sitio Web de la Universidad de Columbia. Disponible 3 de noviembre, 2005 en: http://www.columbia.edu/cu/libraries/inside/projects/ diglib/resources.html

The Journal of Electronic Publishing. Published by the Columbia University Press. Cuatrimestral. Sitio Web de la revista. Disponible 3 de marzo, 2005 en: http://www.press.umich.edu/jep

\section{BASES DE DATOS DOCUMENTALES SOBRE CONSERVACIÓN}

Abstracts of International Conservation Literature (A ATA Online) (100 000 + abstracts). Disponible 3 de noviembre, 2005 en: http://aata. getty.edu/NPS/

Bibliographic Database of the Conservation Information Network (BCIN) (ca. 200000 citas). Disponible 3 de noviembre, 2005 en: http://www. bcin.ca/English/home_english.html 



\section{ANEXOS}

(Todas las referencias electrónicas han sido verificadas como existentes y exactas hasta el 3 de noviembre de 2005.) 

ANEXO 1

PRODUCCIÓN MUNDIAL ESTIMADA DE CONTENIDOS ORIGINALES, ALMACENADOS DIGITALMENTE, USANDO TÉCNICAS ESTÁNDAR DE COMPRESIÓN, ESTIMADO EN TERABYTES, PARA 1999

\begin{tabular}{|l|l|r|r|}
\hline $\begin{array}{l}\text { Medio de } \\
\text { almacenamiento }\end{array}$ & Tipo de contenido & $\begin{array}{r}\text { Terabytes por año, } \\
\text { estimado superior }\end{array}$ & $\begin{array}{r}\text { Terabytes por año, } \\
\text { estimado inferior }\end{array}$ \\
\hline Papel & Libros & 39 & 8 \\
& periódicos & 124 & 25 \\
& Revistas & 9 & 2 \\
& Documentos de oficina & 975 & 195 \\
& Revistas masivas, etc. & 52.8 & 10.2 \\
& Subtotal & 1199.8 & 240.2 \\
\hline \multirow{2}{*}{ Película } & Fotografías & 410000 & 41000 \\
& Cine & 4490 & 9 \\
& Rayos-X & 17200 & 17200 \\
& Subtotal & 431690 & 58209 \\
\hline \multirow{2}{*}{ Óptico } & CD musicales & 58 & 6.7 \\
& CD de datos & 0.7 & 22 \\
& DVD & 22 & 28.7 \\
& Subtotal & 80.7 & 1602000 \\
& Cintas audio video & 1602000 & 290000 \\
& Discos de PC & 996000 & 250000 \\
& Cinta Digital & 250000 & 1690 \\
& Zip & 1690 & 2073760 \\
\hline \multirow{2}{*}{ Total } & Subtotal & 2779760 & 2132237.9 \\
\hline
\end{tabular}

1 Terabayte $=1000$ Gigabytes $=1000000$ Megabytes $=1000000000$ Kilobytes

$=1000000000000$ bytes

Fuente: Lyman y Varian, 2000. 
Un modelo de planeación de bibliotecas digitales para México

ANEXO 1-BIS

PRODUCCIÓN MUNDIAL ESTIMADA DE CONTENIDOS ORIGINALES, ALMACENADOS DIGITALMENTE, USANDO TÉCNICAS ESTÁNDAR DE COMPRESIÓN, ESTIMADO EN TERABYTES, PARA 2002

\begin{tabular}{|c|c|c|c|}
\hline $\begin{array}{l}\text { Medio de } \\
\text { almacenamiento }\end{array}$ & Tipo de contenido & $\begin{array}{l}\text { Terabytes por año, } \\
\text { estimado superior }\end{array}$ & $\begin{array}{l}\text { Terabytes por año, } \\
\text { estimado inferior }\end{array}$ \\
\hline Papel & $\begin{array}{l}\text { Libros } \\
\text { periódicos } \\
\text { Revistas } \\
\text { Documentos de oficina } \\
\text { Revistas masivas, etc. } \\
\text { Subtotal }\end{array}$ & $\begin{array}{r}39 \\
138.4 \\
6 \\
1397.5 \\
52.9 \\
1633.8\end{array}$ & $\begin{array}{r}8 \\
27.7 \\
1.3 \\
279.5 \\
10.2 \\
326.7\end{array}$ \\
\hline Película & $\begin{array}{l}\text { Fotografías } \\
\text { Cine } \\
\text { Rayos-X } \\
\text { video y TV } \\
\text { Subtotal }\end{array}$ & $\begin{array}{r}375000 \\
6078 \\
20000 \\
19176 \\
420254\end{array}$ & $\begin{array}{r}37500 \\
12 \\
20000 \\
19175 \\
74202\end{array}$ \\
\hline Óptico & $\begin{array}{l}\text { CD musicales } \\
\text { CD de datos } \\
\text { DVD } \\
\text { Subtotal }\end{array}$ & $\begin{array}{r}58 \\
1.1 \\
43.8 \\
102.9\end{array}$ & $\begin{array}{r}6 \\
1.1 \\
43.8 \\
50.9\end{array}$ \\
\hline Magnético & $\begin{array}{l}\text { Cintas audio video } \\
\text { Discos de PC } \\
\text { Cinta Digital } \\
\text { Otros } \\
\text { Subtotal }\end{array}$ & $\begin{array}{r}1428800 \\
1986080 \\
250000 \\
1284430 \\
4999230\end{array}$ & $\begin{array}{r}1428800 \\
403080 \\
250000 \\
1284430 \\
3416230\end{array}$ \\
\hline Total & & 5421221 & 3490810 \\
\hline
\end{tabular}

1 Terabayte $=1000$ Gigabytes $=1000000$ Megabytes $=1000000000$ Kilobytes

$=1000000000000$ bytes

Fuente: Lyman y Varian, 2003. 


\section{ANEXO 2}

\section{Proceso eVolutivo de LA INTERnet EN LAS PyME}

\begin{tabular}{|c|c|c|c|}
\hline Fases & Agentes del cambio & Problemas detectados & Soluciones \\
\hline \multicolumn{4}{|c|}{$\begin{array}{l}\text { FASE 1. Descubrimiento de la Internet } \\
\text { OBJETIVO: Obtener beneficios de la información presente en la Internet. } \\
\text { REQUISITO: En la empresa debe haber una persona que lideree la incorporación de las TIC. }\end{array}$} \\
\hline & Informático/Técnico & $\begin{array}{l}\text { Desconocimiento de los sitios web } \\
\text { útiles para cada Departamento }\end{array}$ & $\begin{array}{l}\text { Formación personalizada a } \\
\text { cada persona de la empresa }\end{array}$ \\
\hline & $\begin{array}{l}\text { Directivos y mandos } \\
\text { intermedios }\end{array}$ & $\begin{array}{l}\text { Desconocimiento de los sitios } \\
\text { web útiles para la empresa }\end{array}$ & $\begin{array}{l}\text { Formación personalizada a los } \\
\text { directivos y mandos intermedios }\end{array}$ \\
\hline
\end{tabular}

FASE 2. Introducción de la Internet en sus procesos internos (e-Business)

OBJETIVO: Obtener beneficios por digitalizar la empresa para gestionar mejor toda la información que maneja, de una manera eficiente, segura y desde distintos lugares.

REQUISITO: La empresa debe ver claro dónde están los retornos de la inversión.

\begin{tabular}{|c|c|c|c|}
\hline \multirow[t]{5}{*}{$\begin{array}{l}\text { INTRANET: } \\
\text { Con empleados } \\
\text { y socios }\end{array}$} & Informático/Técnico & $\begin{array}{l}\text { Sin fomación en gestión del } \\
\text { cambio: Han de incentivar a } \\
\text { diario el cambio en la PYME }\end{array}$ & $\begin{array}{l}\text { Formación en último curso } \\
\text { de TODAs las facultades } \\
\text { universitarias de todas las } \\
\text { carreras }\end{array}$ \\
\hline & $\begin{array}{l}\text { Subcontratación } \\
\text { TIC-Empresas de } \\
\text { informática }\end{array}$ & $\begin{array}{l}\text { Priorizan vender sus productos/ } \\
\text { servicios en lugar de asegurar } \\
\text { el retorno de inversión }\end{array}$ & Buscar asesoría imparcial \\
\hline & Marketing / Ventas & $\begin{array}{l}\text { Pasividad: lo ven como } \\
\text { amenaza por retribución por } \\
\text { objetivos }\end{array}$ & $\begin{array}{l}\text { Incentivar el uso del } \\
\text { Mercadeo por la Internet para } \\
\text { tener una retribución mayor }\end{array}$ \\
\hline & $\begin{array}{l}\text { Directivos y mandos } \\
\text { intermedios }\end{array}$ & $\begin{array}{l}\text { Priorizan otras actividades } \\
\text { (ERP, calidad, medio ambiente, } \\
\text { mercadeo tradicional, etc.). } \\
\text { Desconocen las ventajas } \\
\text { del teletrabajo desde el domicilio }\end{array}$ & $\begin{array}{l}\text { Priorizar la implantación de } \\
\text { las TIC en todos los } \\
\text { procesos } \\
\text { Suministrar una PC portátil } \\
\text { y conexión de banda ancha }\end{array}$ \\
\hline & TODA la plantilla & Resistencia al cambio & $\begin{array}{l}\text { Motivar el uso de las TIC: Mostrar } \\
\text { la utilidad para cada persona }\end{array}$ \\
\hline
\end{tabular}

FASE 3. Introducción de la Internet en sus procesos externos (portales)

OBJETIVO: Obtener beneficios por relacionarse con otras empresas mediante la Internet.

REQUISITO: La empresa debe experimentar nuevas formas de colaboración.

\begin{tabular}{|l|l|l|l|}
\hline $\begin{array}{l}\text { EXTRANET: } \\
\text { Con proveedores } \\
\text { y clientes actuales }\end{array}$ & $\begin{array}{l}\text { Informáticos/Técnicos de la } \\
\text { empresa y de los clientes } \\
\text { y proveedores actuales }\end{array}$ & $\begin{array}{l}\text { Diferentes niveles de uso de } \\
\text { las TIC en el resto de clientes } \\
\text { y proveedores actuales }\end{array}$ & $\begin{array}{l}\text { Acelerar el paso de clientes } \\
\text { y proveedores actuales } \\
\text { por las fases 1 y } 2\end{array}$ \\
\hline $\begin{array}{l}\text { INTERNET: } \\
\begin{array}{l}\text { Con proveedores } \\
\text { y clientes nuevos }\end{array}\end{array}$ & $\begin{array}{l}\text { Asociación empresarial/ } \\
\text { Centro tecnológico }\end{array}$ & $\begin{array}{l}\text { Falta agente del cambio de la } \\
\text { asociación y de sus asociados } \\
\text { (fase 1) }\end{array}$ & $\begin{array}{l}\text { Imitar o colaborar con otras } \\
\text { asociaciones que estén } \\
\text { teniendo éxito demostrado. }\end{array}$ \\
\hline
\end{tabular}

Fuente: http://www.anetcom.es/download/download.asp?seccion=Nots\&FILE=InternetyPymes.doc 


\title{
Un modelo de planeación de bibliotecas digitales para México
}

\author{
ANEXO 3 \\ MÉXICO - NUMERALIA
}

1. Población total: 105.9 millones de habitantes a fines de 2004

2. Población aproximada de mexicanos en EUA: 20 millones

3. Población de 15 años y más: 62842638

4. Población de 15 años y más alfabetizada: 56841673 (90.45\%)

5. Número de viviendas: 21858085

6. Porcentaje de viviendas que cuentan con televisión: 85.6\% (18 710 521)

7. Porcentaje de viviendas que cuentan con televisión por cable: 8.9\% (1 945 370)

8. Porcentaje de viviendas que cuentan con videocasetera: $38.6 \%$ (8 437 221)

9. Porcentaje de viviendas que cuentan con teléfono: $36.2 \%$ (7 912 627)

10. Porcentaje de viviendas que cuentan con computadora: 9.3\% (2 032 802)

11. Porcentaje de viviendas con conexión a la Internet: $4.9 \%$ (1 071 046)

12. Número de líneas telefónicas en servicio, por cada 100 habitantes: Estados Unidos 66.5 , Alemania 63.5, Países Bajos 62.1, Japón 59.7, Puerto Rico 33.6, Uruguay 28.3, Chile 23.9, Brasil 21.7, Argentina 21.6, México 15.8.

13. Número de computadoras personales por cada 100 habitantes: Estados Unidos 29.9, Japón 31.5, Australia 45.2, Singapur 41.3, España 14.0, Brasil 4.2, Argentina 6.9, México 5.4.

14. Usuarios de la Internet por cada 100 habitantes: Suecia 74.6, Corea del Sur 61.2, Estados Unidos 69.0, Japón 61.3, Hong Kong 70.0, CEE 29.9, Rusia 17.3, Chile, 30.1, Brasil 11.1, Uruguay 34.7, Argentina 12.3, México 13.22.

15. PC conectadas a la Internet (\%): Estados Unidos 50,Países Bajos 25.8, Nueva Zelanda 25, Canadá 19.7, Australia 18.2, Argentina 14.2, Brasil 11.7, México 11.2, Uruguay 7.7, Chile 5.8. 16. Costo por 20 horas de acceso a la Internet (dólares): Suecia 2.6, Italia 32.2, México 24.1.

17. Total de gastos en TIC's (millones de dólares): Estados Unidos 812 635; Japón 413772 , Alemania 154 645, Reino Unido 137 726, Francia 120 569, Brasil 50 031, México 19 211, Argentina 11642, Colombia 10 434, Chile 5715.

18. Gastos en TIC's como \% del PIB: Nueva Zelanda 14.4; Suecia 11.3; Australia 10.7; Singapur 9.9; Reino Unido 9.7, Colombia 12; Brasil 8.3; Chile 8.1; Argentina 4; Venezuela 4; México 5.4. 19. Gastos en TIC's per cápita (dólares): Japón 3256; Estados Unidos 2924; Suecia 2804; Países Bajos 2327; Reino Unido 2319, Chile 371; Argentina 310; Brasil 287; Colombia 231; Venezuela 199; México 196.

20. Índice de capital social: Finlandia 6.7; Noruega 6.6; Suiza 6.6; República Eslovaca 6.5; Dinamarca 6.5, Uruguay 5.3; Argentina 5.1; Costa Rica 5; Panamá 4.7; Chile 4.6; México 4.3. 21. Índice de competencia de las TIC en los negocios y su entorno económico: Singapur 6.2; Finlandia 6.2; Reino Unido 6.1; Islandia 6.1; Suiza 6; Estados Unidos 6, Chile 4.5; Uruguay 4.3; Costa Rica4.1, Argentina 4; Panamá 3.8; El Salvador 3.7; México 3.4. 
Fuentes:

1. Secretaría de Gobernación. Consejo Nacional de Población y Vivienda (Conapo). Diciembre de 2004.

2. United States Census 2000. US Census Bureau. (http:/www.census.gov/main/www/cen2000.html).

3, 4, 5, 6, 8, 9, 10. XII Censo General de Población y Vivienda, 2000. Tabulados de la Muestra Censal. Cuestionario Ampliado. México, 2000. (http://www.inegi.gob.mx)

7. INEGI, Encuesta Nacional de Ingreso y Gasto de los Hogares, 2000.

11. INEGI, ENCO, Módulo Nacional de Computación Año 2001.

12. International Telecomunications Union (ITU), 2001.

13, 14. European Travel Comission. New Media Review. 2004, y Nationmaster.com. 2004.

15, 16. Harvard University. The Global Information Technology Report 2001-2002. (http:// www.cid.harvard.edu).

17, 18, 19. The World Bank. (http://www.worlbank.org/data/countrydata/countrydata).

20. El índice de capital social está considerado dentro del Índice de Networked Society, definido como la evaluación en la calidad del aprendizaje usando las TIC, la extensión de sus usos en el proceso de aprendizaje, la extensión de oportunidades en la industria de las TIC y factores sociales y demográficos. Harvard University. The Global Information Technology Report 2001-2002: Readiness for the Networked World.

21. El Índice de competencia de las TIC en los negocios y su entorno económico está considerado dentro del índice de Networked Policy, definido como el entorno político de la información y las comunicaciones así como los negocios y el clima económico. Harvard University. The Global Information Technology Report 2001-2002: Readiness for the Networked World. 
Un modelo de planeación de bibliotecas digitales para México

\section{ANEXO 4}

TABLAS DE TIPOS DE DATOS Y FORMATOS UTILIZADOS EN PROYECTOS DE DIGITALIZACIÓN*

\begin{tabular}{|c|c|c|c|}
\hline Tipo de datos & Aplicaciones & Formatos & Referencias \\
\hline $\begin{array}{l}\text { Datos } \\
\text { alfanúmericos }\end{array}$ & $\begin{array}{l}\text { Textos de tipo } \\
\text { literario y } \\
\text { lingüístico } \\
\text { para lectura, } \\
\text { análisis, edición } \\
\text { e intranets. }\end{array}$ & TXT, XML y PDF & $\begin{array}{l}\text { "Text Encoding Initiative: (TEI)". } \\
\text { http://www.tei-c.org/ } \\
\text { "Creating and Documenting Electronic } \\
\text { Texts". (OTA, 1999): } \\
\text { http://ota.ahds.ac.uk/documents/creating/ } \\
\text { "TEI Text Encoding in Libraries } \\
\text { Guidelines for Best Practices". (DLF, 1999). } \\
\text { http://diglib.org/standards/tei.htm }\end{array}$ \\
\hline $\begin{array}{l}\text { Datos } \\
\text { alfanuméricos }\end{array}$ & $\begin{array}{l}\text { Textos literarios } \\
\text { para distribución } \\
\text { en la red }\end{array}$ & HTML, XML, OEB & $\begin{array}{l}\text { Usar DTD o esquema de Tipo } \\
\text { de Elemento. http://w3c.org } \\
\text { "Open eBook Publication Structure } \\
\text { Specification Version 1.2" } \\
\text { http://www.openebook.org/oebps/oebps1.2/ } \\
\text { index.htm }\end{array}$ \\
\hline $\begin{array}{l}\text { Datos } \\
\text { alfanuméricos }\end{array}$ & $\begin{array}{l}\text { Archivos planos, } \\
\text { estadísticas, } \\
\text { bases de datos } \\
\text { jerárquicas o } \\
\text { relacionales. }\end{array}$ & $\begin{array}{l}\text { Texto ASCII O UTF-8, } \\
\text { PDF, SPSS, SAS } \\
\text { con metadatos para } \\
\text { ver columnas, } \\
\text { renglones, etc. }\end{array}$ & $\begin{array}{l}\text { Igual que en el primer renglón, más } \\
\text { "Guide for Social Sciences Data } \\
\text { Preparation \& Archiving" (ICPSR, 2002) } \\
\text { http://www.icpsr.umich.edu/access/dpm.html }\end{array}$ \\
\hline $\begin{array}{l}\text { Datos tipo } \\
\text { imagen de } \\
\text { documentos } \\
\text { de textos, b/n, } \\
\text { grises, o color }\end{array}$ & $\begin{array}{l}\text { Digitalizaciones } \\
\text { retrospectivas } \\
\text { de libros } \\
\text { o revistas }\end{array}$ & $\begin{array}{l}\text { TIFF no } \\
\text { comprimido o } \\
\text { jpeg2000 sin } \\
\text { pérdida con paleta } \\
\text { y resolución } \\
\text { adecuadas al } \\
\text { tipo de material. }\end{array}$ & $\begin{array}{l}\text { "Image Digitization: File Formats, Digital } \\
\text { Still Images". (Harvard, 2000) } \\
\text { http://preserve.harvard.edu/resources/ } \\
\text { imageformats.html } \\
\text { "Benchmark for Faithful Digital } \\
\text { Reproductions of Monographs and } \\
\text { Serials. Version 1". (DLF, 2002) } \\
\text { http://www.diglib.org/standards/bmarkfin.htm } \\
\text { "National Archives Guidelines", UK. } \\
\text { http://www.nationalarchives.gov.uk/ } \\
\text { electronicrecords/advice/guidelines.htm }\end{array}$ \\
\hline $\begin{array}{l}\text { Datos tipo } \\
\text { imagen de } \\
\text { documentos } \\
\text { de textos, b/n, } \\
\text { grises, o color }\end{array}$ & Periódicos & $\begin{array}{l}\text { Formatos escandidos } \\
\text { en escala de grises } \\
\text { a } 400-600 \text { dpi como } \\
\text { originales } \\
\text { acompañados de } \\
\text { pdf y txt para } \\
\text { distribución }\end{array}$ & $\begin{array}{l}\text { "The National Digital Newspaper Program } \\
\text { of the Library of Congress" (NDNP) } \\
\text { http://www.loc.gov/ndnp/ndnp_techguide.pdf } \\
\text { "The british Library Nespaper Pilot". } 2001 \text {. } \\
\text { http://digitalcooperative.oclc.org/digitize/ } \\
\text { BritishLibraryNewspaper.html }\end{array}$ \\
\hline
\end{tabular}




\begin{tabular}{|c|c|c|c|}
\hline Tipo de datos & Aplicaciones & Formatos & Referencias \\
\hline $\begin{array}{l}\text { Imágenes y } \\
\text { datos con } \\
\text { mapeo de bits } \\
\text { escalables al } \\
\text { zoom y } \\
\text { resolución } \\
\text { variada }\end{array}$ & $\begin{array}{l}\text { Mapas, datos } \\
\text { cartográficos y } \\
\text { geoespaciales, } \\
\text { aerofotografía, } \\
\text { estereofotografía }\end{array}$ & $\begin{array}{l}\text { TIFF no } \\
\text { comprimido o } \\
\text { jpeg2000 sin } \\
\text { pérdida con paleta } \\
\text { y resolución } \\
\text { máxima como } \\
\text { originales y } \\
\text { archivos de menor } \\
\text { resolución para } \\
\text { distribuir }\end{array}$ & \\
\hline $\begin{array}{l}\text { Datos con } \\
\text { mapeo de bits } \\
\text { escalables al } \\
\text { zoom y } \\
\text { resolución } \\
\text { variada }\end{array}$ & $\begin{array}{l}\text { Sistemas de } \\
\text { Información } \\
\text { Geoespaciales } \\
\text { (GIS) }\end{array}$ & $\begin{array}{l}\text { Datos } \\
\text { alfanuméricos } \\
\text { rasterizados o } \\
\text { renderizados }\end{array}$ & $\begin{array}{l}\text { "GIS. A Guide to Good Practice". } \\
\text { http://ads.ahds.ac.uk/project/goodguides/ } \\
\text { gis/sect11.html }\end{array}$ \\
\hline Audio & $\begin{array}{l}\text { Archivos de voz } \\
\text { y/o archivos } \\
\text { Musicales, tanto } \\
\text { restrospectivos } \\
\text { como actuales. }\end{array}$ & $\begin{array}{l}\text { Archivos maestros } \\
\text { con algún tipo de } \\
\text { flujo PCM en } \\
\text { formato AIFF, RA, } \\
\text { WAV, MPEG1-IV, } \\
\text { MPEG1-AAC } \\
\text { o MPEG-2 no } \\
\text { comprimido para } \\
\text { preservación. } \\
\text { Formatos ligeros } \\
\text { como el MPEG1-III } \\
\text { (mp3) para } \\
\text { distribuir. }\end{array}$ & $\begin{array}{l}\text { "Eda Kuhn Loeb MusicLibrary of Harvard } \\
\text { College". } \\
\text { http://hcl.harvard.edu/loebmusic/ } \\
\text { audioresources.html } \\
\text { "Audio and Video Preservation Reformatting. } \\
\text { A Library of Congress Perspective". } \\
\text { http://www.archives.gov/preservation/ } \\
\text { conferences/papers_2003/fleischauer.html } \\
\text { "The Library of Congress Digital Audio } \\
\text { Preservation Prototyping Project" } \\
\text { http://www.arl.org/preserv/ } \\
\text { sound_savings_proceedings/fleischhauer.html } \\
\text { "The Safeguarding of the Audio Heritage: } \\
\text { Ethics, Principles and Preservation } \\
\text { Strategy. Version 2, September 2001". } \\
\text { (IASA, 2001) } \\
\text { http://www.iasa-web.org/iasa0013.htm } \\
\text { "Digitizing Speech Records for Archival } \\
\text { Purposes". (Historivcal Voices Project) } \\
\text { http://www.historicalvoices.org/papers/ } \\
\text { audio_digitization.pdf } \\
\text { "Digitizing Speech Records for Archival } \\
\text { Purposes. Digitizing Audio for National } \\
\text { Gallery of Spoken Word". (Historivcal Voices } \\
\text { Project) } \\
\text { http://www.historicalvoices.org/research.php }\end{array}$ \\
\hline
\end{tabular}


Un modelo de planeación de bibliotecas digitales para México

\begin{tabular}{|l|l|l|l|}
\hline Tipo de datos & Aplicaciones & Formatos & Referencias \\
\hline Video & $\begin{array}{l}\text { Digitalización } \\
\text { de video } \\
\text { analógico o cine }\end{array}$ & $\begin{array}{l}\text { MPEG1-IV (MPEG4), } \\
\text { RA O QT de alta } \\
\text { resolución 1.5-2 } \\
\text { Mbps para preservar. } \\
\text { Los mismos en baja } \\
\text { resolución 28-56 } \\
\text { kbps con menos } \\
\text { cuadros por seg. } \\
\text { y cuadros más } \\
\text { pequeños. }\end{array}$ & $\begin{array}{l}\text { "The NINCH Guide to Good Practice in the } \\
\text { Cultural Hepresentation and Management of } \\
\text { http://www.nyu.edu/its/humanities/ninchguide/ } \\
\text { "Capture your collections. Small Museum } \\
\text { version bibliography". } \\
\text { http://www.chin.gc.ca/English/Digital_Content/ } \\
\text { Capture_Collections/Publication/ } \\
\text { bibliography.pdf }\end{array}$ \\
\hline Video & Imágenes actuales \\
& digitales. & Idem & Idem \\
\hline
\end{tabular}

* Basada en: "Introduction to Metadata: Patways to Information". Getty Research Institute. Página web del Instituto. Disponible 3 de enero, 2005 en: http://www.getty.edu/research/conducting_research/ standards/intrometadata/ 
Anexos

\section{ANEXO 5}

TABLAS DE DATOS DE USO DEL PROYECTO E-MÉXICO

Tomadas de: "e-México National System". En: "Fourth India Mexico Joint Commision". Nueva Delhi, India: octubre 21-22, 2005. Presentación Power Point. Láminas 32-35. Disponible noviembre 3, 2005 en: http://www.e-mexico.gob.mx/wb2/eMex/eMex_the_emexico_nationa 


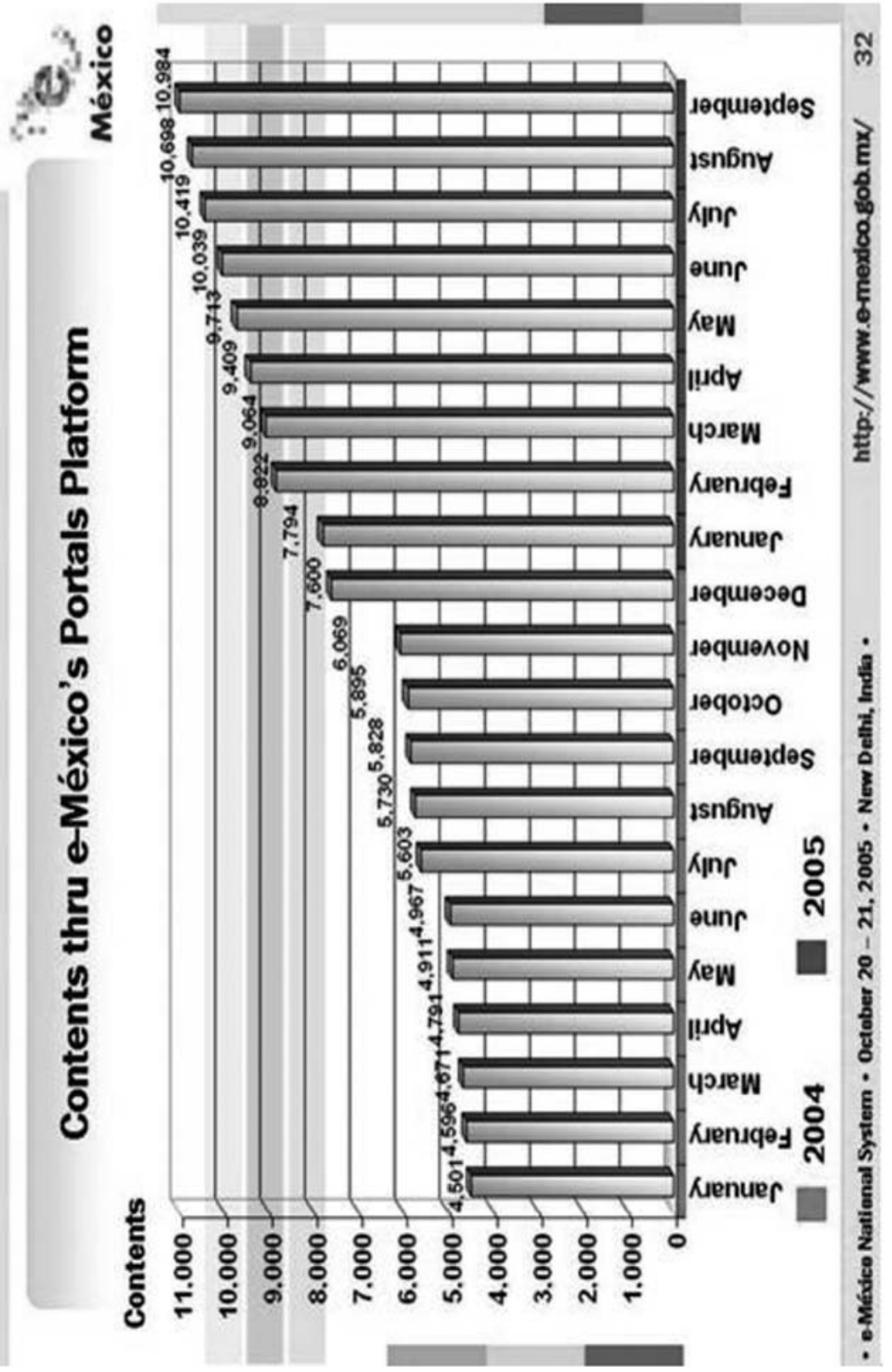


Anexos

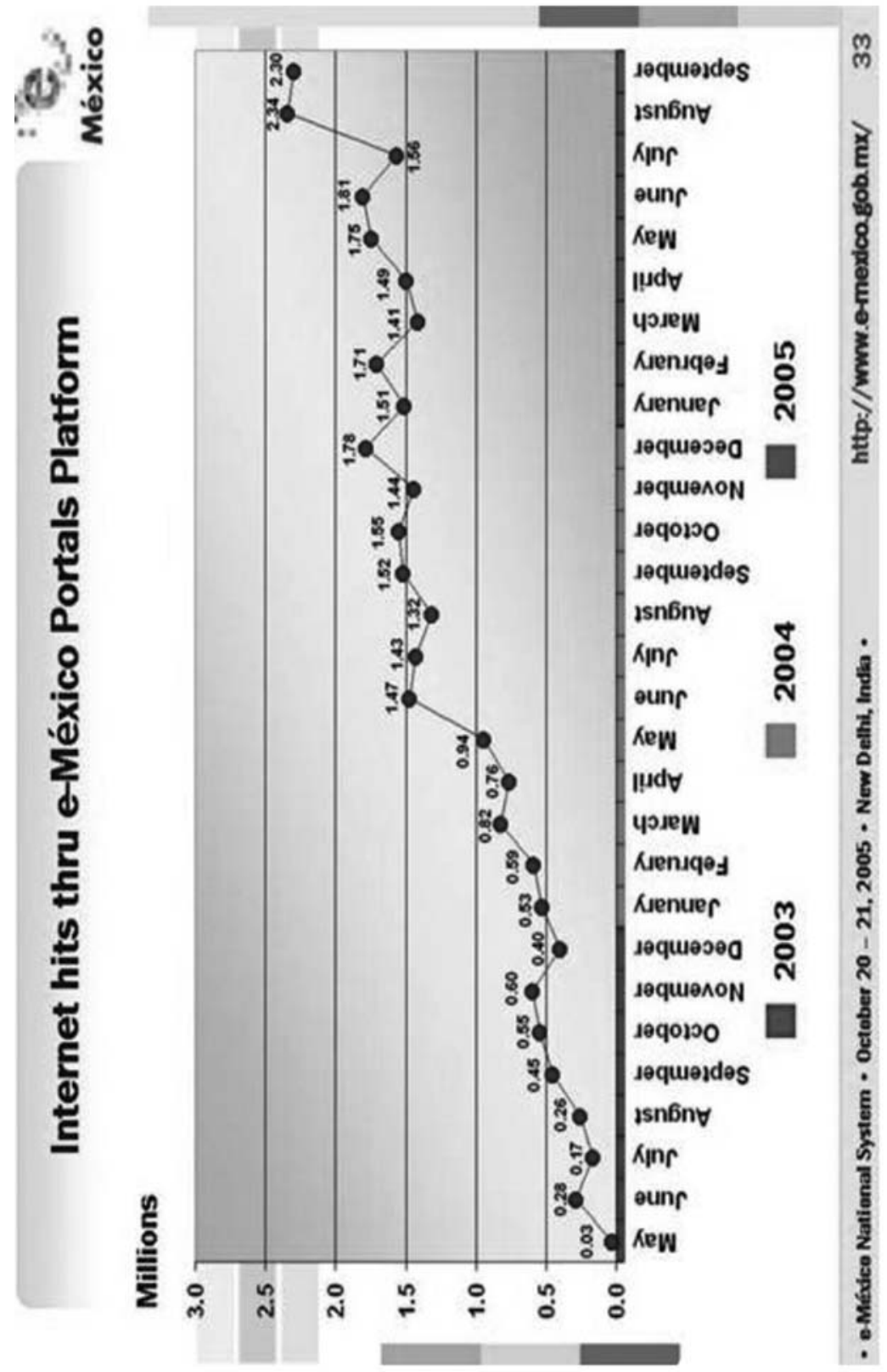







○

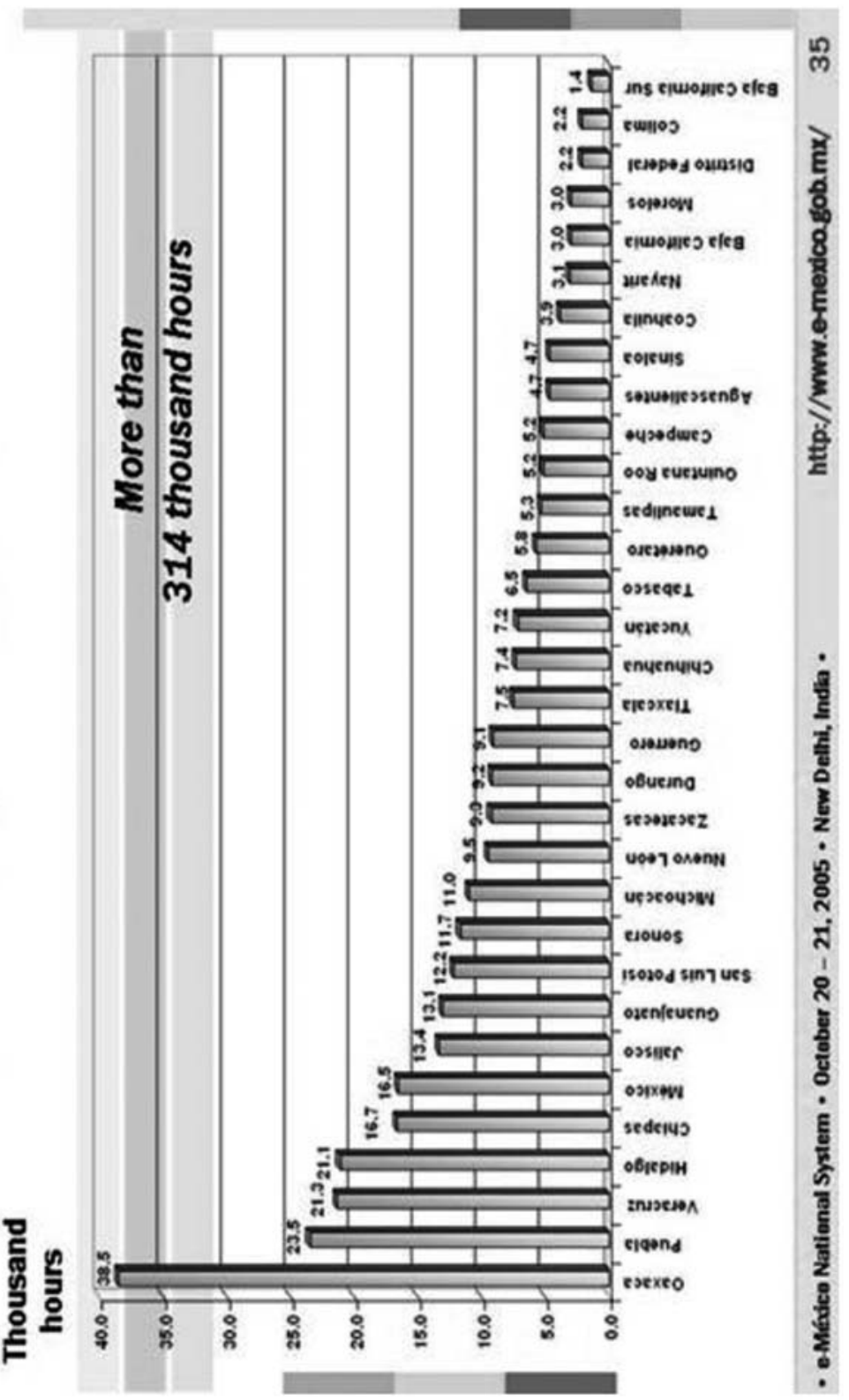



Un modelo de planeación de bibliotecas digitales para México. La edición consta de 500 ejemplares. Coordinación editorial, Zindy E. Rodríguez Tamayo. Formación editorial, Grupo Edición. Revisión especializada, Rebecca Ocaranza Bastida. Centro Universitario de Investigaciones Bibliotecológicas/Unam. Fue impreso en papel Cultural ahuesado de 90 gramos en Grupo Edición, S.A. de C.V., Xochicalco 619, Col. Vértiz-Narvarte, 03600 México, D.F. Se teminó de imprimir en el mes de abril de 2007. 